LUÍS CLÁUDIO DE MATOS LIMA JUNIOR

\title{
AVALIAÇÃO EXPERIMENTAL DAS PERTURBAÇÕES CAUSADAS POR DIFERENTES TIPOS DE SISTEMA DE CONTROLE EM USINAS EÓLICAS
}

Dissertação apresentada ao Programa de PósGraduação em Energia da Universidade de São Paulo (Escola Politécnica / Faculdade de Economia e Administração / Instituto de Energia e Ambiente / Instituto de Física) para a obtenção do título de Mestre em Ciências.

Orientador: Prof. Dr. Alexandre Piantini

Versão Corrigida

(versão original disponível na Biblioteca da Unidade que aloja o Programa e na Biblioteca Digital de Teses e Dissertações da USP)

SÃO PAULO

2013 
AUTORIZO A REPRODUÇÃO E DIVULGAÇÃO TOTAL OU PARCIAL DESTE TRABALHO, POR QUALQUER MEIO CONVENCIONAL OU ELETRÔNICO, PARA FINS DE ESTUDO E PESQUISA, DESDE QUE CITADA A FONTE.

FICHA CATALOGRÁFICA

Lima Junior, Luís Cláudio de Matos.

Avaliação Experimental das Perturbações Causadas pelo sistema de controle de excitação de usinas eólicas e seus impactos no sistema elétrico de potência./ Luís Claudio de Matos Lima Junior; orientador Alexandre Piantini. São Paulo, 2013.

159f.: il.; $30 \mathrm{~cm}$.

Dissertação (Mestrado - Programa de Pós-Graduação em Energia) EP / FEA / IEE / IF da Universidade de São Paulo.

1. Qualidade de energia 2.Compatibilidade eletromagnética 3. Sistemas elétricos de potência I. Título 


\section{UNIVERSIDADE DE SÃO PAULO \\ PROGRAMA DE PÓS-GRADUAÇÃO EM ENERGIA \\ EP - FEA - IEE - IF}

\section{LUIS CLÁUDIO DE MATOS LIMA JUNIOR}

“Avaliação experimental das perturbações causadas por diferentes tipos de sistema de controle em usinas eólicas"

Dissertação aprovada pela Comissão Julgadora:

Prof. Dr. Alexandre Piantini - PPGE/USP

Orientador e Presidente da Comissão Julgadora

Prof. Dr. Arnaldo Gakiya Kanashiro - PPGE/USP

Prof. Dr. Manuel Luis Barreira Martinez - UNIFEI/Itajubá 
Dedico este trabalho a meus filhos Gustavo, Ananda, Leonardo e Guilherme, que sempre me dão muitas alegrias por vê-los a se transformar nestas pessoas maravilhosas e principalmente a minha esposa Cíntia, que além da sua infinita paciência me incentivou muito para que eu chegasse até aqui. 


\section{Agradecimentos}

Ao meu orientador Prof. Dr. Alexandre Piantini pela sua paciência durante a elaboração deste trabalho e por nunca duvidar que eu pudesse concluí-lo. Suas orientações e contribuições foram essenciais para isso.

Ao Prof. Dr. Hédio Tatizawa e aos Prof. Dr. Arnaldo G. Kanashiro e Dr. Kleiber Tadeu Soletto pelo apoio.

Ao Eng. Danilo Caldas pela grande ajuda na coleta de dados laboratoriais e seus conselhos para a conclusão deste trabalho.

Ao Instituto Federal de Educação, Ciência e Tecnologia de São Paulo pelo apoio recebido neste decorrer deste período.

Também agradeço de coração, aos professores Msc. Mario Sergio Cambraia, Msc. Walter Ragnev, Msc. Alberto Akio Shiga e Dr. Alexandre Kenchian do IFSP pela contribuição, apoio e, principalmente, por me cobrarem a todo instante para a conclusão deste trabalho.

Aos professores Eng. João Marcos da Silva Brito, Msc. Luís Clementino Donizeti, Msc. Walter Ragnev e Jorge Pimenidis do IFSP, grandes amigos e companheiros, pelo incentivo, apoio, pelas contribuições, pela amizade e por ter disponibilizado parte de seus tempos e conhecimento para contribuição deste, bem como ao Msc. Lúcio Aparecido Borba que me inspirou para a linha desse tema. 
"Quando nasceste, ao teu redor todos riam, só tu choravas. Faze por viver de tal modo que, à hora de tua morte, todos chorem, só tu rias."

Confúcio 


\section{RESUMO}

LIMA JR., L.C.M. Avaliação Experimental das Perturbações Causadas pelos Diferentes tipos de Sistema de Controle Eletrônico nas Usinas Eólicas e seus Impactos. 2013. 158 p. Dissertação (Mestrado em Ciências) - Programa de Pós Graduação em Energia da Universidade de São Paulo, São Paulo, 2013.

Com o déficit de energia que atualmente preocupa o setor elétrico brasileiro, ameaçando os consumidores com a possibilidade de novos racionamentos, surge a perspectiva de aumento de produção de energia, através da criação de usinas eólicas para suprir essa demanda. Entretanto, esta forma de geração, sabidamente, provoca distorções na qualidade de energia fornecida, principalmente quanto à geração de harmônicas, que acabam por interferir diretamente nas cargas podendo provocar danos a equipamentos e instalações. Por esse motivo, este trabalho visa analisar a contribuição desse tipo de geração no sistema elétrico e discutir, com base em estudos experimentais realizados em modelos de aerogeradores e diretamente em unidades geradoras instaladas em plantas de geração eólica, as perturbações harmônicas geradas pelo controle de tensão e frequência do sistema. A metodologia utilizada será a de medição das distorções harmônicas, através de analisadores de qualidade de energia, instalados primeiramente em modelos laboratoriais dos principais tipos de aerogeradores existentes no mercado, medindo as perturbações em diversas situações de carga, obedecendo ao estabelecido na norma NBR-IEC61400-21/2010 - Medição e Avaliação da Qualidade de Energia de Aerogeradores Conectados a Rede.

Palavras-chave: Geração eólica, harmônicos, potência qualidade, distorção harmônica, a compatibilidade eletromagnética. 


\begin{abstract}
LIMA JR., L.C.M. Experimental Evaluation of Troubles Caused by Excitation Control System of Wind Power Plants and their Impacts on the Electric Power System. 2013. 158 p. Master's Dissertation - Graduate Program on Energy. Universidade de São Paulo, São Paulo, 2013.
\end{abstract}

With the energy deficit that currently worries the Brazilian electric sector, threatening consumers with the possibility of further rationing comes the prospect of increased energy production through the creation of wind farms to meet this demand. However, this form of generation is known to distort the quality of power supplied, especially as the generation of harmonics, which ultimately interfere directly in the loads can cause damage to equipment and facilities. Therefore, this study aims to analyze the contribution of this type of generation on the electrical system and discuss, based on experimental studies in directly generating units installed in wind generation plants, disturbances generated by harmonic voltage and frequency control system. The methodology will be the measurement of harmonic distortion through power quality analyzers, installed primarily in laboratory models of the main types of wind turbines on the market, measuring disturbances in various loading conditions, obeying the established standard NBR-IEC-61400-21/2010 - Measurement and Evaluation of Power Quality of Wind Turbines Connected Network.

Keywords: Wind power, harmonics, power quality, harmonics distortion, electromagnetic compatibility. 


\section{LISTA DE FIGURAS}

Fig. 1 - Capacidade Instalada no Sistema Interligado Nacional - SIN (MW)............................ 24

Fig. 2 - Porcentagem de Energia Armazenada nos Reservatórios das Usinas Hidrelétricas das Regiões SE/CO - Anos 2000(A), 2001(B) e 2002(C) .25

Fig. 3 - Redução da demanda no horário de ponta do Sistema Interligado Nacional - SIN $\mathrm{MWh} / \mathrm{h}$ .26

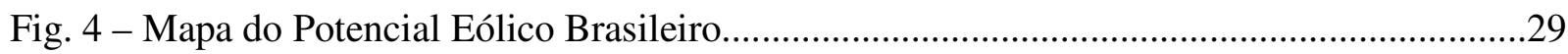

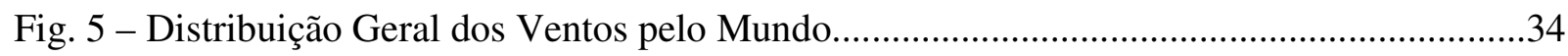

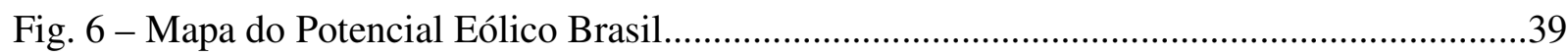

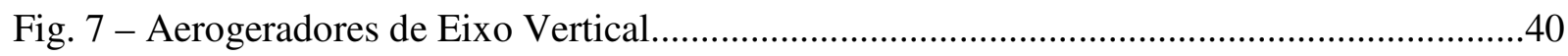

Fig. 8 - Aerogeradores de Eixo Horizontal............................................................................. 41

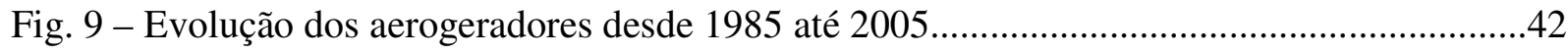

Fig. 10 - Gerador Síncrono com Excitatriz..................................................................................

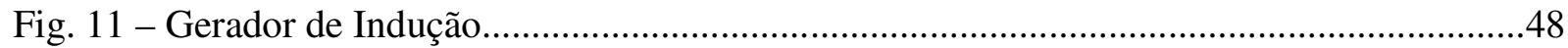

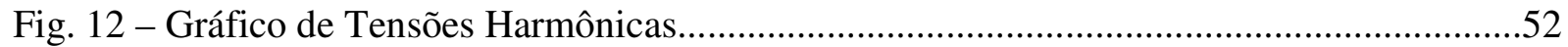

Fig. 13 - Correntes através da impedância da rede elétrica..........................................................53

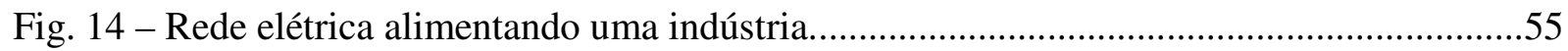

Fig. 15 - Circuito elétrico monofásico equivalente, para a frequência fundamental $(h=1), p / o$

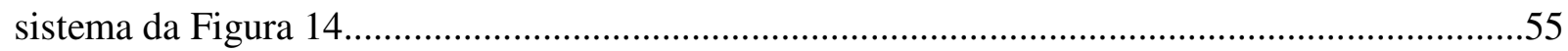

Fig. 16 - Circuito elétrico monofásico equivalente, para as frequências harmônicas $(h>1), p / o$

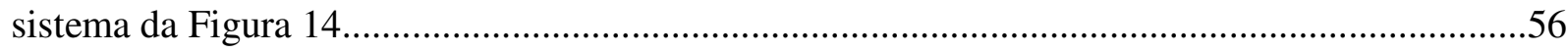

Fig. 17 - Mapa do Sistema Interligado Nacional - SIN..........................................................59

Fig. 18 - Altas correntes no neutro em um circuito alimentando uma carga não linear

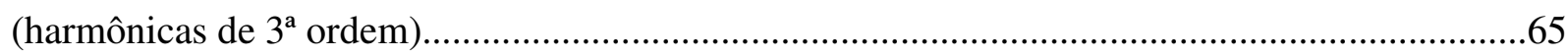

Fig. 19 - (a) Sistema gerador síncrono alimentando motor; (b) Circuito equivalente...................67

Fig. 20 - Configurações de Montagem de Grupos de Aerogeradores para Geração

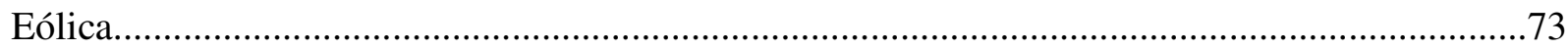

Fig. 21 - Grupo eólico-elétrico conectado diretamente a rede elétrica..........................................74

Fig. 22 - Grupo eólico-elétrico conectado à rede elétrica através de um conversor.......................75 
Fig. 23 - Grupo eólico-elétrico constituído de gerador assíncrono trifásico duplamente

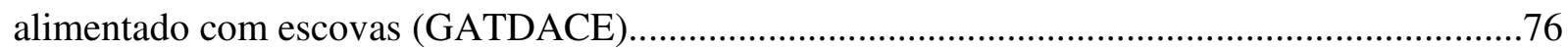

Fig. 24 - Grupo eólico-elétrico conectado à rede elétrica através de um conversor......................77

Fig. 25 - Partes de um Aerogerador padrão com caixa multiplicadora...........................................79

Fig. 26 - Diagrama de fase da rede fictícia para simulação de tensão.........................................82

Fig. 27 - Representação do "Equivalente de Norton" com o Lugar Geométrico (LG) da Rede

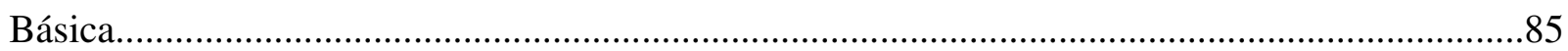

Fig. 28 - Ilustração Gráfica do Método do "Lugar Geométrico"....................................................86

Fig. 29 - Ponto de acoplamento comum (PAC) do Sistema (do inglês "point common coupling" -

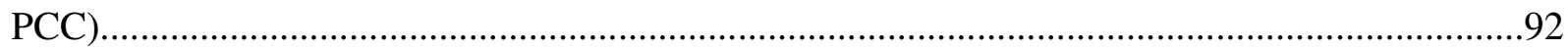

Fig. 30 - Analisador de qualidade de energia Fabricante RMS - Modelo Marh-21 ....................99

Fig. 31 - Forma de conexão do analisador de qualidade de energia em carga..............................99

Fig. 32 - Diagrama básico de ligação da rede elétrica alimentando carga resistiva (variação de carga com degrau de $10 \%$ ) sem paralelismo com os modelos de aerogeradores...

Fig. 33 - Gráfico da Distorção Harmônica Total de Tensão (THDU) da rede elétrica, alimentando carga resistiva (Variação de carga com degraus de 10\%) 101

Fig. 34 - Gráfico da Distorção Harmônica Total de Tensão (THDU) da rede elétrica com formas de onda de tensão e corrente, alimentando carga resistiva (variação de carga com degraus de $10 \%)$

Fig. 35 - Espectro de frequência da rede elétrica na pior situação de distorção harmônica Total de Tensão (THDU), alimentando carga resistiva. 103

Fig. 36 - Gráfico da Distorção Harmônica Total de Corrente (THDI) da rede elétrica, alimentando carga resistiva (variação de carga com degraus de 10\%). 104

Fig. 37 - Gráfico da Distorção Harmônica Total de Corrente (THDI) da rede elétrica com forma de onde de tensão e corrente, alimentando carga resistiva (variação de carga com degraus de $10 \%)$ 105

Fig. 38 - Espectro de frequência da rede elétrica na pior situação de Distorção Harmônica Total

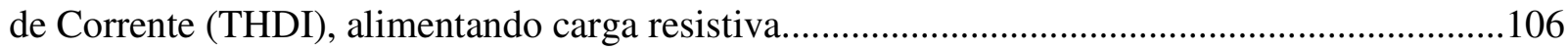
Fig. 39 - Gerador Síncrono com Rotor Bobinado (GSRB). 107 
Fig. 40 - Diagrama Básico de Ligação do Gerador Síncrono com Rotor Bobinado (GSRB) em paralelismo com a rede elétrica alimentando carga resistiva (variação de carga com degrau de 10\%) - montagem em laboratório 108

Fig. 41 - Gráfica THDU com GSRB, alimentando carga resistiva em paralelo com a rede elétrica (variação de carga com degrau de 10\%) 109

Fig. 42 - Gráfico THDU da rede elétrica com formas de onde de tensão e corrente com GSRB, alimentando carga resistiva em paralelo com a rede elétrica (variação de carga com degrau de $10 \%)$

Fig. 43 - Espectro de frequência da rede na pior situação do THDU, com GSRB, alimentando carga resistiva. 111

Fig. 44 - Gráfico THDI com GSRB, alimentando carga resistiva em paralelo com a rede elétrica (variação de carga com degrau de 10\%).

Fig. 45 - Gráfico THDI da rede elétrica com formas de onda de tensão e corrente com GSRB, alimentando carga resistiva em paralelo com a rede elétrica (variação de carga com degrau de $10 \%)$

Fig. 46 - Espectro de frequência da rede na pior situação do THDI, com GSRB, alimentando carga resistiva 114

Fig. 47 - Gerador de Indução em Gaiola de Esquilo (GIGE) 115

Fig. 48 - Diagrama Básico de Ligação do Gerador de Indução com Gaiola de Esquilo (GIGE) em paralelismo com a rede elétrica alimentando carga resistiva (variação de carga com degrau de $10 \%$ ) - montagem em laboratório. 116

Fig. 49 - Gráfico THDU com GIGE, alimentando carga resistiva em paralelo com a rede elétrica (variação de carga com degrau de 10\%)

Fig. 50 - Gráfico THDU da rede elétrica com formas de onda de tensão e corrente com GIGE, alimentando carga resistiva em paralelo com a rede elétrica (variação de carga com degrau de $10 \%)$ .118

Fig. 51 - Espectro de frequência da rede na pior situação do THDU, com GIGE, alimentando carga resistiva. 119

Fig. 52 - Gráfico THDI com GIGE, alimentando carga resistiva em paralelo com a rede elétrica (variação de carga com degrau de 10\%). 120 
Fig. 53 - Gráfico THDI da rede elétrica com formas de onda de tensão e corrente com GIGE, alimentando carga resistiva em paralelo com a rede elétrica (variação de carga com degrau de $10 \%)$ 121

Fig. 54 - Espectro de frequência da rede na pior situação do THDI, com GIGE, alimentando carga resistiva .122

Fig. 55 - Gerador de Indução com Dupla Alimentação (GIDA)

Fig. 56 - Diagrama Básico de Ligação do Gerador de Indução com Dupla Alimentação (GIDA) em paralelismo com a rede elétrica alimentando carga resistiva 124

Fig. 57 - Gráfico THDU com GIDA, alimentando carga resistiva em paralelo com a rede elétrica (variação de carga com degrau de 10\%).

Fig. 58 - Gráfico THDU da rede elétrica com formas de onda de tensão e corrente com GIDA, alimentando carga resistiva em paralelo com a rede elétrica (variação de carga com degrau de $10 \%)$

Fig. 59 - Espectro de frequência da rede na pior situação do THDU, com GIDA, alimentando carga resistiva.

Fig. 60 - Gráfico THDI com GIDA, alimentando carga resistiva em paralelo com a rede elétrica (variação de carga com degrau de $10 \%$ ).

Fig. 61 - Gráfico THDI da rede elétrica com formas de onda de tensão e corrente com GIDA, alimentando carga resistiva em paralelo com a rede elétrica (variação de carga com degrau de $10 \%)$.

Fig. 62 - Espectro de frequência da rede na pior situação do THDI, com GIDA, alimentando carga resistiva 130

Fig. 63 - Gerador Síncrono com Rotor Bobinado (GSRB) - Diagrama Básico 131

Fig. 64 - Diagrama Básico de Ligação do Gerador Síncrono com Rotor Bobinado (GSRB) sem paralelismo com a rede elétrica alimentando carga resistiva (variação de carga com degrau de 10\%) - montagem em laboratório.

Fig. 65 - Gráfica THDU com GSRB, alimentando carga resistiva sem paralelismo com a rede elétrica (variação de carga com degrau de 10\%).

Fig. 66 - Gráfico THDU da rede elétrica com formas de onde de tensão e corrente com GSRB, alimentando carga resistiva sem paralelismo com a rede elétrica (variação de carga com degrau de $10 \%)$ 
Fig. 67 - Espectro de frequência da rede na pior situação do THDU, com GSRB, alimentando carga resistiva sem paralelismo com a rede elétrica

Fig. 68 - Gráfico THDI com GSRB, alimentando carga resistiva sem paralelismo com a rede elétrica (variação de carga com degrau de 10\%)

Fig. 69 - Gráfico THDI da rede elétrica com formas de onda de tensão e corrente com GSRB, alimentando carga resistiva sem paralelismo com a rede elétrica (variação de carga com degrau de $10 \%)$

Fig. 70 - Espectro de frequência da rede na pior situação do THDI, com GSRB, alimentando carga resistiva sem paralelismo com a rede elétrica.

Fig. 71 - Gerador de Indução com Dupla Alimentação (GIDA) - Diagrama Básico.

Fig. 72 - Diagrama Básico de Ligação do Gerador de Indução com Dupla Alimentação (GIDA) sem paralelismo com a rede elétrica alimentando carga resistiva (variação de carga com degrau de $10 \%$ - Montagem em laboratório.

Fig. 73 - Gráfico THDU com GIDA, alimentando carga resistiva sem paralelismo com a rede elétrica (variação de carga com degrau de 10\%)

Fig. 74 - Gráfico THDU da rede elétrica com formas de onda de tensão e corrente com GIDA, alimentando carga resistiva sem paralelismo com a rede elétrica (variação de carga em degrau de $10 \%)$

Fig. 75 - Espectro de frequência da rede na pior situação do THDU, com GIDA, alimentando carga resistiva sem paralelismo com a rede elétrica

Fig. 76 - Gráfico THDI com GIDA, alimentando carga resistiva sem paralelismo com a rede elétrica (variação de carga com degrau de 10\%).

Fig. 77 - Gráfico THDI da rede elétrica com formas de onda de tensão e corrente com GIDA, alimentando carga resistiva sem paralelismo com a rede elétrica (variação de carga com degrau de $10 \%)$

Fig. 78 - Espectro de frequência da rede na pior situação do THDI, com GIDA, alimentando carga resistiva sem paralelismo com a rede elétrica. 145

Fig. 79 - Gerador Síncrono com Rotor Bobinado (GSRB) 146 Fig. 80 - Montagem do Modelo para simulação dos Aerogeradores com analisador de energia acoplado 
Fig. 81 - Detalhe do inversor de frequência utilizado para regulação da frequência dos modelos

Fig. 82 - Vista do modelo utilizado para montagem do Aerogerador duplamente excitado (GIDA)

Fig. 83 - Detalhe da Montagem do Conjunto Gerador de indução utilizado como gerador síncrono (GSRB).

Fig. 84 - Detalhe do Grupo Gerador de Indução com motor CC, usado como turbina. 149

Fig. 85 - Ligação do modelo GIGE nas cargas resistivas de simulação (reostatos) 149

Fig. 86 - Detalhe do motor CC utilizado como turbina e o reostato de campo para variação de velocidade 150

Fig. 87 - Detalhe dos voltímetros ligados às fontes para sincronismo do sistema (redes $\mathrm{x}$ gedrador). 150 


\section{LISTA DE TABELAS}

Tabela 1 - Taxa de Crescimento do Uso de Energia Eólica no Mundo.......................................................

Tabela 2 - Resumo da Evolução da Matriz de Energia Elétrica Brasileira 2002-2011 (GWh)...................22

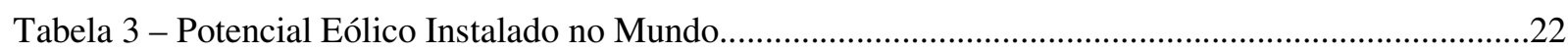

Tabela 4 - Índice Pluviométrico Anual (Total de Chuvas da Região Hidrográfica do Paraná)....................25

Tabela 5 - Capacidade Instalada de Geração Elétrica no Brasil - 2000-2002 (MWmed).......................... 27

Tabela 6 - Capacidade Instalada de Geração Elétrica no Brasil - 2011 (MWmed).....................................30

Tabela 7 - Resumo da Evolução da Matriz de Energia Elétrica Brasileira 2011-2016 (MWmed) 30

Tabela 8 - Velocidade do Vento para uso com Energia Eólica. .38

Tabela 9 - Valores de referência globais das distorções harmônicas totais (em porcentagem da tensão

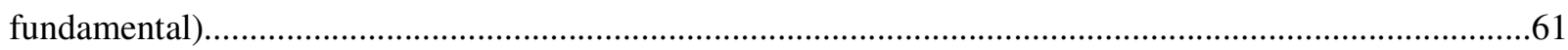

Tabela 10 - Limites globais de tensão, em uma barra, em \% da tensão fundamental.................................62

Tabela 11 - Limites de tensão por consumidor, expresso em \% da Tensão Fundamental............................62 Tabela 12 - Limites de distorção individual e total de harmônicas (para todos os níveis de

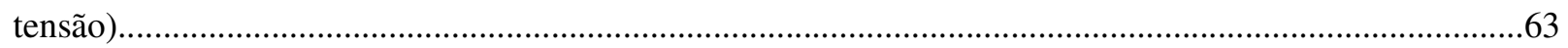

Tabela 13 - Limites de distorção harmônica por ordem harmônica (entre $120 \mathrm{~V}$ e 69 kV)..........................63

Tabela 14 - Limites de distorção harmônicas por ordem harmônica (entre 69,01 kV e 161 kV)................64

Tabela 15 - Especificação de Expoente “ $\beta$ ” de acordo com a NBR-IEC-6100-3-6.....................................83

Tabela 16 - Especificação de Expoente "a" de acordo com o procedimento ONS........................................87

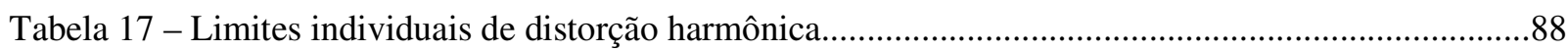

Tabela 18 - Limites de distorção harmônica de tensão para instalações com todos os níveis de

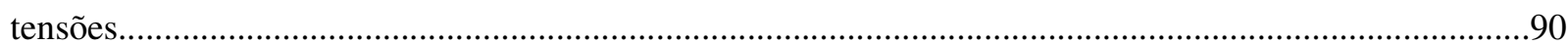

Tabela 19 - Limites de distorção harmônica de corrente para instalações com tensões de $120 \mathrm{~V}$ a 69 $\mathrm{kV}$.

Tabela 20 - Tabela de medição das distorções harmônicas de um modelo de Aerogerador real de 2000 kW de potência e com sistema gerado tipo GSRB

Tabela 21 - Tabela de medição das distorções harmônicas de um modelo de Aerogerador real de $2300 \mathrm{~kW}$ de potência e com sistema gerado tipo GSRB .148

Tabela 22 - Tabela comparativa de valores de THD entre os modelos utilizados no experimentos, em diversas situações de carga e dos aerogeradores reais instalados em parques eólicos. 


\section{LISTA DE ABREVIATURAS E SIGLAS}

ABNT

ANEEL

BEN

CRESESB

DEWI

DFIG

DHI

$\mathrm{DHI}_{\mathrm{U}}$

DHTI $_{I}$

$\mathrm{DHT}_{\mathrm{U}}$

GATDACE

GIDA

GIGE

GSRB

HVDC

IEC

IEEE

PAC

PEN

PRODIST

PROINFA

SCIG

SIN

ONS

THD

THDI

THDU
Associação Brasileira de Normas Técnicas

Agência Nacional de Energia Elétrica

Balanço Energético Nacional

Centro de Referência para Energia Solar e Eólica Sérgio de Salvo Brito

Deutsches Windenergie-Institut

Double Fed Induction Generator

Distorção Harmônica Individual de Corrente

Distorção Harmônica Individual de Tensão

Distorção Harmônica Total de Corrente

Distorção Harmônica Total de Tensão

Geradores Assíncronos Trifásicos de Rotor Bobinado Duplamente

Alimentado com Escovas

Gerador de Indução Duplamente Alimentado

Gerador de Indução com Gaiola de Esquilo

Gerador Síncrono com Rotor Bobinado

High Voltage Direct Current

International Electrotechnical Commission

Institute of Electrical and Electronics Engineers

Ponto de Acoplamento Comum

Plano de Operação Energética

Procedimentos de Distribuição de Energia Elétrica no Sistema Elétrico

Nacional

Programa de incentivo às Fontes Alternativas de Energia Elétrica

Squirrel Cage Generation

Sistema Interligado Nacional

Operador Nacional do Sistema

Taxa de distorção harmônica

Taxa de distorção harmônica de corrente

Taxa de distorção harmônica de tensão 
UFPR

UFRGS

UFRJ
Universidade Federal do Paraná

Universidade Federal do Rio Grande do Sul

Universidade Federal do Rio de Janeiro 


\section{SUMÁRIO}

\section{RESUMO}

\section{ABSTRACT}

\section{LISTA DE FIGURAS}

\section{LISTA DE TABELAS}

\section{LISTA DE ABREVIATURA E SIGLAS}

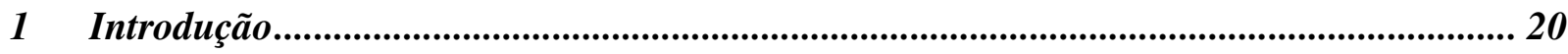

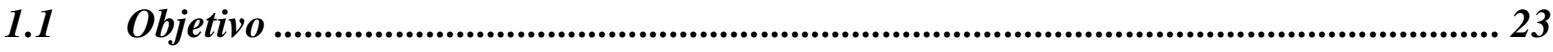

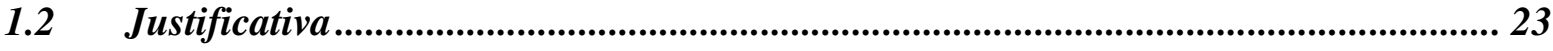

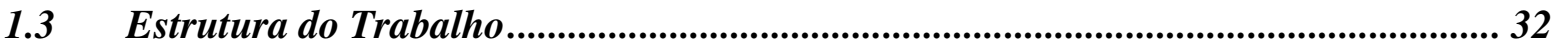

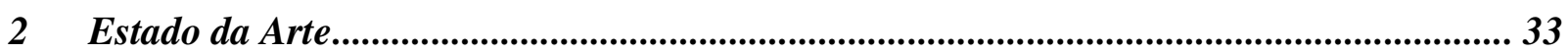

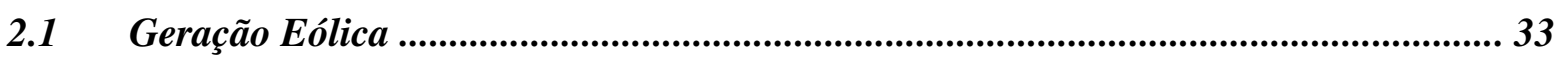

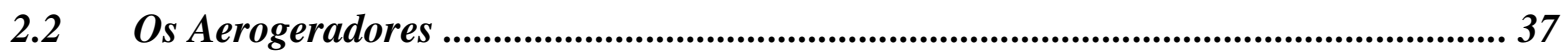

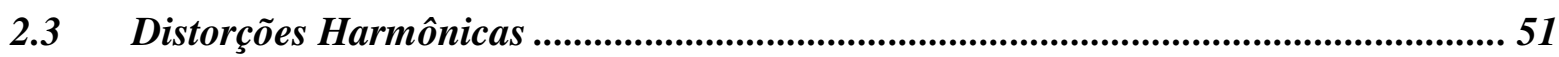

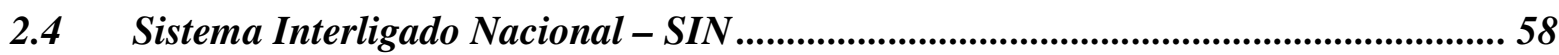

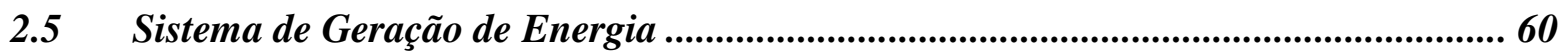

2.6 Legislação sobre Distorções Harmônicas.................................................................60

2.7 Sistema de Controle de Tensão e Frequência de Aerogeradores ................................. 66

3 Análise Comparativa dos Procedimentos de Medição e Avaliação da Qualidade de Energia de Aerogeradores conectados à Rede Elétrica ........................................................... 80

3.1 Norma ABNT-NBR-IEC-61400-21 - Turbinas Eólicas - Parte 21: Medição e Avaliação das Características da Energia de Aerogeradores Conectados à Rede ................. 80

3.2 Procedimento ONS - Instruções para Realização de Estudos e Medições de QEE Relacionados aos Novos Acessos à Rede Básica .................................................................... 84

3.3 Norma IEEE-519-1992 - "Recommended Practices and Requirements for Harmonic Control in Electrical Power Systems"................................................................................ 89

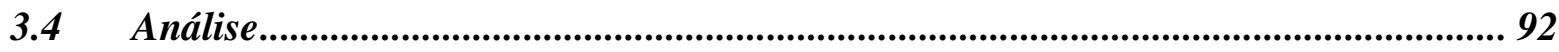

4 Estudo Experimental das Contribuições Harmônicas dos Principais Tipos de

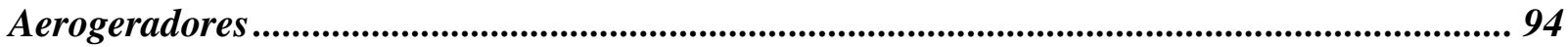

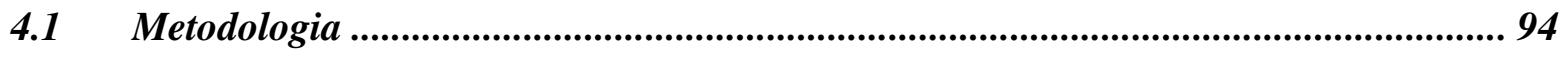

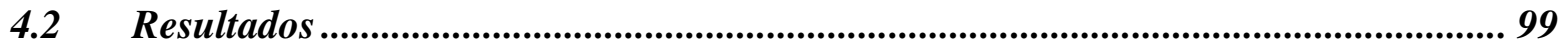

4.2.1 Medição da Rede Elétrica sem acoplamento dos Modelos de Aerogeradores...................................100

4.2.2 Medição do Gerador Síncrono com Rotor Bobinado (GSRB) ....................................................... 107 
4.2.3 Medição do Gerador de Indução com Gaiola de Esquilo (GIGE)

4.2.4 Medição do Gerador de Indução com Dupla Alimentação (GIDA) ................................................123

4.2.5 Medição do Gerador Síncrono com Rotor Bobinado (GSRB) em condição de alimentação direta a carga sem paralelismo da rede.....

4.2.6 Medição do Gerador de Indução Duplamente Alimentado (GIDA) em condição de alimentação direta a carga sem paralelismo da rede

4.2.7 Medição do Gerador Síncrono com Rotor Bobinado (GSRB) realizada em um modelo real por um

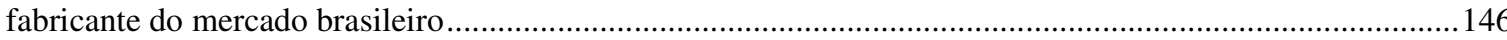

4.2.8 Fotos da Montagem dos Modelos de Aerogeradores.................................................................... 149

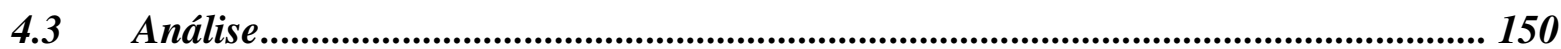

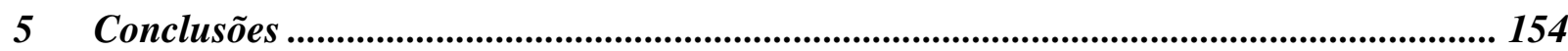

Referências Bibliográficas ................................................................................................... 156 


\section{Introdução}

Uma das principais preocupações atuais tem como foco a disponibilidade de energia para garantir que as taxas de crescimento mundiais praticadas atualmente se mantenham estáveis ou até mesmo que possam ser ampliadas, inclusive garantindo o acesso à energia a todas as populações e comunidades, por mais isoladas que estejam (Programa Luz para Todos).

Entretanto, verifica-se que nos últimos tempos passamos por diversas crises mundiais de disponibilidade de energia, tais como guerras por acesso a fontes de petróleo, desabastecimentos de energia elétrica em locais historicamente com abastecimentos garantidos, o aumento dos custos de produção de energia em função do distanciamento entre as fontes geradoras e os centros de carga, sem falar na pressão por parte da sociedade para a utilização de fontes de energias alternativas, que impactem de forma mais amena o meio ambiente.

Existem suspeitas de que as mudanças climáticas ocorridas nos últimos tempos sejam oriundas de uma má gestão de nossos recursos naturais, principalmente quando da aquisição e utilização de fontes de energia não renováveis e altamente poluidoras.

Vale ressaltar que todas as fontes de energia existentes atualmente, renováveis ou não renováveis, impactam direta ou indiretamente no meio ambiente, em maior ou menor proporção. Portanto, o que se busca é a fonte de energia que provoque o menor impacto possível e que possa atender as necessidades da população mundial.

O crescimento da energia eólica no mundo tem sido muito significativo, conforme pode ser verificado na Tabela 1. Isto se deve ao fato de este tipo de geração ter um impacto pequeno no meio ambiente, o que fomenta o incentivo por sua utilização por parte da sociedade e por estar disponível em praticamente todas as regiões do globo terrestre, sem necessidade de grandes investimentos em infraestrutura. 


\begin{tabular}{lcc}
\hline & $\begin{array}{c}\text { Potência } \\
(\mathbf{M W})\end{array}$ & $\begin{array}{c}\text { Crescimento } \\
(\boldsymbol{\%})\end{array}$ \\
\hline 1997 & 7.475 & - \\
1998 & 9663 & 29,3 \\
1999 & 13696 & 41,7 \\
2000 & 18.039 & 31,7 \\
2001 & 24.320 & 34,8 \\
2002 & 31.164 & 28,1 \\
2003 & 39.290 & 26,1 \\
2004 & 47.693 & 21,4 \\
2005 & 59.033 & 23,8 \\
2006 & 74.153 & 25,6 \\
2007 & 93.849 & 26,6 \\
\hline Crescimento Total & $\mathbf{1 . 1 5 5 , 5}$
\end{tabular}

Tabela 1 - Taxa de Crescimento do Uso de Energia Eólica no Mundo Fonte: Atlas de Energia Elétrica do Brasil - 3 ${ }^{\mathrm{a}}$ Edição - 2008

Este fenômeno ocorre também no Brasil de forma muito significativa (a taxa de crescimento da geração eólica no período de 2002 a 2011 foi de $4.730 \%$, bem superior às demais fontes de energia), mesmo sendo o nosso parque gerador de predominância hidráulica, como pode ser verificado na Tabela 2. Isto se deve ao fato de o Brasil necessitar de novas fontes de energia para atender ao crescimento econômico e consequentemente ao crescimento do consumo de energia verificado nos últimos anos, além do fato de os novos parques hidráulicos estarem localizados cada vez mais distantes dos grandes centros de carga, o que obriga a construção de gigantescas linhas de transmissão que passam por regiões onde a necessidade de preservação ambiental é premente, além de a própria usina estar normalmente localizada neste tipo de região (exemplo: usina de Belo Monte - região Amazônica). 


\begin{tabular}{ccccccccccc}
\hline $\begin{array}{c}\text { Fluxo } \\
(\mathrm{GWh})\end{array}$ & 2002 & 2003 & 2004 & 2005 & 2006 & 2007 & 2008 & 2009 & 2010 & 2011 \\
\hline $\begin{array}{c}\text { Geração } \\
\text { Total }\end{array}$ & 56 & 63 & 74 & 74 & 342 & 668 & 1183 & 1238 & 2177 & 2705 \\
$\begin{array}{c}\text { Consumo } \\
\text { Total }\end{array}$ & 56 & 63 & 74 & 74 & 342 & 668 & 1183 & 1238 & 2177 & 2705 \\
\hline
\end{tabular}

${ }^{1}$ Para estimar dados não informados foi considerado o fator de capacidade médio do parque eólico nacional de $32,0 \%$.

Tabela 2 - Resumo da Evolução da Matriz de Energia Elétrica Brasileira 2002-2011 (GWh) Fonte: Balanço Energético Nacional (BEN-2012) - ANEEL

Embora este panorama seja bem positivo, o Brasil ainda investe pouco neste tipo de geração para solucionar as deficiências do sistema elétrico, isto se deve ao fato de a regulamentação do setor elétrico não estar bem definida e pelas dificuldades de investimentos e obtenção de licenças ambientais. Isto faz com que o Brasil ocupe somente a $25^{\mathrm{a}}$ posição no ranking da geração eólica do mundo, mesmo com o grande potencial de energia existente em nosso território, conforme verificado na Tabela 3.

\begin{tabular}{llcc}
\hline \multicolumn{1}{c}{ País } & $\begin{array}{c}\text { Potência } \\
\text { (MW) }\end{array}$ & $\begin{array}{c}\text { \% em relação } \\
\text { ao total }\end{array}$ \\
\hline $1^{\text {o }}$ & Alemanha & $22.247,40$ & 23,7 \\
$2^{\text {o }}$ & Estados Unidos & $16.818,80$ & 17,9 \\
$3^{\text {o }}$ & Espanha & $15.145,10$ & 16,1 \\
$4^{\text {o }}$ & Índia & $7.850,00$ & 8,4 \\
$5^{\text {o }}$ & China & $5.912,00$ & 6,3 \\
$6^{\mathbf{o}}$ & Dinamarca & $3.125,00$ & 3,3 \\
$7^{\circ}$ & Itália & $2.726,10$ & 2,9 \\
$8^{\mathbf{o}}$ & França & $2.455,00$ & 2,6 \\
$9^{\mathbf{o}}$ & Reino Unido & $2.389,00$ & 2,5 \\
$10^{\text {o }}$ & Portugal & $2.130,00$ & 2,3 \\
$25^{\circ}$ & Brasil & 247,10 & 0,3 \\
\hline Total & & $\mathbf{9 8 . 8 4 9 , 1 0}$ & $\mathbf{1 0 0 , 0}$
\end{tabular}

Tabela 3 - Potencial Eólico Instalado no Mundo

Fonte: Atlas de Energia Elétrica do Brasil - $3^{\text {a }}$ Edição - 2008 


\subsection{Objetivo}

Este trabalho visa analisar, através de medições laboratoriais, as interferências e os níveis das harmônicas dos principais modelos de aerogeradores utilizados no mercado de geração de energia eólica, com base nos parâmetros de qualidade estabelecidos inicialmente pela resolução 345/2008 e modificada pelas resoluções 395/2009 e 424/2010 da ANEEL (PRODIST), em função dos diferentes tipos de controle de tensão e frequência utilizadas neste modelo de geração.

Os objetivos específicos são:

- medir as distorções harmônicas em modelos laboratoriais dos principais tipos de aerogeradores existentes no mercado em diversas condições de carga (conforme norma NBR-IEC-61400-21) para determinar a distorção harmônica da própria unidade geradora, através de registrador de qualidade de energia eletrônico;

- mensurar as distorções geradas pela rede, bem como as oriundas das unidades geradoras;

- comparar os resultados obtidos nas medições em laboratório com as medições reais efetuadas por um fabricante de geradores eólicos do mercado;

- analisar comparativamente os resultados apresentados, quanto às distorções harmônicas, pelos principais tipos de aerogeradores;

- analisar a contribuição harmônica de um grupo de aerogeradores conectados à rede elétrica.

\subsection{Justificativa}

O Brasil tem passado por diversas crises de energia em sua história, como as crises do petróleo de 1973 e 1979, a crise de energia elétrica de 2001 e atualmente repete-se o cenário de pré-crise em 2001. 
Focando exclusivamente nas crises de energia elétrica de 2001 e na atual, desenharemos o cenário destas crises para explicar a importância deste trabalho em função da necessidade da diversificação da matriz energética brasileira. Essa necessidade é amplamente citada toda vez que o quadro de crise se apresenta, ressaltando que a matriz energética brasileira é predominante hidráulica, conforme pode ser verificado na Figura 1.

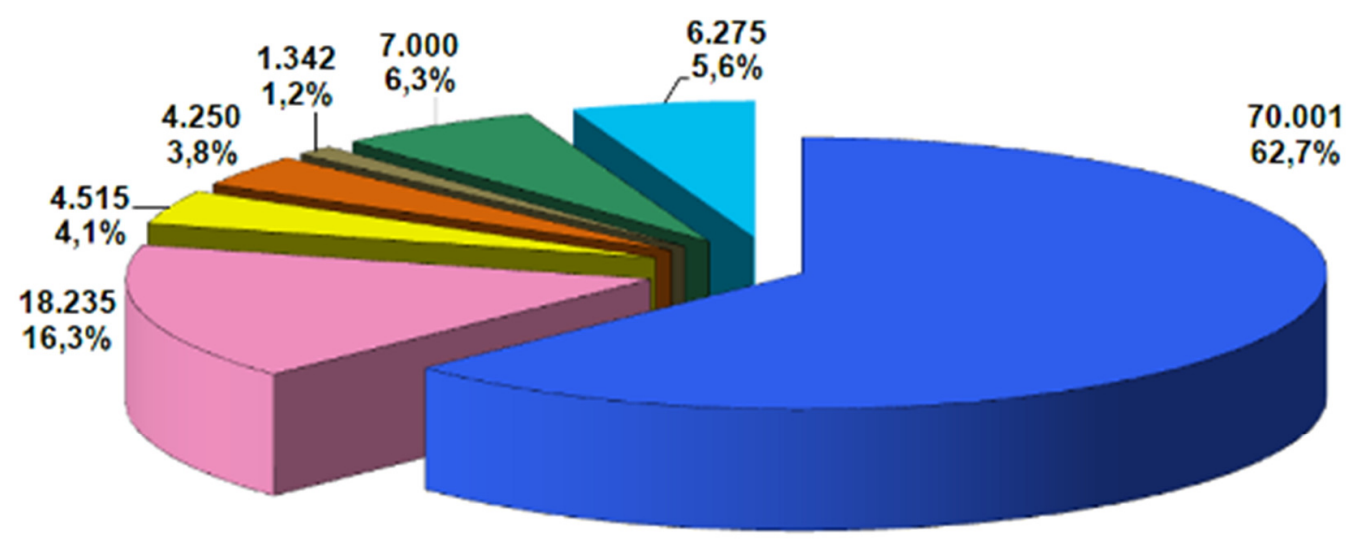

Total Disponível: $111.618 \mathrm{MW}$

\begin{tabular}{|c|c|c|}
\hline DHidráulica & $\sqsupset$ Térmica & $\sqsupset \mathrm{PCHs}$ \\
\hline Biomassa & Eólicas & Itaipu $60 \mathrm{~Hz}$ (Brasil) \\
\hline Compras Itaipu & & \\
\hline
\end{tabular}

Figura 1 - Capacidade Instalada no Sistema Interligado Nacional - SIN (MW) Fonte: Plano de Operação Energética 2012/2016 - PEN-2012 Volume I

Analisando a crise de energia elétrica de 2001, quando os consumidores se viram obrigados a racionar o consumo para evitar o desabastecimento de energia que surgiria em forma de "apagões", o cenário apresentado pelo Governo Federal na época apontava como única causa do problema a falta de chuvas nos reservatórios. Ou seja, a responsabilidade foi atribuída a algo sem nenhum tipo de controle por parte dos responsáveis pelo planejamento estratégico do governo.

Entretanto, ao se analisar os dados pluviométricos e os níveis dos reservatórios da Região Hidrográfica do Paraná nesta época, pode-se verificar que os dados levantados não conferem com aqueles divulgados na época, pois os reservatórios aparentemente estavam com níveis abaixo daqueles dos anos anteriores (28,10\% em 2001 contra 39,21\% em 2000 e 56,64\% em 2002). Isso 
pode ser verificado nos gráficos apresentados na Figura 2, porém o nível de chuvas nestas regiões não estava abaixo da média histórica, conforme verificado na Tabela 4 , inclusive sendo registrado que em 2002 o nível de chuva foi muito abaixo de 2001 (1502,3 mm em 2001 contra 1379,8 mm em 2000 e 1001,2 mm em 2002), fonte: Relatório do Departamento Autônomo de Águas e Esgoto de Penápolis - DAEP e Relatório № 04 do Ministério do Meio Ambiente - Região Hidrográfica do Paraná.

\begin{tabular}{ccc}
\hline Ano & $\begin{array}{c}\text { Índice } \\
\text { Pluviométrico } \\
(\mathbf{m m})\end{array}$ & $\begin{array}{c}\text { Média Anual } \\
\mathbf{( 1 9 6 1} \text { a 2004) }\end{array}$ \\
\hline 1999 & 1456,4 & \\
2000 & 1379,8 & \\
2001 & 1502,3 & 1482,8 \\
2002 & 1001,2 & \\
2003 & 1260,9 & \\
\hline
\end{tabular}

Tabela 4 - Índice Pluviométrico Anual (Total de Chuvas da Região Hidrográfica do Paraná) Fonte: Relatório do Departamento Autônomo de Águas e Esgoto de Penápolis

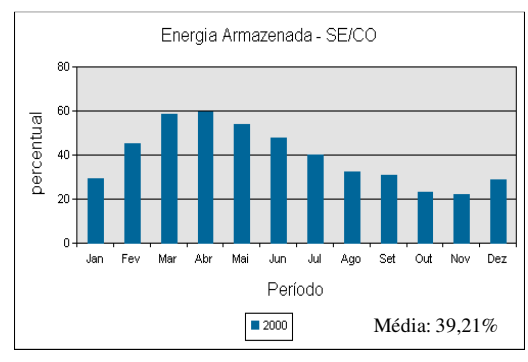

(A)

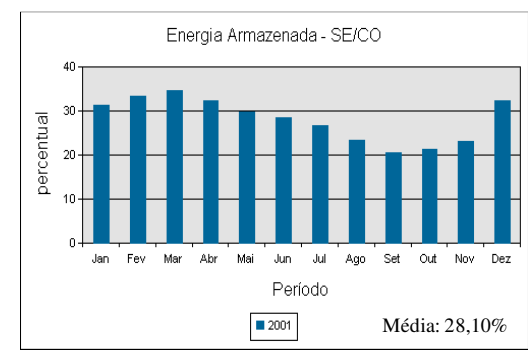

(B)

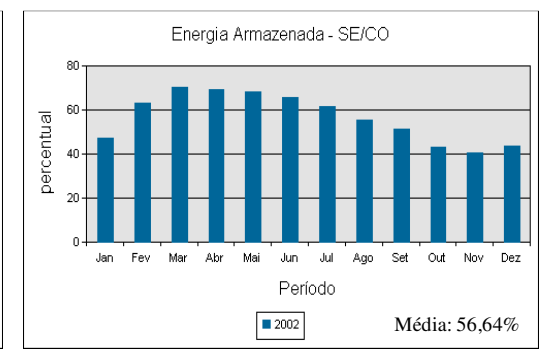

(C)

Figura 2 - Porcentagem de Energia Armazenada nos Reservatórios das Usinas Hidrelétricas das Regiões SE/CO - Anos 2000 (A), 2001 (B) e 2002 (C)

Fonte: Histórico da Situação dos Reservatórios (Energia Armazenada por Região) - ONS

Portanto, se os índices de chuva não contribuíram exclusivamente para a diminuição dos níveis dos reservatórios, conclui-se que isso se deu pelo consumo excessivo das reservas de água desses mesmos reservatórios em função do aumento do consumo de energia, principalmente durante o horário de ponta do sistema, conforme pode ser verificado na curva de carga diária apresentada no Gráfico da Figura 3. 


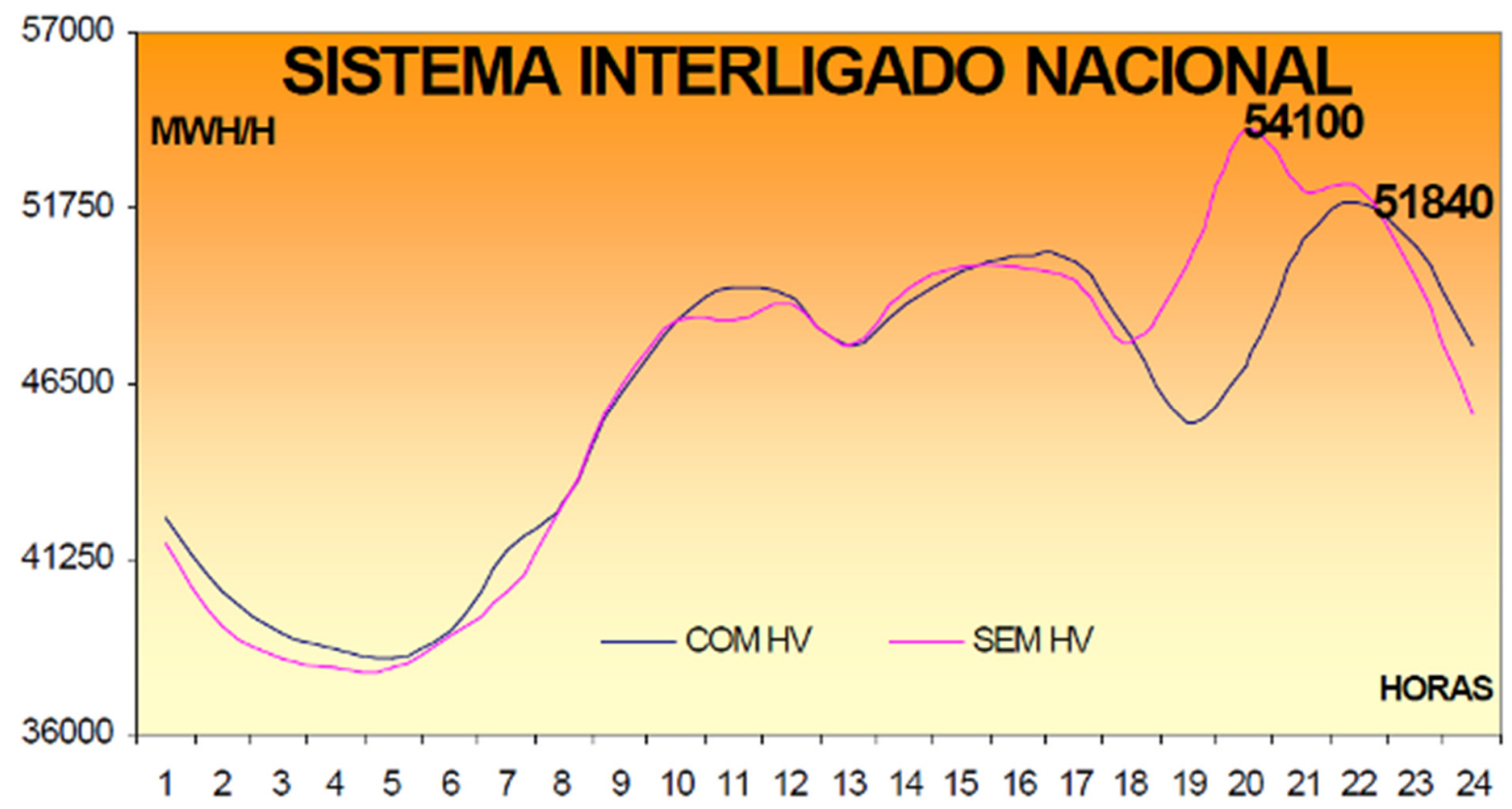

Figura 3 - Redução da demanda no horário de ponta do Sistema Interligado Nacional - SIN - MWh/h Fonte: Relatório ONS-2001 - Resultado da Implantação do Horário de Verão (HV) 2000-2001

Neste caso, verifica-se através deste gráfico, que o pico do consumo de energia no horário de ponta chegou a atingir, no ano de 2001, o valor de $54.100 \mathrm{MWh} / \mathrm{h}$, o que corresponde a um pico desse mesmo valor para a Demanda de Energia em $\mathrm{kW}$ (lembrando que o racionamento ocorreu em Julho de 2001, fora portanto, do horário de verão).

Como pode ser observado na Tabela 5, a capacidade máxima de geração no ano de 2001 era de $71.117 \mathrm{MW}$, de modo que a demanda de carga foi correspondente a aproximadamente $76 \%$ da capacidade máxima de geração. Este fato obrigou os operadores do sistema (ONS) a fazer com que no horário de ponta, diariamente, as unidades geradoras trabalhassem com níveis máximos de geração, consumindo, portanto, todas as reservas hidráulicas dos reservatórios do Sistema Interligado Nacional, diminuindo assim o nível dos reservatórios em todo sistema. 


\begin{tabular}{ccccccccccc}
\hline Anos & \multicolumn{3}{c}{ Hidro } & \multicolumn{3}{c}{ Termo } \\
& $\begin{array}{c}\text { SP e/ou } \\
\text { PIE }\end{array}$ & APE & Total & $\begin{array}{c}\text { SP e/ou } \\
\text { PIE }\end{array}$ & $\begin{array}{c}\text { APE } \\
\text { SPeleo } \\
\text { PIE }\end{array}$ & $\begin{array}{c}\text { Total } \\
\text { PIE e/ou }\end{array}$ & $\begin{array}{c}\text { Totais } \\
\text { APE }\end{array}$ & Total \\
\hline 2000 & 60.095 & 968 & 61.063 & 6.567 & 4.075 & 10.642 & 2.007 & 68.669 & 5.043 & 73.712 \\
2001 & 61.551 & 972 & 62.523 & 7.559 & 4.166 & 11.725 & 2.007 & 71.117 & 5.138 & 76.755 \\
2002 & 64.146 & 1.165 & 65.311 & 10.654 & 4.486 & 15.140 & 2.007 & 76.807 & 5.651 & 82.458 \\
\hline
\end{tabular}

Serviço Público PIE-Produtor Independente $A$

(*) Inclui metade da Usina de Itaipu

Nota 1: As usinas PIE e SP da ANEEL, com parcelas de APE, estão classificadas em SP e/ou PIE (UHE Igarapa, Porto Estrela,

Funil, Canoas I e II, Machadinho, etc.

Nota 2: As usinas PIE da ANEEL, tradicionalmente APE, estão classificadas em APE.

Nota 3: UTE Camaçari BA, de 290MW a óleo, em 31/12/2001, passou a 72MW, a gás natural, em 31/12/2002.

Tabela 5 - Capacidade Instalada de Geração Elétrica no Brasil - 2000-2002 (MWmed)

Fonte: Balanço Energético Nacional (BEN-2003) - ANEEL

Estes fatos puderam ser confirmados no ano de 2002, pois após a crise de energia de 2001 os consumidores, principalmente os industriais, diminuíram o consumo de energia, preferencialmente no horário de ponta, colocando em funcionamento grupos geradores a diesel com intuito de garantir o abastecimento de energia durante os "apagões" e depois, migrando para tarifas horo-sazonais onde estes grupos geradores forneciam energia nos horários de ponta, desligando assim suas cargas das redes das concessionárias, o que fez com que o consumo de energia, principalmente no horário de ponta, diminuísse, recuperando o nível dos reservatórios, mesmo com o nível de chuva ficando abaixo do ano anterior.

Isso obrigou as concessionárias de energia a rever seus planejamentos, pois nesse ano elas registraram prejuízos significativos em função da diminuição do consumo de energia sem haver a respectiva redução dos contratos de fornecimento dessas com as geradoras. Isso provocou a sobra de energia no mercado.

Em função das últimas ocorrências no sistema elétrico brasileiro, principalmente com a nova redução dos níveis dos reservatórios, tudo indica que esse cenário está se repetindo, em parte pela falta de investimentos em novos sistemas de geração para ampliação do parque gerador (que poderiam suprir este aumento da demanda), provocados principalmente pelos altos custos desses investimentos e pelo longo tempo do retorno do capital investido.

Isso se deve em parte à demora da liberação das licenças ambientais necessárias para aprovação desse tipo de investimento e em parte pelo não gerenciamento da carga (falta de 
incentivo ao uso da energia fora do horário de ponta), que se fosse feito adequadamente poderia minimizar investimentos imediatos na área de geração e diminuir a pressão sobre o parque gerador brasileiro.

Dessa forma, surge como opção para atenuar o problema a geração de energia elétrica através de aerogeradores (geração eólica), os quais causam menor impacto no ambiente, necessitando de menores mudanças estruturais, o que deve facilitar a obtenção das licenças ambientais, reduzindo o tempo de retorno do investimento realizado, além de ter um custo de implantação cada vez mais competitivo com relação à geração hidráulica (o custo de implantação vem sendo reduzido com o aumento dos investimentos na área).

Isso se verifica através de uma tendência de aumento de investimentos no segmento da geração eólica, inclusive por incentivos governamentais, tais como as políticas de incentivo a fontes alternativas do Governo Federal (Lei 10.438 de 26 de abril de 2002 - Programa de Incentivo às Fontes Alternativas de Energia Elétrica - PROINFA), o que deve aumentar a oferta desse tipo de geração de energia no país. O potencial eólico brasileiro é de 143,4 GW, como pode ser visto no mapa da Figura 4, sendo que atualmente o Brasil tem implantado somente 1,425 GW, o que representa apenas $0,99 \%$ de aproveitamento do total disponível, como pode ser verificado na Tabela 6. 


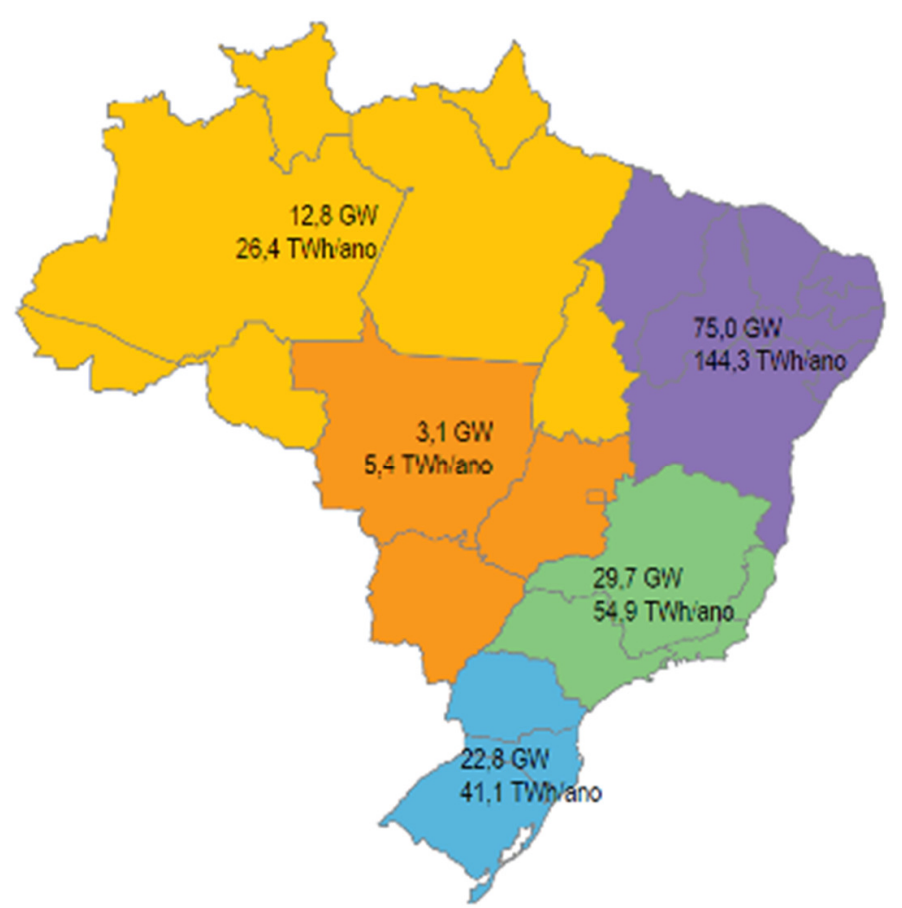

Figura 4: Mapa do Potencial Eólico Brasileiro

Fonte: Atlas de Energia Elétrica do Brasil - 3ª Edição - 2008.

\begin{tabular}{|c|c|c|c|c|c|c|c|c|c|c|c|c|c|}
\hline FSTADO & & HIDRO & & & TERMO & & & EÓLICA & & NUUCLEO & & TOTAL & \\
\hline ESIADO & SP & APE & Total & SP & APE & Total & $\mathrm{SP}$ & APE & Total & SP & SP & APE & Total \\
\hline BRASIL & 78.023 & 4.436 & 82.459 & 17.774 & 13.469 & 31.243 & 1.425 & 0 & 1.425 & $\begin{array}{c}2.00 \\
7\end{array}$ & 99.230 & 17.905 & 117.135 \\
\hline
\end{tabular}

SP - Serviço Público PIE - Produtor Independente APE - Autoprodutor

Tabela 6 - Capacidade Instalada de Geração Elétrica no Brasil - 2011 (MWmed)

Fonte: Balanço Energético Nacional (BEN-2012) - ANEEL

Dessa forma, a quantidade de usinas eólicas a serem instaladas no Brasil nos próximos anos deve aumentar significativamente, com uma previsão de crescimento de 509,2\% até 2016 em relação ao potencial instalado em 2011, como mostrado na Tabela 7. 


\begin{tabular}{|c|c|c|c|c|c|c|}
\hline \multirow[t]{2}{*}{ TIPO } & \multicolumn{2}{|c|}{2011} & \multicolumn{2}{|c|}{2016} & \multicolumn{2}{|c|}{$\begin{array}{c}\text { Crescimento } \\
2011-2016\end{array}$} \\
\hline & MW & $\%$ & MW & $\%$ & MW & $\%$ \\
\hline Hidráulica $^{(1)}$ & 87.791 & 78,7 & 103.447 & 71,2 & 15.656 & 17,8 \\
\hline Nuclear & 2.007 & 1,8 & 3.395 & 2,3 & 1.388 & 69,2 \\
\hline Gás/GNL & 9.263 & 8,3 & 12.686 & 8,7 & 3.423 & 37,0 \\
\hline Carvão & 1.765 & 1,6 & 3.205 & 2,2 & 1.440 & 81,6 \\
\hline Biomassa & 4.250 & 3,8 & 6.062 & 4,2 & 1.812 & 42,6 \\
\hline Outros $(2)$ & 749 & 0,7 & 749 & 0,5 & - & 0,0 \\
\hline Óleo & 4.451 & 4,0 & 7.657 & 5,3 & 3.206 & 72,0 \\
\hline \multicolumn{7}{|c|}{ Combustível/Diesel } \\
\hline Eólica & 1.342 & 1,2 & 8.176 & 5,6 & 6.834 & 509,2 \\
\hline Total & 111.618 & 100,0 & 145.377 & 100,0 & 33.759 & 30,2 \\
\hline
\end{tabular}

Obs.: (1) A contribuição das PCHs e da UHE Itaipu está considerada na parcela "Hidráulica".

(2) A parcela "Outros" se refere a outras usinas térmicas com CVU. $1 \mathrm{w}$

Tabela 7 - Resumo da Evolução da Matriz de Energia Elétrica Brasileira 2011-2016 (MWmed) Fonte: Plano de Operação Energética - 2012-2016 (PEN-2012) - ONS

Entretanto, surge uma questão importante com relação às interferências elétricas que este tipo de geração de energia pode provocar no sistema elétrico caso seja utilizado em larga escala, pois estas interferências podem provocar perdas e danos a equipamentos e instalações, tanto do próprio sistema elétrico como dos consumidores alimentados por suas redes.

Por este motivo é importante a verificação dessas interferências através da análise da qualidade de energia desse tipo de geração, principalmente quanto à geração harmônica que é provocada na geração eólica pelos seus sistemas de controle de tensão e frequência.

Entretanto, faltava ao país uma política pública que estipulasse padrões de qualidade de energia para que as perdas oriundas do fornecimento de energia e distorções provocadas pelas cargas pudessem ser controladas, melhorando o desempenho dos sistemas.

Inicialmente foram publicadas pela Agência Nacional de Energia Elétrica - ANEEL as resoluções 456/2000 (atualizada pela resolução 414/2010) e 024/2002 que estabeleceram os padrões de qualidade de fornecimento de energia, e a resolução 505/2002, que controla exclusivamente o fator de potência das instalações, não entrando no mérito das demais perturbações. 
Em 16/12/2008 foi publicada pela ANEEL a resolução 345/2008, que estabeleceu os "Procedimentos de Distribuição de Energia Elétrica no Sistema Elétrico Nacional - PRODIST", o qual deve ser seguido por todas as concessionárias de energia elétrica do Brasil e alterado pelas resoluções 395/2009 e 424/2010. Analisando esses documentos, verifica-se a preocupação que os órgãos públicos e as concessionárias de energia estão tendo com o nível de harmônicas geradas pela carga, que interferem diretamente na disponibilidade de energia aos consumidores e onera significativamente as concessionárias de energia. Por este motivo, o documento cita que em um prazo de 03 (três) anos, período para levantamento de dados e determinação de valores regulamentares, a ANEEL iria publicar outra resolução, onde seriam acertados os valores de referência e, a partir de então, as concessionárias de distribuição de energia do país poderiam, inclusive, cobrar multas dos consumidores que estivessem gerando níveis de distorção harmônica superiores aos limites estabelecidos nessa nova resolução, conforme texto extraído da resolução 395/2009, nos Procedimentos de Distribuição de Energia Elétrica no Sistema Elétrico Nacional PRODIST, módulo 08 (Qualidade de Energia), item 04 (Harmônicas), porém até o presente momento, isso não ocorreu.

Esse tipo de problema, que surge quando do uso de cargas não lineares como inversores de frequência, equipamentos com núcleo saturado, reatores eletrônicos, fontes chaveadas e equipamentos a arco, provoca danos e interferências às instalações dos demais consumidores e principalmente afeta a disponibilidade de energia oriunda da concessionária, que faz com que seja necessário o aumento da produção de energia para suprir essas perdas geradas pelas próprias cargas dos consumidores.

Ocorre que pela natureza do problema apresentado (harmônicas), surge a necessidade de se determinar se estas distorções não podem também estar sendo geradas pelas próprias empresas que geram energia elétrica com aerogeradores (geradoras eólicas), ou seja, se estas mesmas fontes geradoras eólicas não podem estar contribuindo para aumentar essas distorções em função do controle eletrônico de tensão e frequência utilizadas em seus sistemas. Essa situação ressalta a importância de se analisar o nível de interferência harmônica que as cargas dos consumidores de energia impõem aos circuitos de geração das usinas eólicas e vice-versa, de modo a se poder avaliar a extensão do problema. 


\subsection{Estrutura do Trabalho}

O trabalho está dividido em 05 capítulos, os demais estão assim relacionados:

- O capítulo 02 trata do estado da arte, compreendendo conceitos de geração eólica, aerogeradores, qualidade de energia, distorções harmônicas, sistema interligado nacional, sistema de geração de energia e o controle de tensão e frequência de aerogeradores;

- O capítulo 03 trata da análise comparativa dos procedimentos de medição e avaliação da qualidade de energia de aerogeradores conectados à rede elétrica, a saber: o procedimento de instruções para realização de estudos e medições de qualidade de energia elétrica relacionados aos novos acessos à rede básica da ONS e a norma NBRIEC-61400-21 (requisitos de qualidade de energia de aerogeradores conectados à rede);

- O capítulo 04 trata da metodologia utilizada no estudo dos procedimentos experimentais a serem utilizados para a medição das grandezas elétricas das unidades geradoras eólicas, montagem e coleta de dados e análise das medições efetuadas;

- O capítulo 05 trata das conclusões e propostas de trabalhos futuros. 


\section{Estado da Arte}

\subsection{Geração Eólica}

Os ventos utilizados como fonte primária de energia eólica são gerados pela radiação solar através do aquecimento não uniforme da superfície terrestre, o que faz com que massas de ar se desloquem pelo planeta. Pode-se estimar o total de energia disponível dos ventos ao redor do planeta observando que aproximadamente $2 \%$ da energia solar absorvida pela Terra é convertida em energia cinética dos ventos (fonte: apostila de Energia Eólica - Princípios e Aplicações - CRESESB). Este percentual, embora pequeno, representa centena de vezes a potência anual instalada nas centrais elétricas do mundo.

Um estudo realizado pelas Universidades de Stanford e Delaware (Saturation wind power potential and its implications for wind energy) criou um modelo computacional tridimensional, onde foi calculada a potência total de saturação eólica da Terra, que é de $250 \mathrm{TW}$, considerando o uso de turbinas de 100 metros de altura espalhadas por todas as porções de terra do globo terrestre. Isso é inviável do ponto de vista prático, porém o estudo mostra também que se fosse usado apenas $0,5 \%$ destas áreas, o que é bem mais realista, significaria uma produção de energia aproximada de 5,75 TW, o que corresponderia a 50\% da demanda de energia para 2030. Para isto porém, seria necessária a instalação de algo em torno de 4 milhões de turbinas de 5,0 MW cada, lembrando que a maior turbina eólica atualmente construída tem capacidade de gerar 7,0 MW de energia. Embora estes números possam não parecer significativos, o uso dessa tecnologia deve representar uma redução nos impactos ambientais em função das crescentes demandas de energia, e, juntamente com outras ações, deve garantir o fornecimento de energia por um grande período.

As regiões tropicais, que recebem os raios solares quase que perpendicularmente, são mais aquecidas do que as regiões polares. Consequentemente, o ar quente que se encontra nas baixas altitudes das regiões tropicais tende a subir, sendo substituído por uma massa de ar mais fria que se desloca das regiões polares. O deslocamento de massas de ar determina a formação dos ventos, conforme pode ser verificado na Figura 5. 


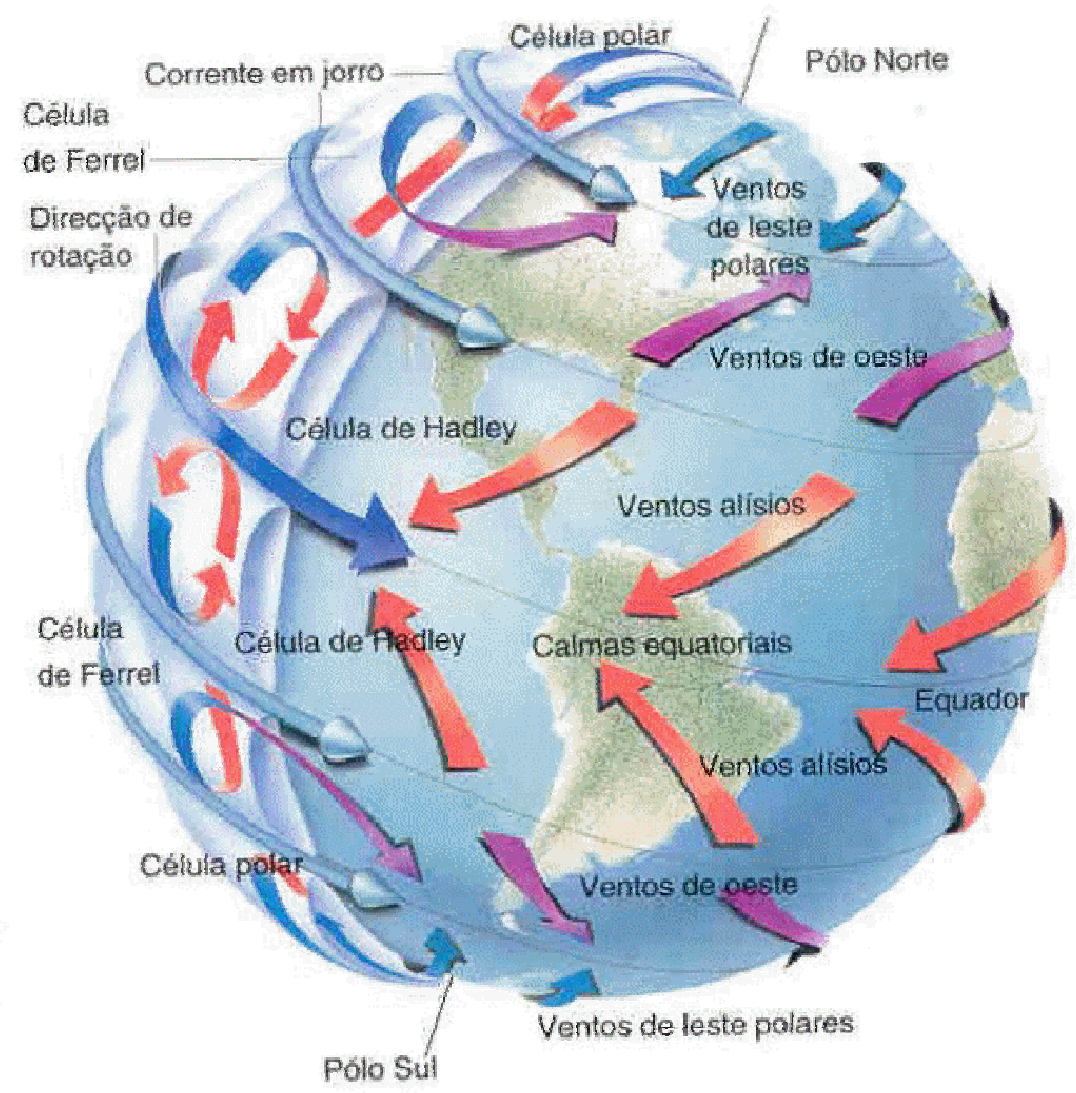

Figura 5 - Distribuição Geral dos Ventos pelo Mundo Fonte: http://ventos.pbworks.com/w/page/9917412/Ventos

Existem locais no globo terrestre nos quais os ventos jamais cessam de "soprar", pois os mecanismos que os produzem (aquecimento no equador e resfriamento nos polos) estão sempre presentes na natureza. São chamados de ventos planetários ou constantes e podem ser classificados em:

- Alísios: ventos que sopram dos trópicos para o Equador, em baixas altitudes;

- Contra-Alísios: ventos que sopram do Equador para os polos, em altas altitudes;

- Ventos do Oeste: ventos que sopram dos trópicos para os polos;

- Polares: ventos frios que sopram dos polos para as zonas temperadas;

Como o eixo da Terra está inclinado de $23,5^{\circ}$ em relação ao plano de sua órbita em torno do Sol, variações sazonais na distribuição de radiação recebida na superfície da Terra 
resultam em variações sazonais na intensidade e duração dos ventos, em qualquer local da superfície terrestre. Como resultado, surgem os ventos continentais ou periódicos e compreendem as monções e as brisas.

As monções são ventos periódicos que mudam de direção a cada seis meses, aproximadamente. Em geral, as monções sopram em determinada direção em uma estação do ano e em sentido contrário em outra estação.

Em função das diferentes capacidades de refletir, absorver e emitir o calor recebido do Sol inerente a cada tipo de superfície (tais como mares e continentes) surgem as brisas, que se caracterizam por serem ventos periódicos que sopram do mar para o continente e vice-versa. No período diurno, devido à maior capacidade da terra de refletir os raios solares, a temperatura do ar aumenta e, como consequência, forma-se uma corrente de ar que sopra do mar para a terra (brisa marítima). À noite, a temperatura da terra esfria mais rapidamente do que a temperatura da água e, assim, ocorre a brisa terrestre, que sopra da terra para o mar. Normalmente, a intensidade da brisa terrestre é menor do que a da brisa marítima devido à menor diferença de temperatura que ocorre no período noturno.

Sobrepostos ao sistema de geração dos ventos descrito acima encontram-se os ventos locais, que são originados por outros mecanismos mais específicos. São ventos que sopram em determinadas regiões e são resultantes das condições locais, que os tornam bastante individualizados. A mais conhecida manifestação local dos ventos é observada nos vales e montanhas. Durante o dia, o ar quente nas encostas da montanha se eleva e o ar mais frio desce sobre o vale para substituir o ar que subiu. No período noturno, a direção em que sopram os ventos é novamente revertida e o ar frio das montanhas se acumula nos cumes.

A direção do vento também é um importante parâmetro a ser analisado, pois mudanças de direção frequentes indicam situações de rajadas de vento. Além disso, a medida da direção do vento auxilia na determinação da localização das turbinas em um parque eólico. Devido à 
existência do problema de "sombra", isto é, a interferência das esteiras das turbinas, é fundamental o conhecimento da direção predominante.

Do ponto de vista do aproveitamento da energia eólica é importante distinguir os vários tipos de variações temporais da velocidade dos ventos, a saber: variações anuais, sazonais, diárias e de curta duração.

Variações Anuais - Para se obter um bom conhecimento do regime dos ventos não é suficiente basear-se na análise de dados de vento de apenas um ano; o ideal é dispor de dados referentes a vários anos. À medida que uma maior quantidade de dados anuais são coletados, as características levantadas do regime local dos ventos tornam-se mais confiáveis.

Variações Sazonais - O aquecimento não uniforme da superfície terrestre resulta em significativas variações no regime dos ventos, resultando na existência de diferentes estações do ano. Em função da relação cúbica entre a potência disponível e a velocidade do vento (na altura do eixo da turbina), em algumas faixas de potência uma pequena variação na velocidade implica numa grande variação na potência. Sendo assim, a utilização de médias anuais (ao invés de médias sazonais) pode levar a resultados que se afastam da realidade.

Variações Diárias - As variações diárias na velocidade do vento (brisas marítimas e terrestres, por exemplo) também são causadas pelo aquecimento não uniforme da superfície da Terra. Essas variações são importantes quando, após a escolha de uma região, procura-se o local mais adequado para a instalação do sistema eólico dentro dessa área. Ao comparar a evolução da velocidade média ao longo do dia percebe-se que há uma significativa variação de um mês para os outros. Com esse tipo de informação pode-se projetar melhor o sistema eólico. Por exemplo, nos locais em que os ventos no período do dia são mais fortes do que os ventos no período da noite e o pico da carga ocorre durante o dia, a carga base pode ser fornecida pelo sistema existente e a carga adicional, pelo sistema eólico. Entretanto, se o pico da carga ocorre durante a noite, a demanda pode ser maior do que a disponível e um sistema de estocagem pode se fazer necessário. 
Variações de Curta Duração - As variações de curta duração estão associadas tanto às pequenas flutuações quanto às rajadas de vento. Num primeiro momento, essas variações não são consideradas na análise do potencial eólico de uma região, desde que não assumam grandes proporções. As flutuações e a turbulência do vento podem afetar a integridade estrutural do sistema eólico devido à fadiga que ocorre especialmente nas pás da turbina. Por outro lado, as rajadas, caracterizadas por aumentos bruscos e de curta duração da velocidade do vento, geralmente acompanhados por mudanças de direção, merecem maior atenção.

\subsection{Os Aerogeradores}

\section{Turbinas Eólicas}

A turbina eólica, ou aerogerador, é uma máquina eólica que absorve parte da potência cinética do vento através de um rotor aerodinâmico, convertendo em potência mecânica de eixo (torque x rotação), a qual é convertida em potência elétrica (tensão x corrente) através de um gerador elétrico. A turbina eólica é composta pelo rotor e pela torre que o sustenta, pela transmissão/multiplicação e pelo conversor. Ela pode extrair energia cinética somente do ar que passa através da área interceptada pelas pás rotativas. Embora combinada com a eficiência do modelo de turbina utilizada, a área varrida pelo rotor circular $\left(\pi r^{2}\right)$ é um fator crucial na determinação da energia entregue pela turbina eólica. A energia cinética bruta por unidade de tempo (potência) do vento passando por uma área $\mathbf{A}$ perpendicular ao seu vetor velocidade instantânea $\mathbf{V}$ é dada por:

$$
P=\frac{C_{p} \times \rho \times A \times V^{3}}{2}
$$

onde:

$\boldsymbol{\rho}=$ densidade do ar, que varia com a latitude e as condições atmosféricas; $\rho \approx 1.2 \mathrm{~kg} / \mathrm{m}^{3}$;

$\mathbf{C p}=$ é o coeficiente da performance que se relaciona com a energia cinética de saída e depende do modelo de turbina utilizada e na relação entre a velocidade do rotor e a velocidade do vento.

$\mathbf{V}=$ velocidade do vento $\mathrm{em} \mathrm{m} / \mathrm{s}$.

$\mathbf{A}=$ Área total da circunferência formada pela circulação das pás do rotor em $\mathrm{m}^{2}$. 
A energia potencial da turbina eólica depende do cubo da velocidade do vento; isto significa, por exemplo, que se a velocidade do vento em um local dobrar, a energia potencial de saída de uma turbina eólica é multiplicada por 8. Esta sensibilidade da energia com a velocidade do vento mostra a importância da obtenção dos dados do vento para a estimativa da energia disponível.

A velocidade média anual é um bom parâmetro para pesquisar o vento. Além da velocidade média anual do vento, as médias mensais são úteis, já que elas dão uma melhor ideia das variações sazonais. Isto é importante quando a investigação do abastecimento de energia parte da demanda mensal.

A velocidade mínima do vento para garantir uma geração eólica competitiva é de 5,0 m/s, conforme pode ser verificado na Tabela 8. Isto implica que somente algumas regiões do País possuem viabilidade para implantação de parques eólicos, como pode ser verificado na Figura 6.

\begin{tabular}{ll}
\hline Velocidade média anual $10 \mathrm{~m}$ acima do nível do solo & Possibilidades de uso para a energia eólica \\
\hline Abaixo de $3 \mathrm{~m} / \mathrm{s}$ & $\begin{array}{l}\text { Usualmente não viável, a menos em situações } \\
\text { especiais. }\end{array}$ \\
de $3-4 \mathrm{~m} / \mathrm{s}$ & $\begin{array}{l}\text { Pode ser uma opção para bombas eólicas, } \\
\text { improvável para geradores eólicos. }\end{array}$ \\
de $4-5 \mathrm{~m} / \mathrm{s}$ & $\begin{array}{l}\text { Bombas eólicas podem ser competitivas com } \\
\text { bombas a Diesel. Pode ser viável para geradores }\end{array}$ \\
& eólicos isolados \\
Mais que $5 \mathrm{~m} / \mathrm{s}$ & Viável tanto para bombas eólicas quanto para \\
& geradores eólicos isolados \\
Mais que $7 \mathrm{~m} / \mathrm{s}$ & Viável para bombas eólicas, geradores eólicos \\
& isolados e conectados à rede. \\
\hline
\end{tabular}

Tabela 8 - Velocidade do Vento para uso com Energia Eólica.

Fonte: Apostila de Fontes de Energia Renováveis - UFRJ 


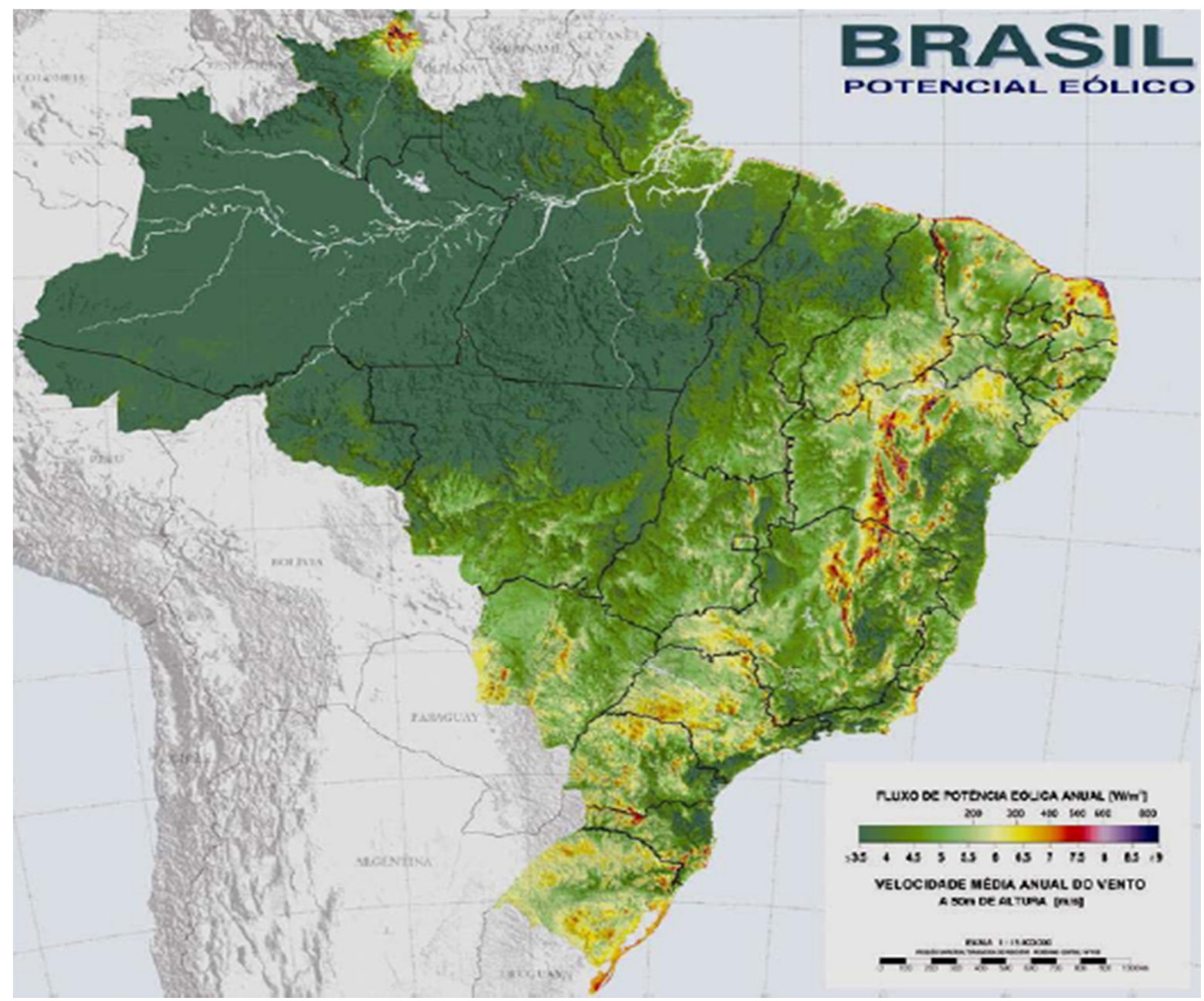

Figura 6 - Mapa do Potencial Eólico do Brasil

Fonte: Atlas de Energia Elétrica do Brasil - $3^{\mathrm{a}}$ Edição - 2008

A velocidade do vento decresce à medida que se aproxima da superfície da terra devido à fricção entre o ar e a solo. A quantidade de decréscimo depende da rugosidade do solo; por exemplo, áreas florestais têm menor escoamento de ar que áreas descampadas. Medições em estações meteorológicas são geralmente tomadas em duas alturas-padrão: 2 metros (para propósitos agrícolas) e 10 metros (o padrão internacional para medições meteorológicas e geração de energia eólica). 


\section{Rotor}

Componente destinado a captar energia cinética dos ventos e convertê-la em energia mecânica no eixo. Se o eixo do rotor for posicionado horizontal ou verticalmente, teremos um rotor de eixo horizontal (rotor hélice, rotor multipás, multivane fans, rotor holandês, etc.) ou um rotor de eixo vertical (rotor Savonius, rotor Darrieus, etc.), conforme visto nas Figuras 7 e 8.

Em geral, os rotores de eixo vertical têm a vantagem de não necessitarem de mecanismos de acompanhamento para variações da direção do vento, o que reduz a complexidade do projeto e os esforços devido às forças de Coriolis (fonte: Apostila de Física da UFPR - site: http://fisica.ufpr.br/grimm/aposmeteo/cap7/cap7-3.html). Os rotores de eixo vertical também podem ser movidos por forças de sustentação (lift) e por forças de arrasto (drag) (fonte: Apostila O que faz um avião voar da UFRGS - site: http://www.if.ufrgs.br/tex/fis01043/20031/Andre/index.htm).

Os principais tipos de rotores de eixo vertical são Darrieus, Savonius e turbinas com torre de vórtices. Os rotores do tipo Darrieus são movidos por forças de sustentação e constituem-se de lâminas curvas (duas ou três) de perfil aerodinâmico, atadas pelas duas pontas ao eixo vertical.
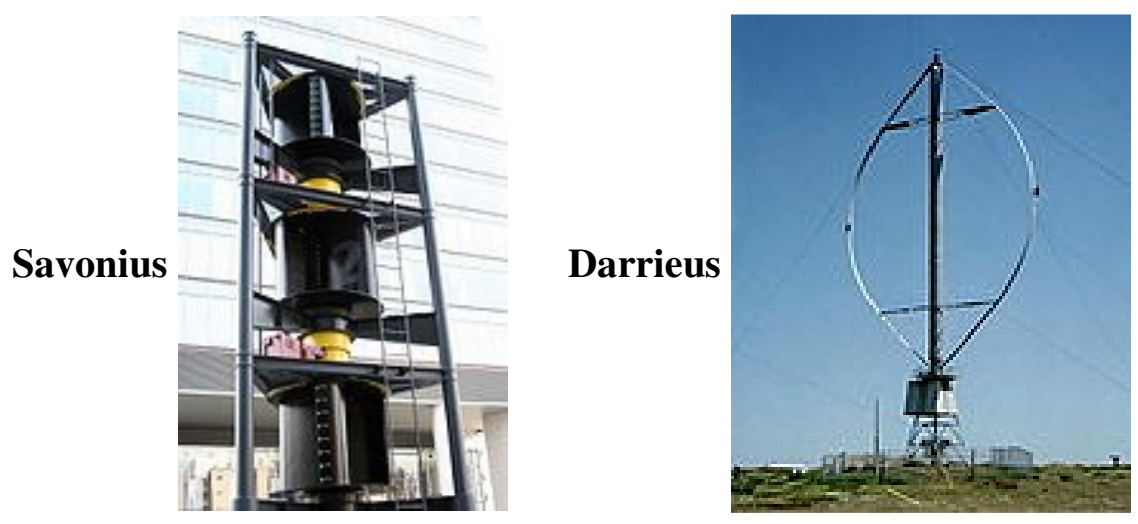

Figura 7 - Aerogeradores de EixoVertical Fonte: Relatório do Centro Brasileiro de Energia Eólica - 2008 

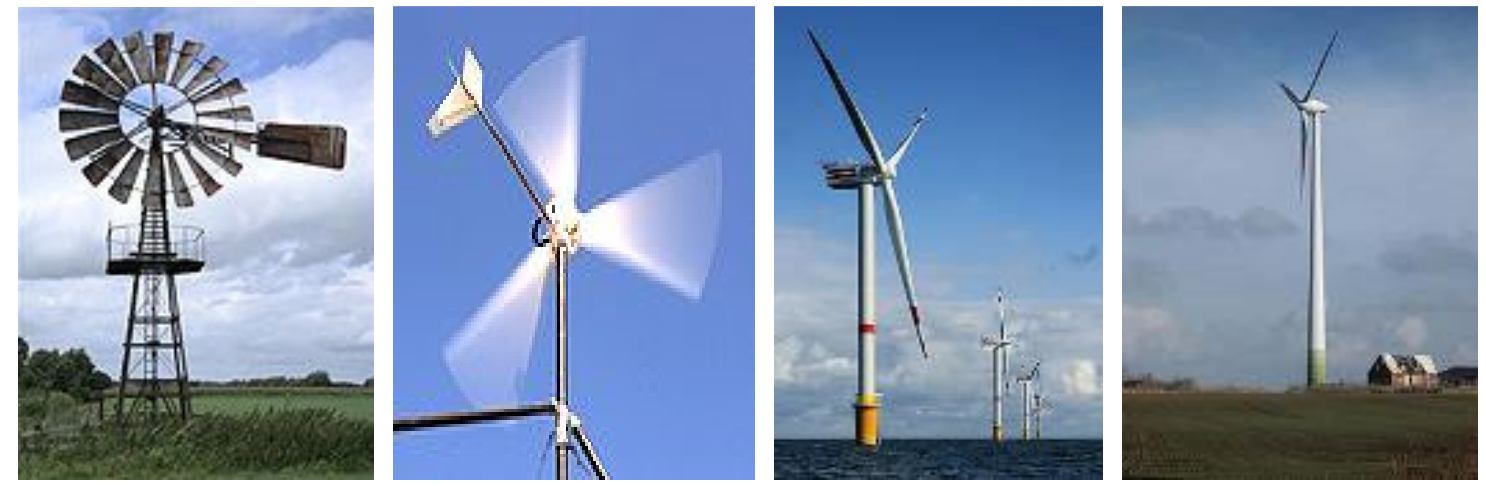

Figura 8 - Aerogeradores de Eixo Horizontal

Fonte: Relatório do Centro Brasileiro de Energia Eólica - 2008

Rotores de eixo horizontal são movidos por forças aerodinâmicas chamadas de forças de "lift" e forças de "drag". Um corpo que obstrui o movimento do vento sofre a ação de forças perpendiculares ao fluxo de vento relativo (forças de "lift") e de forças paralelas ao fluxo de vento relativo (forças de "drag", de arraste). Ambas são proporcionais ao quadrado da velocidade relativa do vento. Adicionalmente, forças de "lift" dependem fortemente da geometria do corpo e do ângulo entre a velocidade relativa do vento e o eixo do corpo, dito "ângulo de ataque".

Os rotores de eixo horizontal são os mais utilizados atualmente e o desenvolvimento destes, quanto à capacidade de geração, pode ser verificado na Figura 9. 


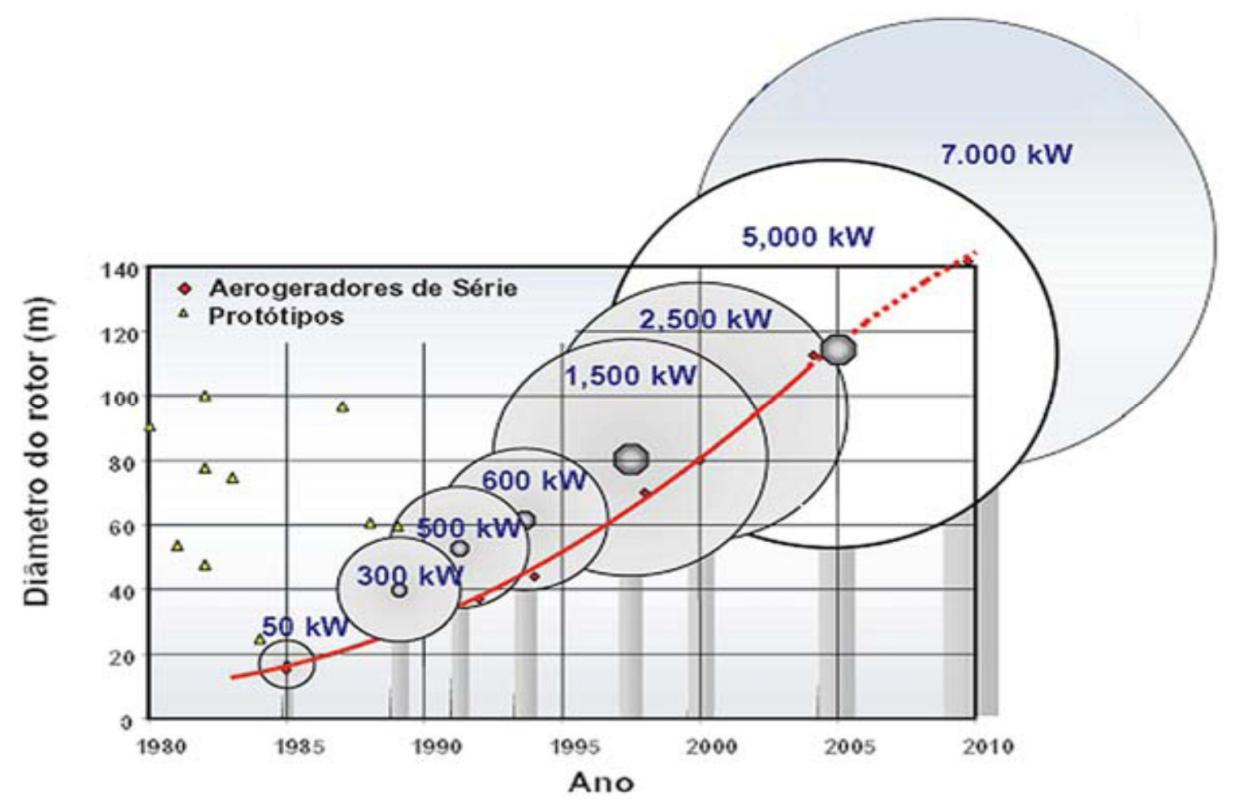

Figura 9 - Evolução dos aerogeradores desde 1985 até 2005

Fonte: Relatório do Deutsches Windenergie-Institut - DEWI - 2005

Rotores que giram predominantemente sob forças de "lift" permitem liberar muito mais potência do que aqueles que giram sob o efeito de forças de "drag", para uma mesma velocidade do vento.

Construtivamente, as pás podem ter as mais variadas formas e empregar os mais variados materiais. Em particular, pás rígidas de madeira, alumínio, aço, fibra de vidro, fibra de carbono e/ou Kevlar são as mais promissoras.

A maioria dos rotores modernos tem duas ou três pás. Os projetistas americanos têm escolhido geralmente duas pás com base no argumento de que o custo de duas pás é menor que o de três. Outros, especialmente os dinamarqueses, argumentam que o custo extra da terceira pá é compensado pelo comportamento dinâmico mais suave do rotor de três pás, e que o custo total do aerogerador é virtualmente idêntico quer se usem duas ou três pás. Um rotor de três pás fornece oscilações menores de torque no eixo, o que simplifica a transmissão mecânica. 
Rotores modernos com mais de três pás são apenas usados quando se necessita de um grande torque de partida, o que é basicamente o caso de bombeamento mecânico de água. Aerodinamicamente, no entanto, grande número de pás e alto torque de partida implicam em menor eficiência. O rotor deve ser fabricado com grande esbeltez, precisão nos perfis aerodinâmicos, bom acabamento superficial, que são requisitos para maximizar a eficiência aerodinâmica.

A potência contida no vento é proporcional ao cubo da velocidade do vento, mas velocidades muito altas de vento ocorrem com uma frequência relativa muito pequena. Estes ventos pouco frequentes contribuem muito pouco para a energia gerada, e não seria economicamente adequado projetar aerogeradores para operar eficientemente sob tais condições; os elevados carregamentos nas pás e as grandes potências de pico acrescentariam custos extras substanciais ao custo do aerogerador e dariam um incremento de energia gerada muito pequeno. Estes custos extras podem ser evitados se for limitada a potência do aerogerador para ventos fortes. Isto é mais frequentemente conseguido arranjando-se para que toda extensão da pá (ou apenas parte dela) seja girada em torno de seu eixo longitudinal, de forma a aumentar o ângulo de passo da hélice, o que reduz as cargas e a eficiência aerodinâmica durante o período de ventos fortes. A variação de passo limita a rotação e as cargas aerodinâmicas. O enfoque alternativo é usar pás de passo fixo, que tornam o cubo da pá mais barato e simples de fabricar, em conjunto com gerador de rotação constante, e deixar que a pá estole e limite a potência quando sob ventos fortes. A rotação constante pode ser facilmente obtida para geradores conectados à rede pelo emprego de gerador síncrono ou de indução. Então à medida que a velocidade do vento aumenta, o ângulo de ataque em que o escoamento encontra a pá aumenta até que o escoamento sobre o rotor descola e a potência gerada se reduz.

\section{Transmissão/Multiplicação}

A velocidade angular de rotores varia habitualmente na faixa de 15 a $220 \mathrm{rpm}$ devido a restrições de velocidade na ponta da pá (tangenciais). As pás giram a velocidades na faixa de 50 a $110 \mathrm{~m} / \mathrm{s}$, quase independentemente do diâmetro. Como geradores, sobretudo geradores síncronos, operam a rotações mais altas (comumente entre 1200 e $1800 \mathrm{rpm}$ ), torna-se necessária a 
instalação de sistemas de multiplicação entre o eixo do rotor e o eixo do gerador. Isso significa geralmente um multiplicador convencional, com dois ou três estágios de engrenagens, apesar de transmissões metálicas também terem sido experimentadas. Nos aerogeradores conectados às redes de distribuição elétrica, a rotação no gerador é de, tipicamente, $1500 \mathrm{rpm}$ (para $50 \mathrm{~Hz}$ ) e de $1800 \mathrm{rpm}$ (para $60 \mathrm{~Hz}$ ). Para aplicações onde a rede é de alta potência, o simples e confiável gerador de indução (assíncrono) pode ser usado; a rotação é então mantida dentro de certa porcentagem da rotação síncrona (um pequeno ângulo de "escorregamento" é essencial para a operação deste tipo de gerador). Devido a esta pequena, mas finita, margem de velocidades é permitida alguma absorção de energia das flutuações rápidas de vento na forma de energia cinética do rotor pela sua inércia. Desta forma, as flutuações de carga nas engrenagens da caixa de multiplicação são levemente suavizadas.

Para alguns rotores de tamanhos pequenos, é possível a conexão direta, pois, por exemplo, rotores de $1 \mathrm{~m}$ de diâmetro podem atingir rotações de até $2000 \mathrm{rpm}$. Também, para potências na ordem de poucos quilowatts, geradores especiais podem ser construídos, com baixa rotação, para conexão direta aos rotores.

Para potências acima de 1 a $2 \mathrm{~kW}$, e rotores com mais de $3 \mathrm{~m}$ de diâmetro, a regra geral é a utilização de alguma forma de multiplicador de velocidades entre o rotor e o gerador. Correias, correntes e transmissões hidráulicas têm sido utilizadas, mas a forma mais amplamente utilizada é a transmissão por engrenagens, nas suas várias formas, desde engrenagens de dentes paralelos a dentes helicoidais, sistemas planetários ou não. A multiplicação por engrenagens é a de maior eficiência. Multiplicação por correias ou correntes tem a possibilidade de baixos custos, porém são viáveis apenas para pequenas potências.

\section{Geradores}

A transformação de energia mecânica de rotação em energia elétrica através de equipamentos de conversão eletromecânica é um problema tecnologicamente dominado. 
Grupos geradores são correntemente industrializados e comercialmente disponíveis. A problemática na integração dos grupos geradores existentes a sistemas de conversão eólica envolve:

- variações na velocidade do vento (extensa faixa de variação de rotações por minuto para a geração de energia);

- variações do torque de entrada (posto que variações na velocidade do vento induzem variações de potência disponível no eixo - conjunto gerador);

- exigência de frequência e tensão constante na energia final produzida;

- facilidade de instalação, operação e manutenção de tais engenhos devido ao isolamento geográfico de muitos desses sistemas, sobretudo em caso de pequena escala de produção, em outras palavras, os equipamentos devem ter alta confiabilidade;

- baixos custos de aquisição e manutenção.

Para aplicações isoladas, onde geralmente o objetivo é carregar baterias, existem duas opções: gerador de corrente contínua ou gerador síncrono com retificador. Em geradores DC não há necessidade de controle da velocidade do rotor e a tensão é independente de velocidade constante, uma vez que se exerce um controle sobre o campo. Entretanto, geralmente são mais pesados, mais caros, a fabricação é principalmente para baixas potências, necessita de regulador de tensão acoplado ao campo e de manutenção periódica. No Brasil, para potências maiores que 1 kW são usados os geradores síncronos com retificador. Geradores e alternadores automotivos são produzidos em grande quantidade, têm baixo custo (por watt) e têm assistência técnica em praticamente todo o território nacional. No entanto, existem apenas para potências abaixo de 1 kW (os mais comuns são de 200-500 watts), têm baixa eficiência e alta rotação, o que faz de seu uso um compromisso técnico-econômico difícil.

Já para os aerogeradores conectados à rede, as principais opções que existem são: geradores síncronos, geradores assíncronos (de indução) e geradores de comutador de corrente alternada. 
O tipo de gerador decididamente influencia o comportamento em operação do aerogerador e suas interações com a rede. As tensões mecânicas e as flutuações rápidas de potência gerada diminuem quanto maior for a capacidade e a amplitude das variações de rotação permissíveis no gerador.

\section{Geradores Síncronos (Alternadores)}

Grande parte dos sistemas de conversão de energia eólica construídos até hoje, de média e grande escala de produção, usam geradores síncronos para a conversão eletromecânica. O estado de desenvolvimento tecnológico de tais equipamentos os recomenda fortemente. Dois tipos de excitação de campo são permitidos: (1) excitatriz independente, por baterias, com carregamento, (2) excitatriz acoplada à rotação do eixo com campo de ímã permanente e (3) o controle eletrônico da excitação.

\section{Vantagens:}

- não há virtualmente limitação de potência para sua fabricação;

- podem ser ligados diretamente à rede;

- alta eficiência (rendimento $\eta_{\mathrm{g}}=0,98$ );

- permitem melhor controle do fator de potência da carga.

Desvantagens:

- se ligados à rede, é necessário manter velocidade de rotação constante no sistema, posto que a constância de sua frequência depende intrinsecamente da constância da velocidade de rotação. Caso contrário podem apresentar problemas de instabilidade;

- necessitam de regulador de tensão acoplado ao campo;

- no caso do controle eletrônico de excitação, geram harmônicas no sistema. 


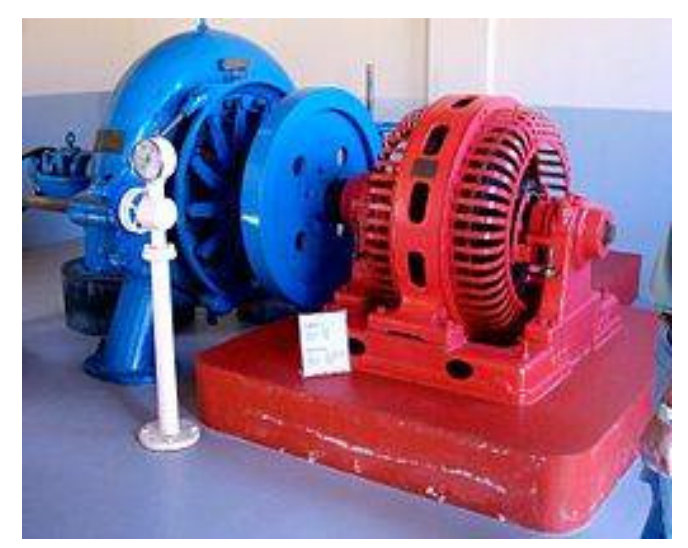

Figura 10 - Gerador Síncrono com Excitatriz

Fonte: http://www.rmsenergia.com.pt

\section{Geradores Assíncronos (Indução)}

Esses geradores não possuem campo de excitação. Comparativamente com geradores síncronos, entretanto, necessitam de maior torque de partida para "cut-in" (acoplamento). Para o gerador de indução, variações limitadas de rotação são possíveis dentro da margem de "escorregamento" do gerador. Isto permite maior elasticidade em rotação do que o gerador síncrono, o que reduz tensões mecânicas e flutuações elevadas de potência gerada quando da ocorrência de rajadas de curta duração, permitindo alguma absorção da energia da rajada de vento na forma de energia cinética pela inércia do rotor, e são eliminados os problemas de instabilidades em transientes. Além disso, geradores de indução são mais robustos, requerem mínima manutenção e têm longa vida em operação.

O gerador de indução também possibilita conexão direta à rede sem a necessidade de sincronização ou de regulação de tensão. Entretanto, alguns problemas podem ocorrer com a magnetização, a corrente de partida e com o controle de potência reativa, especialmente nas seções de alta impedância da rede elétrica onde estiver instalado. No caso dos parques eólicos, praticamente todos os aerogeradores em uso têm geradores de indução. Entretanto, em função das variações das correntes de vento e consequentemente das variações de velocidade impostas ao rotor, fica notório que a conexão deste tipo de gerador diretamente ao sistema pode provocar perdas significativas em função das variações de tensão e corrente que podem surgir, principalmente em ambientes de larga escala de utilização. Por esse motivo, a maioria dos 
equipamentos instalados utiliza um sistema de controle de tensão e frequência baseado no binômio retificação-conversão, a fim de garantir a estabilidade do sistema. Ocorre que este sistema eletrônico de controle é responsável pela geração de harmônicos no sistema que podem prejudicar as instalações e as cargas.

\section{Vantagens:}

- baixo custo de aquisição e manutenção (cerca de $40 \%$ do gerador síncrono);

- maior amortecimento eletromecânico;

- dispensa sincronização (colunas de sincronização e disjuntores de transferência).

Desvantagens:

- necessita de fonte externa de excitação;

- menor controlabilidade de tensão e frequência;

- alta corrente de partida;

- possibilidade de geração harmônica quando do controle eletrônico de tensão e frequência.

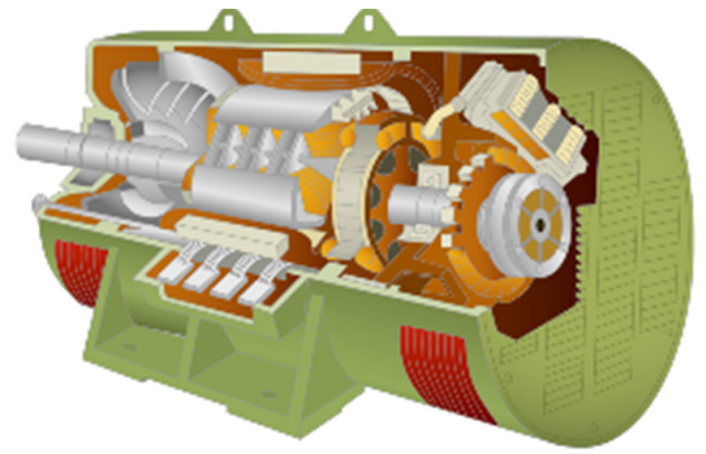

Figura 11 - Gerador de Indução

Fonte: http://www.ebah.com.br/content/ABAAAALKYAJ/maquinas-inducao 


\section{Geradores de Comutador de Corrente Alternada}

São geradores adaptados especialmente para produção de frequência variável. Têm excitação independente por gerador de baixa potência, pulsando com a frequência desejada. Sua concepção é similar às das excitatrizes de grandes turbo-geradores (1000 MW) do tipo conhecido sob o nome de "brushless excitation system". A limitação tecnológica de potência situa-se na faixa de $5 \mathrm{MW}$.

Vantagens:

- a frequência de saída é sempre igual à frequência de excitação: independe da velocidade de rotação do eixo do gerador;

- melhor controle do fator de potência da carga;

- podem ser usados eventualmente como geradores síncronos.

Desvantagens:

- custo da ordem de $20 \%$ acima de geradores de corrente contínua;

- exigem manutenção periódica: troca de escovas, etc.

A tecnologia eletrônica moderna de estado sólido para grandes potências tornou comerciais retificadores e inversores de estado sólido capazes de operar em potências comuns de sistemas de conversão. Conjuntos de gerador síncrono - transformador - retificador - inversor de estado sólido e gerador são sistemas disponíveis e utilizáveis comercialmente para o caso de sistemas de conversão de energia eólica de velocidade variável e frequência constante. Estão em investigação: conversores cíclicos, alternadores de frequência, geradores de campo modulado, entre outros exemplos. Geradores de corrente contínua não considerados anteriormente em faixas superiores de potência devido ao alto custo de alternadores associados para a geração de corrente alternada começam a ser reconsiderados em média ou larga escala de produção pela facilidade de armazenamento elétrico em conjuntos de baterias e o desenvolvimento de inversores. 


\section{Torre}

As torres que elevam os rotores à altura desejada estão sujeitas a inúmeros esforços. Primeiramente, forças horizontais devem ser levadas em conta: resistência do rotor ("drag") e da própria torre à força do vento. Em seguida, forças torsionais, impostas pelo mecanismo de controle de rotação da gávea giratória e esforços verticais (peso do próprio equipamento) não devem ser desprezados.

Quanto ao material, as torres podem ser de aço (em treliças ou tubulares) ou tubulares de concreto. Para aerogeradores menores, é possível a utilização de torres de madeira sobre um poste de eucalipto com estais de aço.

A torre suporta a massa da cela e das pás; as pás, em rotação, excitam cargas cíclicas no conjunto com a frequência da rotação e seus múltiplos, e assim uma questão fundamental no projeto da torre é a sua frequência natural, que deve ser desacoplada das excitações para evitar o fenômeno de ressonância, o qual aumenta a amplitude das vibrações e tensões resultantes e reduz a vida em fadiga dos componentes, entre outros efeitos desagradáveis. Logo após 1973, a primeira geração de aerogeradores ditos modernos foi projetada com torres rígidas, com frequências naturais bem acima das forças de rotação do rotor. Entretanto, esse enfoque conduziu a torres desnecessariamente pesadas e caras.

À medida que a compreensão dos problemas dinâmicos de aerogeradores foi aumentando, durante a última década, tornou-se possível construir aerogeradores mais leves, consequentemente menos rígidos e significativamente mais baratos que seus antecessores.

Desde que tenham as suas frequências naturais desacopladas das da excitação do rotor, as torres podem ser estaiadas ou não. De modo geral, as frequências naturais de uma torre estaiada podem ser melhor reguladas variando-se a tensão de estaiamento. Interessante notar que um estaiamento por barras de aço é preferível ao uso de cabos, pois estes são mais elásticos e necessitam de pré-tensões muito maiores do que as que seriam necessárias em barras para atingir a mesma frequência natural, numa mesma configuração. 
Um aerogerador moderno constitui uma estrutura esbelta, com a massa das pás em rotação sobre uma torre, excitando cargas cíclicas sobre todo o sistema. Um problema básico do projeto é determinar todos os modos e frequências naturais de vibração dos componentes, em especial pás e torre, para evitar ressonância com as frequências de excitação do rotor em operação. A ressonância causa aumento das amplitudes de carregamento cíclico no sistema, comprometendo a resistência à fadiga e reduzindo a vida útil prevista para o aerogerador, que é de aproximadamente 20 anos.

\subsection{Distorções Harmônicas}

As distorções harmônicas representam um tipo de perturbação elétrica provocada no sistema pela utilização de cargas não lineares, como fontes chaveadas de equipamentos eletrônicos (computadores, fax, televisores, etc.), equipamentos a arco (soldas elétricas e fornos a arco) e equipamentos que trabalhem com núcleo saturado (fornos de indução e reatores eletrônicos de lâmpadas). Causam perdas de energia e podem provocar a queima de outros equipamentos instalados no circuito, aquecimento de condutores elétricos, falha no funcionamento de motores, atuação errada de equipamentos de proteção e aumento do consumo de energia elétrica. Prejudicam tanto os consumidores de energia (sociedade em geral), como as próprias concessionárias de energia, pois estas precisam reforçar o seu sistema, aumentando a capacidade de geração e obrigando-as à construção de novas usinas geradoras, ampliação das redes de transmissão, distribuição e subestações para atender a demanda.

A Figura 12 mostra uma onda periódica, não senoidal, representada por uma soma de ondas senoidais, de diversas frequências múltiplas inteiras da frequência fundamental. Essas frequências múltiplas são denominadas de harmônicas da fundamental. A soma dessas senóides é denominada de Série de Fourier. 


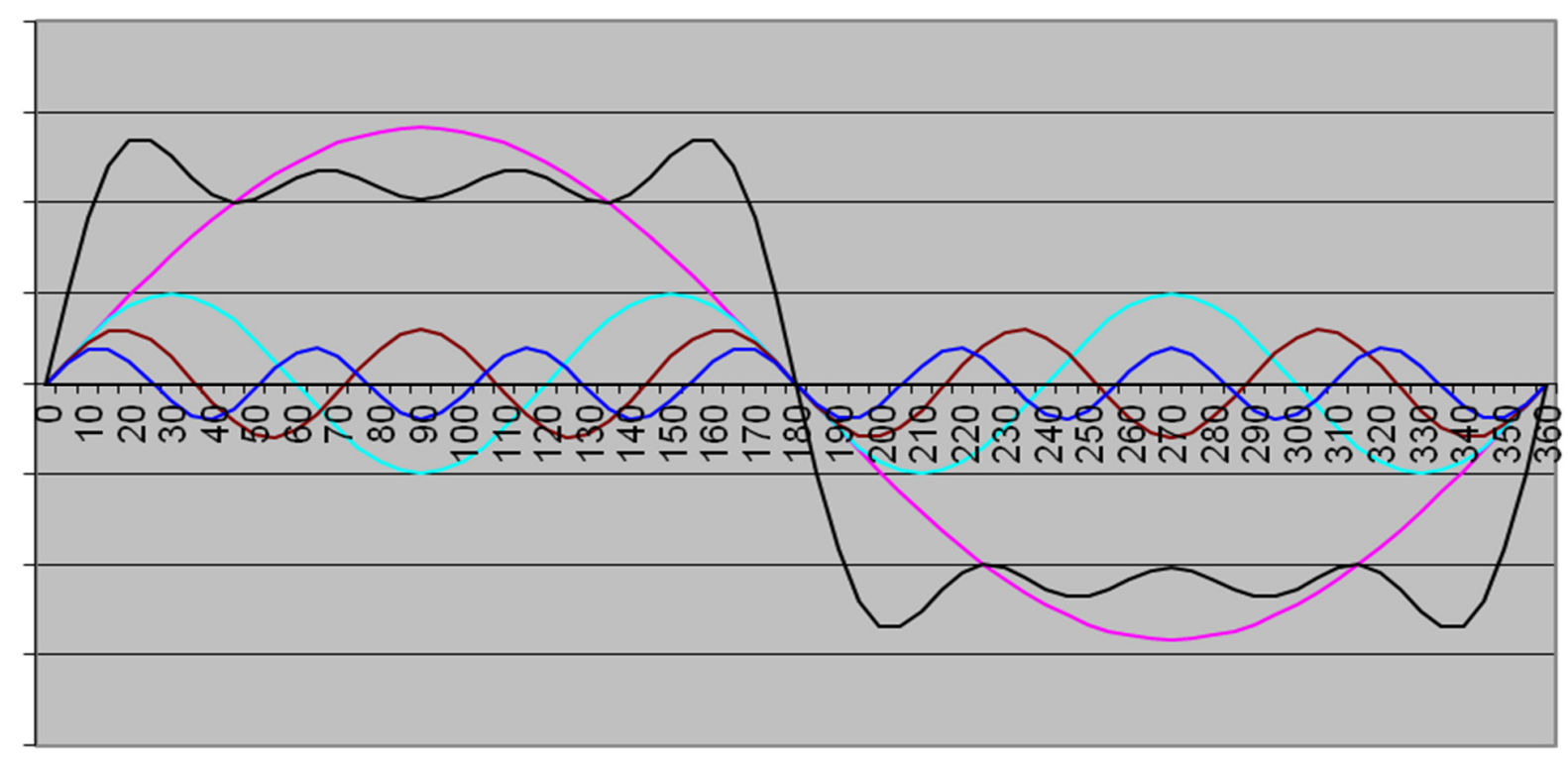

Figura 12 - Gráfico de Tensões Harmônicas

As áreas cobertas pelos semi-ciclos positivo e negativo da onda não senoidal acima são de mesmo valor. Devido a isso, todas as correspondentes ondas senoidais harmônicas são de ordem ímpar (na Figura acima são mostradas, além da fundamental, a $3^{\mathrm{a}}, 5^{\mathrm{a}}, 7^{\mathrm{a}}$ e a $9^{\mathrm{a}}$ ordem harmônica). Nessas condições, diz-se que a onda não senoidal possui simetria de meia-onda. Caso essa simetria não ocorra, a onda não senoidal pode possuir componentes harmônicas de ordem par e, até mesmo, a componente contínua.

A vantagem de se usar uma série de senóides para representar uma onda distorcida está no fato de que, desta forma, a teoria convencional de análise de circuitos elétricos senoidais pode ser aplicada. A desvantagem disso é que o sistema deve ser analisado para cada frequência, separadamente.

A palavra harmônico é, em geral, usada para denotar problemas de tensão ou corrente. Um "problema harmônico" pode estar relacionado com altas correntes harmônicas (que pode, por exemplo, sobreaquecer um condutor ou um equipamento, como um transformador) ou altas tensões harmônicas (que pode, por exemplo, causar a má operação de um sistema de controle ou reduzir a vida útil de um banco de capacitores). Pode-se, assim, perceber que existem diversas causas e efeitos para as tensões e correntes harmônicas, bem como uma relação entre ambas. 
Assim, alerta-se para o fato de que o termo harmônicas é muito ambíguo para definir, por si só, um problema.

Alguns problemas surgidos devido a transitórios de chaveamento (por exemplo, de bancos de capacitores) são confundidos com problemas harmônicos simplesmente em função da presença de componentes de alta frequência na onda. Embora os distúrbios transitórios realmente contenham componentes de alta frequência, os transitórios e os harmônicos são fenômenos distintos. As formas de onda, durante os transitórios, possuem altas frequências apenas por um pequeno período de tempo (em geral, desaparecem após alguns ciclos). Essas frequências nem sempre são múltiplas da frequência fundamental.

As harmônicas de tensão e corrente estão presentes no sistema em qualquer instante do regime permanente de operação do mesmo e são múltiplas da frequência fundamental.

De maneira geral, a distorção de tensão é uma consequência da passagem de uma corrente distorcida através de uma impedância série. Embora uma central elétrica gere tensão praticamente senoidal pura, as correntes harmônicas, oriundas, por exemplo, de uma carga não linear (como um conversor), ao fluírem através da impedância do sistema $Z(h)$, podem causar quedas de tensão do tipo $Z(h)$. $I(h)$ na mesma, para cada ordem harmônica. A Figura 13 ilustra o fluxo da corrente fundamental em um pequeno sistema radial, que é no sentido gerador-carga. O fluxo das correntes harmônicas é, neste caso, de sentido oposto (carga-gerador), pois essas correntes são geradas pela carga e não pelo gerador.

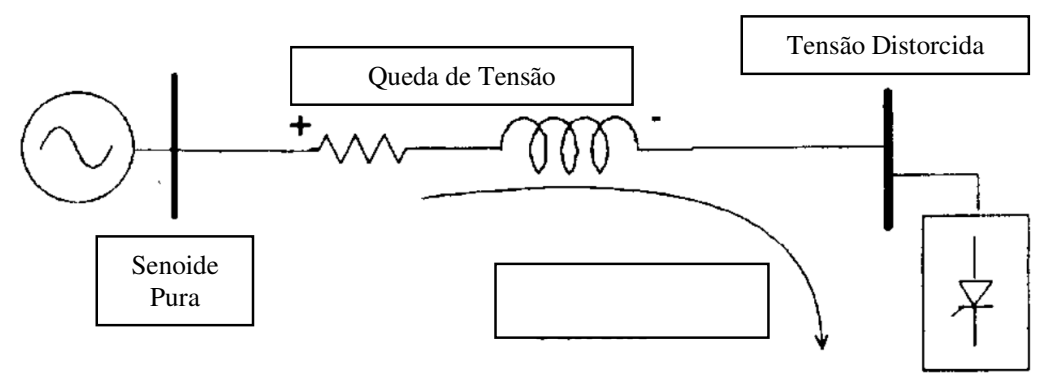

Figura 13 - Correntes através da impedância da rede elétrica. 
Assim, pode-se afirmar que:

- o fluxo das correntes harmônicas é que pode causar o surgimento de tensões distorcidas no barramento da carga;

- o tamanho da distorção de tensão depende da impedância da rede e da corrente harmônica gerada pela carga;

- a mesma carga, gerando a mesma corrente harmônica $I(h)$, porém se instalada em uma outra barra, pode causar uma distorção de tensão diferente daquela da primeira barra. Isso acontece porque a tensão harmônica é o resultado do produto $Z(h)$. $I(h)$ e a impedância do sistema $Z(h)$ varia de uma barra para outra.

Diante dessas considerações, a norma IEEE Standard 519-1992 prevê que o controle sobre a quantidade de correntes harmônicas injetadas em uma barra de acoplamento consumidorfonte geradora é de responsabilidade do consumidor.

Caso a corrente harmônica injetada na rede esteja dentro dos limites, o controle sobre a distorção harmônica é de responsabilidade da proprietária da rede elétrica, pois somente ela tem controle sobre a impedância da rede.

Muitos problemas harmônicos nos sistemas elétricos surgem nas barras onde bancos de capacitores são instalados para correção de fator de potência. Isso pode ser mais bem explicado com o auxílio da Figura 14, que mostra o diagrama unifilar simplificado de uma indústria, a qual está sendo representada por um conversor. O circuito elétrico equivalente à Figura 14 está representado na Figura 15 para a frequência fundamental. Nesta Figura nota-se que, na frequência fundamental, a rede elétrica fornece, através de um transformador rebaixador $(\mathrm{T})$, a corrente fundamental i(1) para esta carga. 


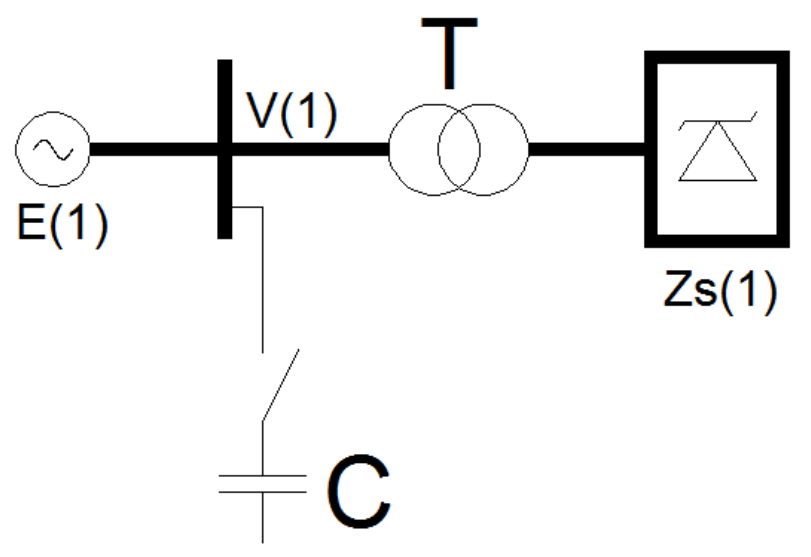

Figura 14 - Rede elétrica alimentando uma indústria

Como é sabido pela teoria da "correção de fator de potência", a tensão fundamental V(1) pode ser regulada com a instalação de bancos de capacitores, os quais fornecem reativo para a carga, reduzindo, assim, a corrente vinda do sistema. Em consequência, a queda de tensão na impedância Zs (1) da rede é reduzida e a tensão fundamental, V(1), fica mais próxima da tensão $\mathrm{E}(1)$.

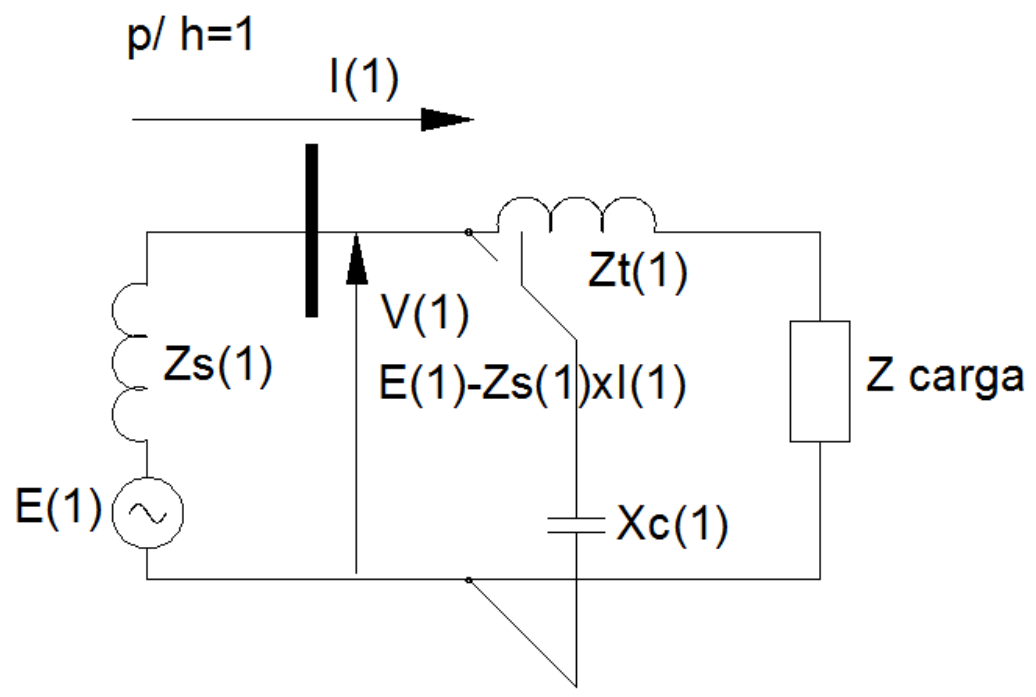

Figura 15 - Circuito elétrico monofásico equivalente, para a frequência fundamental $(h=1)$, para o sistema da Figura 14

A Figura 16 representa o diagrama unifilar da Figura 14, visto para as frequências harmônicas. Nestas condições, a corrente é gerada pelo conversor, localizado na indústria. O 
sistema elétrico, agora, é apenas uma impedância $\mathrm{Zs}(\mathrm{h})$. Se o banco de capacitores não estiver conectado à rede, a tensão $V(h)$, medida para cada ordem harmônica " $h$ ", é dada por $V(h)=Z s(h) . i(h)$ e pode não trazer transtornos ao sistema elétrico. Com o banco de capacitores ligado à rede, a expressão matemática que fornece a nova tensão $V(h)$ possui um denominador $[Z s(h)-X c(h)]$. Por outro lado, sabe-se que, em sistemas industriais, a impedância $Z s(h)$, por ser de característica indutiva, cresce com a frequência, enquanto que a reatância dos bancos de capacitores decresce com a frequência. Nestas condições, pode acontecer a hipótese em que $Z s(h)$ e $X c(h)$ possuam módulos semelhantes, o que pode levar o denominador " $Z s(h)-X c(h)$ “" a possuir um valor numérico pequeno. Isso reflete em um valor às vezes altamente proibitivo para a tensão $V(h)$, a qual pode até ser da mesma ordem de grandeza da tensão fundamental $V(1)$. Esse fenômeno é conhecido como ressonância paralela. Ao aumento exagerado da tensão "V" diz-se que ocorreu uma amplificação da tensão. Esse efeito é maior em redes com baixo valor de resistência elétrica na rede.

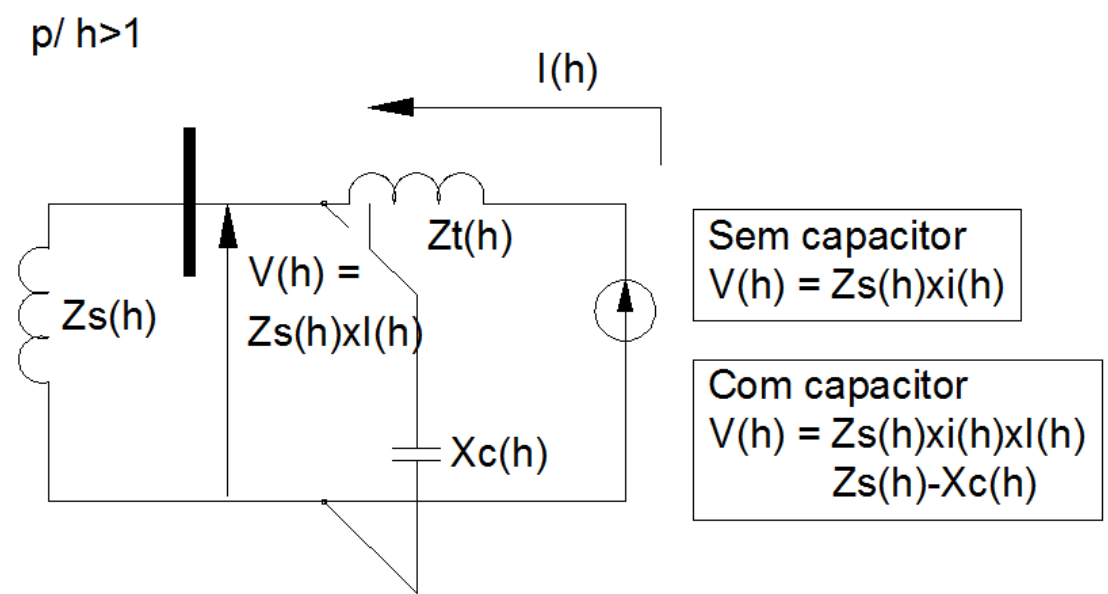

\section{Figura 16 - Circuito elétrico monofásico equivalente, para as frequências harmônicas $(h>1)$, p/ o sistema da Figura 14}

Portanto, um engenheiro que tenha estudado esse sistema apenas para a frequência fundamental não observa o risco que a instalação está correndo. Se o banco de capacitores for danificado, provavelmente ele pode responsabilizar o fabricante do mesmo, por acreditar que o mesmo falhou por algum problema interno. 
Existem vários parâmetros comumente adotados para indicar o conteúdo harmônico de uma onda elétrica. Um dos mais usados é a "Distorção Harmônica Individual", que pode ser usada para formas de onda de tensão e de corrente. A expressão da "distorção harmônica individual de tensão" é:

$$
D H I_{U}(\%)=\frac{U_{h}}{U_{1}} \times 100 \%
$$

onde:

DHIU: distorção harmônica individual de tensão.

$U h$ : valor eficaz da tensão de ordem harmônica "h".

$U$ 1: valor eficaz da tensão fundamental $(60 \mathrm{~Hz}$, no Brasil).

De maneira análoga, a "distorção harmônica individual de corrente" pode ser expressa por:

$$
D H I_{I}(\%)=\frac{I_{h}}{I_{1}} \times 100 \%
$$

Onde:

DHI $:$ distorção harmônica individual de corrente.

$I h$ : valor eficaz da corrente de ordem harmônica " $h$ ".

I1: valor eficaz da corrente fundamental $(60 \mathrm{~Hz}$, no Brasil).

Outro parâmetro bastante usado para avaliar o nível de distorção harmônica é denominado “distorção harmônica total”, também conhecida como DHT. Assim, para a tensão, o DHT é dado por:

$$
D_{U} T_{U}=\frac{\sqrt{\sum_{h=2}^{h_{\text {máx }}} U_{h}^{2}}}{U_{1}} \times 100 \%
$$

O análogo deste parâmetro, para a corrente, é:

$$
D H T_{I}=\frac{\sqrt{\sum_{h=2}^{h_{\text {máx }}} I_{h}^{2}}}{I_{1}} \times 100 \%
$$


Como as correntes variam muito de valor em um sistema, destaca-se que uma carga operando com uma pequena corrente pode ter uma componente fundamental de valor baixo e, consequentemente, uma $D H T_{I}$ alta. Apesar disso, por se tratar de uma corrente total de baixo valor, a mesma pode não ser um problema para o sistema. Assim, recomenda-se calcular o $D H T_{I}$ usando para I 1 a componente fundamental nominal da carga e não a componente fundamental do momento da amostragem.

O valor eficaz de uma onda constituída por várias componentes harmônicas não é a soma dos valores eficazes das componentes individuais, mas sim a raiz quadrada da soma dos quadrados. Ou seja, nos casos de tensão, tem-se:

$$
U_{e f}=\sqrt{\sum_{h=1}^{h m a ́ x} U_{h}^{2}}
$$

\subsection{Sistema Interligado Nacional - SIN}

Com tamanho e características que permitem considerá-lo único em âmbito mundial, o sistema de produção e transmissão de energia elétrica do Brasil é um sistema hidrotérmico de grande porte, com forte predominância de usinas hidrelétricas e com múltiplos proprietários. O Sistema Interligado Nacional é formado pelas empresas das regiões Sul, Sudeste, Centro-Oeste, Nordeste e parte da região Norte, conforme pode ser verificado na Figura 17. Apenas 3,4\% da capacidade de produção de eletricidade do país encontra-se fora do SIN, em pequenos sistemas isolados localizados principalmente na região amazônica.

É administrado diretamente pelo Operador Nacional do Sistema - ONS, que atua através das concessionárias de energia de todo território nacional, que por sua vez, obtêm as concessões diretamente por parte do Governo Federal. 
Os custos das tarifas cobradas pelas concessionárias de distribuição são diretamente proporcionais aos gastos destas no gerenciamento da energia, o que faz com que no caso de aumento das perdas o custo da tarifa aumente.

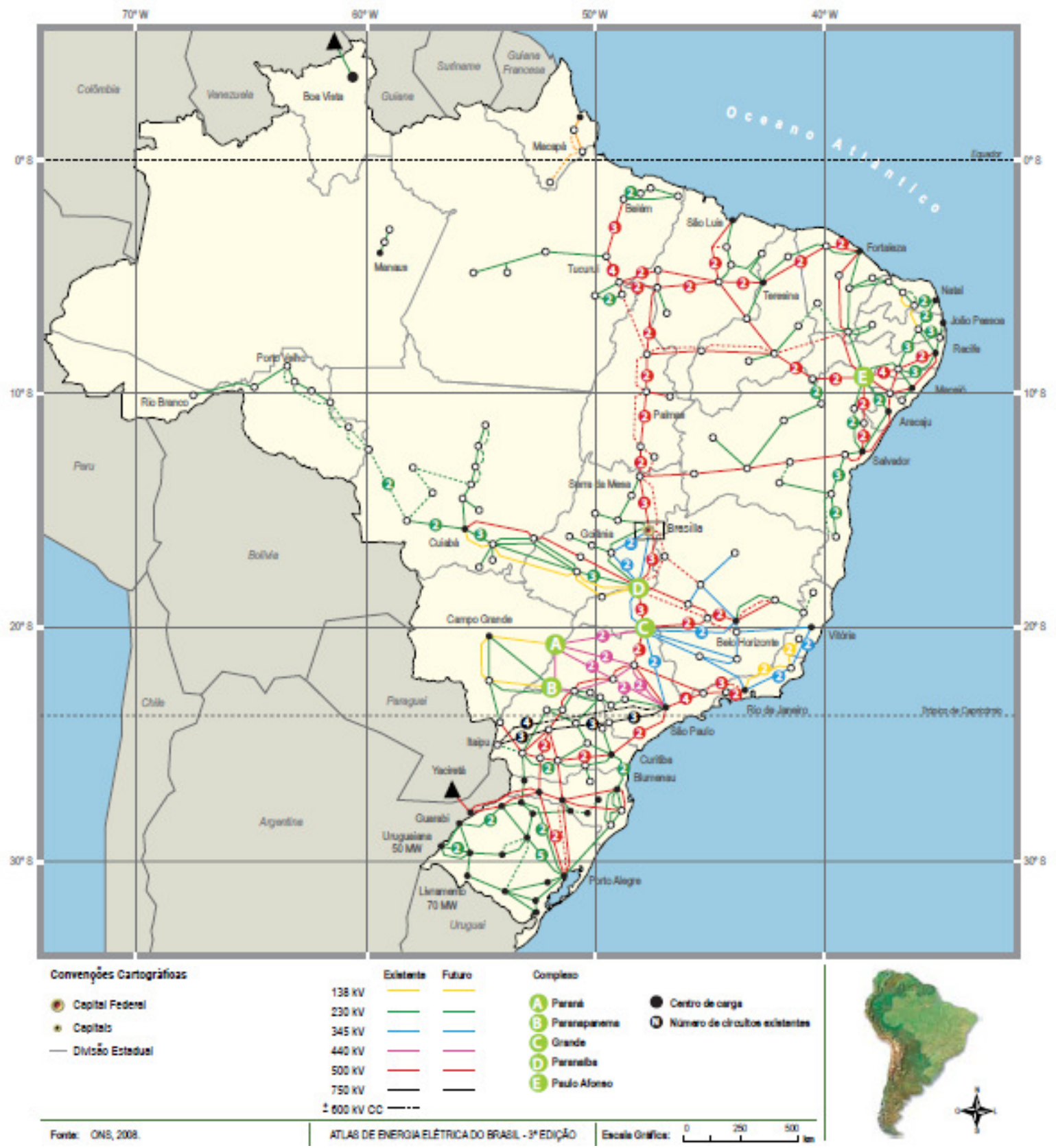

Figura 17 - Mapa do Sistema Interligado Nacional - SIN

Fonte: Atlas de Energia Elétrica do Brasil - $3^{\text {a }}$ Edição - ANEEL - 2008 


\subsection{Sistema de Geração de Energia}

O sistema de geração de energia é composto pelas Unidades Geradoras das Usinas Elétricas, que alimentam diretamente as concessionárias de distribuição. É administrado também por uma concessionária de energia que obtém a concessão diretamente por parte do Governo Federal.

Os custos das tarifas cobradas pelas concessionárias de geração também são diretamente proporcionais aos gastos destas no gerenciamento e produção da energia, o que faz com que no caso de aumento das perdas o custo da tarifa aumente.

\subsection{Legislação sobre Distorções Harmônicas}

Como este estudo baseia-se na análise de distorções harmônicas oriundas dos sistemas de controle de tensão e frequência utilizados na geração eólica, a seguir é feito um breve relato desse tipo de fenômeno e suas principais consequências no sistema elétrico.

A preocupação com o controle de qualidade de energia surgiu com a publicação da Resolução 345/2008 (PRODIST), modificada pelas resoluções 395/2009 e 424/2010, através do Módulo 8, que estabelece como objetivos específicos:

a. estabelecer os procedimentos relativos à qualidade da energia elétrica - QEE, abordando a qualidade do produto e a qualidade do serviço prestado.

b. para a qualidade do produto, este módulo define a terminologia, caracteriza os fenômenos, parâmetros e valores de referência relativos à conformidade de tensão em regime permanente e às perturbações na forma de onda de tensão, estabelecendo mecanismos que possibilitem à ANEEL fixar padrões para os indicadores de QEE.

c. para a qualidade dos serviços prestados, este módulo estabelece a metodologia para apuração dos indicadores de continuidade e dos tempos de atendimento a ocorrências emergenciais, definindo padrões e responsabilidades. 
Os procedimentos de qualidade de energia elétrica definidos no documento devem ser observados por:

a) consumidores com instalações conectadas em qualquer classe de tensão de distribuição;

b) produtores de energia;

c) distribuidoras;

d) agentes importadores ou exportadores de energia elétrica;

e) demais instalações de Transmissão (DITs);

f) Operador Nacional do Sistema (ONS).

O Módulo 8 caracteriza os fenômenos de QEE, estabelece os critérios de amostragem, os valores de referência e os procedimentos relativos à qualidade do produto. Dessa forma, um dos parâmetros que devem ser monitorados para garantir a QEE é a distorção harmônica de tensão e corrente nas redes de distribuição de energia, observando-se os valores de referência da Tabela 9:

\begin{tabular}{cc}
\hline Tensão nominal do Barramento & $\begin{array}{c}\text { Distorção Harmônica Total } \\
\text { de Tensão (DTT) [\%] }\end{array}$ \\
\hline $\mathrm{U}_{\mathrm{N}} \leq 1 \mathrm{kV}$ & 10 \\
$1 \mathrm{kV}<\mathrm{U}_{\mathrm{N}}<13,8 \mathrm{kV}$ & 8 \\
$13,8 \mathrm{kV}<\mathrm{U}_{\mathrm{N}}<69 \mathrm{kV}$ & 6 \\
$69 \mathrm{kV}<\mathrm{U}_{\mathrm{N}}<230 \mathrm{kV}$ & 3 \\
\hline
\end{tabular}

Tabela 9 - Valores de referência globais das distorções harmônicas totais (em porcentagem da tensão fundamental) Fonte: Resolução ANEEL 395/2009 - PRODIST - Módulo 8

Outro parâmetro que deve ser monitorado é a variação de frequência, observando-se os valores de referência a seguir (Fonte - Resolução ANEEL 395/2009 - PRODIST - Módulo 8).

Valores de referência de Variação de Frequência - PRODIST (em Hertz):

- Condição Normal de Operação: 59,9 $\leq \mathrm{f} \leq 60,1 \mathrm{~Hz}$;

- Para $\mathrm{f} \leq 59,5$ ou $\mathrm{f} \geq 60,5 \mathrm{~Hz}$, o tempo tem de ser inferior a $30 \mathrm{~s}$ quando houver distúrbios no sistema de distribuição, a fim de permitir a recuperação do equilíbrio carga-geração. 
Por esse motivo, faz-se necessária a análise e a mensuração das contribuições das distorções harmônicas não somente nas cargas, mas também nas fontes geradoras de energia, pois as distorções oriundas destas impactam diretamente naquelas, podendo provocar o não atendimento dos limites estabelecidos pela resolução.

No Brasil, o Operador Nacional do Sistema Elétrico (ONS) definiu os limites máximos para as distorções harmônicas de tensão individual e total que devem ser praticados pelas empresas concessionárias de energia elétrica (Tabela 10), que expressa os limites máximos de tensão que podem ser atingidos em uma barra, com todas as fontes de perturbação dos consumidores e eventualmente, da concessionária, em operação.

\begin{tabular}{|c|c|c|c|c|c|c|c|}
\hline \multicolumn{4}{|c|}{$\mathrm{U}<69 \mathrm{kV}$} & \multicolumn{4}{|c|}{$\mathrm{U} \geq 69 \mathrm{kV}$} \\
\hline \multicolumn{2}{|c|}{ Impares } & \multicolumn{2}{|c|}{ Pares } & \multicolumn{2}{|c|}{ Impares } & \multicolumn{2}{|c|}{ Pares } \\
\hline Ordem & Valor & Ordem & Valor & Ordem & Valor & Ordem & Valor \\
\hline $\begin{array}{c}3,5,7 \\
9,11,13\end{array}$ & $\begin{array}{l}5 \% \\
3 \%\end{array}$ & $2,4,6$ & $2 \%$ & $\begin{array}{c}3,5,7 \\
9,11,13\end{array}$ & $\begin{array}{c}2 \% \\
1,5 \%\end{array}$ & $2,4,6$ & $1 \%$ \\
\hline $\begin{array}{c}15 \text { e } 25 \\
\geq 27\end{array}$ & $\begin{array}{l}2 \% \\
1 \%\end{array}$ & $8, \ldots$ & $1 \%$ & $\begin{array}{c}15 \text { e } 25 \\
\geq 27\end{array}$ & $\begin{array}{c}1 \% \\
0,5 \%\end{array}$ & $8, \ldots$ & $1 \%$ \\
\hline & & $6 \%$ & & & DH & $3 \%$ & \\
\hline
\end{tabular}

Tabela 10 - Limites globais de tensão, em uma barra, em \% da tensão fundamental Fonte: Resolução Normativa 372/09 - Procedimentos de Rede - ONS - Submódulo 2.8

A Tabela 10 refere-se aos limites de tensão máximos permitidos aos consumidores (também denominados de acessantes). Os acessantes devem assegurar que a operação de seus equipamentos, quando existirem cargas não lineares, bem como outros efeitos dentro de suas instalações, incluindo ressonâncias, não causem distorções harmônicas no ponto de conexão acima dos limites individuais e totais indicados na Tabela 11.

\begin{tabular}{cccccccc}
\hline \multicolumn{3}{c}{$13,8 \mathrm{kV} \leq \mathrm{U}<69 \mathrm{kV}$} & \multicolumn{3}{c}{$\mathrm{U} \geq 69 \mathrm{kV}$} \\
Impares & \multicolumn{2}{c}{ Pares } & Impares & \multicolumn{2}{c}{ Pares } \\
Ordem & Valor & Ordem & Valor & Ordem & Valor & Ordem & Valor \\
\hline 3 a 25 & $1,5 \%$ & \multirow{2}{*}{ Todos } & \multirow{2}{*}{$0,6 \%$} & 3 a 25 & $0,6 \%$ & \multirow{2}{*}{ Todos } & \multirow{2}{*}{$0,3 \%$} \\
$\geq 27$ & $0,7 \%$ & & $\geq 27$ & $0,4 \%$ & DHT $=1,5 \%$ & \\
& \multicolumn{2}{c}{ DHT $=3 \%$} & & & DH & \\
\hline
\end{tabular}

Tabela 11 - Limites de tensão por consumidor, expresso em \% da Tensão Fundamental Fonte: Resolução Normativa 372/09 - Procedimentos de Rede - ONS - Submódulo 2.8 
Nos Estados Unidos, o IEEE [1] define limites máximos também para as correntes harmônicas passíveis de serem injetadas na rede elétrica pelos consumidores. Esses limites dependem dos seguintes fatores:

- nível de tensão com que o consumidor é alimentado (três faixas de níveis de tensão são consideradas: $120 \mathrm{~V} \leq \mathrm{U}<69 \mathrm{kV}, 69 \mathrm{kV} \leq \mathrm{U}<161 \mathrm{kV}$ e $\mathrm{U} \geq 161 \mathrm{kV})$, conforme pode ser visto nas Tabelas 12, 13 e 14 respectivamente.

- relação entre a corrente de curto-circuito da barra e a corrente nominal do consumidor conectado à mesma barra.

\begin{tabular}{ccc}
\hline Nível de tensão na barra & Harmônica Individual (\%) & $\begin{array}{c}\text { Distorção harmônica Total } \\
\text { THD }(\%)\end{array}$ \\
\hline $1,0 \mathrm{kV}$ ou menos & 5,0 & 8,0 \\
$1.001 \mathrm{kV}$ até $69 \mathrm{kV}$ & 3,0 & 5,0 \\
$69 \mathrm{kV}$ até $161 \mathrm{kV}$ & 1,5 & 2,5 \\
Acima de $161 \mathrm{kV}$ & 1,0 & 1,5 \\
\hline
\end{tabular}

Nota: Sistemas de Alta Tensão podem ter mais que 2,0\% de THD onde a causa é um sinal de tensão de corrente contínua que será atenuado.

Tabela 12 - Limites de distorção individual e total de harmônicas (para todos os níveis de tensão) Fonte: Norma IEEE-519 - IEEE - 1992

\section{Máxima corrente Harmônica em \% da corrente de carga (Io - valor da componente fundamental)}

Harmônicas Ímpares

\begin{tabular}{ccccccc} 
Icc/Io & $<11$ & $11 \leq \mathrm{n}<17$ & $17 \leq \mathrm{n}<23$ & $23 \leq \mathrm{n}<35$ & $35<\mathrm{n}$ & $\mathrm{THD}(\%)$ \\
\hline$<20$ & 4,0 & 2,0 & 1,5 & 0,6 & 0,3 & 5,0 \\
$20<50$ & 7,0 & 3,5 & 2,5 & 1,0 & 0,5 & 8,0 \\
$50<100$ & 10,0 & 4,5 & 4,0 & 1,5 & 0,7 & 12,0 \\
$100<1000$ & 12,0 & 5,5 & 5,0 & 2,0 & 1,0 & 15,0 \\
$>1000$ & 15,0 & 7,0 & 6,0 & 6,0 & 1,4 & 20,0 \\
\hline
\end{tabular}

Cada Harmônica é limitada a 25\% dos limites das harmônicas ímpares acima.

Distorções de corrente que resultam em um sinal contínuo, como por exemplo, conversores de meia onda, não são permitidos.

Todo equipamento de geração de energia é limitado a estes valores de distorção de corrente, independentemente do valor real de Icc/Io. Onde:

Icc = Máxima corrente de curto circuito em Pcc; Io = Máxima corrente de carga demandada (componente da frequência fundamental) em Pcc nas condições normais de operação.

Tabela 13 - Limites de distorção harmônica por ordem harmônica (entre 120 V e 69 kV) Fonte: Norma IEEE-519 - IEEE - 1992

No Brasil o ONS ainda não tem se preocupado em indicar limites para a injeção de corrente harmônica por parte dos consumidores. Esse monitoramento, no entanto, pode ser útil, 
por exemplo, para detectar, em uma barra onde vários consumidores estão conectados, qual consumidor está injetando corrente acima de seus limites. Este consumidor certamente deveria ser responsabilizado pela instalação de filtros.

\begin{tabular}{|c|c|c|c|c|c|c|}
\hline \multicolumn{7}{|c|}{$\begin{array}{c}\text { Máxima corrente Harmônica em \% da corrente de carga } \\
\text { (Io - valor da componente fundamental) } \\
\text { Harmônicas Ímpares }\end{array}$} \\
\hline Icc/Io & $<11$ & $11 \leq \mathrm{n}<17$ & $17 \leq \mathrm{n}<23$ & $23 \leq n<35$ & $35<n$ & $\mathrm{TDD}(\%)$ \\
\hline$<20$ & 2,0 & 1,0 & 0,75 & 0,3 & 0,15 & 2,5 \\
\hline $20<50$ & 3,5 & 1,75 & 1,25 & 0,5 & 0,25 & 4,0 \\
\hline $50<100$ & 5,0 & 2,25 & 2,0 & 0,75 & 0,35 & 6,0 \\
\hline $100<1000$ & 6,0 & 2,75 & 2,5 & 1,0 & 0,5 & 7,5 \\
\hline$>1000$ & 7,5 & 3,5 & 3,0 & 1,25 & 0,7 & 10,0 \\
\hline \multicolumn{7}{|c|}{$\begin{array}{l}\text { Cada Harmônica é limitada a } 25 \% \text { dos limites das harmônicas ímpares acima. } \\
\text { Distorçōes de corrente que resultam em um sinal contínuo, como por exemplo, conversores de meia onda, não são permitidos. } \\
\text { Todo equipamento de geração de energia é limitado a estes valores de distorção de corrente, independentemente do valor real de Icc/Io. } \\
\text { Onde: } \\
\text { Icc = Máxima corrente de curto circuito em Pcc; Io = Máxima corrente de carga demandada (componente da frequência fundamental) em Pcc } \\
\text { nas condições normais de operação. }\end{array}$} \\
\hline
\end{tabular}

Tabela 14 - Limites de distorção harmônicas por ordem harmônica (entre 69,01 V e 161 kV) Fonte: Norma IEEE-519 - IEEE - 1992

A análise dos limites de correntes harmônicas injetados pode ser útil também para se determinar, em uma barra, se a distorção de tensão é devida à grande corrente emitida pelo consumidor ou à alta impedância harmônica da barra (o que é de responsabilidade, em geral, da empresa que distribui a energia elétrica).

As correntes harmônicas de $3^{\text {a }}$ ordem e suas múltiplas ímpares devem ser observadas com cuidado especial, porque elas podem sobrecarregar o condutor neutro e também causar interferências. Na Figura 18 tem-se um sistema aparentemente balanceado. Apenas as componentes fundamental (balanceadas) e terceira harmônica da corrente estão presentes. Somando-se essas correntes no neutro, observa-se que o resultado é nulo para a componente fundamental. O mesmo já não é verdade para a terceira harmônica. Essas correntes, que estão em fase nas três linhas, ao chegarem ao neutro, se somam. Em consequência, em muitos casos, as correntes nos neutros podem ser maiores do que as correntes de fase. Este pode ser o caso, por exemplo, quando uma grande quantidade de microcomputadores e lâmpadas fluorescentes compactas está presente. Essas lâmpadas geram correntes harmônicas de terceira ordem, em cada 
fase, de cerca de $80 \%$ do valor da fundamental. Assim, em um raciocínio simples, nota-se que, enquanto a corrente por fase, considerando-se apenas a fundamental e a terceira harmônica em uma soma linear é de 1,8 pu da fundamental, a correspondente corrente no condutor neutro será de 2,4 pu da fundamental.

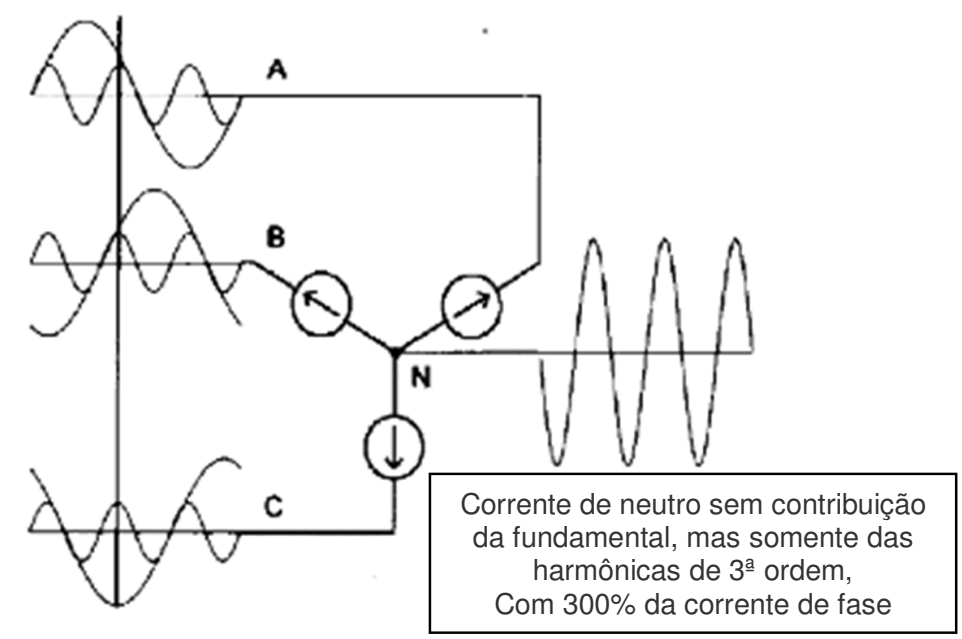

Figura 18 - Altas correntes no neutro em um circuito alimentando uma carga não linear (harmônicas de $3^{\text {a }}$ ordem)

Fonte: Apostila de harmônicas - IFSP

Em situações semelhantes, algumas possíveis soluções podem ser:

- quando houver muitas cargas não lineares monofásicas: providenciar um condutor neutro para cada fase;

- quando houver cargas trifásicas e cargas não lineares monofásicas compartilhando o mesmo neutro: dobrar a capacidade do condutor neutro em relação ao condutor fase;

- instalar filtros "shunt" sintonizados para a terceira harmônica;

- usar transformadores delta-estrela (transformador isolador).

As conexões dos transformadores são importantes para o fluxo das terceiras harmônicas. Por exemplo, em transformadores delta-estrela, aonde a alimentação venha pelo lado em estrela, as correntes de ordem 3 estarão se somando no neutro. 
No lado delta as correspondentes correntes ficam confinadas ao interior do delta. Logo, neste lado do transformador, nenhuma corrente de terceira ordem está presente. No entanto, dentro do lado em delta, há corrente de $3^{\mathrm{a}}$ ordem. Neste ponto deve ser ressaltado que a simples medição da corrente de linha no lado delta de um transformador, não apontando a presença de correntes de terceira harmônica, pode dar a falsa impressão de que o transformador não está sobrecarregado.

Todos esses comentários são válidos para a grande maioria das correntes de terceira harmônica, que agem como correntes de sequência zero. Certas cargas, no entanto, como os fornos a arco, que normalmente operam em condições desbalanceadas, irão gerar correntes de terceira ordem que possuem características das correntes de sequência (+) ou (-). Nesses casos, essas correntes circulam apenas pelas fases e não são evitadas pelo uso de transformadores deltaestrela.

\subsection{Sistema de Controle de Tensão e Frequência de Aerogeradores}

Como a principal fonte geradora de harmônicas dos aerogeradores é justamente o sistema de controle de tensão e frequência utilizado para garantir o sincronismo destes ao sistema elétrico, descrevemos neste item o processo de como isso é realizado e as formas existentes para tanto.

O termo "estabilidade de sistemas de potência" é aplicável a sistemas de potência em corrente alternada para denotar uma condição em que as várias máquinas geradoras do sistema permanecem mutuamente em sincronismo. Por outro lado, “instabilidade” denota uma condição que envolve perda de sincronismo.

Para se entender o problema de estabilidade dos sistemas elétricos de potência, considerese um gerador síncrono alimentando um motor síncrono através de um circuito composto de uma reatância indutiva série, $\mathrm{X}_{\mathrm{L}}$, conforme pode ser visto na Figura 19. As máquinas são representadas por tensões constantes atrás de reatâncias. 


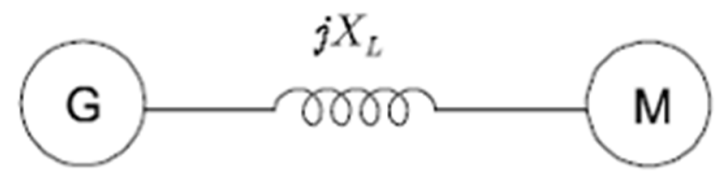

(a)

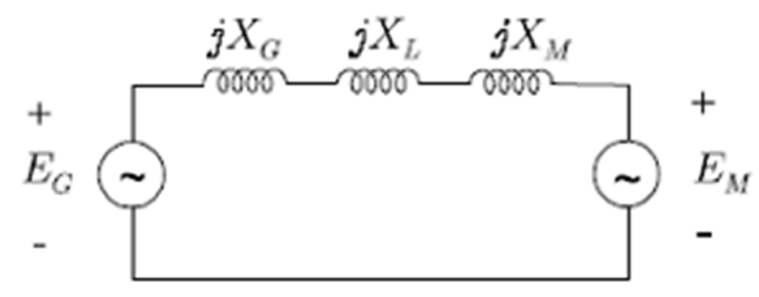

(b)

Figura 19 - (a) Sistema gerador síncrono alimentando motor; (b) Circuito equivalente Fonte: Apostila de Controle e Estabilidade de Sistemas Elétricos de Potência

Se:

$$
X=X_{G}+X_{L}+X_{M}
$$

Então:

$$
I=\frac{\left(E_{G}-E_{M}\right)}{j X}
$$

A potência de saída do gerador (que é igual à potência de entrada do motor, já que não estão sendo consideradas as perdas) é dada por:

$$
P=\frac{E_{G} \times E_{M}}{X} \times \operatorname{sen} \delta
$$

Onde $\delta$ é o deslocamento angular entre os dois rotores. Por esta expressão, nota-se que a máxima potência que pode ser transmitida em regime, com a reatância dada $\mathrm{X}$ e as tensões internas $\mathrm{Eg}_{\mathrm{g}}$ e Ем, ocorre para $\delta=90$ graus ( $\operatorname{sen} \delta=1$ ). Este valor máximo pode ser aumentado tanto através da elevação das tensões internas (EG e EM) quanto se reduzindo a reatância X. 


$$
P=\frac{E_{G} \times E_{M}}{X}
$$

Se o sistema estiver operando em um ponto onde $\delta<90^{\circ}$, a potência mecânica de entrada do gerador e a potência mecânica de saída do motor (se corrigidas pelas perdas rotacionais) são iguais à potência elétrica $\mathrm{P}$.

Considere-se então um pequeno incremento de carga mecânica no eixo do motor. Há em consequência um acréscimo no torque líquido no rotor do motor que tende a retardar a sua rotação, de modo que sua velocidade decresce temporariamente. Disso resulta um aumento no ângulo $\delta$ e um consequente incremento na potência de entrada para o motor, até que finalmente a entrada e saída alcancem novamente o equilíbrio.

Embora pareça que a velocidade do gerador permaneça constante, na realidade o gerador desacelera momentaneamente (aumento de sua carga mecânica) até que o seu regulador de velocidade atue no sentido de aumentar a potência mecânica de entrada, de modo a equilibrar o aumento da potência elétrica de saída.

Se a carga do motor é aumentada de maneira gradual, qualquer aumento adicional de carga acarretará um aumento no ângulo $\delta$ como antes, mas agora este último não provoca aumento na potência de entrada. Ao invés disso, ocorre um decréscimo na entrada, o que aumenta ainda mais a diferença entre entrada e saída, retardando o motor mais rapidamente. O motor sai finalmente de sincronismo. O valor $\mathrm{P}_{\max }$ é, portanto o limite de estabilidade estática do sistema.

O sincronismo é perdido caso se tente transmitir mais potência ao gerador do que este valor. Se um grande incremento de carga for adicionado subitamente ao motor, este pode perder o sincronismo mesmo se a nova carga não exceder o limite estático. Neste caso, a saída de potência mecânica do motor torna-se muito maior que a entrada de potência elétrica, e a diferença é suprida pelo decréscimo de energia cinética. O motor desacelera, resultando em um aumento no ângulo $\delta$ e um consequente aumento da entrada. Se a nova carga não excede $P_{\max }, \delta$ aumenta para o valor correspondente à operação estática, em que entrada = saída. Mas quando $\delta$ atinge este valor, o motor está girando a uma velocidade muito baixa e seu momento de inércia impede que 
sua velocidade aumente de imediato para o valor normal. Assim, $\delta$ aumenta mais, ultrapassando o valor adequado. Além deste ponto, o torque líquido é de aceleração, e a velocidade do motor aumenta, aproximando-se do valor normal. Antes disso, é possível que o ângulo $\delta$ tenha aumentado tanto que o ponto de operação não somente ultrapassou o pico da curva potênciaângulo, mas deslocou-se de tal maneira sobre a curva que a entrada decresce para um valor menor que a saída. O torque resultante passa a ser de novo de desaceleração e a velocidade, ainda menor que a normal, decresce ainda mais. O sistema torna-se, portanto, instável.

Se, contudo, o incremento súbito de carga não é tão grande, o motor pode recuperar sua velocidade nominal antes que $\delta$ atinja um valor demasiado alto. Neste caso, o torque líquido é ainda de aceleração e provoca um decréscimo em $\delta$, que se aproxima do valor adequado. Em razão da inércia, $\delta$ ultrapassa ainda este valor, ocorrendo diversas oscilações em torno do novo ponto de operação. Estas oscilações são finalmente amortecidas devido à presença de torques de amortecimento, aqui desprezados. Este movimento oscilatório amortecido caracteriza operação estável.

Para um dado incremento de carga, há um limite superior para a carga que o motor suporta sem sair de sincronismo. Este é o Limite de Estabilidade Transitória do sistema para as condições dadas. Este limite está sempre abaixo do limite estático, mas ao contrário do último, pode ter valores distintos, dependendo da natureza e intensidade da perturbação, que pode ser um súbito incremento de carga, um súbito aumento de reatância (causado, por exemplo, pela desconexão de um circuito de linhas em paralelo, em decorrência de manobra normal) ou ainda um curto-circuito, que se constitui na perturbação mais severa. O efeito de curtos-circuitos é geralmente determinado em todos os estudos de estabilidade. Um curto trifásico na linha que conecta o gerador ao motor, por exemplo, provoca o surgimento de um torque de aceleração no gerador e um torque de desaceleração no motor. O sincronismo é perdido, exceto se o curto for rapidamente removido.

Para outros tipos de curtos-circuitos (monofásicos, bifásicos, bifásicos para terra) ou para curtos em um de dois circuitos em paralelo, subsistirá ainda algum torque de sincronização, mas com redução da amplitude da curva potência-ângulo em comparação com as condições de antes da falta. A estabilidade do sistema depende nestes casos não somente do sistema, mas também do 
tipo e da posição do defeito, rapidez de abertura de disjuntores, religamento, etc. Para qualquer perturbação especificada, a questão da manutenção ou não do sincronismo depende do valor da potência que estava sendo transmitida antes da ocorrência da falta. Há assim um valor de potência transmitida para cada perturbação especificada que é o limite de estabilidade transitória, acima do qual o sistema é instável.

Este tipo de problema demonstra a importância de se manter o sincronismo entre as máquinas geradoras do sistema mesmo com a utilização de geradores assíncronos (geradores de indução), muito utilizados na geração eólica, pois a perda do sincronismo pode significar perdas no sistema e danos aos equipamentos e às próprias instalações.

Dois tipos de estudos de estabilidade são normalmente conduzidos nas empresas de energia elétrica. Os fenômenos que se seguem à ocorrência de uma grande e súbita perturbação em um sistema de potência são normalmente associados ao termo "Estabilidade Transitória" e a solução é obtida no domínio do tempo. O período de tempo sob estudo pode variar de uma fração de segundo, quando a estabilidade da primeira oscilação é determinada, para períodos superiores a 10 segundos, nos casos em que a estabilidade para múltiplas oscilações deve ser examinada.

O termo "Estabilidade Dinâmica" é empregado para descrever a resposta de um sistema a pequenas perturbações ou a controles automáticos mal ajustados. O problema pode ser resolvido tanto no domínio do tempo quanto no domínio da frequência.

O fato de que as constantes de tempo da malha de excitação são significativamente menores do que as constantes de tempo das malhas de regulação de velocidade tornam o controle de excitação muito mais efetivo no que diz respeito à manutenção da estabilidade do que o controle de velocidade. As exigências sobre o controle de excitação em estudos de estabilidade transitória são normalmente rapidez de resposta e um alto valor de tensão máxima ("ceiling"'). O objetivo é tentar reduzir a magnitude das primeiras oscilações aumentando a potência de sincronização. 
No caso de estabilidade dinâmica, espera-se que o controle de excitação propicie não apenas o reforço da potência de sincronização, mas também um aumento do amortecimento de oscilações decorrentes de uma pequena perturbação. Em alguns casos, a rapidez de resposta exigida em problemas de estabilidade transitória (e que caracteriza os sistemas de excitação tiristorizados modernos para hidrogeradores) pode ser conflitante com a manutenção da estabilidade dinâmica, como será visto no capítulo.

Em uma concessionária típica de geração e transmissão de energia elétrica, os estudos de controle e estabilidade são importantes em diversos setores dentro da empresa. Na operação, por exemplo, é frequente a realização de estudos de análise de estabilidade para os quais são importantes ajustes adequados dos diversos controladores do sistema. É, portanto, necessário que os engenheiros que atuam neste setor disponham de meios para projetar adequadamente os parâmetros dos diversos controladores, bem como detenham os conhecimentos necessários para analisar os resultados de simulações dinâmicas do sistema e propor alterações em ajustes previamente estabelecidos.

Em estudos de planejamento da expansão, torna-se cada vez mais importante a consideração de restrições de estabilidade para as diversas configurações de geração, carga e topologia da rede contemplada para a expansão futura do sistema.

Finalmente, nas áreas ligadas à geração eólica, estudos visando obter os sistemas mais eficazes para parâmetros de regulagem de tensão e frequência e a consequente redução dos impactos destes na qualidade de energia do sistema, constituem-se uma das tarefas regulares dos engenheiros atuantes nestes setores das empresas.

Os principais impactos deste tipo de geração nas redes elétricas são:

- variações rápidas e lentas das tensões no sistema, relativamente ao seu valor nominal;

- congestionamento de ramos da rede e de subestações;

- aumento dos níveis de potência de curto-circuito;

- qualidade da onda:

- níveis de flicker; 
- nível de distorção harmônica;

- problemas de estabilidade (componentes dinâmicos, estabilidade de tensão);

- pré-despacho e despacho das unidades convencionais.

Os geradores de corrente alternada (AC) utilizados na geração eólica possuem um inconveniente na produção de eletricidade, que é o fato de gerarem correntes em frequências que variam com a velocidade de giro do rotor, e como os ventos variam muito, as frequências geradas pelo gerador também podem variar muito, o que é prejudicial ao sistema. Para controlar este problema, visto que no Brasil o sistema de energia tem que se manter em torno de $60 \mathrm{~Hz}$, é preciso ligar o gerador ao sistema através de um dispositivo que mantenha a frequência em torno disso. Este dispositivo é chamado de conversor.

Existem diversas configurações para montagem dos geradores eólicos, conforme pode ser verificado na Figura 20. A seguir são analisadas as características das configurações mais utilizadas. 


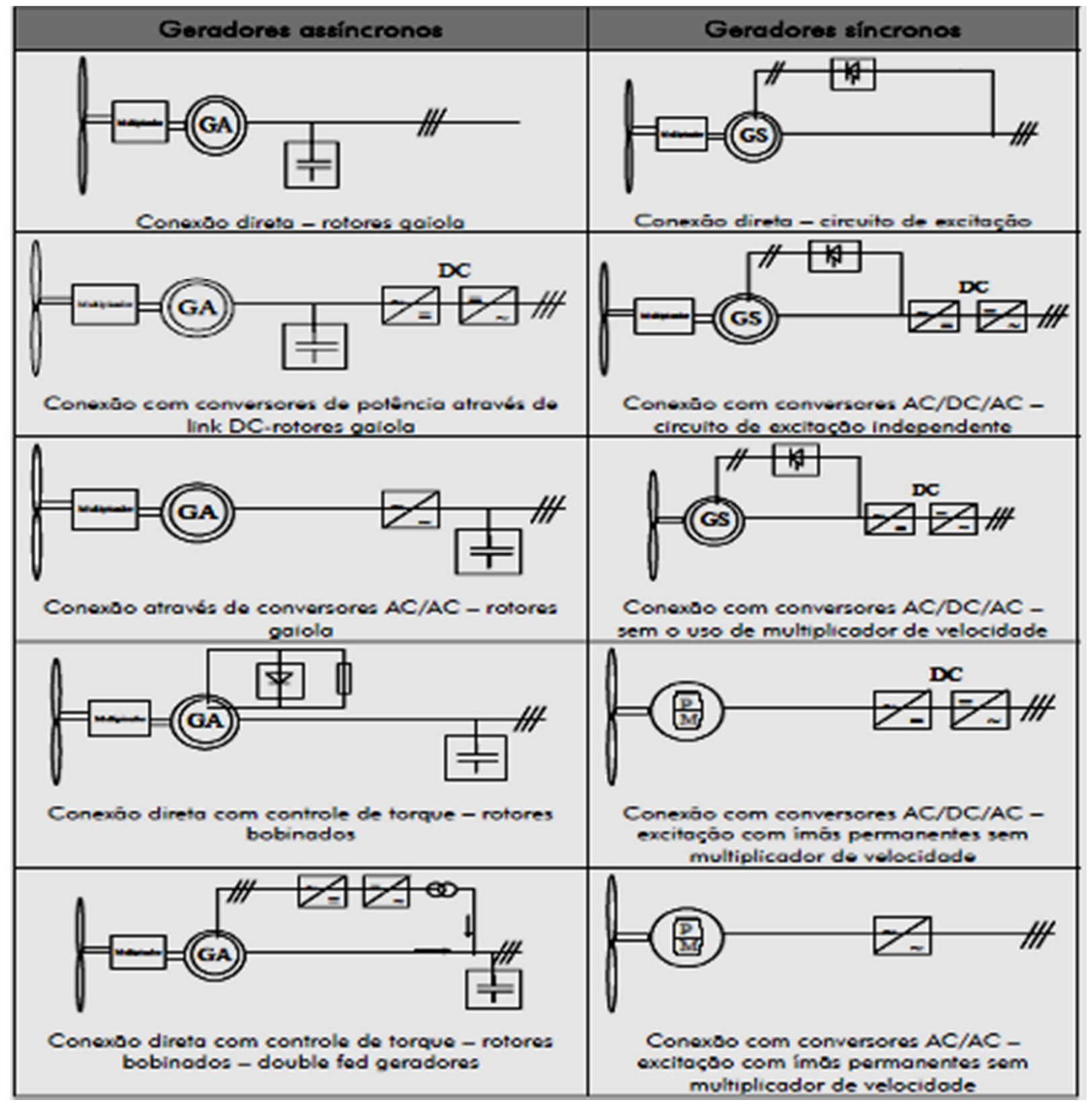

Figura 20 - Configurações de Montagem de Grupos de Aerogeradores para Geração Eólica Fonte: Guia de Projeto de Centrais Eólicas

Caso fosse possível manter a velocidade do vento constante, seria possível utilizar um gerador conectado diretamente à rede elétrica operando com velocidade fixa. Nesta configuração o grupo eólico-elétrico poderia ser constituído de um gerador assíncrono ou um gerador síncrono, conforme mostrado esquematicamente na Figura 21. 


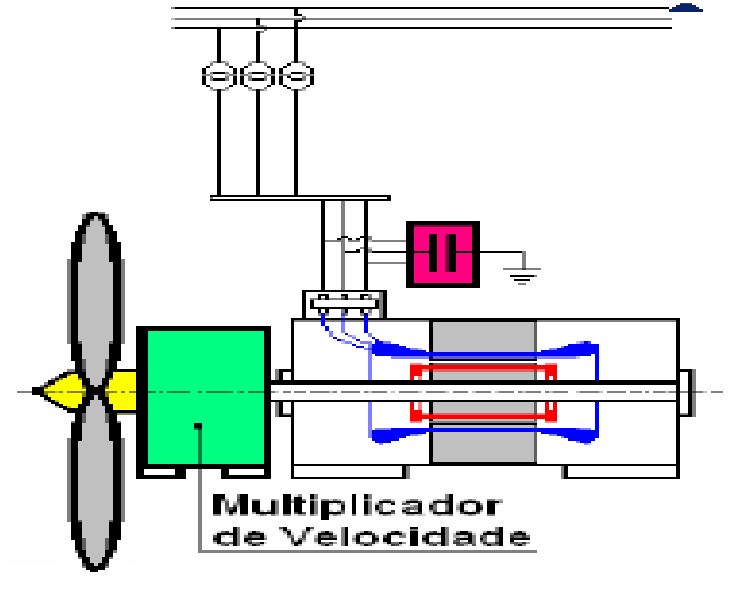

(a)

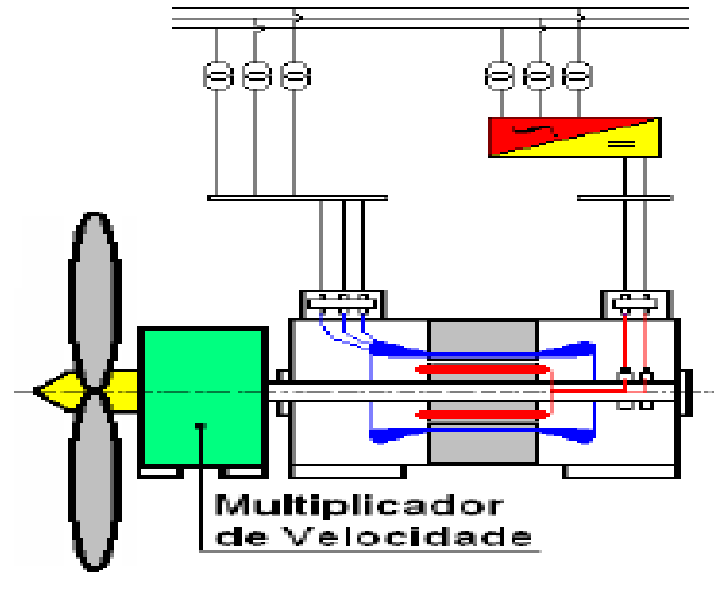

(b)

Figura 21 - Grupo eólico-elétrico conectado diretamente a rede elétrica a) gerador assíncrono de gaiola. b) gerador síncrono com excitação independente Fonte: Apostila de Geração Eólica - UNESA - 2010

Ambos devem operar com velocidades acima da velocidade da turbina, exigindo um multiplicador de velocidades acoplado às mesmas. O link DC do conversor do gerador síncrono (b) desacopla o gerador da rede, permitindo uma grande flexibilidade na regulação de velocidade. Esta filosofia de grupo eólico-elétrico apresenta uma boa eficiência na transformação de energia quando comparada com a do grupo com gerador assíncrono, o que inviabiliza este quando existem variações na velocidade da turbina.

A solução do grupo eólico-elétrico com gerador assíncrono apresenta a vantagem de ser robusto e de menor custo. O gerador síncrono compensa os reativos através da excitação independente. A demanda dos reativos necessários para excitar o gerador assíncrono provém do conversor, não exigindo um banco adicional de capacitores. Nas duas soluções o conversor CA/CA apresenta um grande impacto no custo, já que toda a potência do grupo eólico-elétrico passa para a rede através do conversor. Esta solução não apresenta limite de potência, podendo ser empregada para qualquer potência, respeitando apenas critérios técnicos econômicos.

Como a velocidade dos ventos para aerogeradores sofre muita variação (pode variar de $2,5 \mathrm{~m} / \mathrm{s}$ até $25 \mathrm{~m} / \mathrm{s})^{1}$, é mais conveniente o uso de gerador conectado à rede elétrica através de um

\footnotetext{
${ }^{1}$ Fonte: Apostila de Geração Eólica - UNESA - 2010
} 
conversor. Nesta configuração o grupo eólico-elétrico pode ser constituído de um gerador assíncrono ou um gerador síncrono, conforme mostrado esquematicamente na Figura 22.

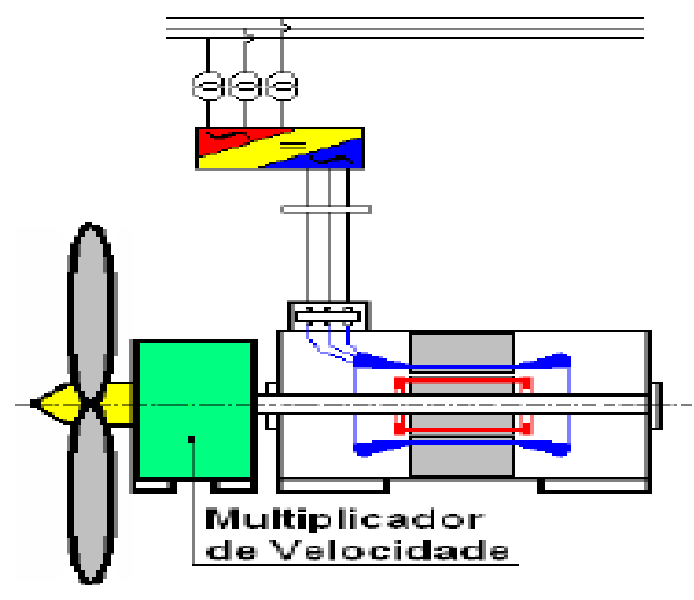

(a)

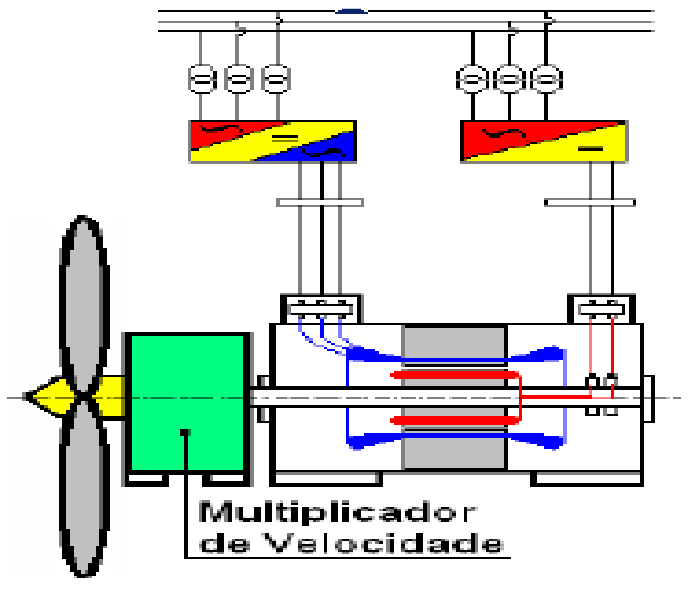

(b)

Figura 22 - Grupo eólico-elétrico conectado à rede elétrica através de um conversor a) gerador assíncrono de gaiola. b) gerador síncrono com excitação independente Fonte: Apostila de Geração Eólica - UNESA - 2010

Ambos também operam com velocidades acima da turbina, exigindo um multiplicador de velocidades. Aqui também a solução do grupo eólico-elétrico com gerador assíncrono apresenta a vantagem de ser robusto e de menor custo. O gerador síncrono compensa os reativos através da excitação independente. A demanda dos reativos necessários para excitar o gerador assíncrono provém do conversor, não exigindo um banco adicional de capacitores.

Outra possibilidade é a utilização de Geradores Assíncronos Trifásicos de Rotor Bobinado Duplamente Alimentado com Escovas (GATDACE). Nesta configuração o grupo eólico-elétrico é constituído de um GATDACE, conforme mostrado esquematicamente na Figura 23. 


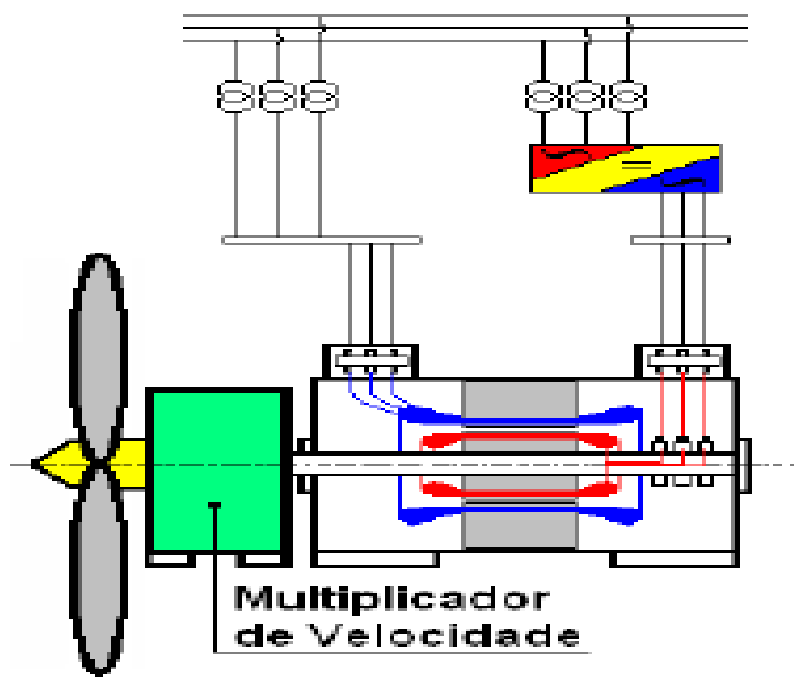

Figura 23 - Grupo eólico-elétrico constituído de gerador assíncrono trifásico duplamente alimentado com escovas (GATDACE) Fonte: Apostila de Geração Eólica - UNESA - 2010

Este gerador permite uma faixa de regulação de velocidade da ordem de $\pm 30 \%$ em torno de sua rotação síncrona. O controle da velocidade é feito através do conversor conectado ao circuito rotórico. Devido a esta característica de regulação de velocidade, esta solução é utilizada em regiões onde a velocidade dos ventos é bastante variável. Aqui também, como nas soluções anteriores, o gerador trabalha numa rotação acima da turbina, exigindo um multiplicador de velocidade, que normalmente é de vários estágios. Projetando-se o circuito rotórico adequadamente, o conversor de frequência para este grupo eólico-elétrico necessita ser dimensionado para no máximo $30 \%$ da potência do grupo, devendo ser bidirecional para permitir o fluxo de potência nos dois sentidos, isto é, do gerador para a rede e da rede para o gerador, dependendo do ponto de operação. Esta é uma grande vantagem de custos, fazendo com que esta solução seja bastante competitiva. Esta filosofia apresenta uma grande eficiência na transformação eletromecânica da energia dos ventos devido a sua característica de regulação de velocidade, que permite o aproveitamento energético em toda a faixa de velocidade dos ventos, ou seja, região I, II e III. A outra grande vantagem é devido ao fato de o estator estar ligado diretamente à rede gerando uma onda senoidal muito próxima de uma senóide pura. Dessa forma diminui a introdução no sistema elétrico de poluição harmônica, consequentemente não exigindo o uso de filtros harmônicos. Esta configuração é largamente utilizada pela maioria dos fabricantes 
de grupos eólico-elétricos para potências da ordem de até 5MW por apresentar custo inicial baixo, robustez e grande eficiência na transformação eletromecânica da energia dos ventos. Porém, apresenta dois pontos fracos que são o uso do multiplicador de velocidades e o uso de escovas, onde principalmente o segundo aumenta os custos de manutenção do grupo.

Também é utilizado o Gerador Síncrono Trifásico conectado à rede através de um conversor sem multiplicador de velocidade. Nesta configuração o grupo eólico-elétrico é constituído de um gerador síncrono trifásico com excitação independente ou com rotor de ímãs permanentes, conforme mostrado esquematicamente na Figura 24.

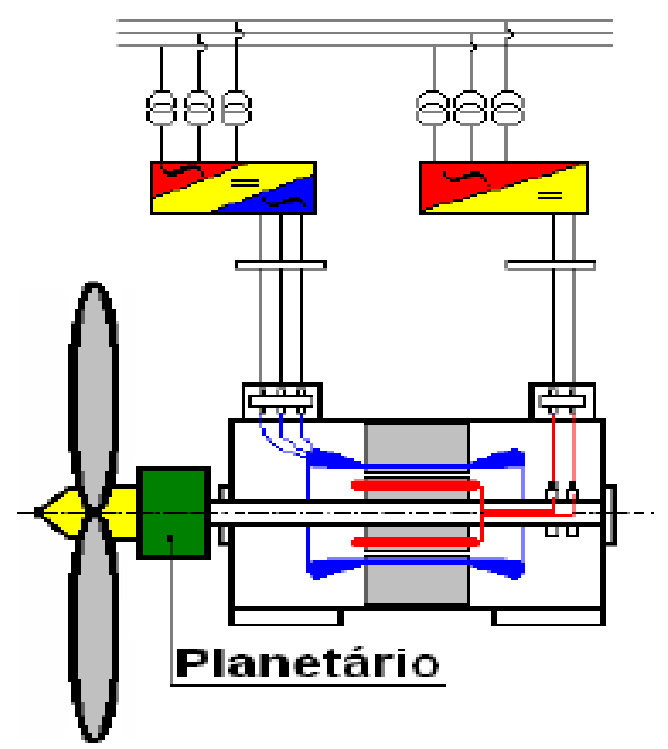

(a)

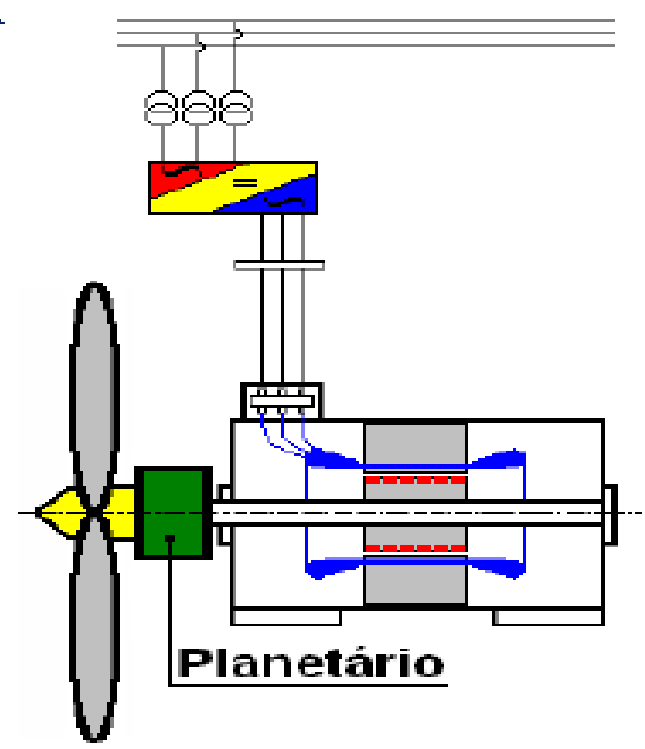

(b)

Figura 24 - Grupo eólico-elétrico conectado à rede elétrica através de um conversor a) Gerador síncrono com excitação independente b) Gerador síncrono de ímãs permanente Fonte: Apostila de Geração Eólica - UNESA - 2010

Nesta solução, tanto a configuração (a) como a (b) requerem um gerador de grande número de pólos, gerando em frequência baixa e variável de acordo com a velocidade da turbina.

O conversor desacopla o gerador da rede permitindo a conversão eletromecânica da energia numa ampla faixa de velocidade dos ventos. Como os geradores apresentam um grande 
número de pólos, trabalham em rotação mais baixa, não exigindo um multiplicador de velocidade, mas apenas um planetário de um único estágio com custo e manutenção menor.

$\mathrm{Na}$ configuração (a) a regulação da tensão gerada é feita através da excitação independente, enquanto que na (b) não é permitida a regulação da tensão gerada devido ao rotor ser de imãs permanentes. Porém a solução com imãs permanentes no rotor apresenta um rendimento maior porque praticamente não há perdas no rotor. Esta filosofia é utilizada por alguns fabricantes de grupos eólico-elétricos para potências da ordem de até 5MW, por apresentar uma grande eficiência na transformação eletromecânica da energia dos ventos e por não necessitar do multiplicador de vários estágios de velocidade. Porém apresenta um custo inicial elevado e necessita de filtros para evitar a poluição da rede através dos harmônicos provenientes do conversor.

A Figura 25 mostra o diagrama esquemático das partes de gerador eólico padrão com caixa multiplicadora e detalhe do painel de controle de tensão e frequência.

As três configurações atualmente mais utilizadas no mercado de geração eólica são: conexão de turbinas eólicas de velocidade fixa a geradores de indução com rotor em gaiola de esquilo (Squirrel Cage Induction Generation - SCIG), conexão de turbinas eólicas de velocidade variável a geradores de indução duplamente alimentados (Double Fed Induction Generator $D F I G)$ e o gerador síncrono com rotor bobinado. 


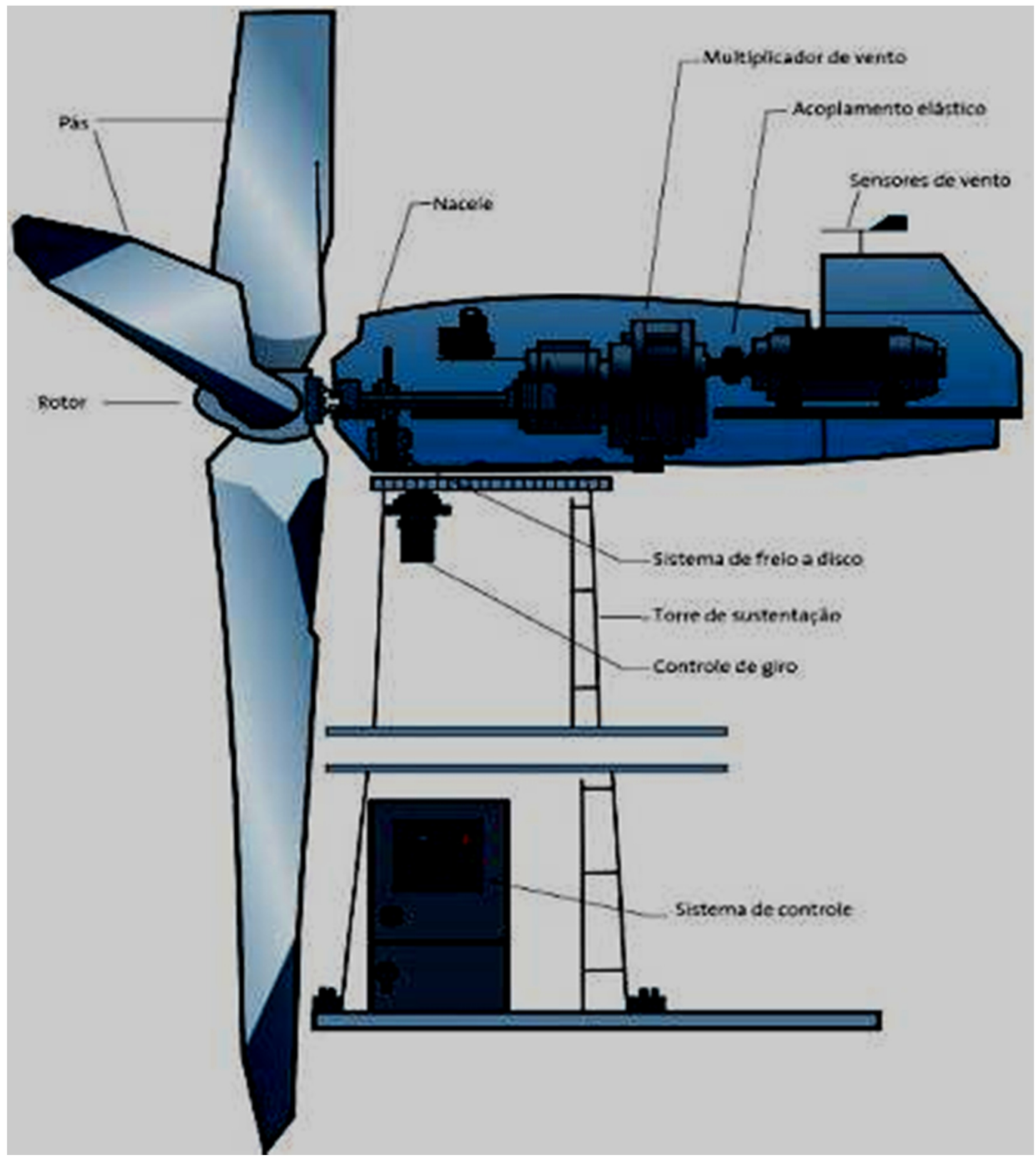

Figura 25 - Partes de um Aerogerador padrão com caixa multiplicadora Fonte: Wobben/Windpower/Enercon, 2012 


\section{Análise Comparativa dos Procedimentos de Medição e Avaliação da Qualidade de Energia de Aerogeradores conectados à Rede Elétrica}

Em função da existência de diversos procedimentos e normas aplicáveis a medição de distúrbios harmônicos em redes do sistema elétrico, foram analisadas as três principais publicações sobre o tema, com intuito de discutir a melhor forma de realizar as medições nos experimentos.

A análise incluiu as formas de cálculo das distorções harmônicas, a forma da medição dos valores e os limites estabelecidos por cada um dos documentos.

\subsection{Norma ABNT-NBR-IEC-61400-21 - Turbinas Eólicas - Parte 21: Medição e Avaliação das Características da Energia de Aerogeradores Conectados à Rede}

A finalidade desta norma, baseada na norma europeia IEC-61400-21 é oferecer uma metodologia uniforme que assegure a consistência e a exatidão na apresentação, ensaios e avaliação das características da qualidade de energia elétrica de aerogeradores conectados à rede.

Ela fornece recomendações para a preparação das medições e da avaliação das características da qualidade de energia elétrica de aerogeradores conectados a rede.

Estes procedimentos são válidos para aerogeradores individuais de qualquer tamanho, ligados em média ou alta tensão, com conexão trifásica à rede, com variação máxima de frequência de $\pm 1 \mathrm{~Hz}$, e deve ser adotada a convenção positiva para o fluxo de potência no sentido do aerogerador para a rede elétrica.

A norma estabelece que os valores das componentes individuais de corrente e a distorção harmônica total de corrente devem ser apresentados em Tabelas em porcentagem da corrente nominal (In) e para operação do aerogerador em intervalos de potência de $0,10,20, \ldots, 100 \%$ da 
potência nominal $(\mathrm{Pn})$, com valores de frequência de até 50 vezes a frequência fundamental da rede elétrica em intervalos de 10 minutos para cada condição e em situações com a mínima distorção harmônica da rede, sendo necessários a coleta de no mínimo nove séries temporais de 10 minutos de medidas da corrente instantânea para cada intervalo de $10 \%$ da potência.

Esta norma também estabelece que as componentes de frequências harmônicas devem ser determinadas para o aerogerador operando com potência reativa o mais próximo de zero, além de não requerer especificações das harmônicas de curta duração causadas pela partida dos aerogeradores ou outras operações de chaveamento.

As medições visam de um modo geral verificar os parâmetros característicos da qualidade de energia para toda a faixa operacional do aerogerador sob avaliação e são válidas para a configuração específica do aerogerador em ensaio. Tal avaliação pode ser feita através de simulações.

Algumas configurações de aerogeradores incluem um transformador incorporado. As medições das características elétricas devem ser realizadas nos terminais do aerogerador. Não se espera que haja modificações em parâmetros de qualidade da energia devido à mudança do nível de tensão do transformador. Dessa maneira, uma avaliação específica não é necessária se a tensão de saída do transformador for alterada.

Para os ensaios, as seguintes condições devem ser medidas e documentadas como parte do procedimento de ensaios:

- O aerogerador deve ser conectado diretamente a rede através de um transformador padrão cuja potência aparente nominal corresponda pelo menos à potência aparente nominal do aerogerador em avaliação;

- A distorção harmônica total de tensão, incluindo todos os harmônicos, deve ser inferior a 5\%, enquanto o aerogerador não estiver gerando energia;

- A frequência da rede deve apresentar uma tolerância de $\pm 1 \%$ em relação a frequência nominal; 
- A tensão medida nos terminais do aerogerador deve variar no máximo $\pm 10 \%$ de seu valor nominal;

- O fator de desequilíbrio de tensão medido nos terminais do aerogerador deve ser inferior a $\pm 2 \%$;

- Os ensaios devem ser realizados em condições ambientais que atendam as especificações do fabricante para os instrumentos e para o aerogerador.

A conexão do aerogerador a rede básica é representado pelo diagrama de fase da Figura 26, sendo que a fonte de tensão ideal Uo(t) deve manter duas propriedades:

- Convém que a tensão ideal não apresente nenhuma flutuação, isto é, que a cintilação seja zero (Flicker);

- Uo(t) deve apresentar o mesmo ângulo elétrico $\alpha m(t)$ da componente fundamental da tensão medida. Isso assegura que o ângulo de fase entre Ufic(t) e $\operatorname{Im}(\mathrm{t})$ estará correto, desde que $|U f i c(t)-U o(t)|<<|U o(t)|$.

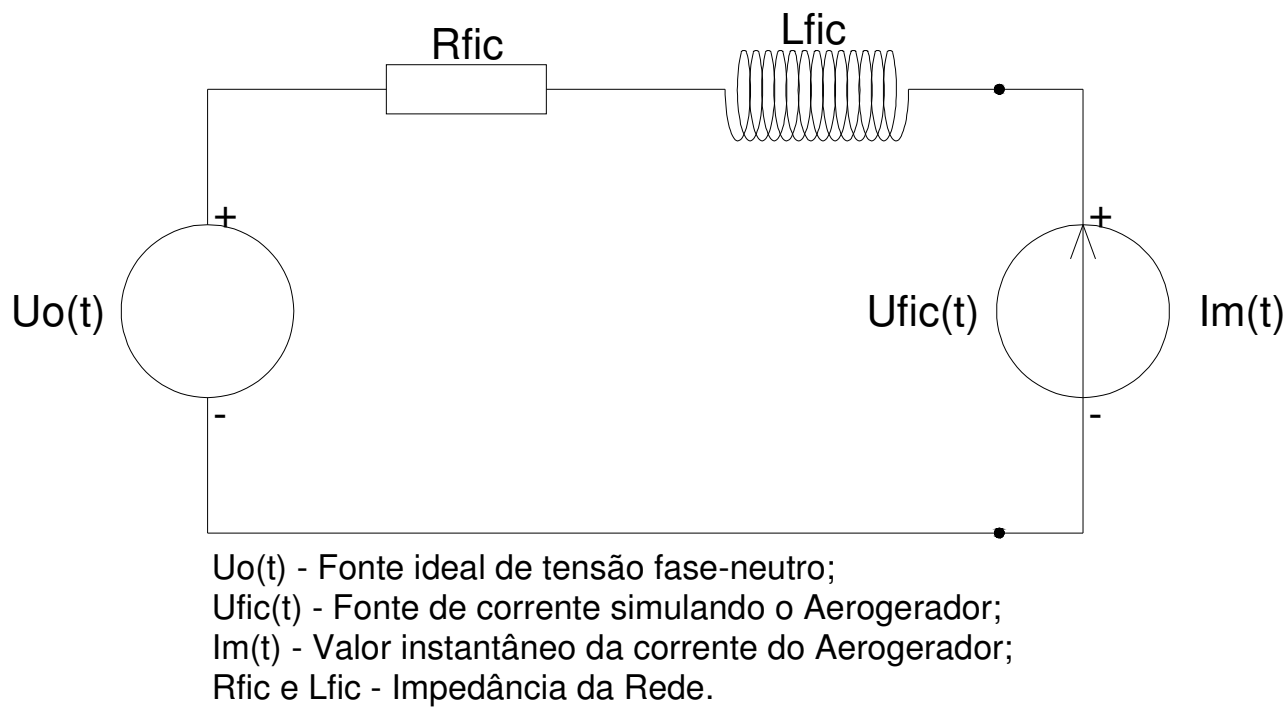

Figura 26 - Diagrama de fase da rede fictícia para simulação de tensão Fonte: ABNT-NBR-IEC-61400-21

Para as medições, são recomendadas pela NBR-IEC-61400-21, janelas de 12 ciclos, sendo que o tamanho das janelas devem ser informadas no relatório de ensaio. 
As correntes harmônicas devem ser limitadas suficientemente para evitar tensões harmônicas inaceitáveis no ponto de conexão comum com a rede (PCC), sendo que o limite aplicável para essas emissões harmônicas podem ser determinados aplicando-se as orientações dispostas na IEC-61000-3-6, que dispõe de orientações para o somatório de distorção harmônica de corrente proveniente das cargas conectadas ao sistema. Com base nestas orientações, a corrente harmônica no PCC decorrente de uma instalação com um determinado número de aerogeradores pode ser estimada utilizando-se a equação abaixo:

$$
\operatorname{Ih} \sum=\sqrt[\beta]{\sum_{i=1}^{N w t}\left(\frac{I h, i}{N i}\right)^{\beta}}
$$

Onde:

- $\mathrm{N}_{\mathrm{wt}}$ é o número de aerogeradores conectados ao mesmo PCC;

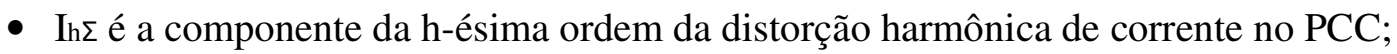

- Ni é a relação de transformação do transformador do i-ésimo aerogerador;

- Ihi é a componente de h-ésima ordem da distorção harmônica de corrente do aerogerador de i-ésima ordem;

- $\beta$ é um expoente cujo valor deve ser escolhido a partir da norma NBR-IEC-61400-21, representada na Tabela 15 .

\begin{tabular}{cc}
\hline $\begin{array}{c}\text { Ordem } \\
\text { harmônica }\end{array}$ & $\boldsymbol{\beta}$ \\
\hline $\mathrm{h}<5$ & 1,0 \\
$5<\mathrm{h}<10$ & 1,4 \\
$\mathrm{~h}>10$ & 2,0 \\
\hline
\end{tabular}

Tabela 15 - Especificação de Expoente “ $\beta$ ” de acordo com a NBR-IEC-61000-3-6 Fonte: ABNT-NBR-IEC-61400-21 Turbinas Eólicas

Nas situações onde os aerogeradores forem iguais e seus conversores forem de comutação natural, os harmônicos provavelmente estão em fase e um valor de $\beta=1$ deve ser utilizado para todas as ordens harmônicas, fazendo com que a corrente harmônica no PCC decorrente de uma 
instalação com um determinado número de aerogeradores passa a ser estimada utilizando-se a equação abaixo:

$$
\operatorname{Ih} \sum=\sum_{i=1}^{N w t}\left(\frac{I h, i}{N i}\right)
$$

\subsection{Procedimento ONS - Instruções para Realização de Estudos e Medições de QEE Relacionados aos Novos Acessos à Rede Básica}

Segundo o próprio procedimento do Operador Nacional do Sistema (ONS), o objetivo desta instrução é apresentar aos futuros agentes acessantes da rede básica ou aqueles que já acessem a rede, mas estejam buscando um novo ponto de conexão ou ampliando suas instalações em conexões pré-existentes, informações que possam apoiá-los quanto à realização de estudos e campanhas de medição relacionadas à avaliação do impacto das novas condições de conexão na rede básica ao ponto de acoplamento comum (PAC) no que diz respeito aos indicadores de conformidade de tensão, que são, distorção harmônica, desequilíbrio e flutuação de tensão e considerando as limitações ainda presentes nos estudos do tipo "fluxo de harmônicos", quer seja do ponto de vista da validade dos modelos adotados por toda faixa de frequência de interesse, quer seja pela disponibilidade de dados. Basicamente, os estudos tratam das avaliações de desempenho quanto à distorção harmônica e flutuação de tensão.

O procedimento estabelece o método do "lugar geométrico" (LG) da impedância harmônica da rede básica no plano complexo X versus R, conforme descrito no procedimento do ONS e recomendado por esse para calcular os piores valores de tensão harmônica no PAC. Não é prático efetuar um cálculo de fluxo harmônico para cada ponto do Lugar Geométrico, visando escolher valores máximos pois a quantidade de cálculos seria exorbitante. A forma tradicional de avaliação é determinar “equivalentes Norton” (Ih, Żih) da rede interna do agente acessante vistos do PAC (instalação desconectada da rede básica), para cada harmônica significativa, considerando as condições operativas possíveis desta instalação.

A Figura 27 mostra o circuito equivalente de Norton com o LG da rede básica, incluindo a admitância representativa do circuito Norton da instalação, com os filtros considerados como 
parte desta instalação, a admitância representativa da rede elétrica externa a instalação, a partir do PAC, e a fonte de corrente harmônica equivalente, resultante da combinação das fontes harmônicas principais presentes na instalação.

\section{PAC}

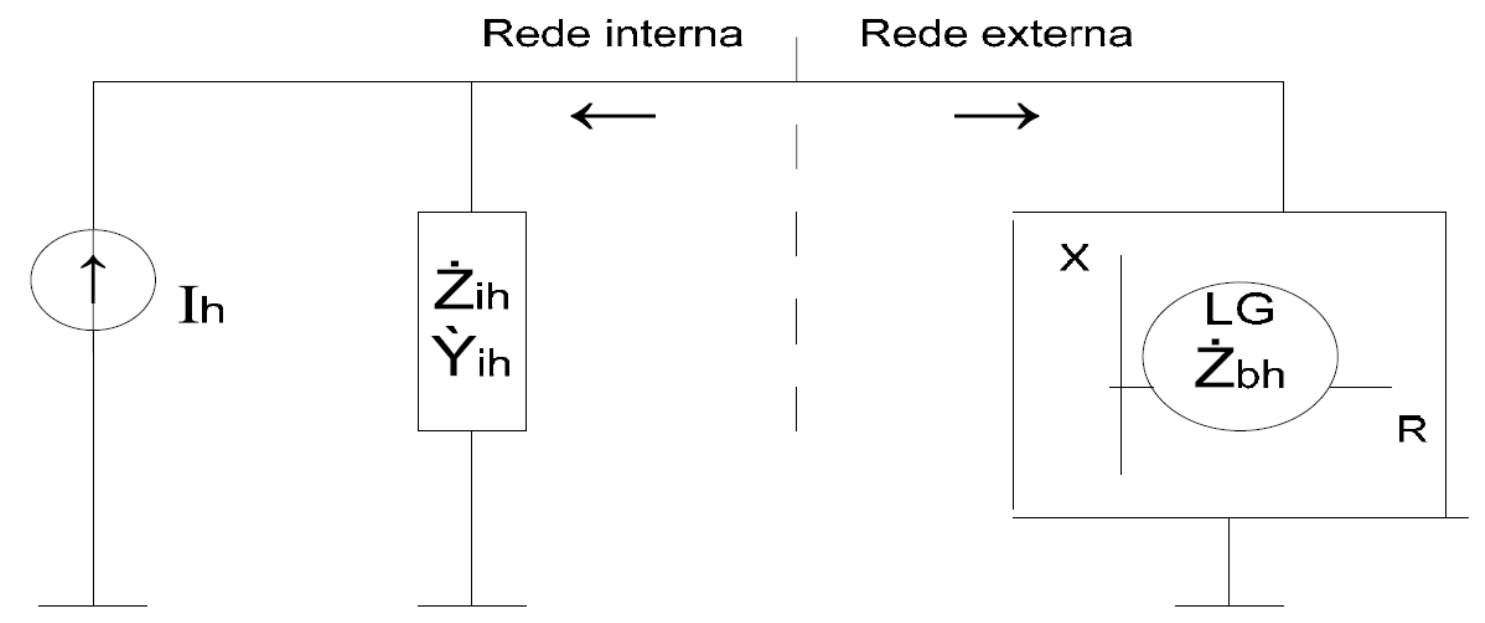

Figura 27 - Representação do “Equivalente de Norton” com o Lugar Geométrico (LG) da Rede Básica. Fonte: Procedimento ONS - Instruções para Realização de Estudos e Medições de QEE Relacionados aos Novos Acessos à Rede Básica.

O valor da impedância representativa da rede básica, pertencente ao LG da mesma, que maximiza o valor da tensão harmônica no PAC, para cada ordem harmônica (h), é obtido por cálculo geométrico no plano complexo de admitâncias, sendo a tensão harmônica máxima: Uhmax $=\mathrm{Ih} /$ Yhmin. $\mathrm{O}$ denominador Yhmin é o módulo da soma vetorial em paralelo da admitância Norton equivalente da rede do agente (Ỳih =1/Żih) com a admitância correspondente ao ponto do envelope do LG de admitância da rede básica (Ỳbh) que minimiza Yhmin. O ponto no envelope que corresponde a esse menor módulo é encontrado geometricamente como a menor distância do extremo do vetor -Ỳih ao LG de admitância harmônica da rede básica, conforme pode ser verificado na Figura 28, que apresenta de forma gráfica a utilização do método do "lugar geométrico" para obtenção do ponto do envelope do LG de admitância da rede básica (Ỳbh) que minimiza Yhmin $=\mid \grave{\text { ì }}+$ Ỳbhl, considerando uma particular representação de LG. 


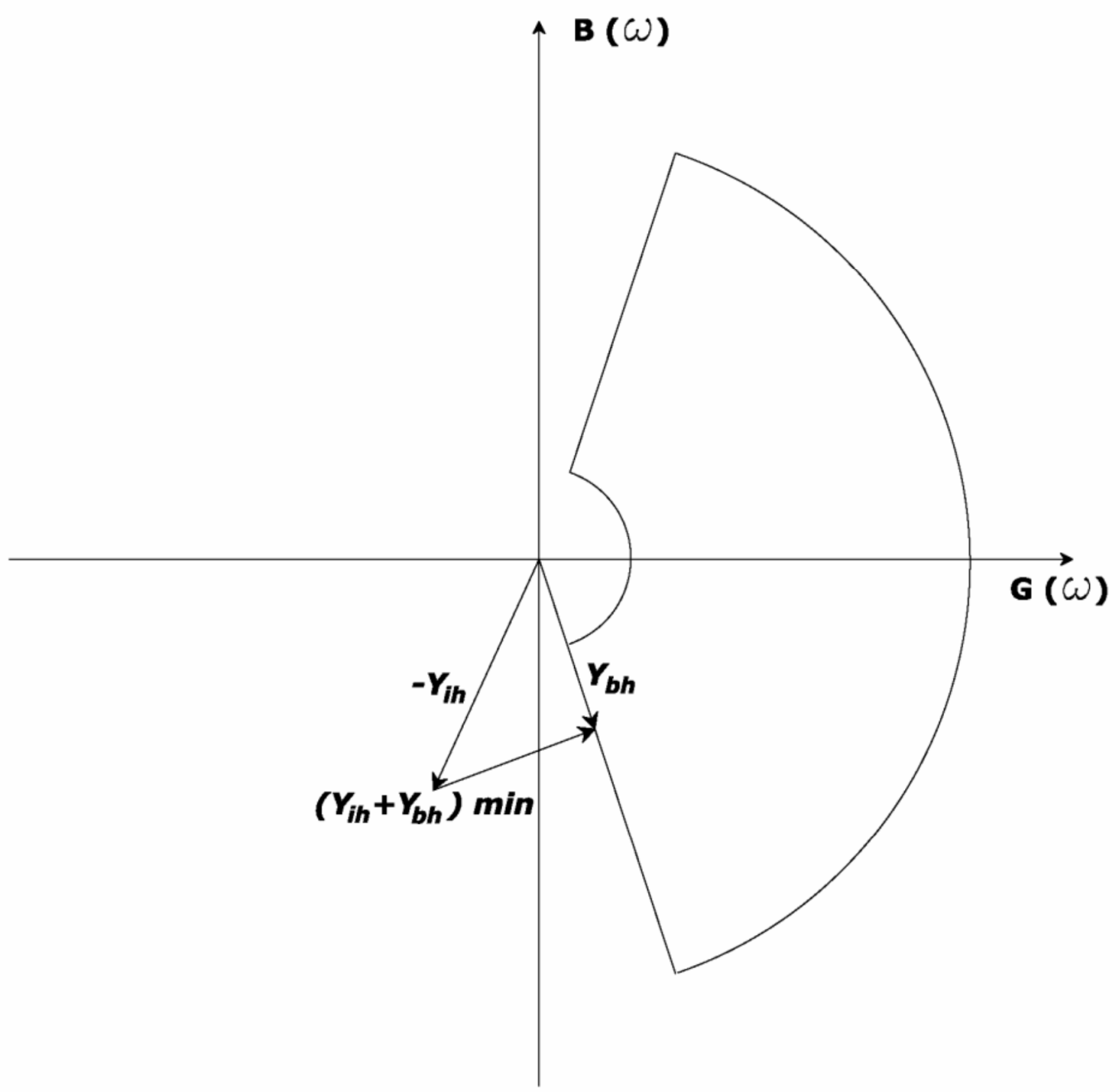

Figura 28 - Ilustração gráfica do método do "lugar geométrico". Fonte: Procedimento ONS - Instruções para Realização de Estudos e Medições de QEE Relacionados aos Novos Acessos à Rede Básica.

As correntes harmônicas (Ih) utilizadas no cálculo de Uhmax podem ser determinadas a partir dos valores de correntes harmônicas geradas por cada um dos equipamentos não lineares presentes na instalação (aerogeradores). Tais valores poderão ser determinados por simulação ou por medição. Observa-se que valores medidos, quando disponíveis, são os mais recomendados.

$\mathrm{O}$ procedimento estabelece que os valores das correntes harmônicas geradas por equipamento conversor, quando obtidos por simulação, devem corresponder aos máximos individuais por harmônico, considerando tanto sua faixa de potência como seus modos de 
operação (normal ou degradada), bem como eventuais desequilíbrios de impedâncias e relações de transformação dos transformadores conversores, erros relacionados com os ângulos de disparo e/ou extinção do processo de conversão, assim como máximo desequilíbrio de tensão (sequência negativa). Tais valores são, normalmente, informados pelo fabricante do equipamento.

Considerando a dificuldade do estabelecimento dos ângulos entre as correntes geradas pelas diferentes fontes, independentemente controladas, para uma mesma harmônica, a corrente resultante deverá ser obtida através da formulação proposta pela IEC 61000-3-6, reproduzida abaixo:

$$
I_{n, t o t a l}=\left(\sum_{i=1}^{m} I_{n, 1}^{a}\right)^{1 / a}
$$

Onde:

$\mathrm{n}$ - ordem harmônica;

$\mathrm{m}$ - número total de fontes.

O valor de "a" é determinado pela Tabela 16.

\begin{tabular}{cc}
\hline Valor de "a" & $\begin{array}{c}\text { Ordem da } \\
\text { harmônica }\end{array}$ \\
\hline 1,0 & $\mathrm{n}<5$ \\
1,4 & $5 \leq \mathrm{n} \leq 10$ \\
2,0 & $\mathrm{n}>10$ \\
\hline
\end{tabular}

Tabela 16 - Especificação de Expoente "a" de acordo com o procedimento ONS Fonte: Procedimento ONS - Instruções para Realização de Estudos e Medições de QEE Relacionados aos Novos Acessos à Rede Básica

Os critérios de aceitação da nova instalação estabelecidos pelo ONS quanto aos limites individuais relacionados à distorção harmônica são apresentados na Tabela 17, sendo que no caso do estudo resultarem valores de distorção harmônica superiores aos estabelecidos acima, o agente deverá apresentar solução, normalmente relacionada com a instalação de filtragem, que levem ao adequado desempenho da instalação no PAC. 


\begin{tabular}{|c|c|c|c|c|c|c|c|}
\hline \multicolumn{4}{|c|}{$13,8 \mathrm{kV} \leq \mathrm{U}<69 \mathrm{kV}$} & \multicolumn{4}{|c|}{$\mathrm{U} \geq 69 \mathrm{kV}$} \\
\hline \multicolumn{2}{|c|}{ Impares } & \multicolumn{2}{|c|}{ Pares } & \multicolumn{2}{|c|}{ Impares } & \multicolumn{2}{|c|}{ Pares } \\
\hline Ordem & Valor & Ordem & Valor & Ordem & Valor & Ordem & Valor \\
\hline $\begin{array}{l}3 \text { a } 25 \\
\geq 27\end{array}$ & $\begin{array}{l}1,5 \% \\
0,7 \%\end{array}$ & Todos & $0,6 \%$ & $\begin{array}{c}3 \text { a } 25 \\
\geq 27\end{array}$ & $\begin{array}{l}0,6 \% \\
0,4 \%\end{array}$ & Todos & $0,3 \%$ \\
\hline \multicolumn{4}{|c|}{$\mathrm{DHT}=3 \%$} & \multicolumn{4}{|c|}{$\mathrm{DHT}=1,5 \%$} \\
\hline
\end{tabular}

Tabela 17 - Limites individuais de distorção harmônica

Fonte: Resolução Normativa 372/09 - Procedimentos de Rede - ONS

Algumas condições devem ser atendidas para a medição de avaliação de desempenho das instalações com característica não linear, em conformidade com o submódulo 2.8 dos procedimentos de rede e o relatório Re.ONS - 2.1 - 028/2005 "Definição das Metodologias e Procedimentos Necessários às Campanhas de Medição dos Indicadores de Desempenho", que são:

- O período de medição não pode ser inferior a 7 (sete) dias consecutivos, considerando os valores dos indicadores integralizados em intervalos de 10 (dez) minutos;

- Estas devem envolver medições de flutuação, desequilíbrio e distorção harmônica de tensão. Dependendo das características da instalação e da sua conexão à rede básica e barramentos dos transformadores de fronteira, também devem ser medidas as correntes harmônicas resultantes da operação de cargas/dispositivos não lineares pertencentes a estas instalações;

- De uma maneira geral, as medições devem ser realizadas imediatamente antes e imediatamente depois da entrada em operação da instalação com característica não linear;

- Pelo menos noventa por cento das unidades geradoras que compõem o complexo eólico devem estar em operação ao longo de todo o período de medição;

- A produção do complexo eólico, durante o período de medição, devem corresponder, no mínimo, aquela estabelecida pelo seu fator de capacidade.

De acordo com o submódulo 2.8 dos procedimentos de rede e o relatório Re.ONS - 2.1 028/2005 "Definição das Metodologias e Procedimentos Necessários às Campanhas de Medição dos Indicadores de Desempenho", os indicadores a serem obtidos para a medição harmônica a 
partir da medição, é a distorção harmônica de tensão: DTHTS95\% e os indicadores correspondentes relativos aos harmônicos individuais.

\subsection{Norma IEEE-519-1992 - "Recommended Practices and Requirements for Harmonic Control in Electrical Power Systems"}

As normas IEEE não tratam de forma específica os limites de geração harmônica para aerogeradores, ficando quase que exclusivamente para a norma IEEE-519-1992 as recomendações para o controle harmônico em sistemas elétricos de potência, definindo os limites máximos que devem atender os sistemas para geração de frequências harmônicas.

A norma estabelece alguns conceitos como:

- A concessionária de energia é responsável por fornecer energia "limpa" aos consumidores;

- O consumidor é responsável por não causar correntes harmônicas excessivas ao sistema de energia;

- A concessionária de energia só pode ser razoavelmente julgada se o cliente está dentro de seus limites atuais;

- Os limites de geração harmônica são mais rigorosos quanto maior for o nível de tensão do sistema elétrico;

- Harmônicas individuais devem ser limitadas para diminuir os níveis do THD da instalação;

- A concessionária de energia deve tentar impedir que as distorções oriundas de algum consumidor ou do próprio sistema, atinja outros consumidores.

Os limites estabelecidos pela norma IEEE-519-1992 para todos os tipos de instalações em qualquer nível de tensão estão mostrados na Tabela 18 e embora as faixas de tensão sejam bastante amplas, os limites estabelecido são mais rígidos do que os estabelecidos pelas normas brasileiras, como exemplo a Resolução ANEEL-395/2009 (PRODIST). 
A Tabela 18 estabelece os limites da distorção harmônica total de tensão (THD), mas também estabelece os limites de distorção harmônica individual para cada ordem harmônica, mesmo que o THD não ultrapasse o estabelecido na Tabela.

\begin{tabular}{|c|c|c|}
\hline $\begin{array}{c}\text { Tensão no Barramento no } \\
\text { PCC }\end{array}$ & $\begin{array}{c}\text { Limites de Distorção de Tensão } \\
\text { Distorção Individual de } \\
\text { Tensão }(\%)\end{array}$ & $\begin{array}{c}\text { Distorção Total de Tensão } \\
\text { THD }(\%)\end{array}$ \\
\hline $69 \mathrm{kV}$ e abaixo & 3,0 & 5,0 \\
\hline $69,001 \mathrm{kV}$ até $161 \mathrm{kV}$ & 1,5 & 2,5 \\
\hline 161,001 e acima & 1,0 & 1,5 \\
\hline
\end{tabular}

Tabela 18 - Limites de distorção harmônica de tensão para instalações com todos os níveis de tensões Fonte: Norma IEEE-519 - IEEE - 1992

A norma por sua vez, também estabelece os limites máximos de harmônicas de corrente para cada grupo de ordem harmônica, como pode ser visto na Tabela 19, para tensões de $120 \mathrm{~V}$ a $69 \mathrm{kV}$, limitando dessa forma, a geração harmônica proveniente das cargas, que interferem diretamente na qualidade de energia dos sistemas elétricos de potência. 
Máxima corrente Harmônica em \% da corrente de carga (Io - valor da componente fundamental)

Harmônicas Ímpares

\begin{tabular}{ccccccc} 
Icc/Io & $<11$ & $11 \leq \mathrm{n}<17$ & $17 \leq \mathrm{n}<23$ & $23 \leq \mathrm{n}<35$ & $35<\mathrm{n}$ & $\mathrm{THD}(\%)$ \\
\hline$<20$ & 4,0 & 2,0 & 1,5 & 0,6 & 0,3 & 5,0 \\
$20<50$ & 7,0 & 3,5 & 2,5 & 1,0 & 0,5 & 8,0 \\
$50<100$ & 10,0 & 4,5 & 4,0 & 1,5 & 0,7 & 12,0 \\
$100<1000$ & 12,0 & 5,5 & 5,0 & 2,0 & 1,0 & 15,0 \\
$>1000$ & 15,0 & 7,0 & 6,0 & 6,0 & 1,4 & 20,0 \\
\hline
\end{tabular}

Cada Harmônica é limitada a $25 \%$ dos limites das harmônicas ímpares acima.

Distorções de corrente que resultam em um sinal contínuo, como por exemplo, conversores de meia onda, não são permitidos.

Todo equipamento de geração de energia é limitado a estes valores de distorção de corrente, independentemente do valor real de Icc/Io. Onde:

Icc = Máxima corrente de curto circuito em Pcc; Io = Máxima corrente de carga demandada (componente da frequência fundamental) em Pcc nas condições normais de operação.

Tabela 19 - Limites de distorção harmônicas de corrente para instalações com tensões de $120 \mathrm{~V}$ à $69 \mathrm{kV}$ Fonte: Norma IEEE-519-1992

$\mathrm{O}$ ponto de acoplamento comum (PAC), na interligação do consumidor com a concessionária de energia é o ponto mais próximo do lado da concessionária de serviço do consumidor, onde outro consumidor pode ser alimentado. A utilização de qualquer aparelho tal como um transformador que a concessionária pode prover no sistema do consumidor é irrelevante para a definição do PAC.

O PAC é o ponto onde as concessionárias de energia devem avaliar os limites das interferência harmônicas provenientes do sistema e das cargas oriundas dos consumidores, para mensuração das interferências totais no sistema e a partir dessas informações, traçar os planos para redução dessas interferências nas instalações do sistema elétrico.

A recomendação descrita na Norma IEEE-519-1992 visa reduzir os efeitos harmônicos em qualquer ponto de todo o sistema, estabelecendo os limites dos índices de harmônicas (correntes e tensões) no ponto de acoplamento comum (PAC), no ponto de medição de energia ou em qualquer outro ponto, de forma que tanto a concessionária quanto o consumidor podem acessar estes pontos para medição direta dos índices de harmônicas mais significativos para ambos. Dentro de uma planta industrial, o PAC (PCC) é o ponto entre a carga não-linear e as demais cargas ". 


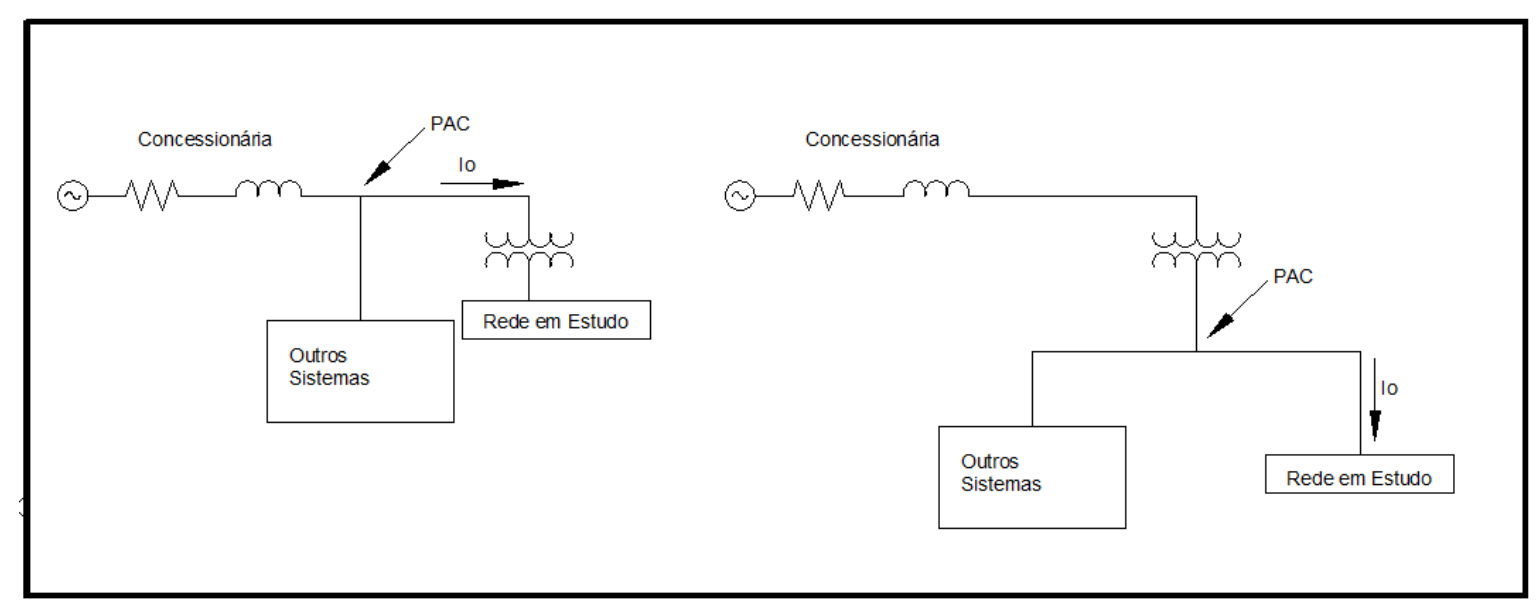

Figura 29 - Ponto de acoplamento comum (PAC) do sistema (do inglês point of commom coupling - PCC) Fonte: Norma IEEE-519-1992

\subsection{Análise}

Após análise das três principais normas que estabelecem os limites das distorções harmônicas e a metodologia para medição desta grandeza elétrica nos sistemas elétricos de potência, foi verificado que elas se complementam e caminham juntas para dar aos investigadores desse tipo de distúrbio que ocorre nas redes, ferramentas que podem facilitar os diagnósticos necessários a correta análise do problema.

Fica claro que a norma NBR-IEC-61400-21, é uma norma de aplicação mais prática, não entrando em muitos detalhes de cálculos sobre a forma do tratamento das harmônicas medidas, restringindo-se quase que exclusivamente as metodologias de medição das distorções harmônicas oriundas do ponto de acoplamento comum (PAC), inclusive referendando o fato das harmônicas individuais provenientes de grupos aerogeradores idênticos ligados no mesmo PAC, estarem em fase entre si.

Os princípios descritos na NBR-IEC-61400-21 para se avaliar a qualidade da energia elétrica de um aerogerador ou grupo de aerogeradores podem ser utilizados como guia, ainda que operadores da rede elétrica e autoridades reguladoras apliquem seus próprios requisitos em substituição ou em adição a outras publicações da IEC ("International Electrical Comission”). 
O procedimento da ONS estabelecem critérios mais técnicos para determinação correta da distorção harmônica total em relação a norma NBR-IEC-61400-21, proveniente das fontes de aerogeradores acoplados no PAC, tais como o método do lugar geométrico e diagrama equivalente de Norton para representar uma fonte aerogeradora e dessa forma pontuá-los nas instalações do sistema elétrico.

Os cálculos para determinação das contribuições de cada fonte geradora são mais complexos e envolvem informações de fabricante e as características construtivas de cada máquina, podendo assim, alterar o resultado final das medições. Porém, no quesito medição especificamente, o procedimento admite, assim como na norma NBR-IEC-61400-21, que as interferências harmônicas oriundas de diversas fontes estão em fase, possibilitando a soma de suas componentes harmônicas.

Os procedimentos de medição se equivalem para as duas normas (NBR-IEC-61400-21 e Procedimento ONS), ou seja, estabelecem os mesmos períodos de amostragem, o mesmo número de amostras e o mesmo período de medição, além de utilizarem o mesmo método para determinação da distorção harmônica total de corrente de todas as fontes ligadas ao mesmo PAC. Os limites máximos de distorção harmônica individual para as duas normas também são os mesmos.

A norma IEEE-519-1992, por ser mais antiga que as demais, estabelece limites máximos individuais para cada frequência harmônica, maiores que as outras duas, além de não estabelecer critérios de medição para análise das interferências harmônicas.

Por esse motivo, a aplicação da norma NBR-IEC-61400-21, garante, para efeito de medição dos distúrbios harmônicos, o método mais abrangente para os resultados deste tipo de fenômeno na rede elétrica. 


\section{Estudo Experimental das Contribuições Harmônicas dos Principais Tipos de Aerogeradores}

A principal finalidade desse capítulo é apresentar a metodologia, os resultados e a análise relativa às medições das distorções harmônicas causadas pelos três principais tipos de aerogeradores comercializados no mercado e estimar o impacto que o tipo de controle de frequência desses modelos pode gerar no sistema elétrico.

\subsection{Metodologia}

Após a análise envolvendo a ABNT-NBR-IEC-61400-21/2010 - "Medição e Avaliação da Qualidade de Energia de Aerogeradores Conectados à Rede”, o procedimento da ONS "Instruções para Realização de Estudos e Medições de QEE Relacionados aos Novos Acessos à Rede Básica" e o documento IEEE-519-1992 - "Recommended Practices and Requirements for Harmonic Control in Electrical Power Systems", optou-se pela adoção do procedimento da ABNT-NBR-IEC-61400-21, com base nas considerações apresentadas no Capítulo 3.

Foram analisados, neste trabalho, os três modelos de gerador eólico mais utilizados nos segmentos dos autoprodutores, produtores independentes e concessionárias de energia, a saber: gerador síncrono com rotor bobinado (GSRB), gerador de indução duplamente alimentado (GIDA) e gerador de indução com gaiola de esquilo (GIGE). Através de analisador de qualidade de energia, foram obtidas as grandezas elétricas correspondentes a cada um desses modelos.

A metodologia adotada para medição das contribuições harmônicas dos modelos de aerogeradores envolveu os seguintes passos:

- montagem de cada um dos três modelos de aerogeradores em condição de paralelismo com a rede elétrica da concessionária de energia, conforme padrão de montagem dos modelos reais utilizados em usinas eólicas. Foram utilizados equipamentos de 
laboratório de baixa tensão e baixa potência similares aos utilizados nos grandes parques eólicos;

- foi utilizado um motor de corrente contínua com excitação shunt e reostato de campo para simular a turbina eólica e a caixa de engrenagens utilizadas nos aerogeradores convencionais, possibilitando a variação de velocidade de rotação. A velocidade de rotação foi mantida constante em $3.600 \mathrm{rpm}$ para garantir o fornecimento de energia em $60 \mathrm{~Hz}$, visto que o gerador utilizado é de 2 polos;

- a carga foi simulada através de um banco de reostatos ligados em estrela, garantindo a variação da mesma em condição puramente resistiva, a fim de minimizar a geração harmônica oriunda da própria carga;

- na primeira etapa foram realizadas as medições das interferências harmônicas exclusivas da rede elétrica da concessionária de energia sem a contribuição dos modelos dos aerogeradores, a fim de se determinar a contribuição dessas nas análises efetuadas;

- em seguida, cada um dos modelos de aerogeradores estudados foi ligado em condição de paralelismo à rede, garantindo o sincronismo com a rede, em diversas condições de carga, iniciando em $0 \%$ até atingir $100 \%$ da carga do equipamento, com variação de 10\% em cada medição, conforme estabelece a ABNT-NBR-IEC-61400-21;

- na medição com o gerador síncrono com rotor bobinado (GSRB) foi efetuada também a medição do mesmo alimentando a carga sem a contribuição da rede (alimentação do campo por fonte externa de corrente contínua), a fim de se determinar a interferência harmônica desse modelo sem a atenuação da rede elétrica;

- da mesma forma, na medição com gerador de indução duplamente alimentado (GIDA), o sistema foi ligado em condição de paralelismo com a rede e em seguida desligado este paralelismo, ficando a alimentação da carga por conta exclusiva do gerador para mensuração das interferências harmônicas do mesmo na alimentação da carga.

Para a montagem dos modelos foram utilizados geradores, transformadores e inversores de frequência na tensão de 48-220 V, sendo que no modelo real a tensão de saída dos geradores está na faixa de $400 \mathrm{~V}$, sendo então elevada para alta tensão. 
Após a coleta dos dados nas diversas situações apresentadas, foram realizados os estudos das informações levantadas para formatação do trabalho, que consiste em:

- analisar as distorções harmônicas nos modelos de unidades geradoras em diversas condições de carga em condição de paralelismo com a rede, para análise da contribuição individual desses no sistema;

- analisar as interferências harmônicas oriundas exclusivamente da rede para isolar a parcela proveniente desta no sistema;

- analisar as interferências harmônicas oriundas exclusivamente do modelo de aerogerador estudado para isolar a verificação deste quando sozinho na rede;

- analisar cada espectro de frequência dentro das informações coletadas, para verificar os principais efeitos das distorções geradas nas cargas alimentadas pelo sistema;

- comparar os resultados aqui apresentados a medições reais de um modelo de aerogerador com gerador síncrono e rotor bobinado (GSRB), realizado por um fabricante nacional, dentro dos padrões das medições da norma ABNT-NBR-IEC61400-21 e que foram gentilmente fornecidos para realização desse trabalho;

- finalizar a análise especificando que tipo de gerador contribui de forma mais expressiva com as distorções harmônicas e quais as interferências dessas na rede elétrica.

Para captação dos dados foi utilizado o aparelho Analisador de Qualidade de Energia MARH-21-993, de fabricação RMS Indústria de Equipamentos Eletrônicos Ltda., devidamente calibrado em laboratório certificador, com alicates de medição de corrente flexível de 3000:5, 100:5 A e 10:5 A, garras de tensão com limite de medição para 690 VCA e software de aquisição de dados ANAWIN versão 348, conforme pode ser visto nas Figuras 26 e 27, sendo este equipado com os módulos para medição das seguintes grandezas:

- tensões de fase (fase-neutro), fases A, B e C;

- tensões de linha (fase-fase), AB, BC e CA (valores obtidos por cálculo fasorial);

- correntes, fases A, B e C;

- fatores de potência, fases A, B e C; 
- fator de potência total;

- potências ativas, fases A, B e C;

- potência ativa total;

- potências reativas, fases A, B e C;

- potência reativa total;

- potências aparentes, fases A, B e C;

- potência aparente total;

- energia ativa total (consumida ou fornecida);

- energia reativa capacitiva total;

- energia reativa indutiva total;

- distorção harmônica total de tensão, fases A, B e C;

- distorção harmônica de tensão (porcentagem por faixa de frequência), fases A, B e C;

- distorção harmônica total de corrente, fases A, B e C;

- distorção harmônica de corrente (porcentagem por faixa de frequência), fases A, B e $\mathrm{C}$;

- potência reativa total necessária para alteração do fator de potência;

- grandezas auxiliares, canais 1, 2 e 3;

- frequência da tensão, fase A. (na falta da fase A, mede-se na fase B, na falta da fase B, mede na fase $\mathrm{C})$;

- máximo e mínimo de frequência da tensão (ciclo a ciclo);

- sequência de fases ${ }^{2}$;

- máximo e mínimo de tensão (“true rms", 1/2 ciclo, com indicação da fase) $)^{3}$;

- máximo de corrente (“true rms”, 1/2 ciclo, com indicação da fase) $)^{3}$;

- tempo com tensão fora da faixa programada ${ }^{3}$;

- tempo com corrente acima do valor programado ${ }^{3}$;

\footnotetext{
${ }^{2}$ Valores somente medidos, não registrados.

${ }^{3}$ Valores somente disponíveis via Software ANAWIN, não exibidos diretamente no mostrador do MARH-21
} 
- grau de desequilíbrio de tensão (IEC) ${ }^{3}$;

- grau de desequilíbrio de tensão (NEMA) ${ }^{3}$;

- demandas, fases A, B e C, ponta e fora de ponta ${ }^{3}$;

- demandas, valores totais, ponta e fora de ponta ${ }^{3}$;

- harmônicas continuamente, até $31^{\mathrm{a}}$ harmônica (3 fases) ou até $61^{\mathrm{a}}$ harmônica ( 1 fase); Registro de forma de onda das correntes e tensões. Captação acionada manualmente;

- harmônicas com janelas de 2 ciclos a cada intervalo programado, até $31^{\text {a }}$ harmônica (3 fases) ou até $61^{\text {a }}$ harmônica (1 fase). Registro de forma de onda das tensões e correntes. Captação com acionamento automático a cada intervalo programado;

- harmônicas médias (até $50^{\mathrm{a}}$ harmônica) e potências por fase;

- registro de forma de onda dos sinais de tensão e corrente nas três fases com captação acionada por variações do valor instantâneo da tensão, "sag", "swell", DHT e frequência. O número de ciclos captados (tamanho da janela de captação) é programável;

- registro de grandezas integralizadas e captação de forma de onda (tensão e corrente) simultaneamente.

As medições foram realizadas diretamente na saída do modelo do aerogerador, após a passagem da energia pelo sistema de controle de tensão e frequência (PAC), para mensuração total de todas as interferências do equipamento estudado.

Embora a norma estabeleça que as medições das frequências harmônicas devam ser realizadas considerando a frequência de até 50 vezes a frequência fundamental (harmônica de $50^{\mathrm{a}}$ ordem), o experimento foi realizado com o aparelho citado, visto que o número de amostras por período é muito superior ao estabelecido pela norma (mínimo de 9 séries temporais no intervalo de 10 minutos), o que permite uma análise mais detalhada das distorções momentâneas do circuito (foram realizadas amostras a cada 5 segundos dentro do intervalo). Também não se julgou necessária, considerando a finalidade do presente trabalho, a realização de medições em frequências inter-harmônicas e harmônicas de alta frequência. 


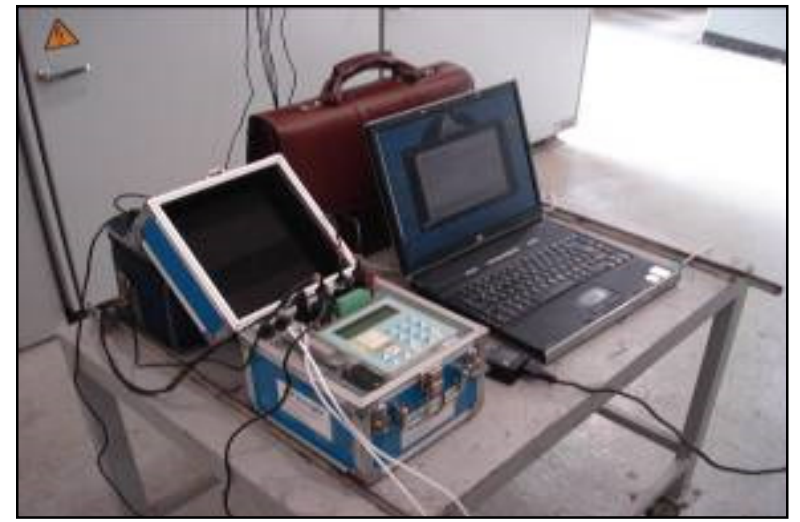

Figura 30 - Analisador de qualidade de energia Fabricante RMS - Modelo Marh-21

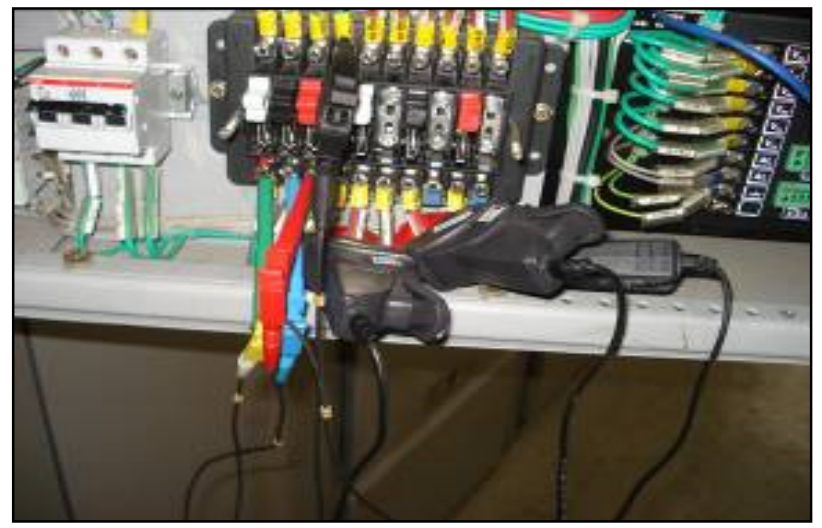

Figura 31 - Forma de conexão do analisador de qualidade de energia em carga

\subsection{Resultados}

São apresentados neste item os resultados referentes às medições efetuadas considerando os três principais tipos de aerogeradores utilizados no mercado para avaliação do impacto de cada um quanto à geração de harmônicas no sistema. Foram consideradas as seguintes situações:

- medição das interferências harmônicas da rede elétrica da concessionária de energia em alimentação direta à carga, sem a condição de paralelismo de outras fontes geradoras;

- medição dos modelos de aerogerador utilizados nos ensaios em condição em vazio e em paralelismo com a rede da concessionária;

- medição dos modelos de aerogerador utilizados nos ensaios em condição em carga e em paralelismo com a rede da concessionária, com variação decimal da porcentagem de carga até a situação de plena carga;

- medição de alguns dos modelos na condição de fornecimento de energia de forma singela e isolada com ligação direta à carga (sem a condição de paralelismo com a rede da concessionária de energia). 


\subsubsection{Medição da Rede Elétrica sem acoplamento dos Modelos de Aerogeradores}

Inicialmente foi realizada a medição das distorções harmônicas oriundas exclusivamente da rede de alimentação da concessionária de energia, com a carga (banco de reostatos ligados em estrela) conectada diretamente à rede, com o objetivo de mensurar o nível de distorção harmônica proveniente da rede de modo a possibilitar a análise das contribuições dos modelos dos aerogeradores. A Figura 32 mostra o diagrama de ligação utilizado para essa medição.

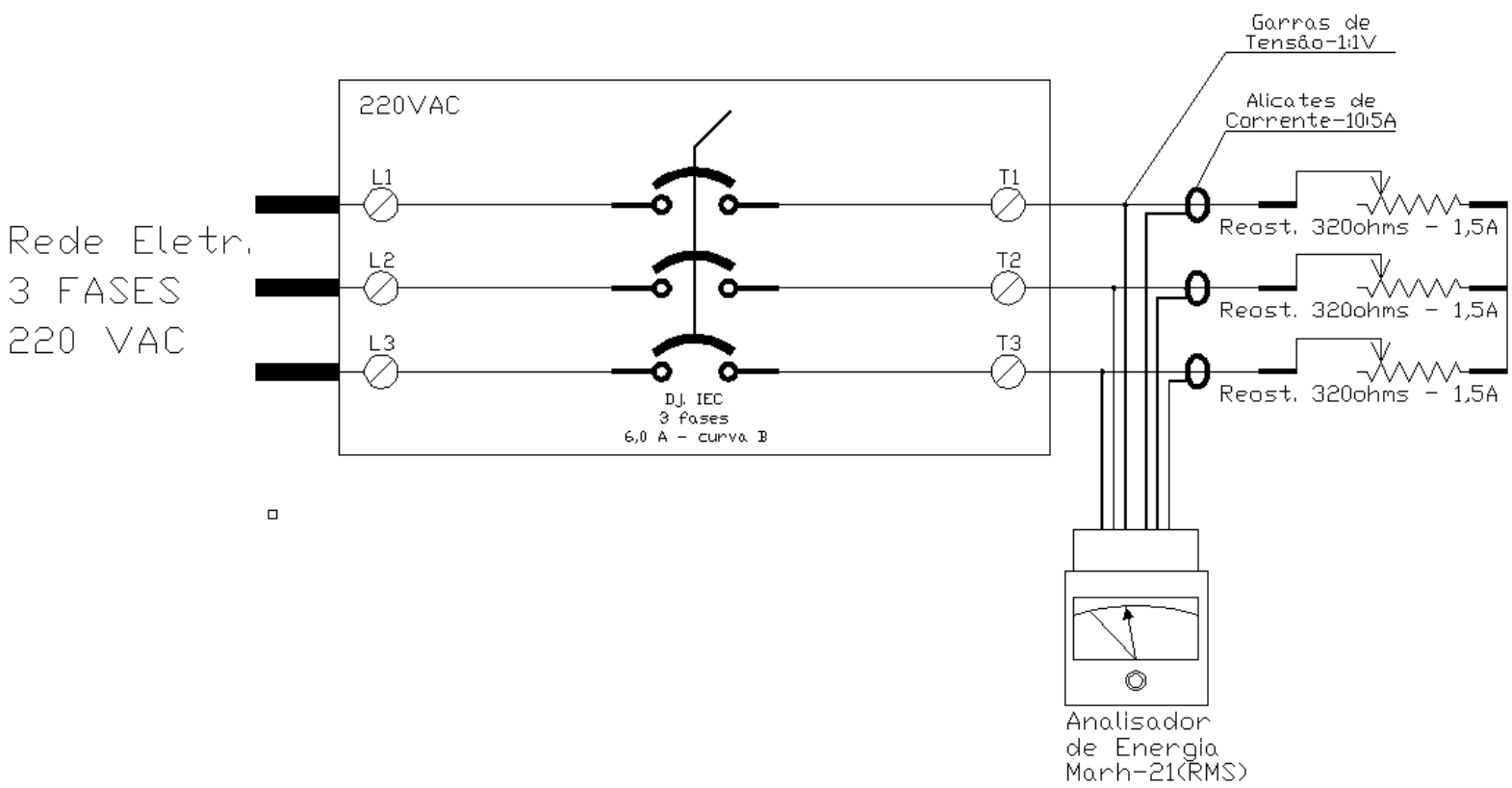

Figura 32 - Diagrama básico de ligação da rede elétrica alimentando carga resistiva (variação de carga com degrau de $\mathbf{1 0 \%}$.) sem paralelismo com os modelos de aerogeradores 
A Figura 33 mostra a curva de distorção harmônica total de tensão (THDU) da rede elétrica em função da variação de carga resistiva durante todo período de monitoramento, considerando desde a situação em vazio até a condição de plena carga, com acréscimo de carga em degraus de 10\%. Em destaque a distorção harmônica de tensão no período de medição.

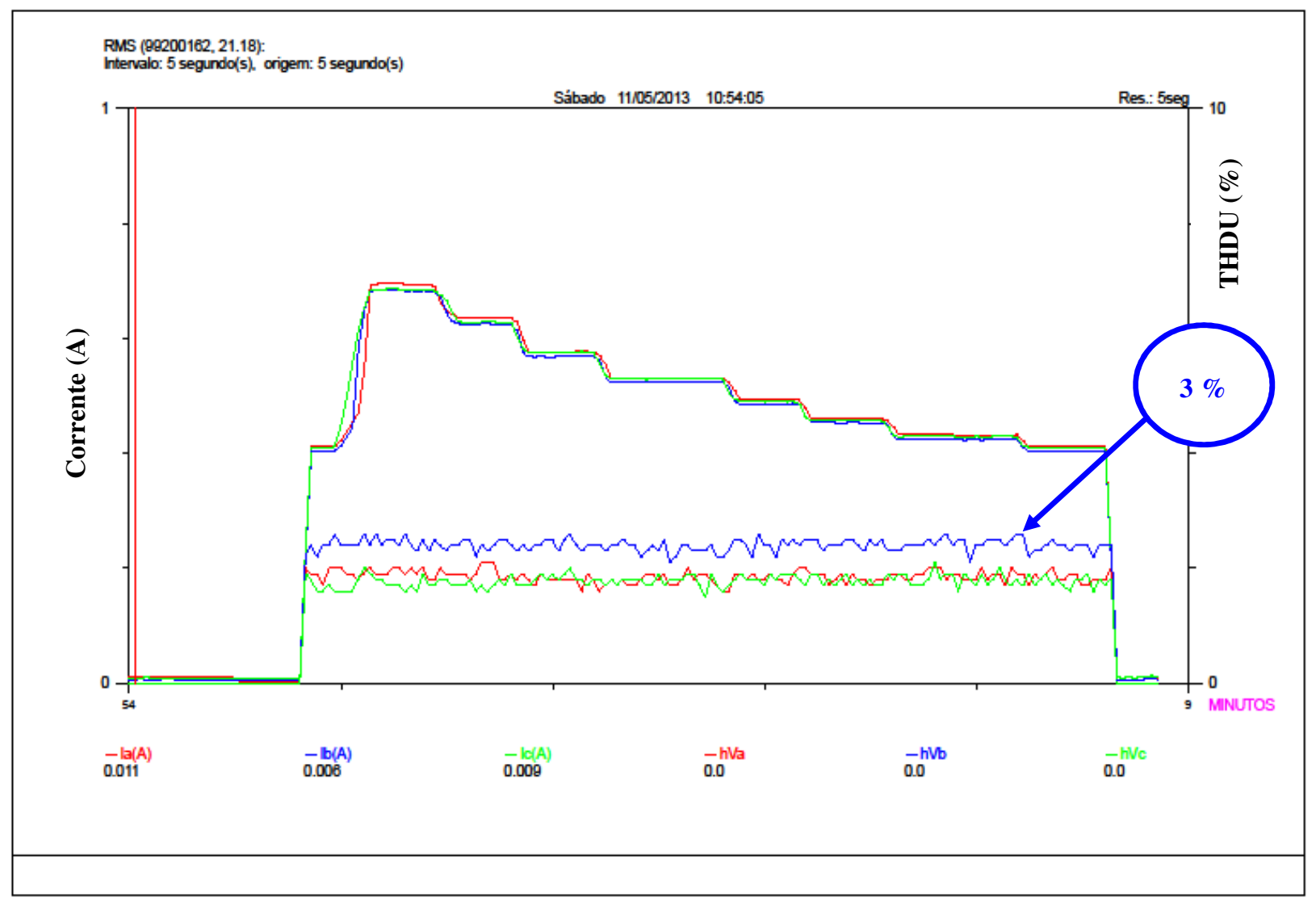

Figura 33 - Gráfico da distorção harmônica total de tensão (THDU) da rede elétrica alimentando carga resistiva (variação de carga com degraus de 10\%) 
A Figura 34 mostra a curva de distorção harmônica total de tensão da rede elétrica em função da variação de carga resistiva durante todo período de monitoramento e as formas de onda de tensão no caso mais crítico de distorção, considerando desde a situação em vazio até a condição de plena carga, com acréscimo de carga em degraus de $10 \%$.

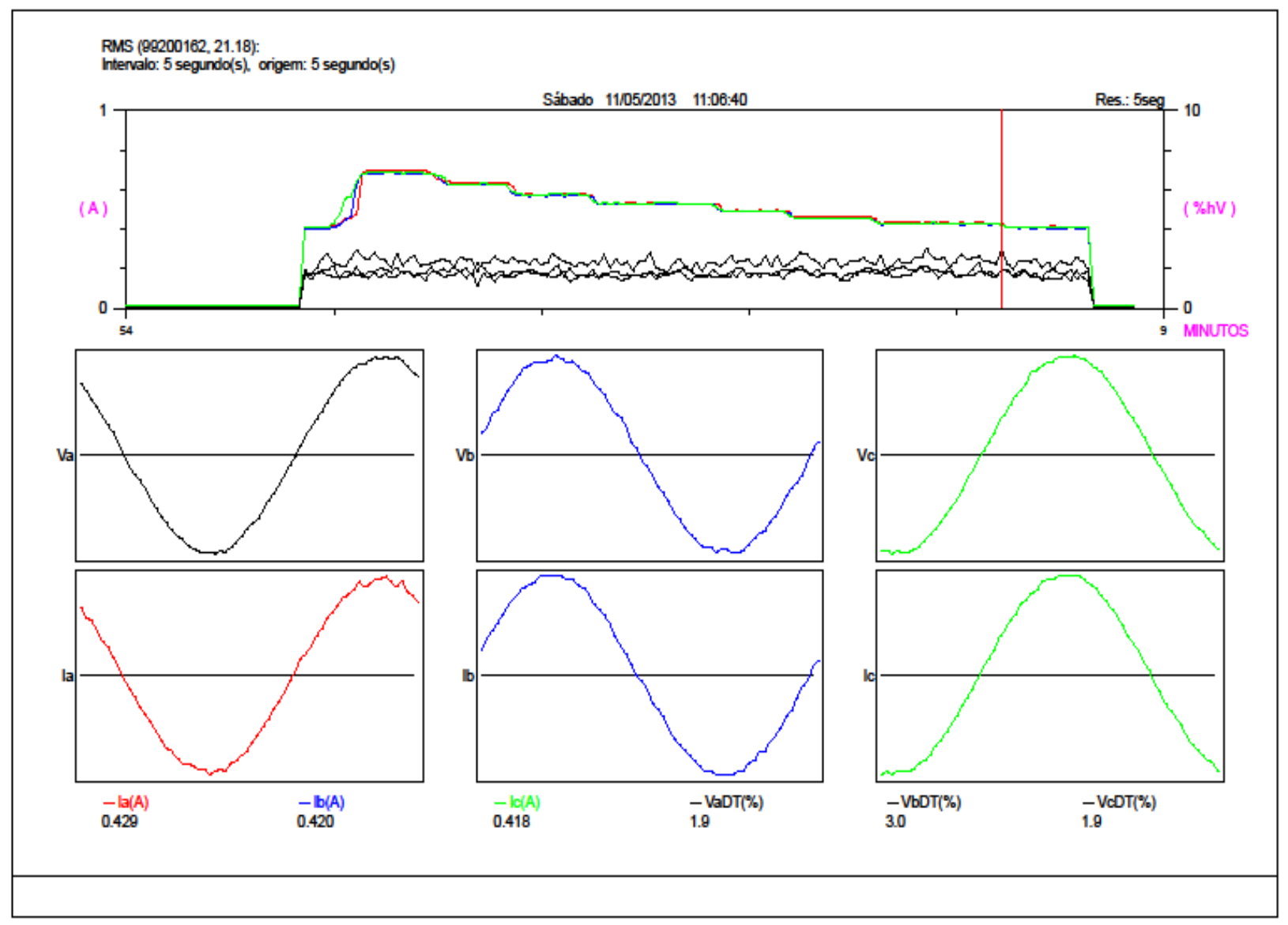

Figura 34 - Gráfico da distorção harmônica total de tensão (THDU) da rede elétrica com formas de onda de tensão e corrente, alimentando carga resistiva (variação de carga com degraus de $10 \%$ ) 
A Figura 35 mostra o espectro de frequência de tensão da rede elétrica no caso mais crítico de distorção, considerando desde a situação em vazio até a condição de plena carga, com acréscimo de carga em degraus de $10 \%$.

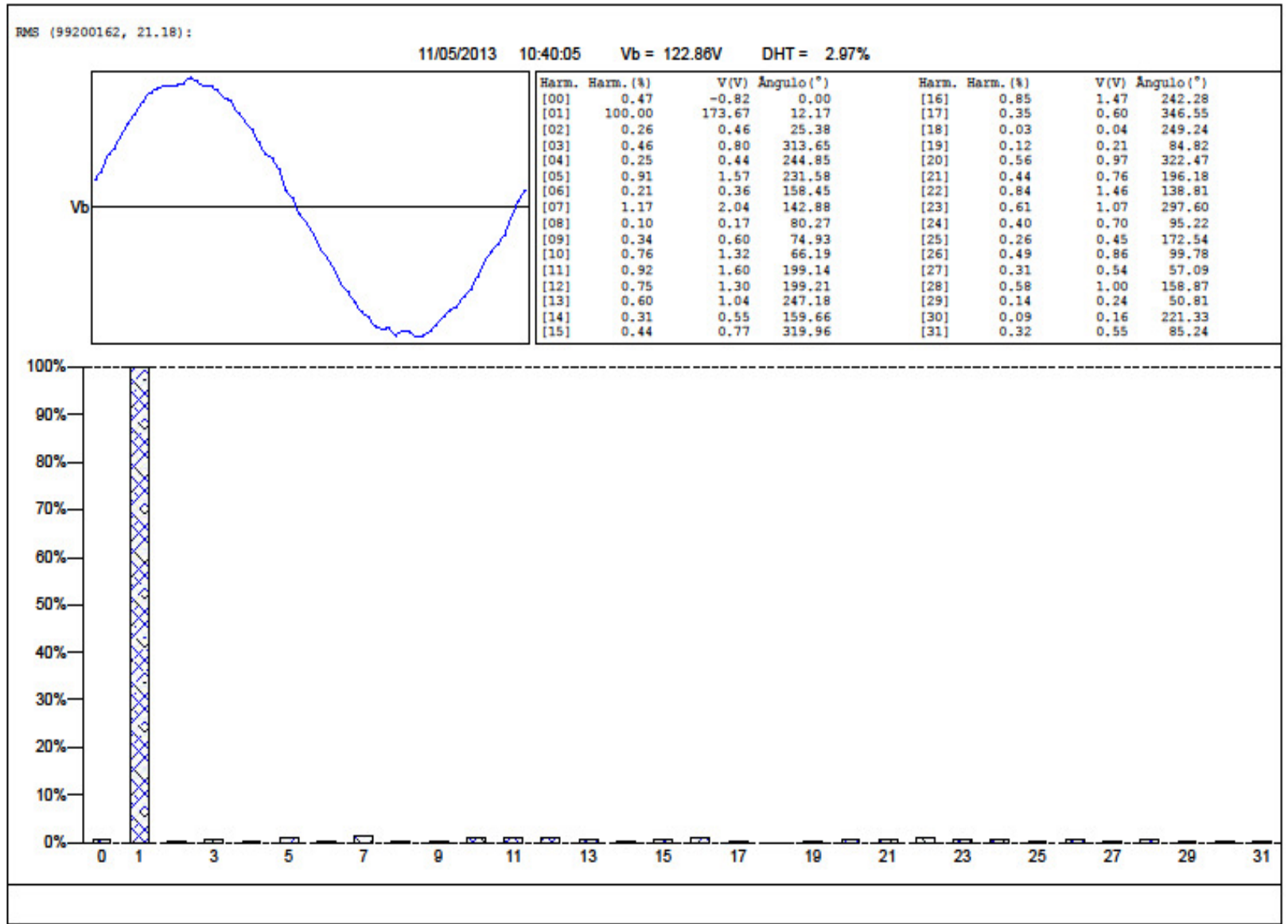

Figura 35 - Espectro de frequência da rede elétrica na pior situação de distorção harmônica total de tensão (THDU), alimentando carga resistiva 
A Figura 36 mostra a curva de distorção harmônica total de corrente (THDI) da rede elétrica em função da variação de carga resistiva durante todo período de monitoramento, considerando desde a situação em vazio até a condição de plena carga, com acréscimo de carga em degraus de 10\%. Em destaque a distorção harmônica de corrente no período de medição.

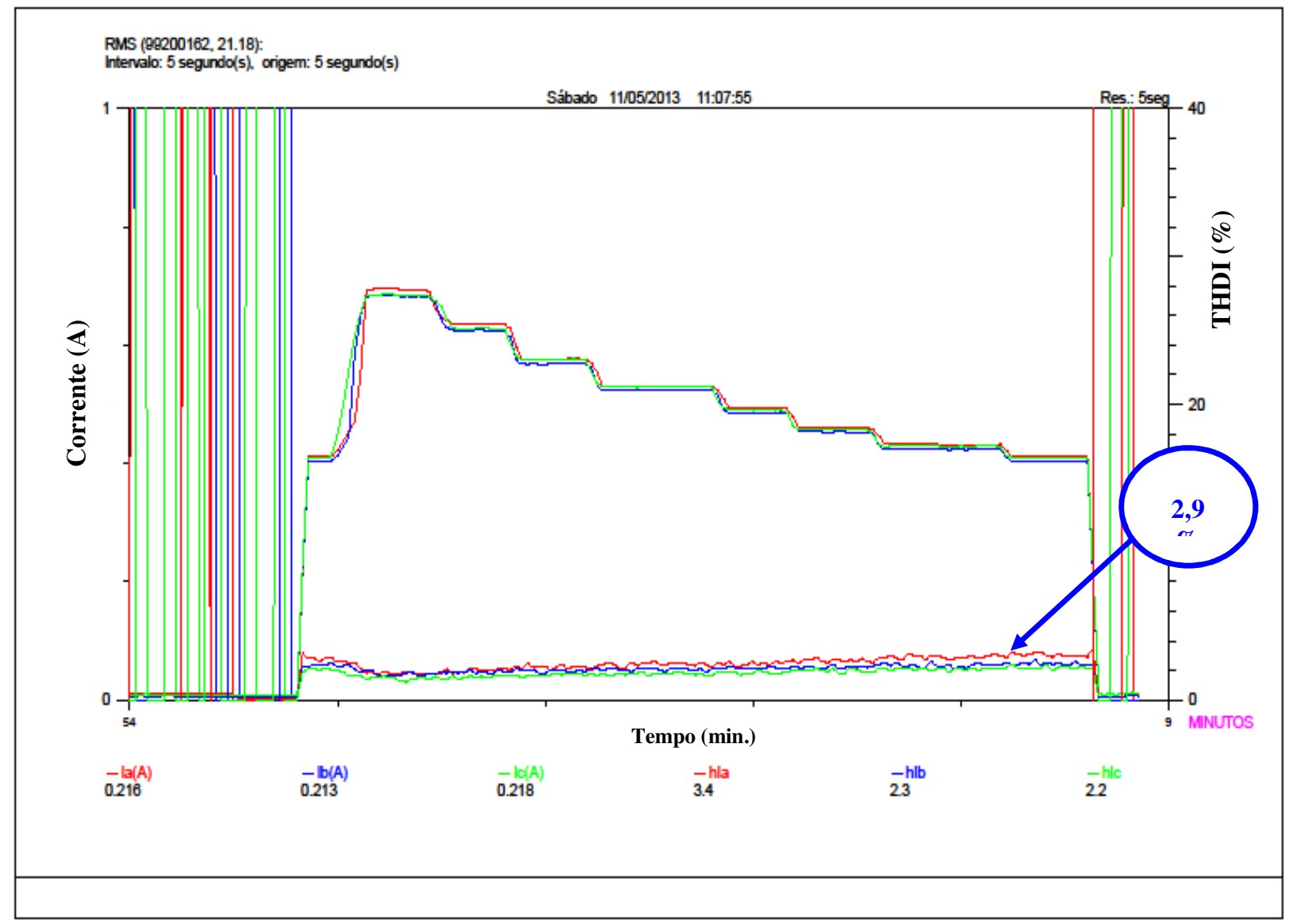

Figura 36 - Gráfico da distorção harmônica total de corrente (THDI) da rede elétrica, alimentando carga resistiva (variação de carga com degraus de $10 \%$ ) 
A Figura 37 mostra a curva de distorção harmônica total de corrente da rede elétrica em função da variação de carga resistiva durante todo período de monitoramento e as formas de onda de tensão no caso mais crítico de distorção, considerando desde a situação em vazio até a condição de plena carga, com acréscimo de carga em degraus de $10 \%$.

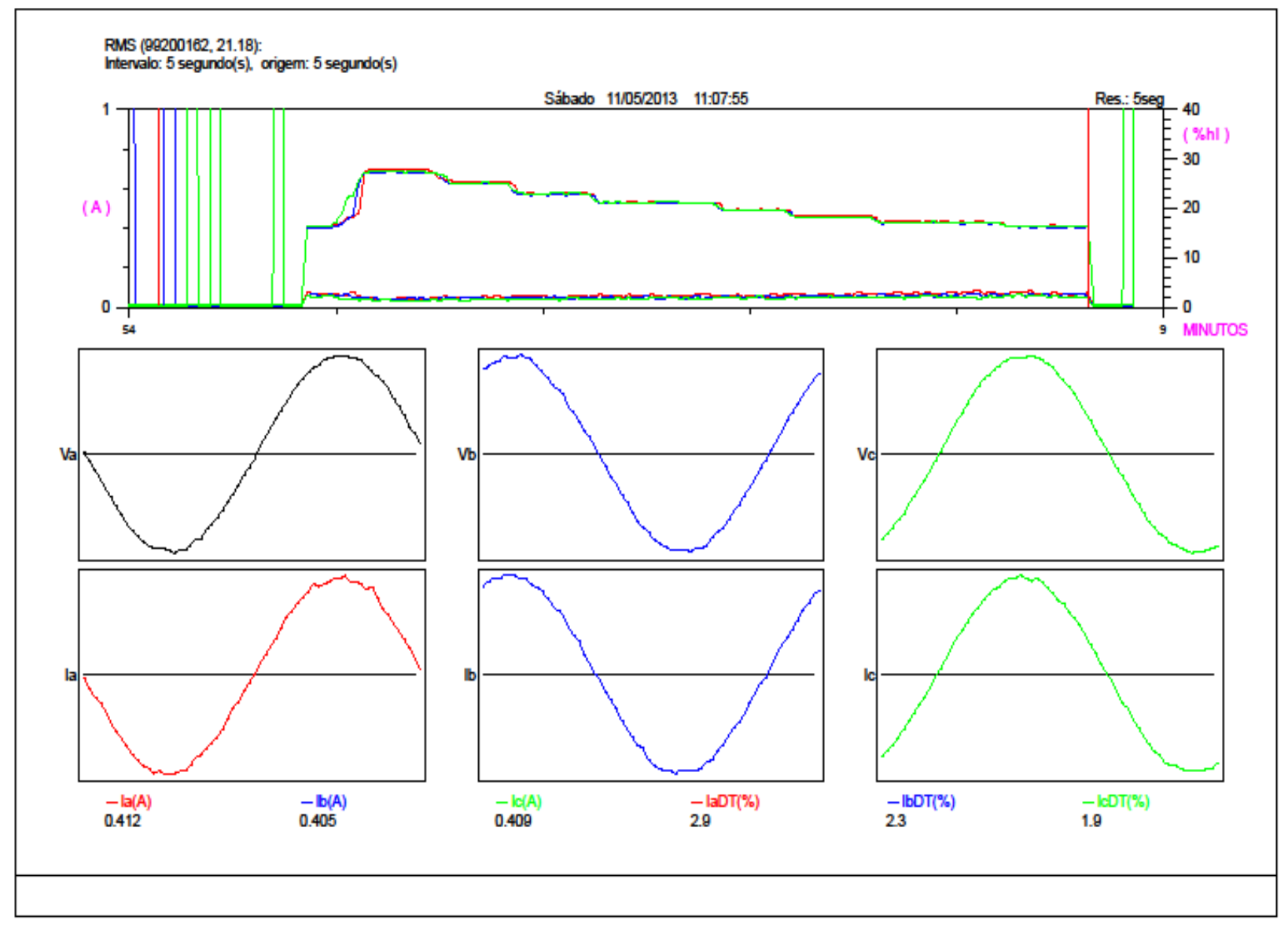

Figura 37 - Gráfico da distorção harmônica total de corrente (THDI) da rede elétrica com formas de onda de tensão e corrente, alimentando carga resistiva (variação de carga com degraus de $10 \%$.) 
A Figura 38 mostra o espectro de frequência de corrente da rede elétrica no caso mais crítico de distorção, considerando desde a situação em vazio até a condição de plena carga, com acréscimo de carga em degraus de $10 \%$.

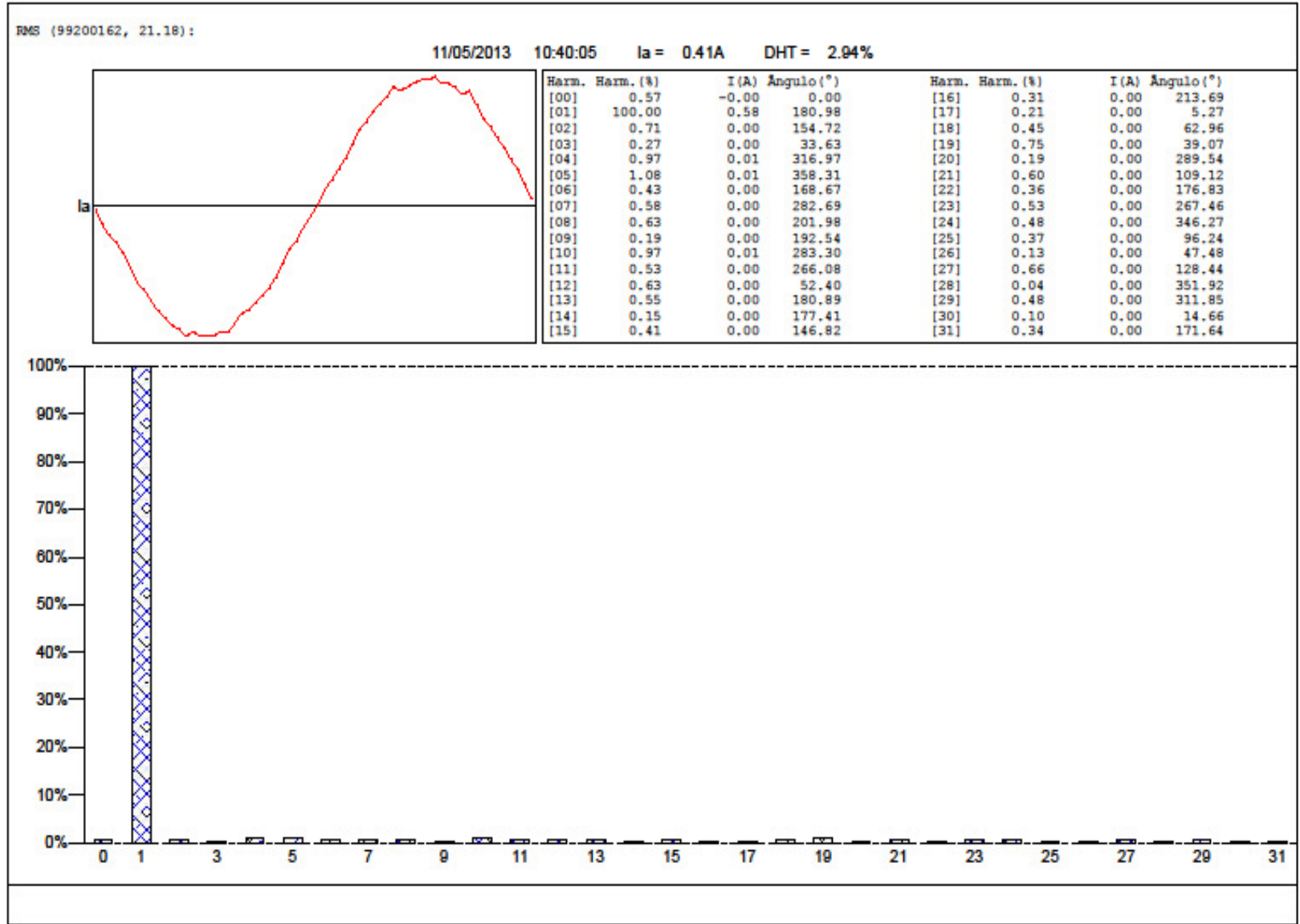

Figura 38 - Espectro de frequência da rede elétrica na pior situação de distorção harmônica total de corrente (THDI), alimentando carga resistiva 


\subsubsection{Medição do Gerador Síncrono com Rotor Bobinado (GSRB)}

Neste item são apresentados os resultados de medição das distorções harmônicas referentes ao modelo do aerogerador com Gerador Síncrono com Rotor Bobinado (GSRB) ligado diretamente à carga (banco de reostatos ligados em estrela) e em paralelismo com a rede da concessionária, a fim de mensurar a sua contribuição em termos de distorções harmônicas.

A Figura 39 mostra o esquema de ligação do modelo real utilizado em parques eólicos e a Figura 40 apresenta o diagrama básico de ligação do modelo montado em laboratório.

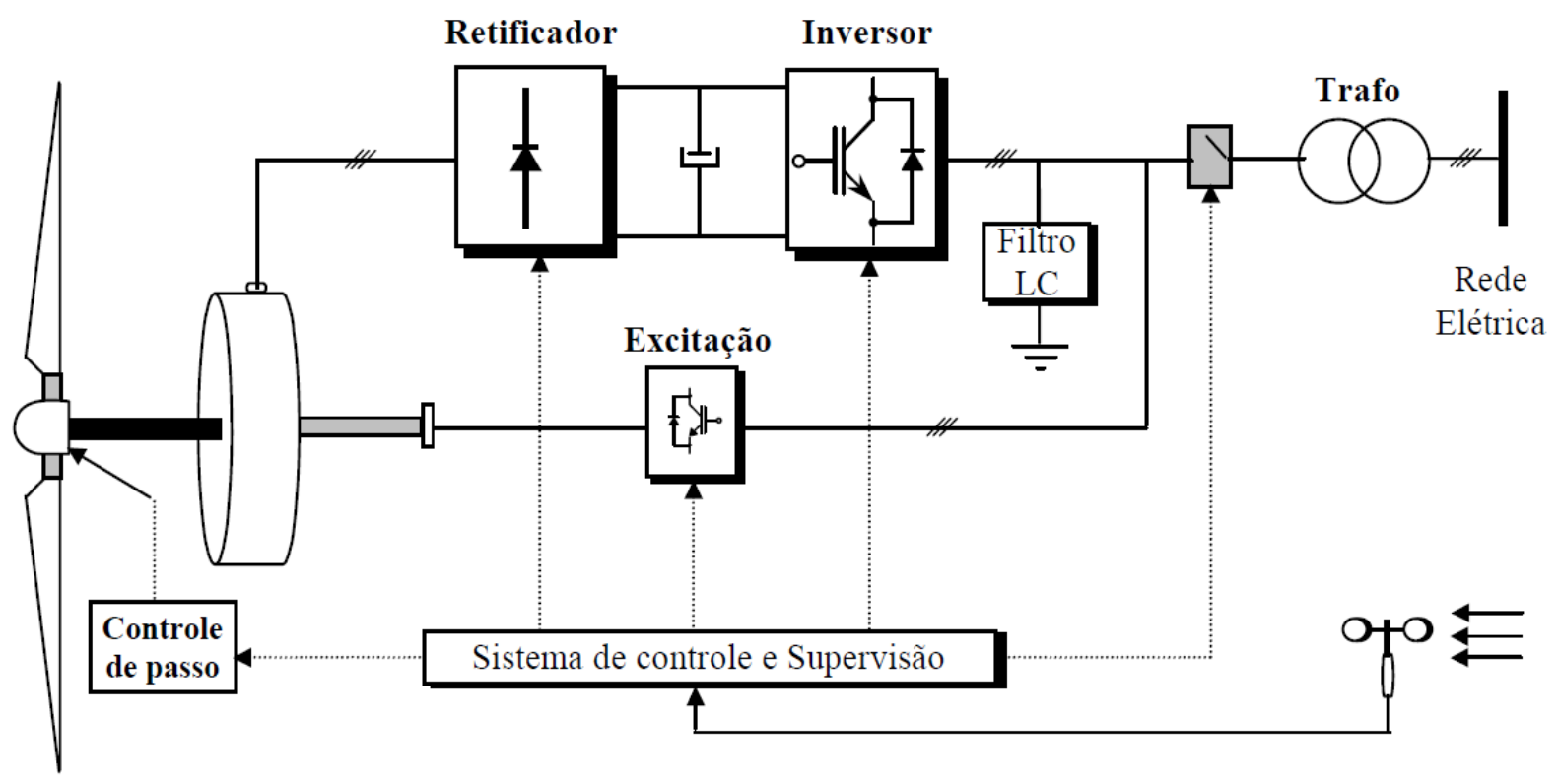

Figura 39 - Gerador Síncrono com Rotor Bobinado (GSRB)

Fonte: Turbinas Eólicas: Modelo, Análise e Controle do Gerador de Indução com Dupla Alimentação 


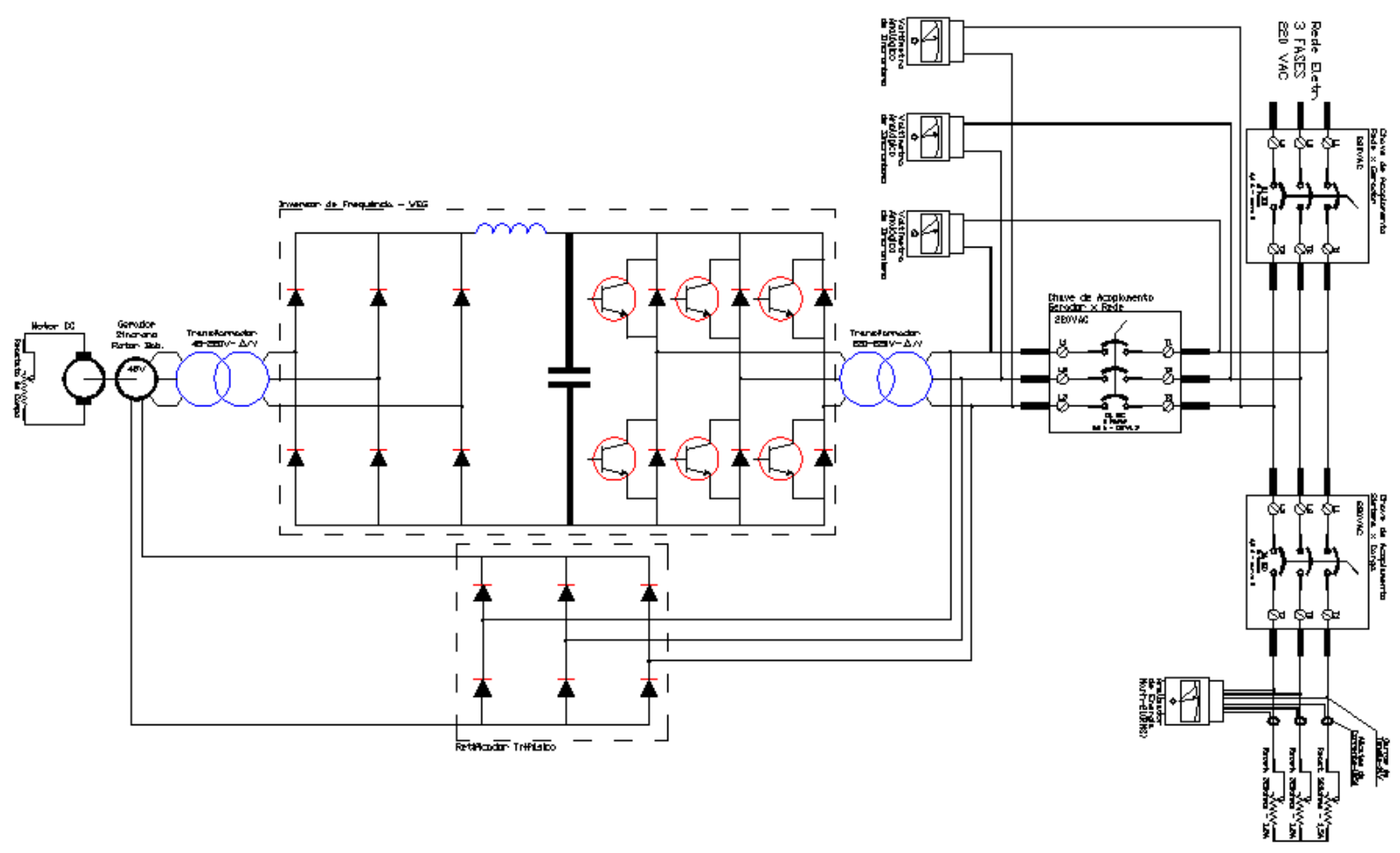

Figura 40 - Diagrama Básico de Ligação do Gerador Síncrono com Rotor Bobinado (GSRB) em paralelismo com a rede elétrica alimentando carga resistiva (variação de carga com degraus de 10\%) montagem em laboratório 
A Figura 41 mostra a curva de distorção harmônica total de tensão no ponto de acoplamento comum (PAC) para este modelo de aerogerador em função da variação de carga resistiva durante todo período de monitoramento, considerando desde a situação em vazio até a condição de plena carga, com acréscimo de carga em degraus de 10\%. Em destaque a distorção harmônica de tensão no período de medição.

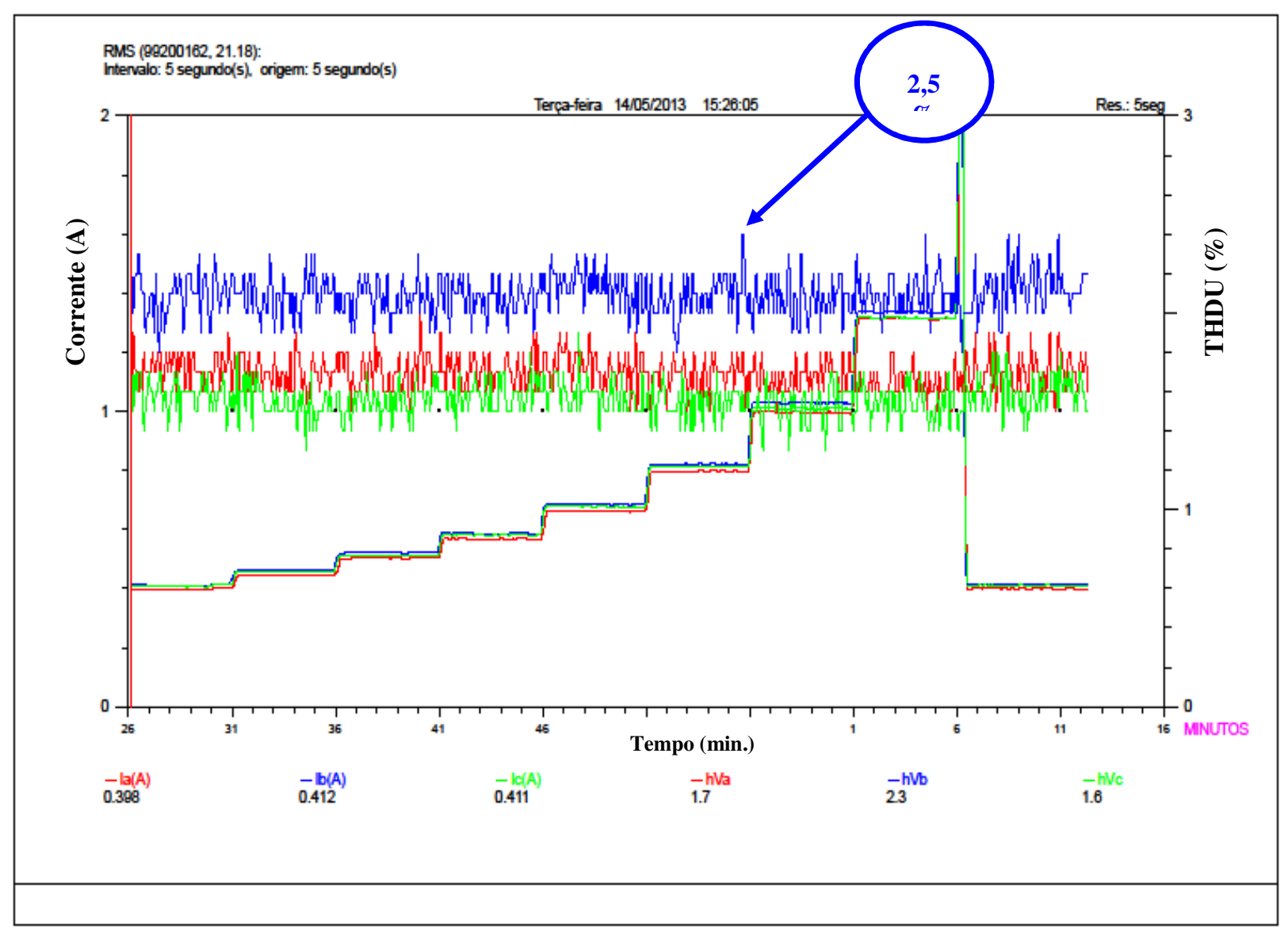

Figura 41 - Gráfico THDU com GSRB, alimentando carga resistiva em paralelo com a rede elétrica (variação de carga com degrau de $10 \%$.) 
A Figura 42 mostra a curva de distorção harmônica total de tensão no ponto de acoplamento comum (PAC) para este modelo de aerogerador em função da variação de carga resistiva durante todo período de monitoramento e as formas de onda de tensão no caso mais crítico de distorção, considerando desde a situação em vazio até a condição de plena carga, com acréscimo de carga em degraus de $10 \%$.

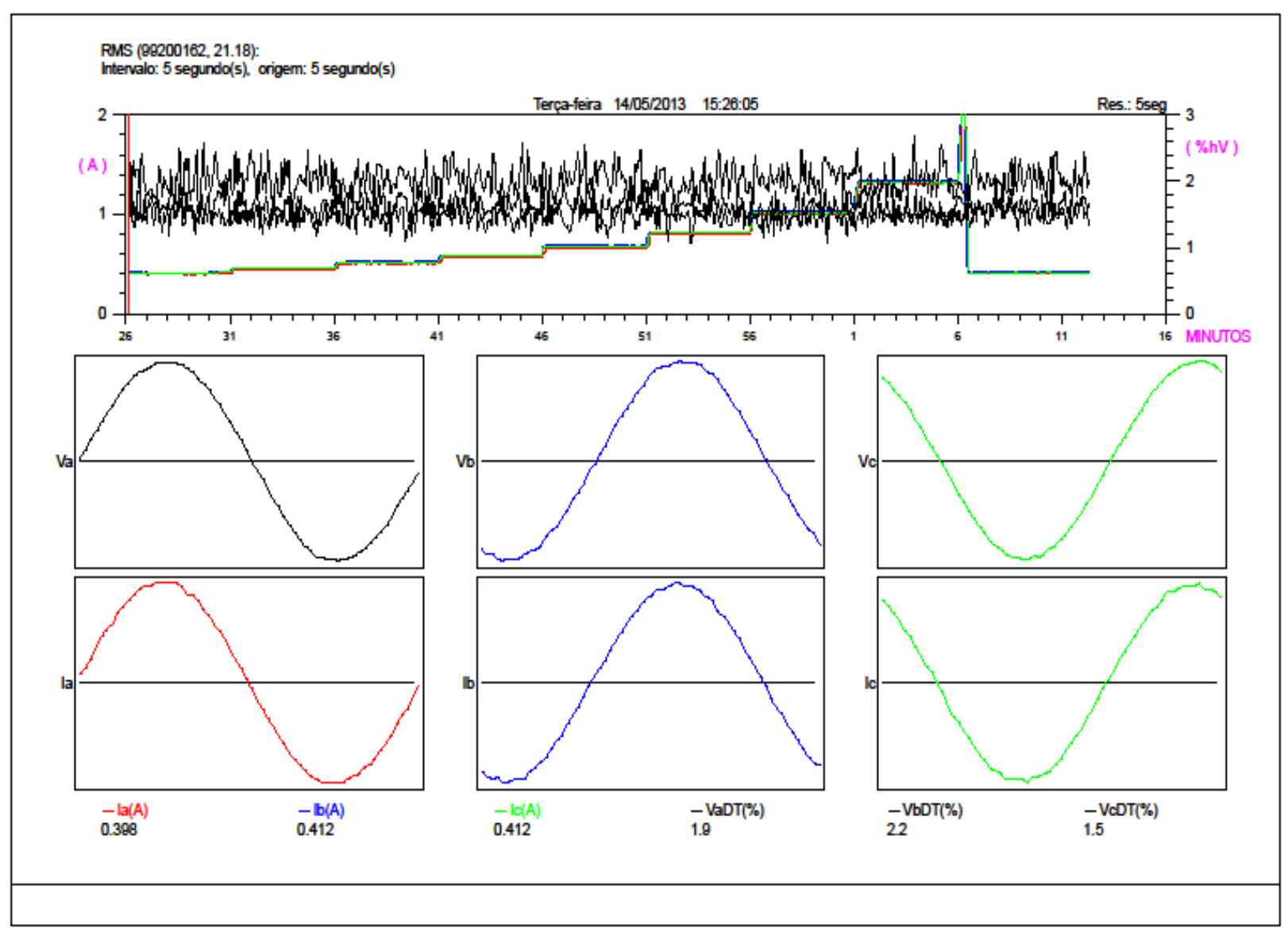

Figura 42 - Gráfico THDU da rede elétrica com formas de onda de tensão e corrente com GSRB, alimentando carga resistiva em paralelo com a rede elétrica (variação de carga com degrau de $10 \%$.) 
A Figura 43 mostra o espectro de frequência de tensão no ponto de acoplamento comum (PAC) para este modelo de aerogerador no caso mais crítico de distorção, considerando desde a situação em vazio até a condição de plena carga, com acréscimo de carga em degraus de 10\%.

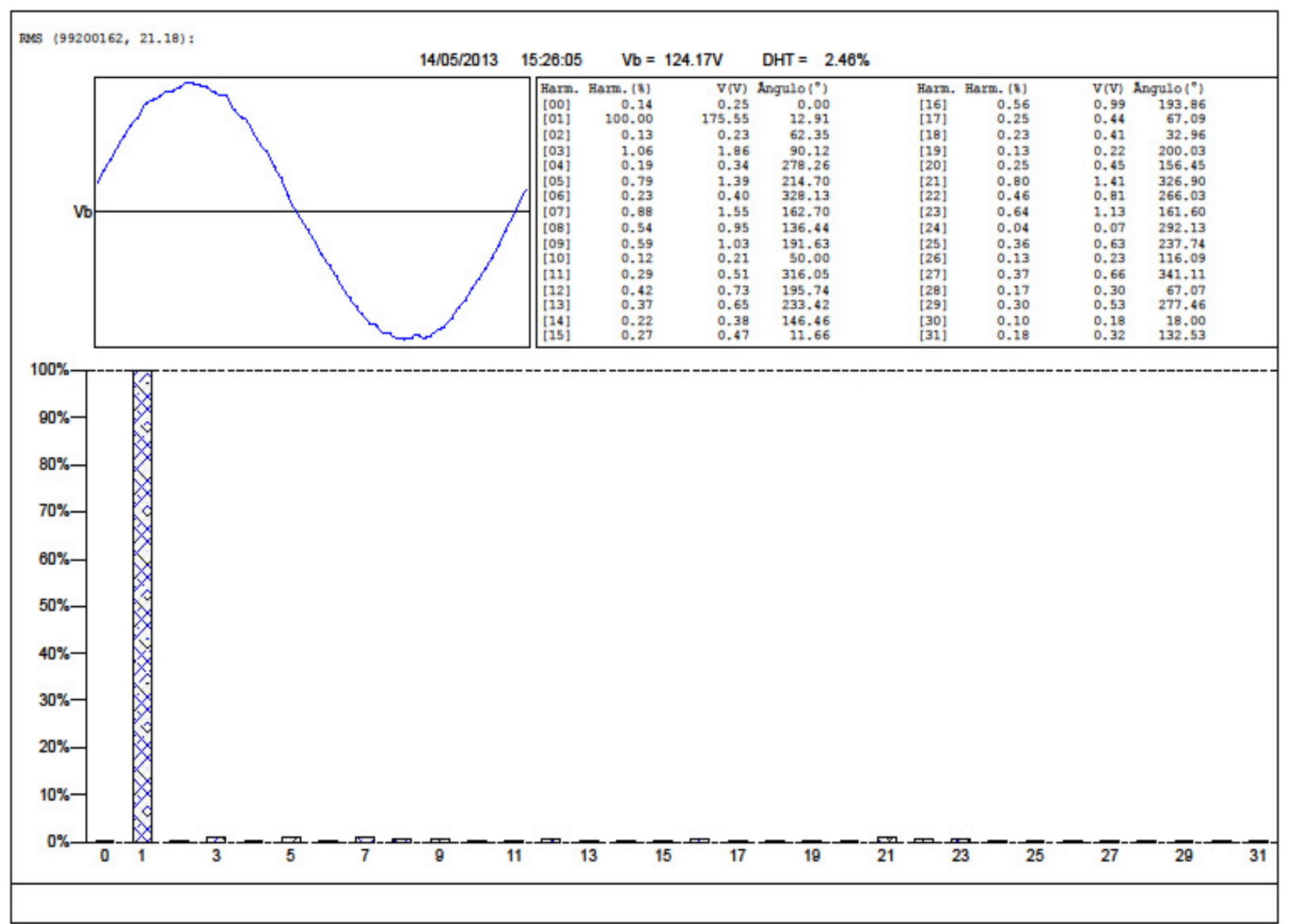

Figura 43 - Espectro de frequência da rede na pior situação do THDU, com GSRB, alimentando carga resistiva 
A Figura 44 mostra a curva de distorção harmônica total de corrente no ponto de acoplamento comum (PAC) para este modelo de aerogerador em função da variação de carga resistiva durante todo período de monitoramento, considerando desde a situação em vazio até a condição de plena carga, com acréscimo de carga em degraus de 10\%. Em destaque a distorção harmônica de corrente no período de medição.

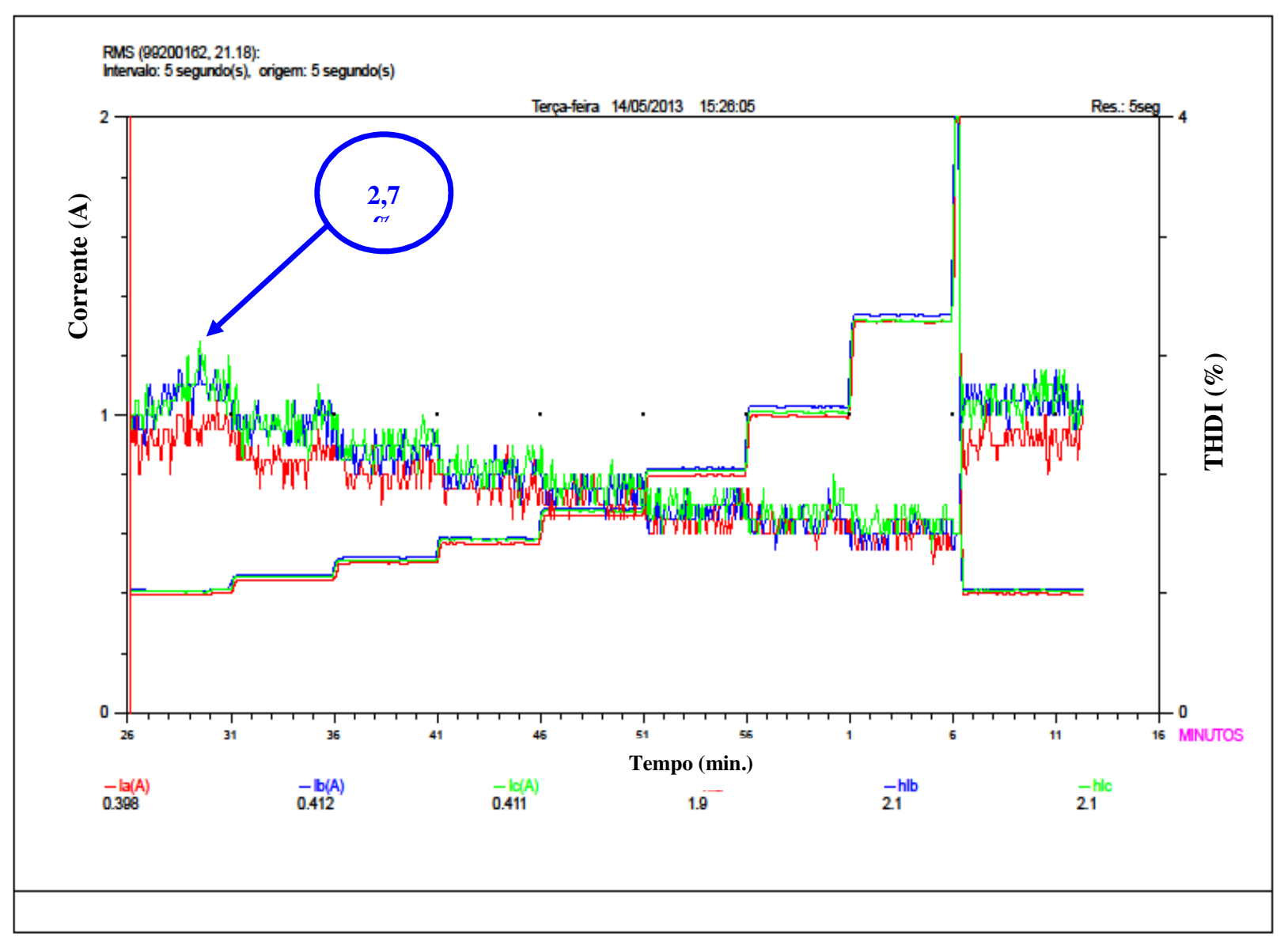

Figura 44 - Gráfico THDI com GSRB, alimentando carga resistiva em paralelo com a rede elétrica (variação de carga com degrau de $10 \%$.) 
A Figura 45 mostra a curva de distorção harmônica total de corrente no ponto de acoplamento comum (PAC) para este modelo de aerogerador em função da variação de carga resistiva durante todo período de monitoramento, considerando desde a situação em vazio até a condição de plena carga, com acréscimo de carga em degraus de $10 \%$.

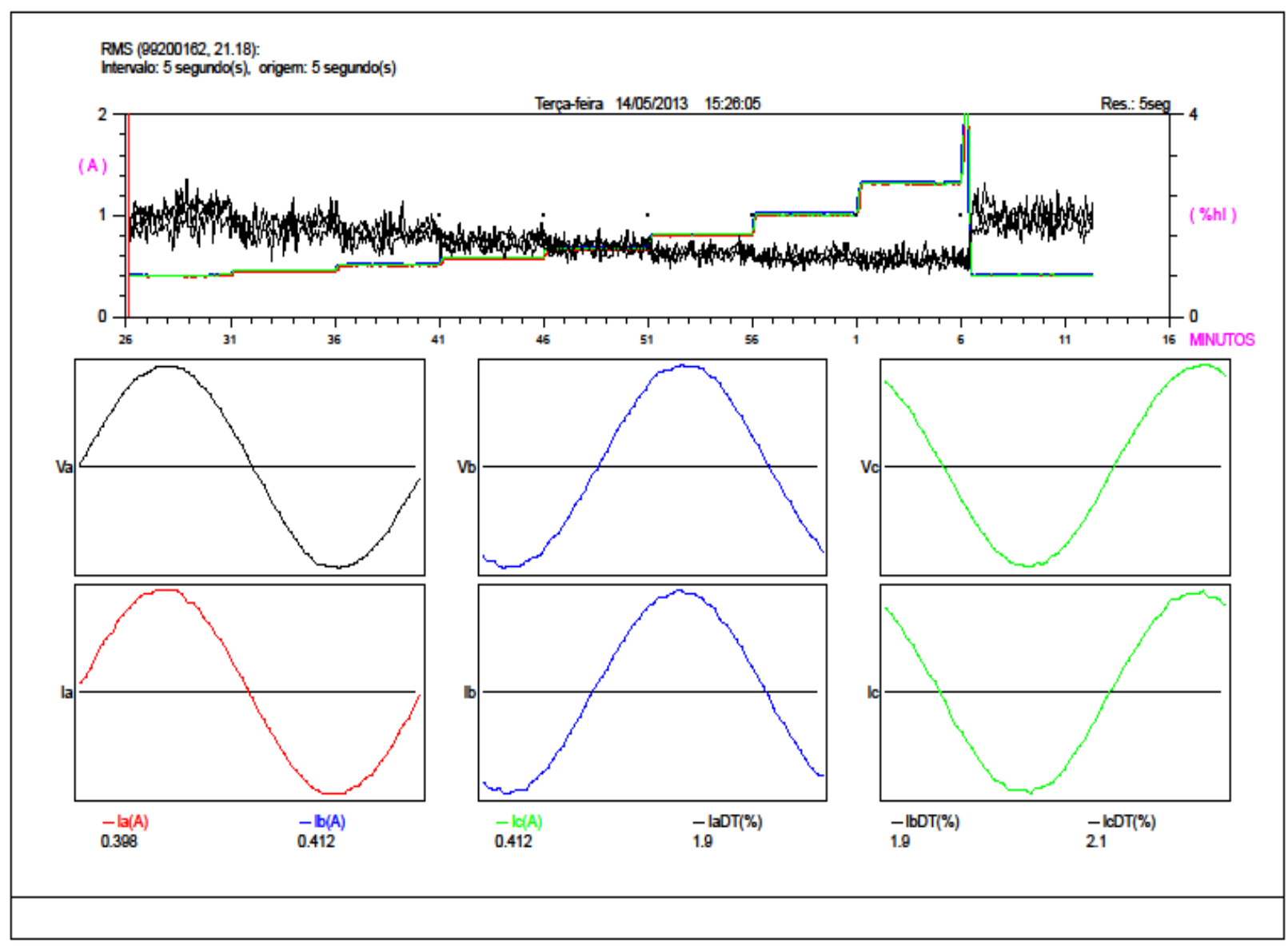

Figura 45 - Gráfico THDI da rede elétrica com formas de onda de tensão e corrente com GSRB, alimentando carga resistiva em paralelo com a rede elétrica (variação de carga com degrau de $10 \%$.) 
A Figura 46 mostra o espectro de frequência de corrente no ponto de acoplamento comum (PAC) para este modelo de aerogerador no caso mais crítico de distorção, considerando desde a situação em vazio até a condição de plena carga, com acréscimo de carga em degraus de $10 \%$.

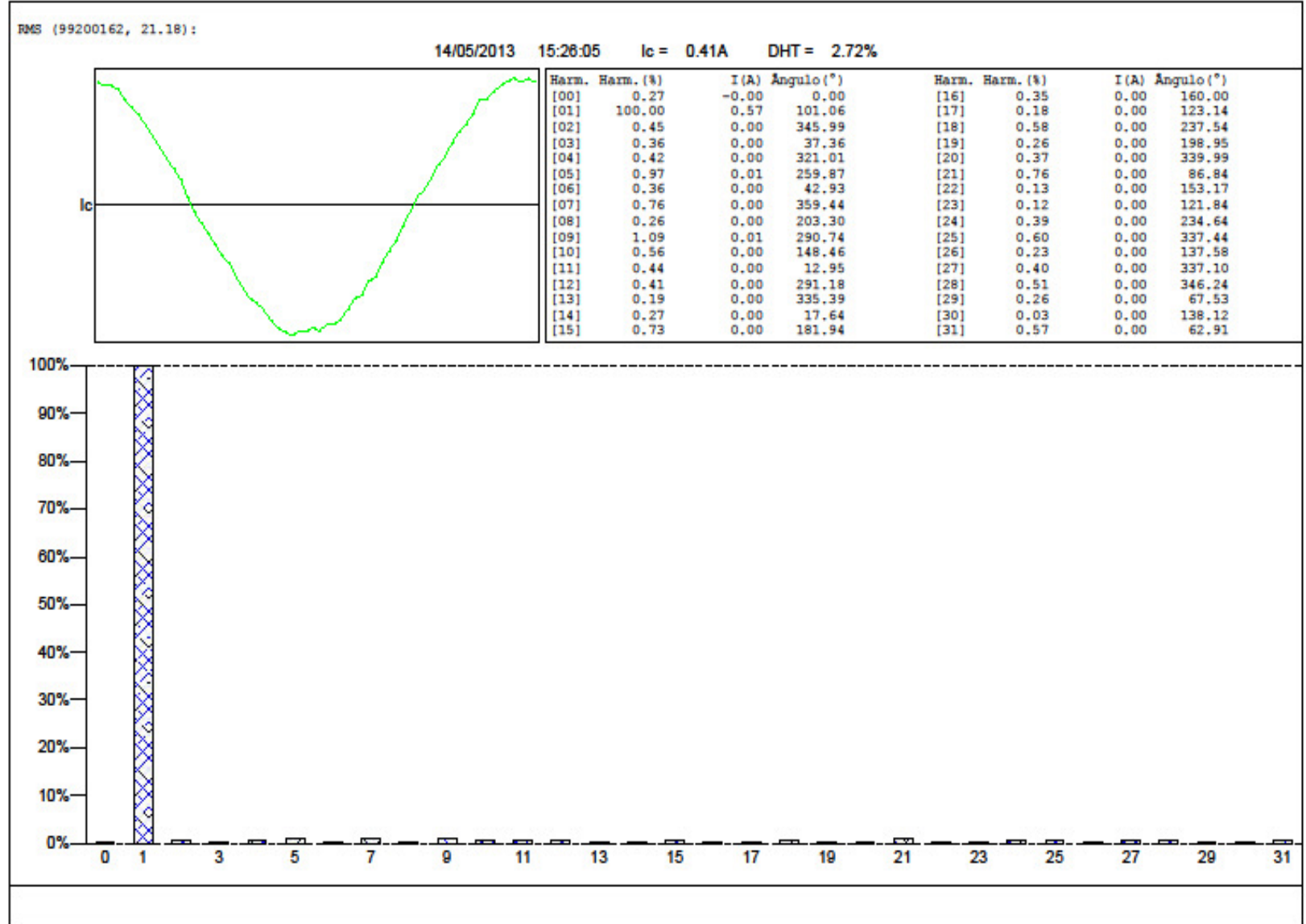

Figura 46 - Espectro de frequência da rede na pior situação do THDI, com GSRB, alimentando carga resistiva 


\subsubsection{Medição do Gerador de Indução com Gaiola de Esquilo (GIGE)}

Neste item são apresentados os resultados de medição das distorções harmônicas referentes ao modelo do aerogerador com Gerador de Indução com Gaiola de Esquilo (GIGE), ligado diretamente à carga (banco de reostatos ligados em estrela) e em paralelismo com a rede da concessionária a fim de mensurar a sua contribuição em termos de distorções harmônicas. A Figura 47 mostra o esquema de ligação do modelo real utilizado em parques eólicos e a Figura 48 apresenta o diagrama básico de ligação do modelo montado em laboratório.

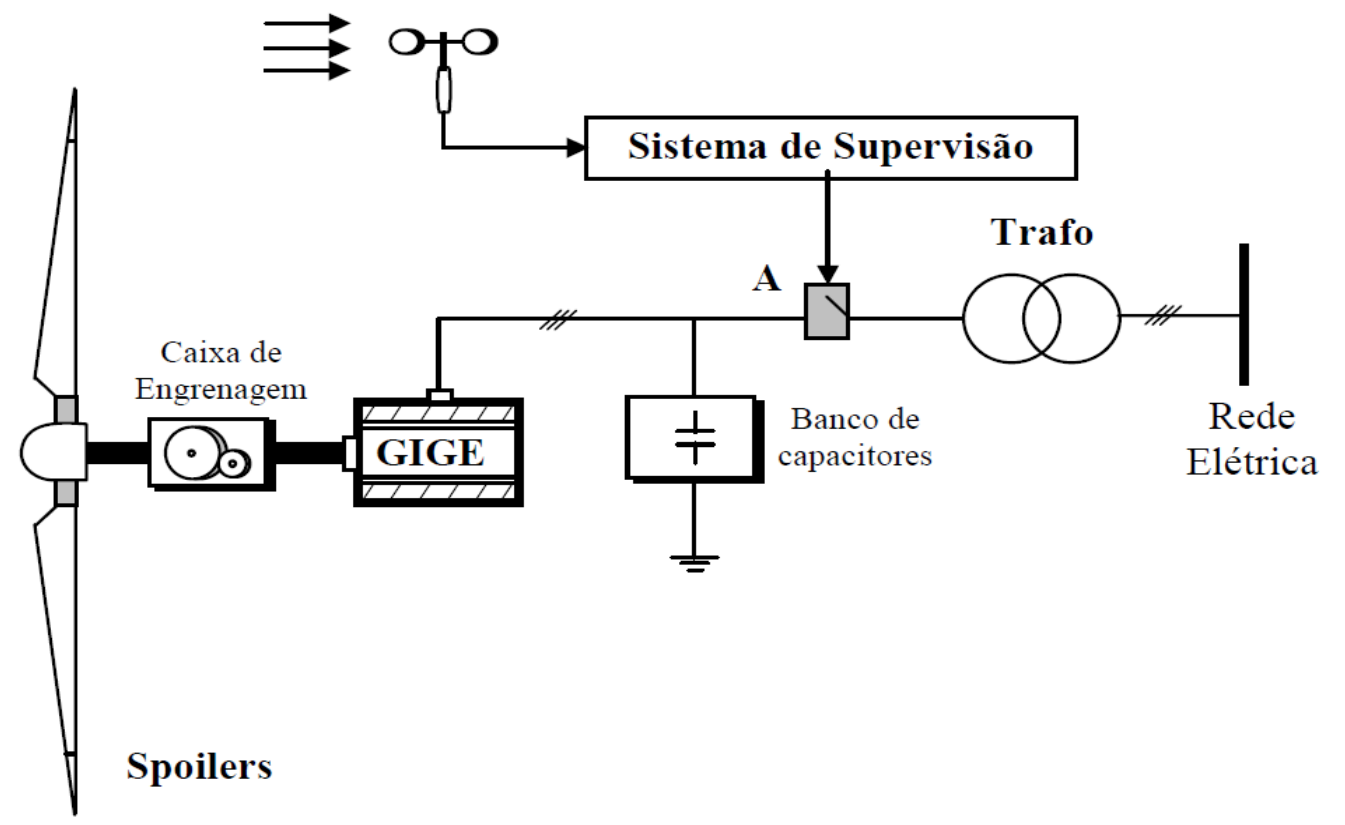

Figura 47 - Gerador de Indução em Gaiola de Esquilo (GIGE). Fonte: Turbinas Eólicas: Modelo, Análise e Controle do Gerador de Indução com Dupla Alimentação. 


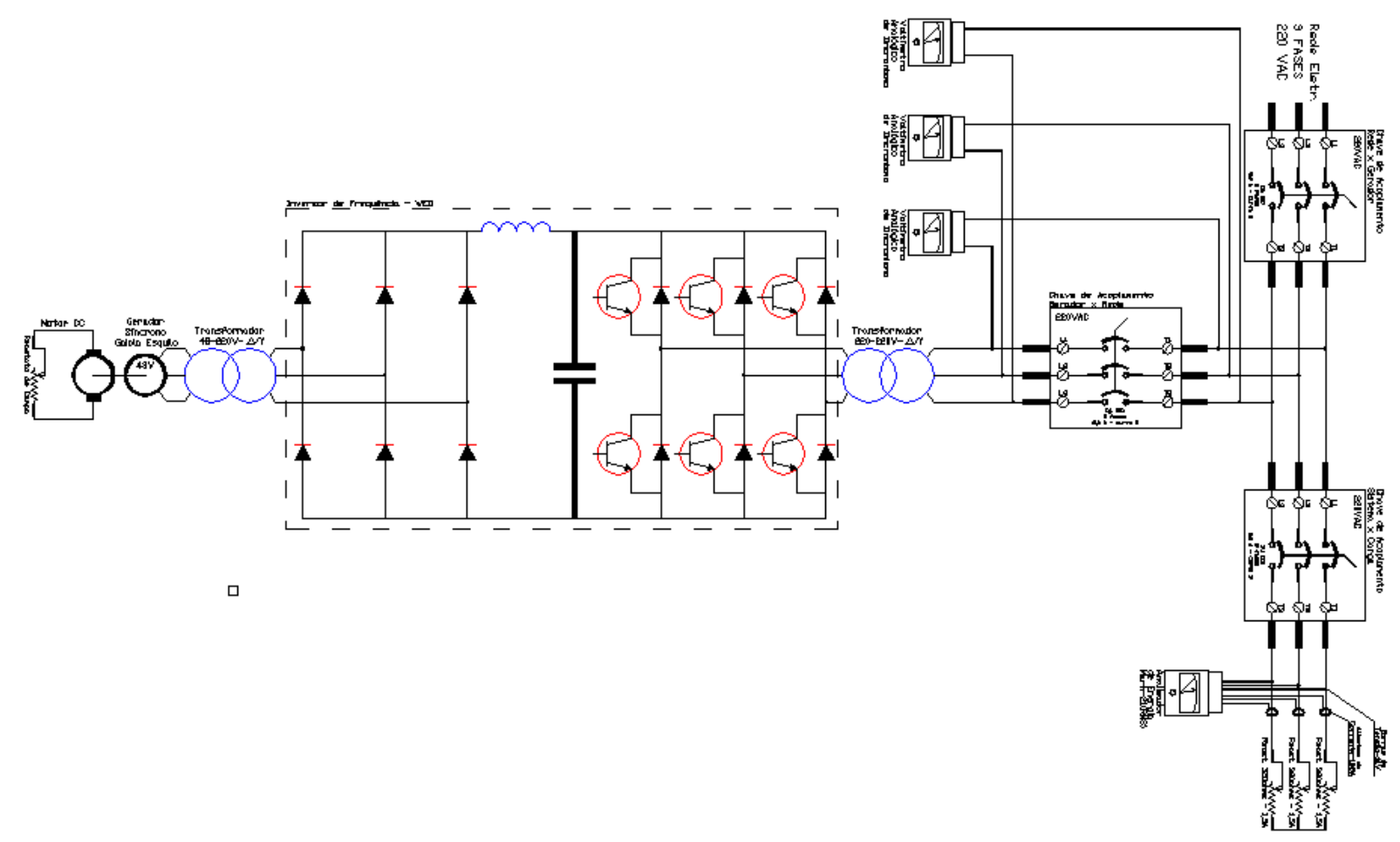

Figura 48 - Diagrama Básico de Ligação do Gerador de Indução com Gaiola de Esquilo (GIGE) em paralelismo com a rede elétrica alimentando carga resistiva

(variação de carga em degraus de 10\%) - montagem em laboratório 
A Figura 49 mostra a curva de distorção harmônica total de tensão no ponto de acoplamento comum (PAC) para este modelo de aerogerador em função da variação de carga resistiva durante todo período de monitoramento, considerando desde a situação em vazio até a condição de plena carga, com acréscimo de carga em degraus de 10\%. Em destaque a distorção harmônica de tensão no período de medição.

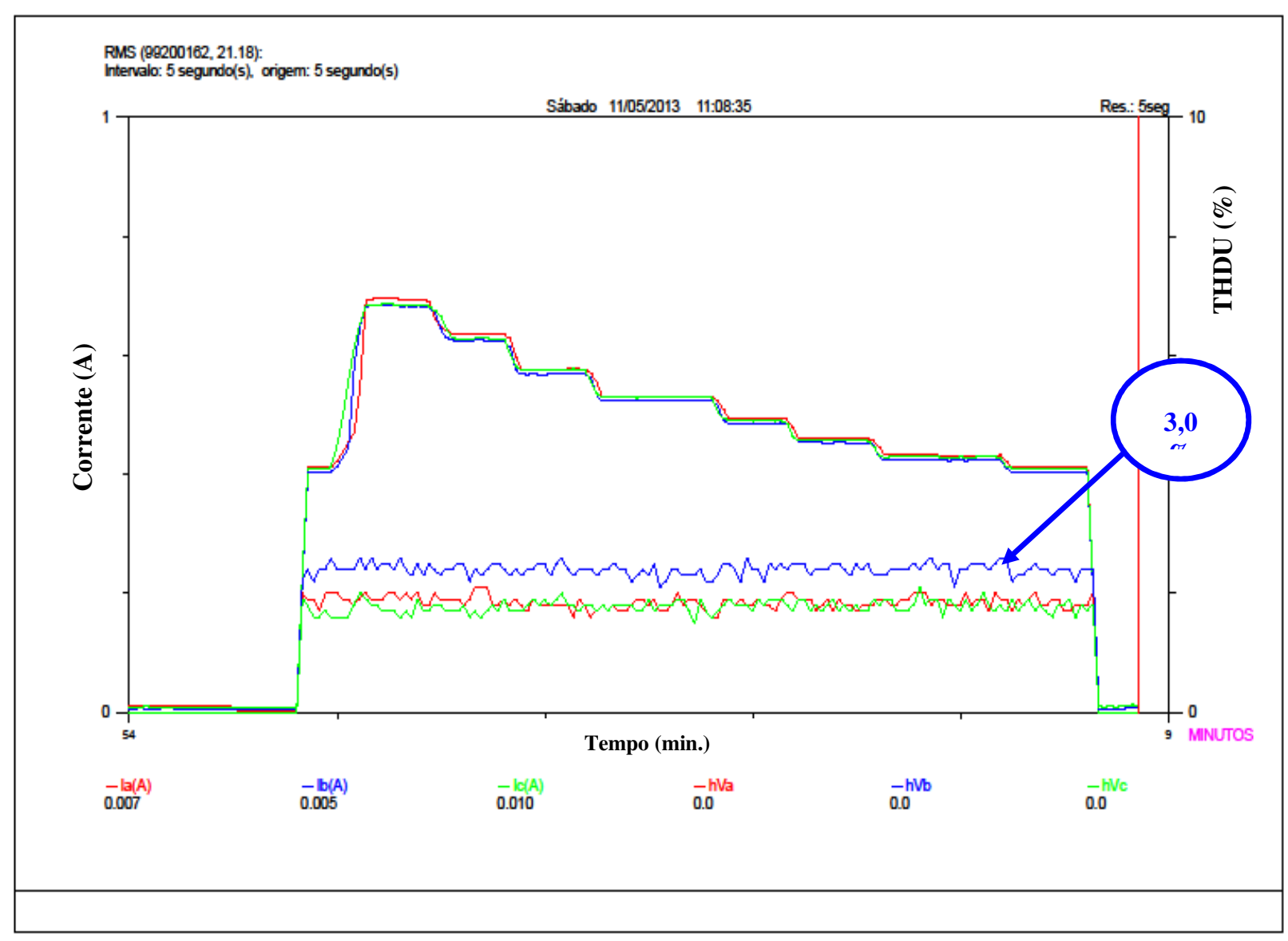

Figura 49 - Gráfico THDU com GIGE, alimentando carga resistiva em paralelo com a rede elétrica (variação de carga com degrau de $10 \%$.) 
A Figura 50 mostra a curva de distorção harmônica total de tensão no ponto de acoplamento comum (PAC) para este modelo de aerogerador em função da variação de carga resistiva durante todo período de monitoramento e as formas de onda de tensão no caso mais crítico de distorção, considerando desde a situação em vazio até a condição de plena carga, com acréscimo de carga em degraus de $10 \%$.

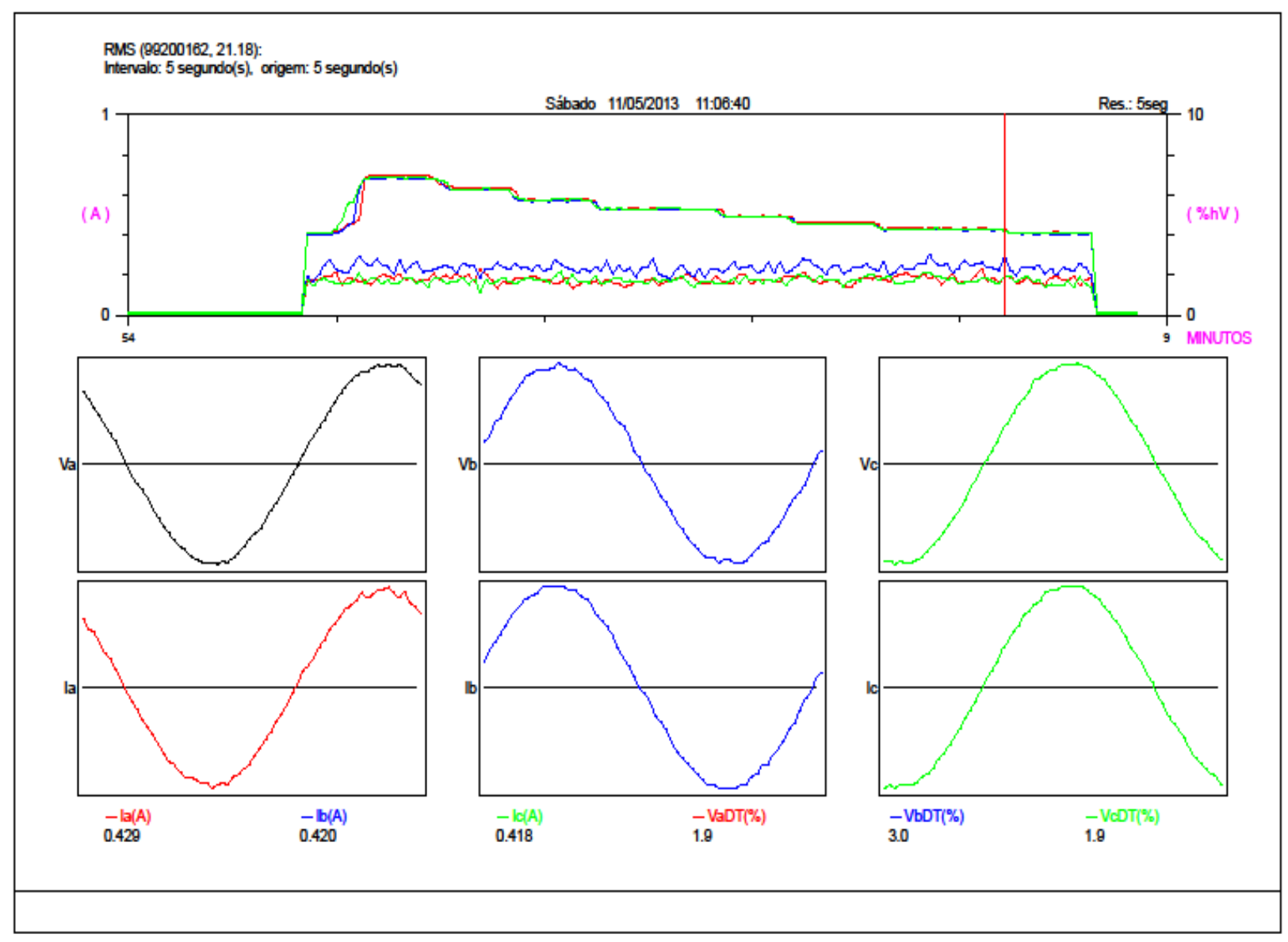

Figura 50 - Gráfico THDU da rede elétrica com formas de onda de tensão e corrente com GIGE, alimentando carga resistiva em paralelo com a rede elétrica (variação de carga com degrau de $10 \%$.) 
A Figura 51 mostra o espectro de frequência de tensão no ponto de acoplamento comum (PAC) para este modelo de aerogerador no caso mais crítico de distorção, considerando desde a situação em vazio até a condição de plena carga, com acréscimo de carga em degraus de 10\%.

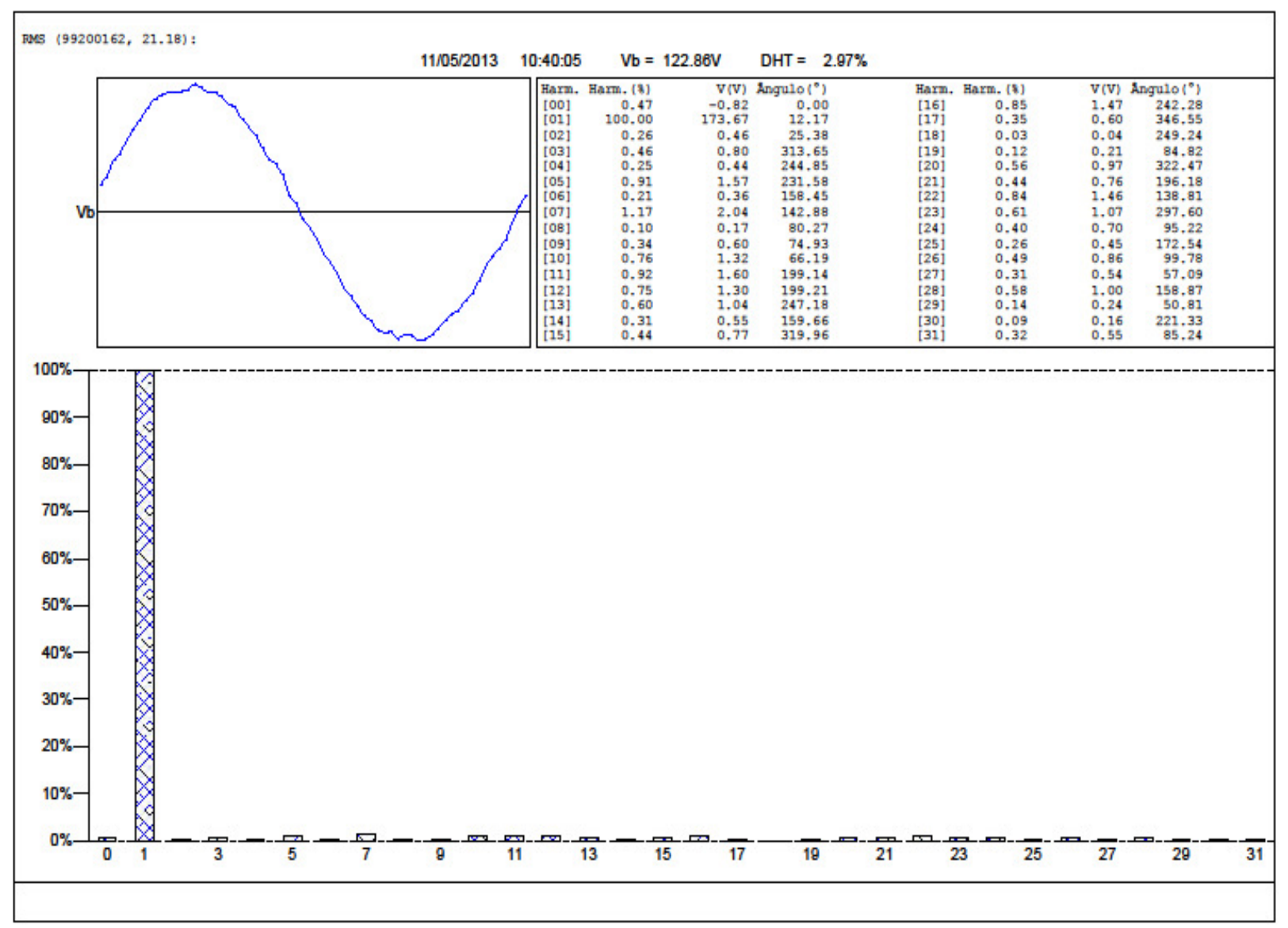

Figura 51 - Espectro de frequência da rede na pior situação do THDU, com GIGE, alimentando carga resistiva 
A Figura 52 mostra a curva de distorção harmônica total de corrente no ponto de acoplamento comum (PAC) para este modelo de aerogerador em função da variação de carga resistiva durante todo período de monitoramento, considerando desde a situação em vazio até a condição de plena carga, com acréscimo de carga em degraus de 10\%. Em destaque a distorção harmônica de corrente no período de medição.

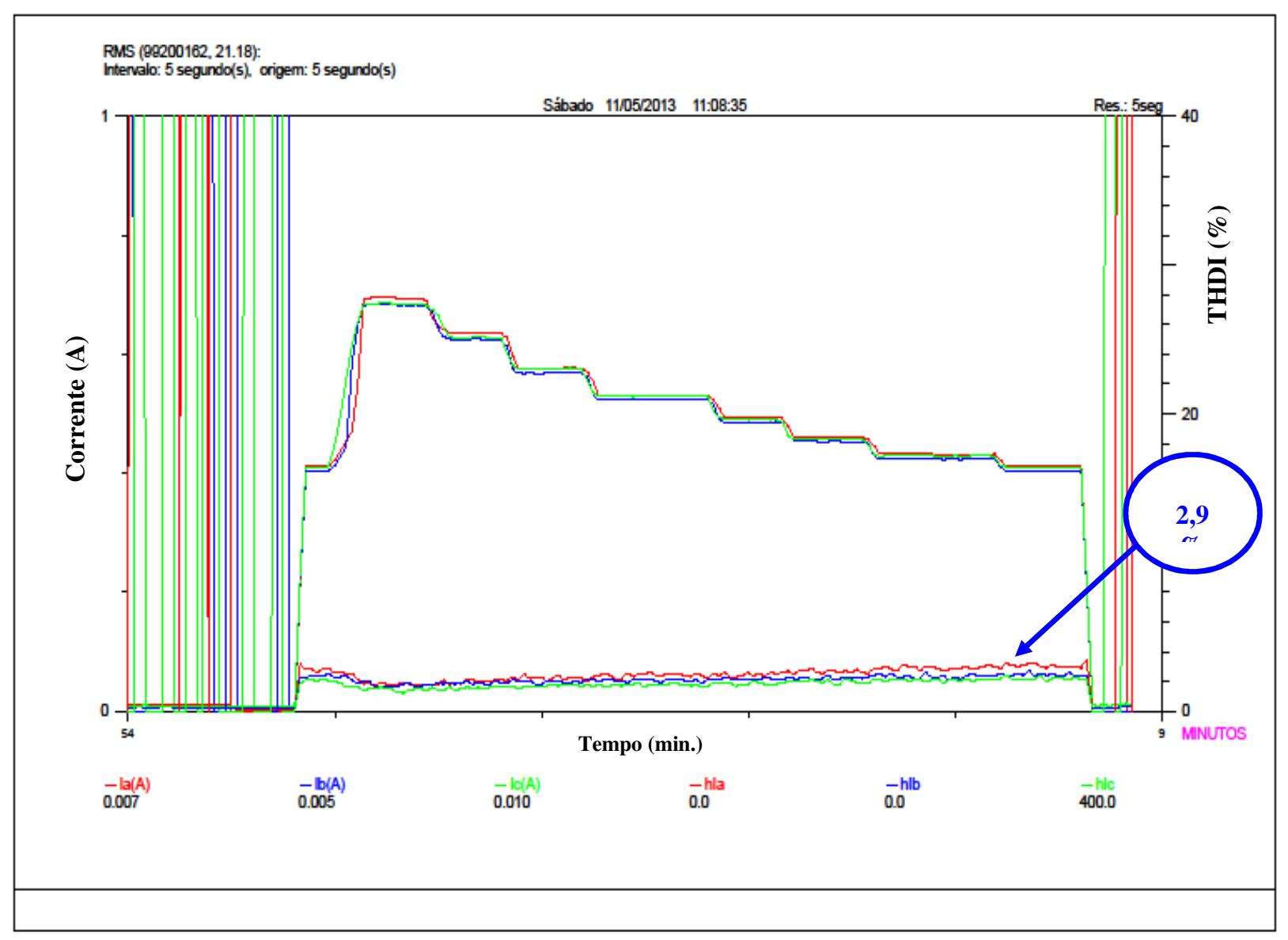

Figura 52 - Gráfico THDI com GIGE, alimentando carga resistiva em paralelo com a rede elétrica (variação de carga com degrau de $10 \%$.) 
A Figura 53 mostra a curva de distorção harmônica total de corrente no ponto de acoplamento comum (PAC) para este modelo de aerogerador em função da variação de carga resistiva durante todo período de monitoramento e as formas de onda de tensão no caso mais crítico de distorção, considerando desde a situação em vazio até a condição de plena carga, com acréscimo de carga em degraus de $10 \%$.

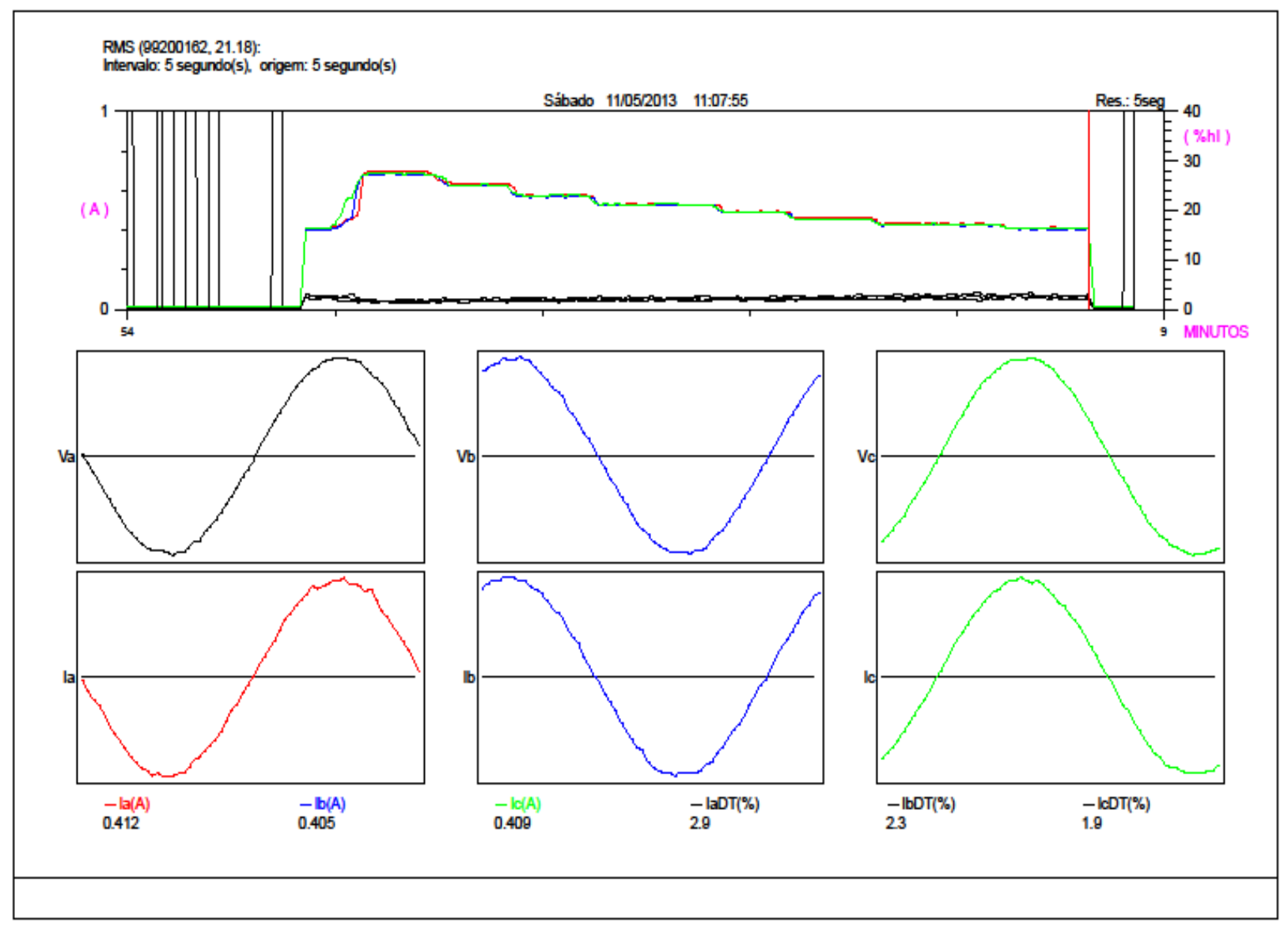

Figura 53 - Gráfico THDI da rede elétrica com formas de onda de tensão e corrente com GIGE, alimentando carga resistiva em paralelo com a rede elétrica (variação de carga com degrau de $10 \%$.) 
A Figura 54 mostra o espectro de frequência de corrente no ponto de acoplamento comum (PAC) para este modelo de aerogerador no caso mais crítico de distorção, considerando desde a situação em vazio até a condição de plena carga, com acréscimo de carga em degraus de $10 \%$.

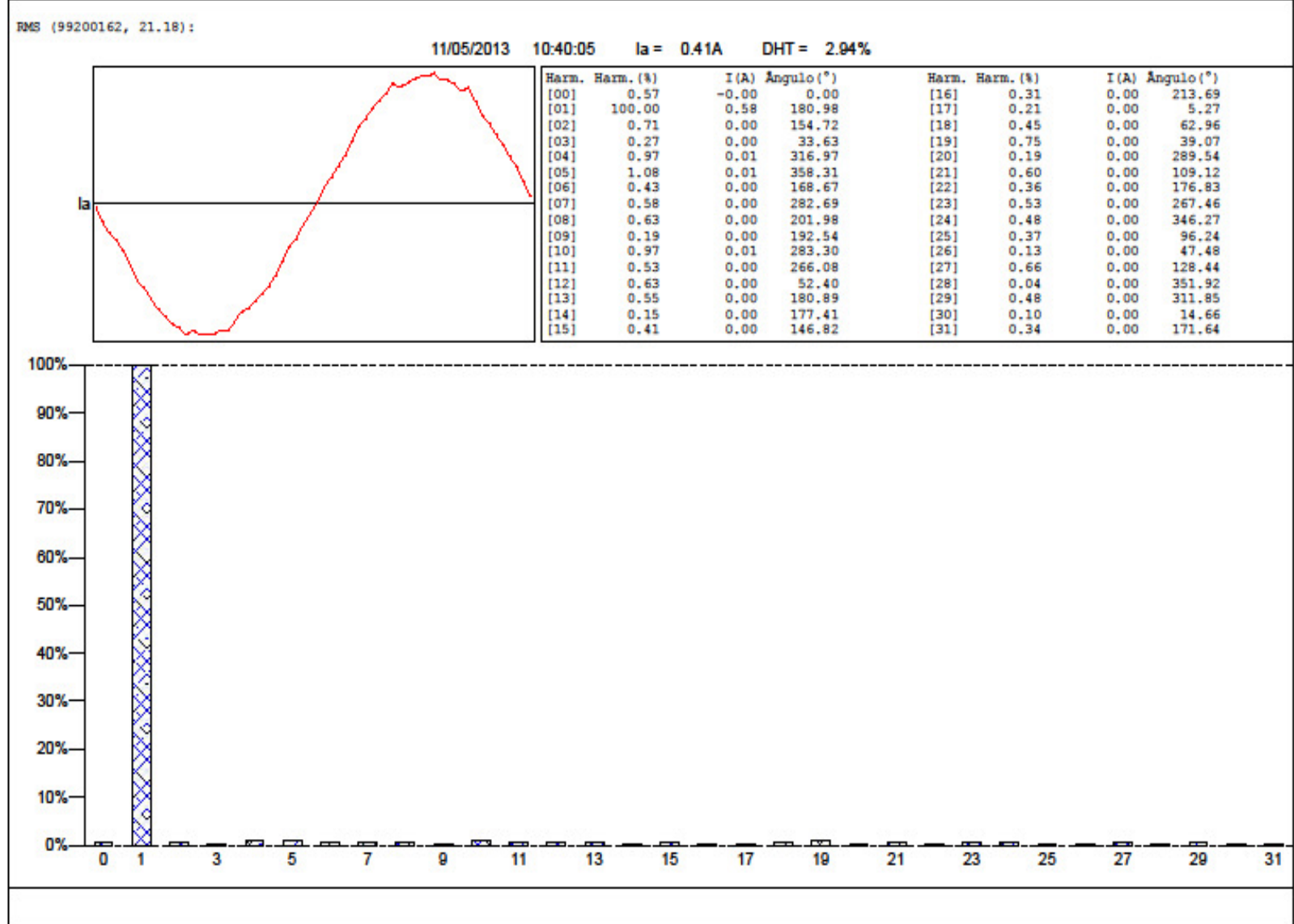

Figura 54 - Espectro de frequência da rede na pior situação do THDI, com GIGE, alimentando carga resistiva 


\subsubsection{Medição do Gerador de Indução com Dupla Alimentação (GIDA)}

Neste item são apresentados os resultados de medição das distorções harmônicas referentes ao modelo do aerogerador com Gerador de Indução com Dupla Alimentação (GIDA), ligado diretamente a carga (banco de reostatos ligados em estrela) e em paralelismo com a rede da concessionária, a fim de mensurar a sua contribuição em termos de distorções harmônicas. A Figura 55 mostra o esquema de ligação do modelo real utilizado em parques eólicos e a Figura 56 apresenta o diagrama básico de ligação do modelo montado em laboratório.

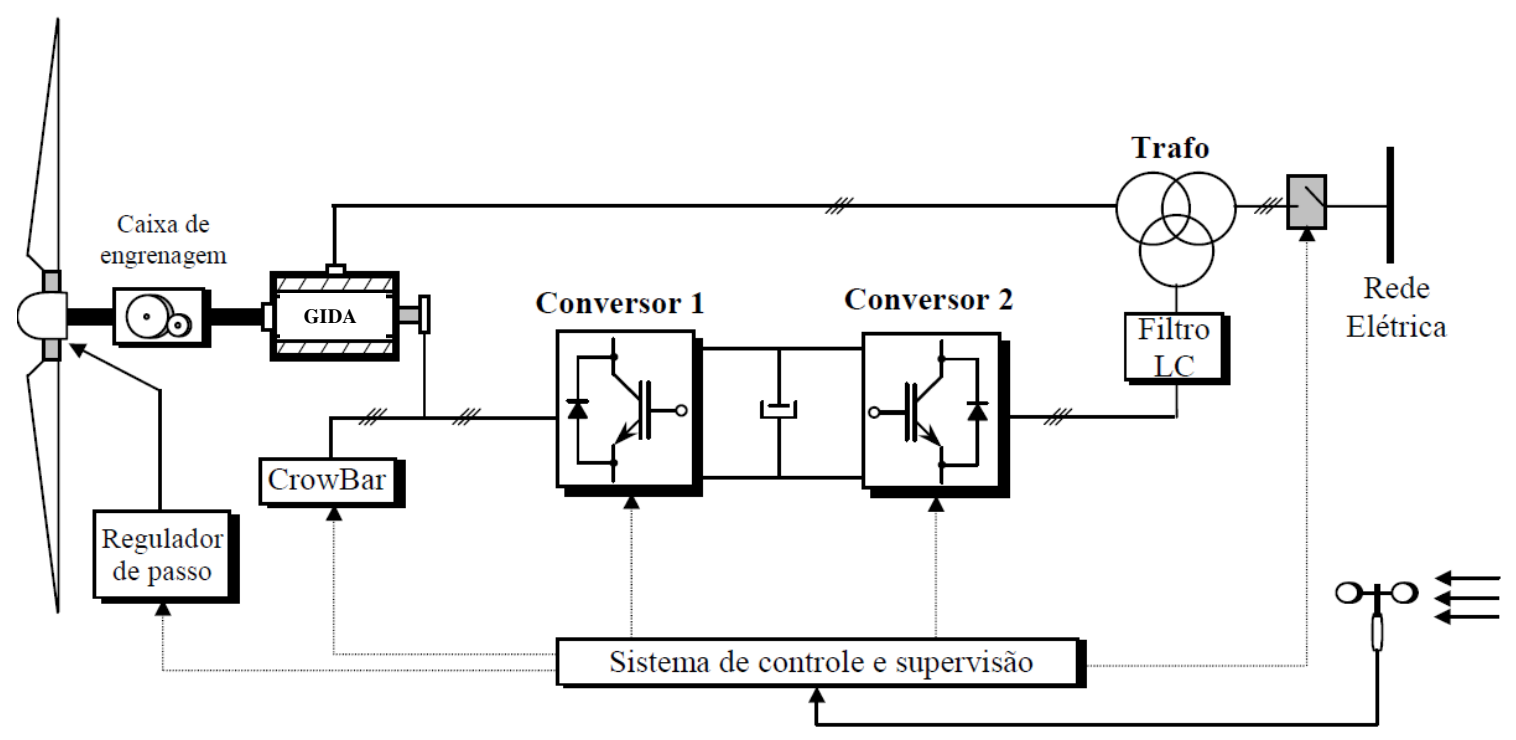

Figura 55 - Gerador de Indução com Dupla Alimentação (GIDA)

Fonte: Turbinas Eólicas: Modelo, Análise e Controle do Gerador de Indução com Dupla Alimentação 


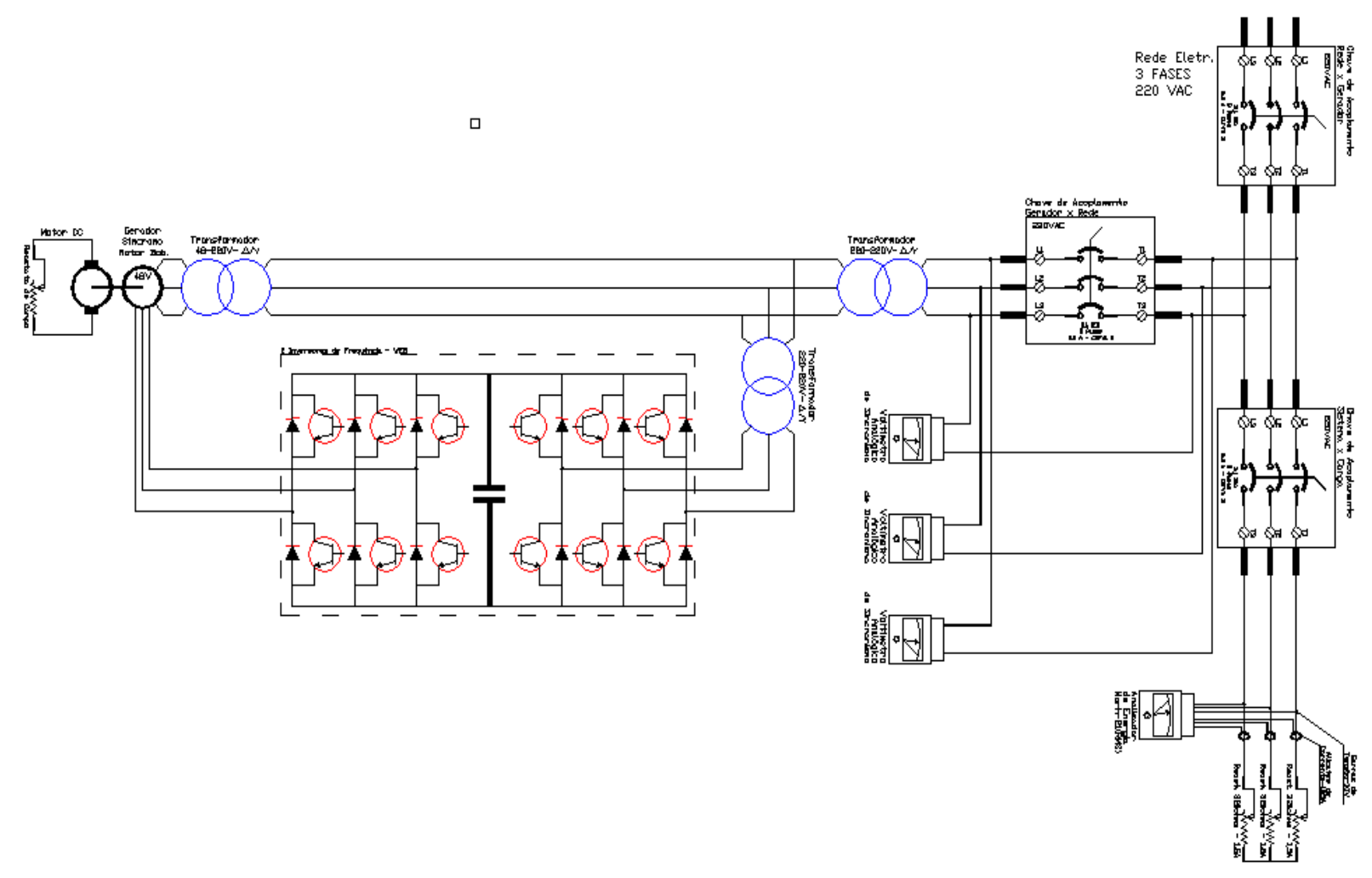

Figura 56 - Diagrama Básico de Ligação do Gerador Síncrono com Dupla Alimentação (GIDA) em paralelismo com a rede elétrica alimentando carga resistiva (variação de carga em degraus de 10\%) - montagem em laboratório 
A Figura 57 mostra a curva de distorção harmônica total de tensão no ponto de acoplamento comum (PAC) para este modelo de aerogerador em função da variação de carga resistiva durante todo período de monitoramento, considerando desde a situação em vazio até a condição de plena carga, com acréscimo de carga em degraus de 10\%. Em destaque a distorção harmônica de tensão no período de medição.

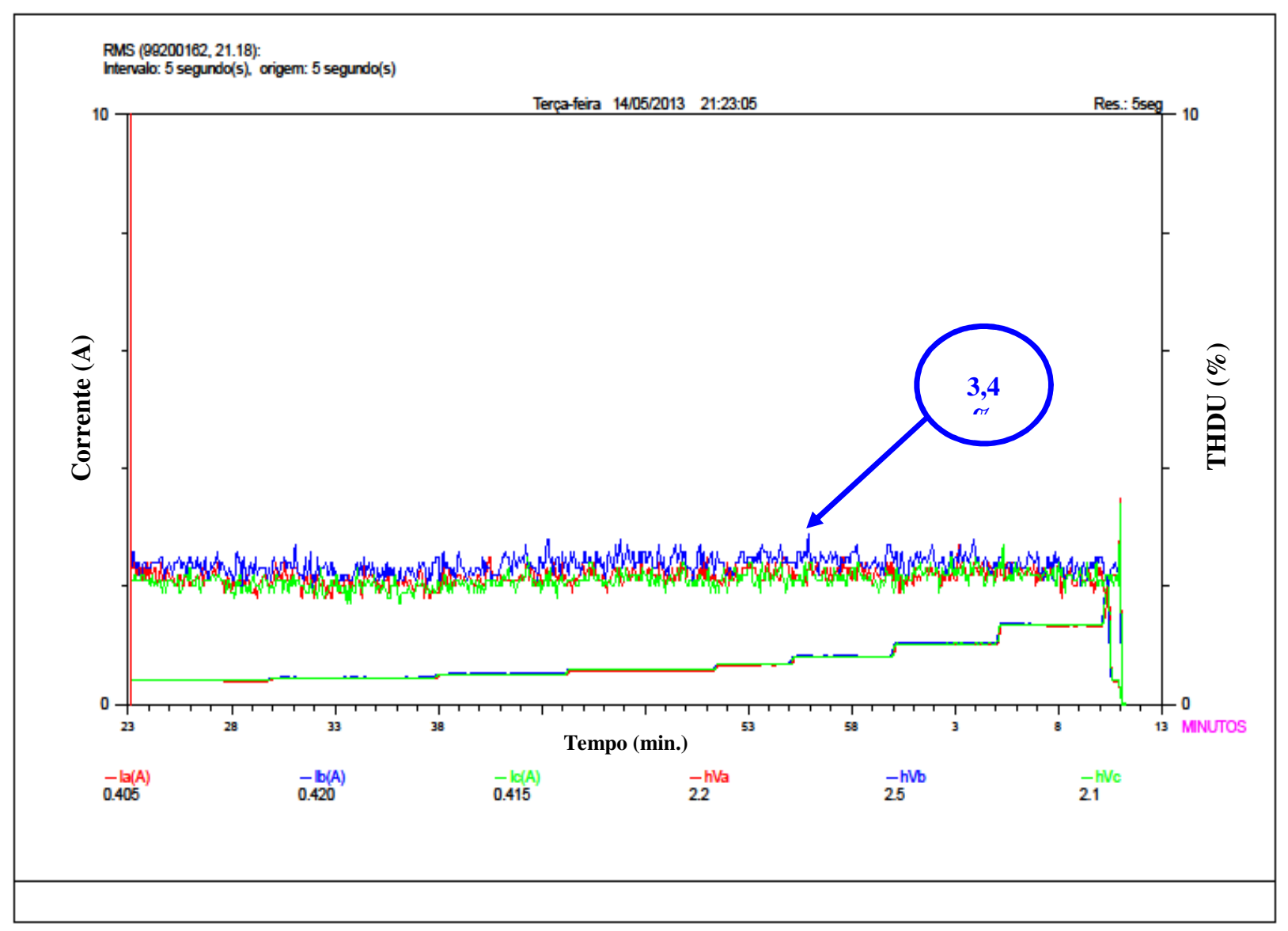

Figura 57 - Gráfico THDU com GIDA, alimentando carga resistiva em paralelo com a rede elétrica (variação de carga com degrau de $10 \%$.) 
A Figura 58 mostra a curva de distorção harmônica total de tensão no ponto de acoplamento comum (PAC) para este modelo de aerogerador em função da variação de carga resistiva durante todo período de monitoramento e as formas de onda de tensão no caso mais crítico de distorção, considerando desde a situação em vazio até a condição de plena carga, com acréscimo de carga em degraus de $10 \%$.

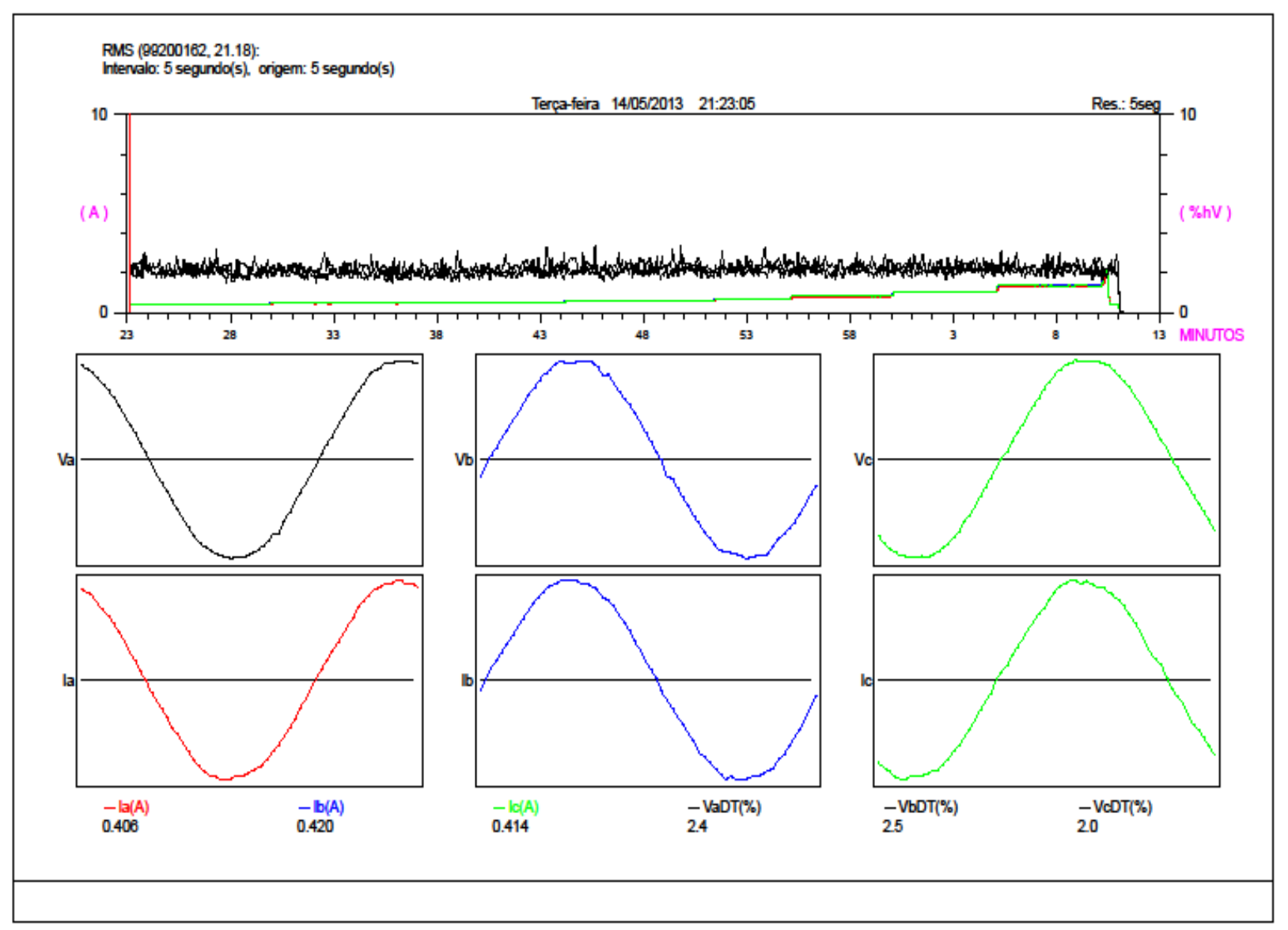

Figura 58 - Gráfico THDU da rede elétrica com formas de onda de tensão e corrente com GIDA, alimentando carga resistiva em paralelo com a rede elétrica (variação de carga com degrau de $10 \%$.) 
A Figura 59 mostra o espectro de frequência de tensão no ponto de acoplamento comum (PAC) para este modelo de aerogerador no caso mais crítico de distorção, considerando desde a situação em vazio até a condição de plena carga, com acréscimo de carga em degraus de $10 \%$.

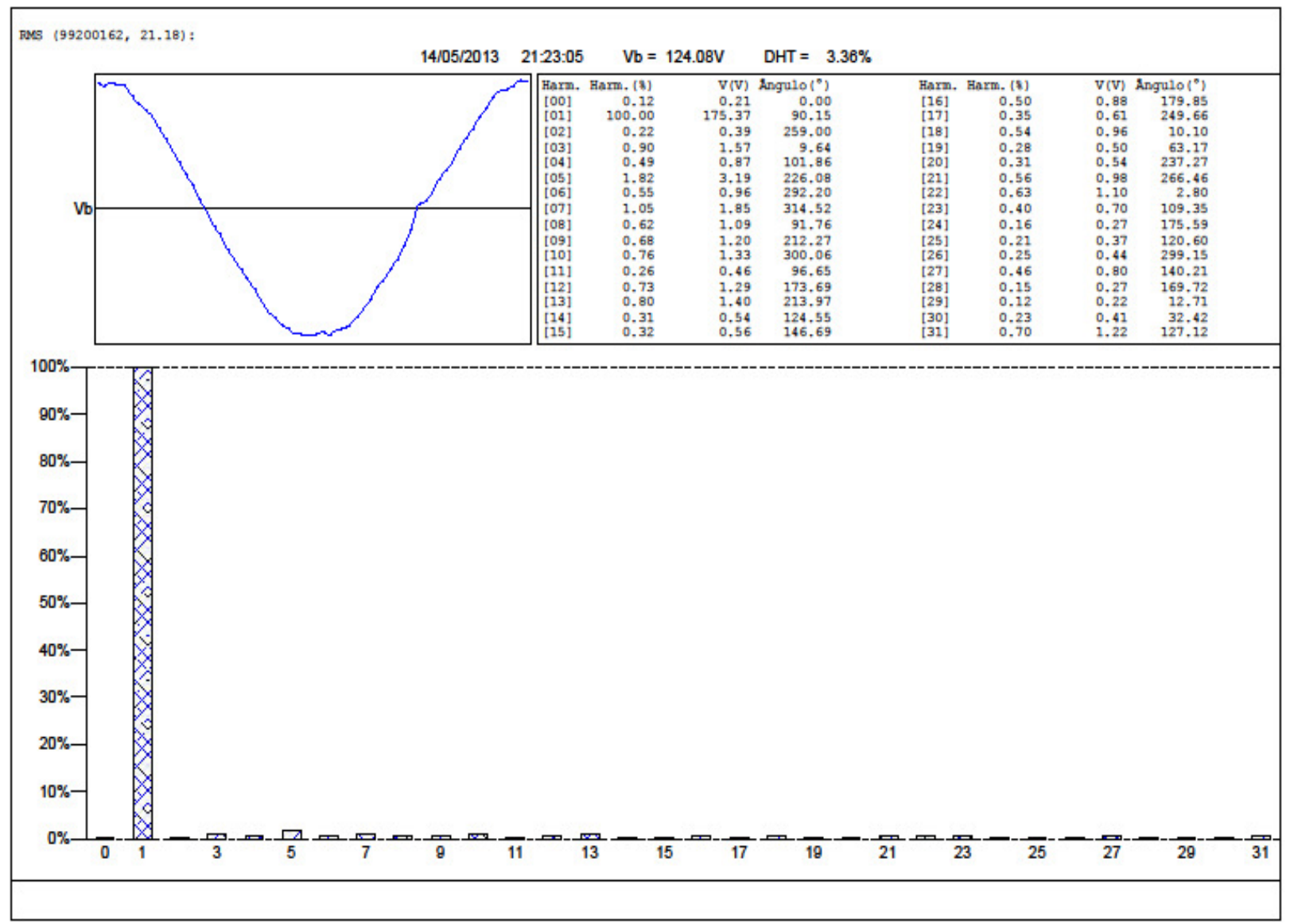

Figura 59 - Espectro de frequência da rede na pior situação do THDU, com GIDA, alimentando carga resistiva 
A Figura 60 mostra a curva de distorção harmônica total de corrente no ponto de acoplamento comum (PAC) para este modelo de aerogerador em função da variação de carga resistiva durante todo período de monitoramento, considerando desde a situação em vazio até a condição de plena carga, com acréscimo de carga em degraus de 10\%. Em destaque a distorção harmônica de corrente no período de medição.

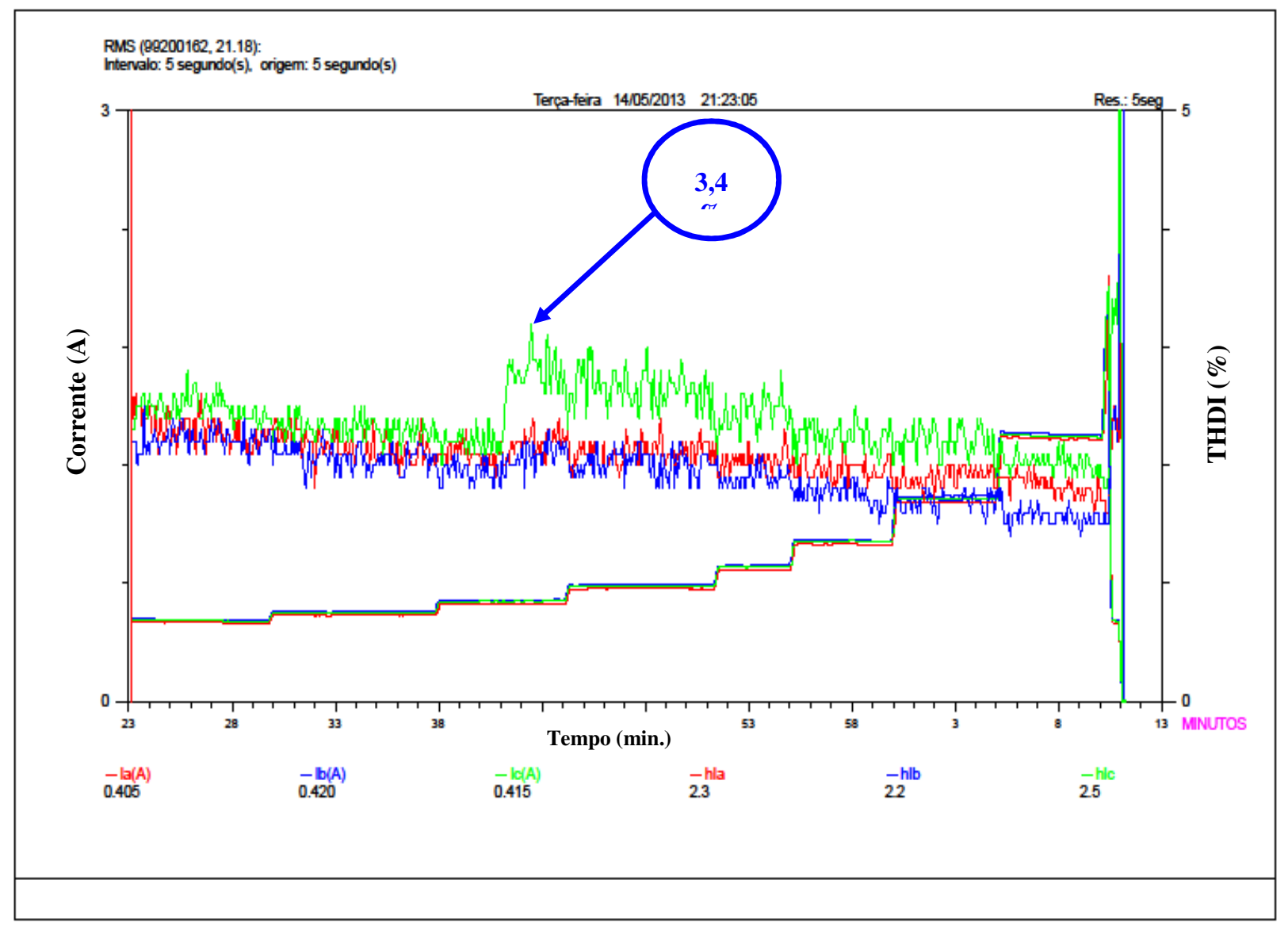

Figura 60 - Gráfico THDI com GIDA, alimentando carga resistiva em paralelo com a rede elétrica (variação de carga com degrau de $10 \%$.) 
A Figura 61 mostra a curva de distorção harmônica total de corrente no ponto de acoplamento comum (PAC) para este modelo de aerogerador em função da variação de carga resistiva durante todo período de monitoramento e as formas de onda de tensão no caso mais crítico de distorção, considerando desde a situação em vazio até a condição de plena carga, com acréscimo de carga em degraus de $10 \%$.

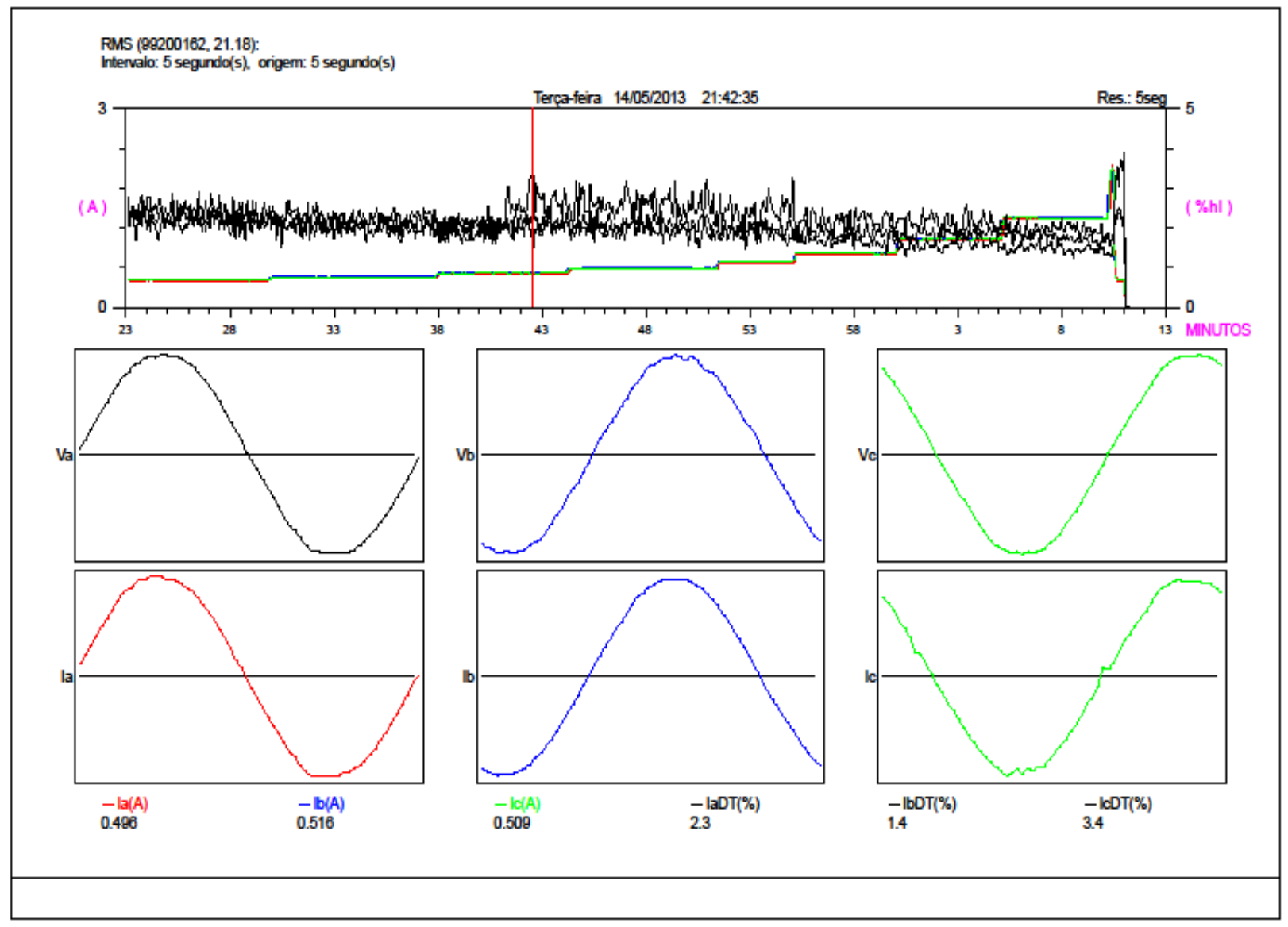

Figura 61 - Gráfico THDI da rede elétrica com formas de onda de tensão e corrente com GIDA, alimentando carga resistiva em paralelo com a rede elétrica (variação de carga com degrau de $10 \%$.) 
A Figura 62 mostra o espectro de frequência de tensão no ponto de acoplamento comum (PAC) para este modelo de aerogerador no caso mais crítico de distorção, considerando desde a situação em vazio até a condição de plena carga, com acréscimo de carga em degraus de $10 \%$.

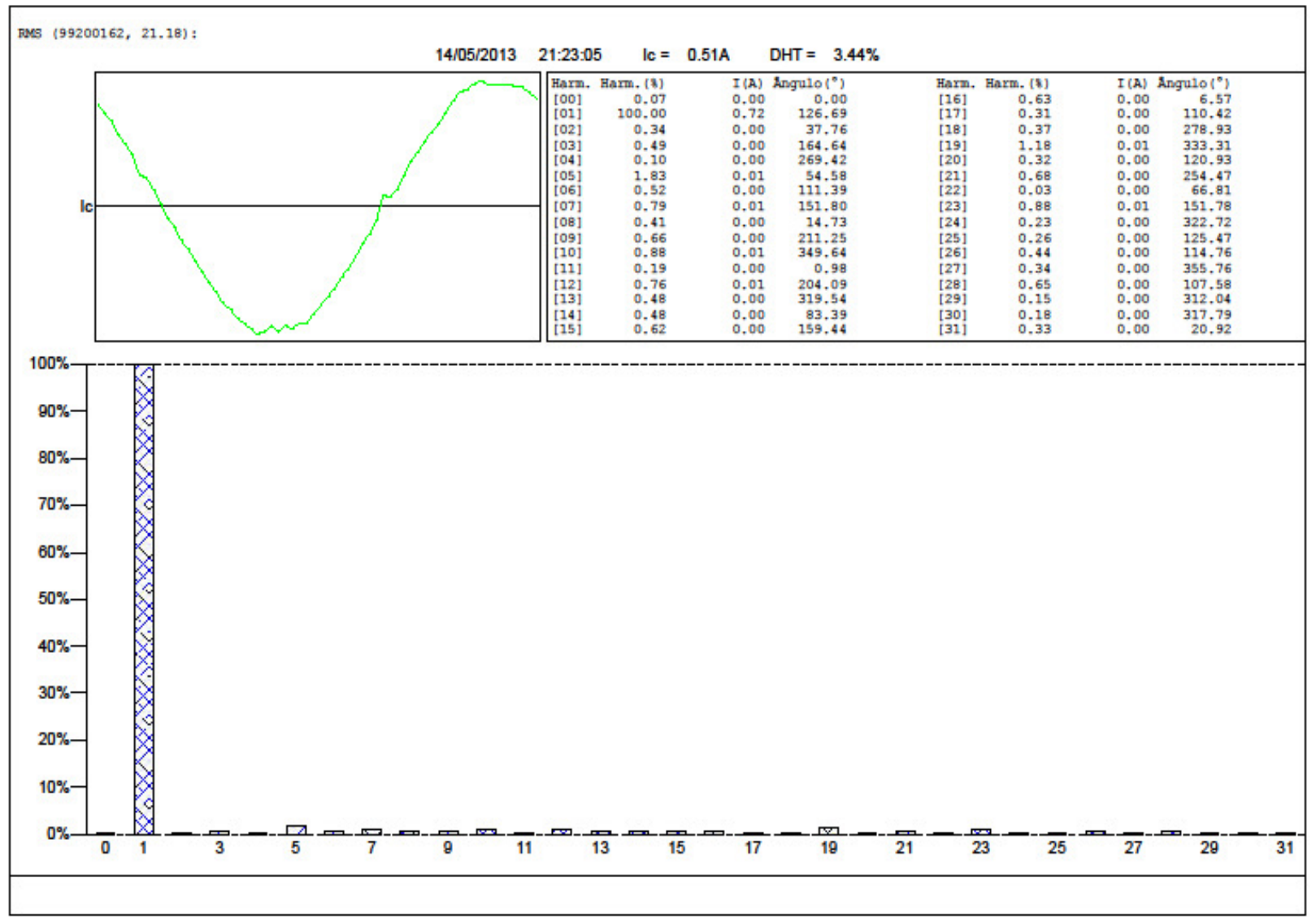

Figura 62 - Espectro de frequência da rede na pior situação do THDI, com GIDA, alimentando carga resistiva

\subsubsection{Medição do Gerador Síncrono com Rotor Bobinado (GSRB) em condição de alimentação direta a carga sem paralelismo da rede}

Neste item são apresentados os resultados de medição das distorções harmônicas referentes ao modelo do aerogerador com Gerador Síncrono com Rotor Bobinado (GSRB) ligado diretamente à carga (banco de reostatos ligados em estrela) e sem paralelismo com a rede da 
concessionária, a fim de mensurar a sua contribuição em termos de distorções harmônicas. Para isso a alimentação do campo do rotor foi realizada através de fonte externa de corrente contínua.

A Figura 63 mostra o esquema de ligação do modelo utilizado em parques eólicos e a Figura 64 apresenta o diagrama básico de ligação do modelo montado em laboratório

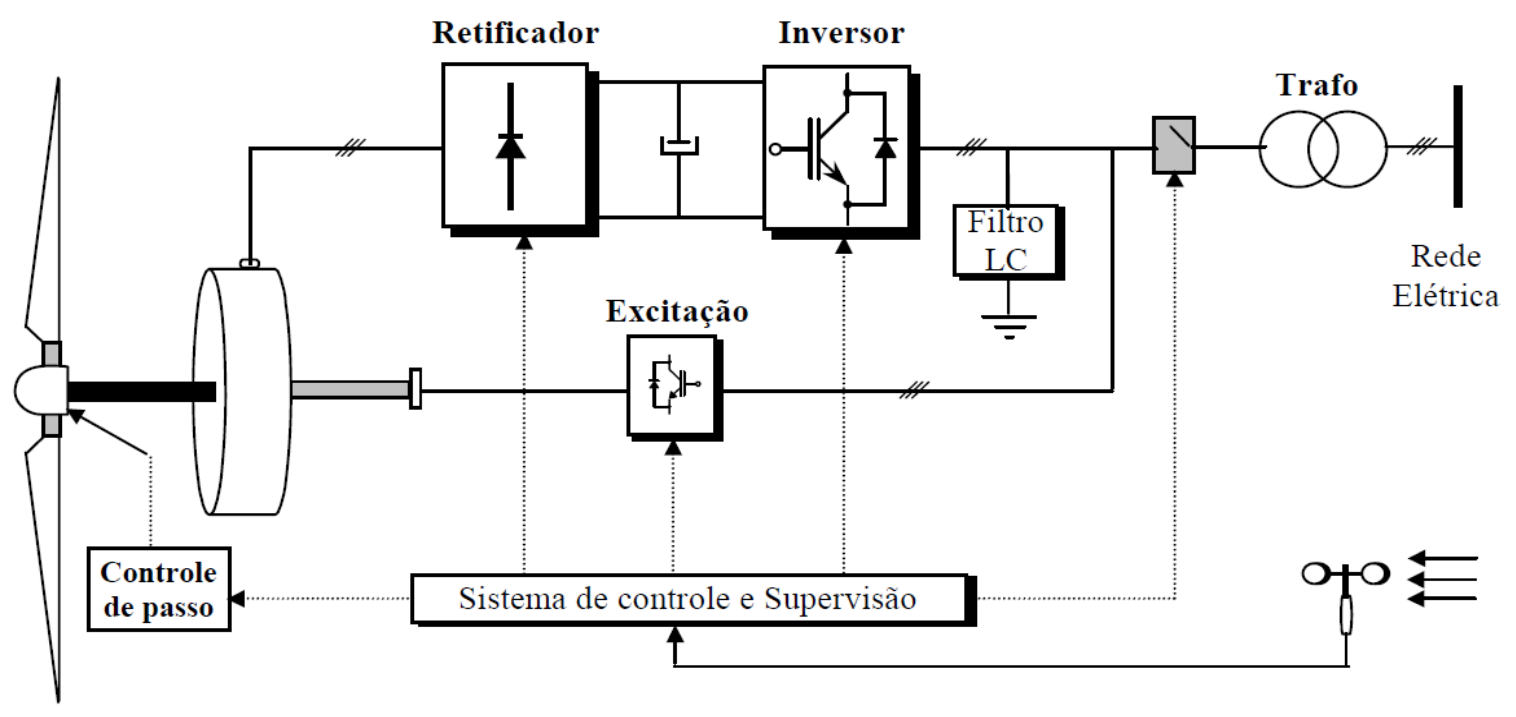

Figura 63 - Gerador Síncrono com Rotor Bobinado (GSRB) - Diagrama Básico Fonte: Modelagem e Simulação de Unidades Eólicas para Estudos de Indicadores de Qualidade de Energia Elétrica - Trabalho de Pós Graduação - UFU

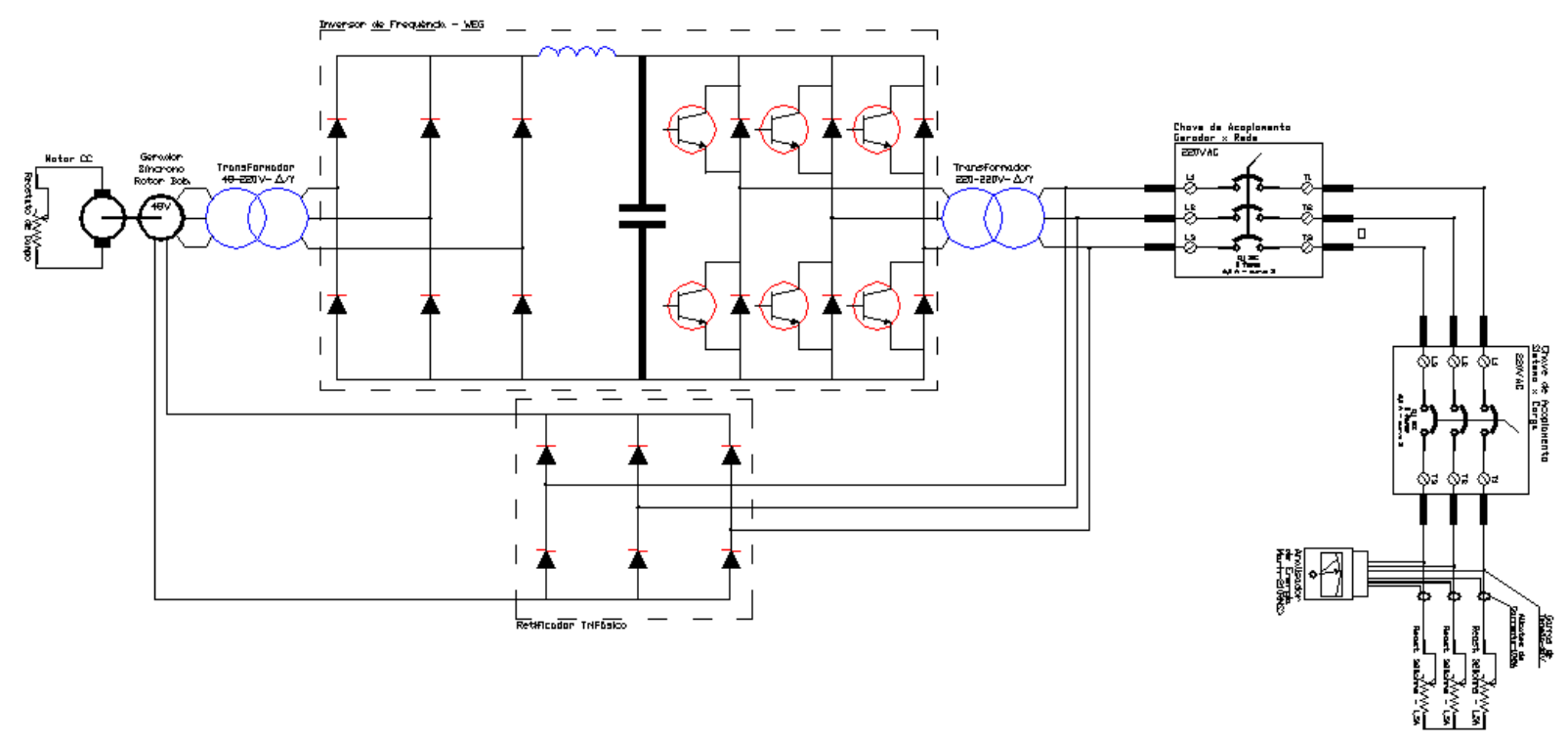

Figura 64 - Diagrama Básico de Ligação do Gerador Síncrono com Rotor Bobinado (GSRB) sem paralelismo com a rede elétrica alimentando carga resistiva (variação de carga em degraus de 10\%) montagem em laboratório 
A Figura 65 mostra a curva de distorção harmônica total de tensão no ponto de acoplamento comum (PAC), sem o paralelismo com a rede elétrica, para este modelo de aerogerador em função da variação de carga resistiva durante todo período de monitoramento, considerando desde a situação em vazio até a condição de plena carga, com acréscimo de carga em degraus de 10\%. Em destaque a distorção harmônica de tensão no período de medição.

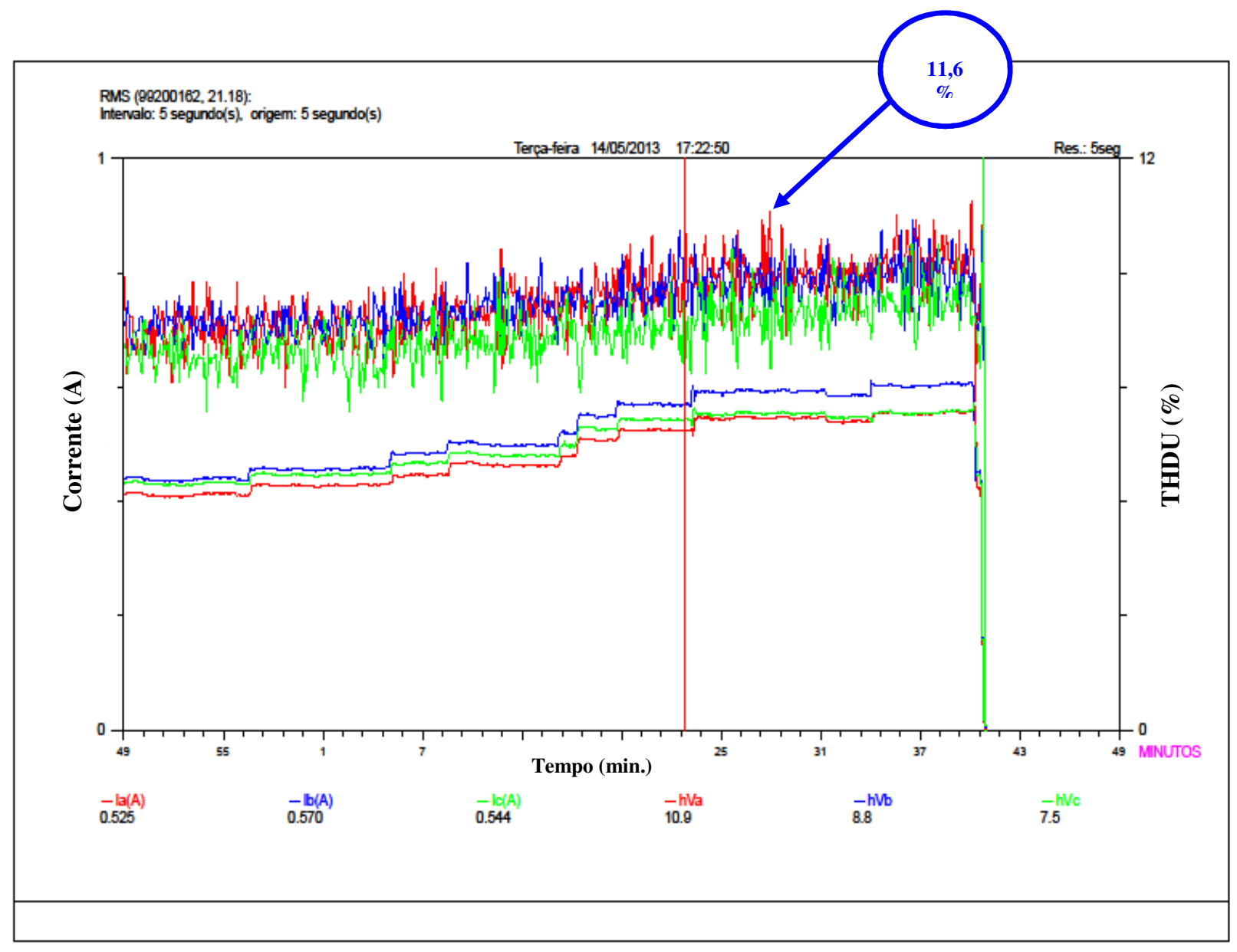

Figura 65 - Gráfico THDU com GSRB, alimentando carga resistiva diretamente sem paralelismo com a rede elétrica (variação de carga com degrau de 10\%.) 
A Figura 66 mostra a curva de distorção harmônica total de tensão no ponto de acoplamento comum (PAC) para este modelo de aerogerador, sem o paralelismo com a rede elétrica, em função da variação de carga resistiva durante todo período de monitoramento e as formas de onda de tensão no caso mais crítico de distorção, considerando desde a situação em vazio até a condição de plena carga, com acréscimo de carga em degraus de $10 \%$.

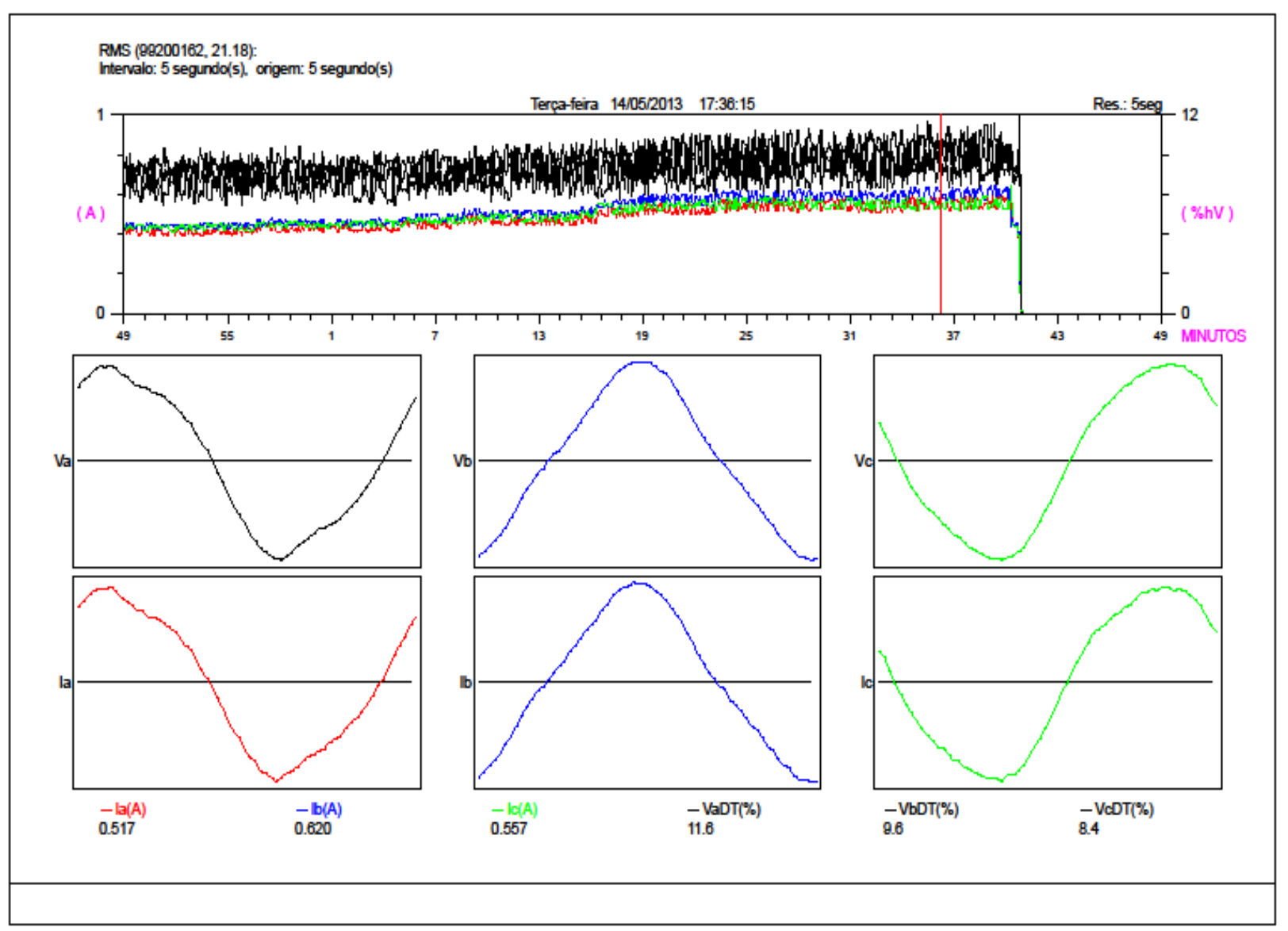

Figura 66 - Gráfico THDU da rede elétrica com formas de onda de tensão e corrente com GSRB, alimentando carga resistiva diretamente sem paralelismo com a rede elétrica

(variação de carga com degrau de $10 \%$.) 
A Figura 67 mostra o espectro de frequência de tensão no ponto de acoplamento comum (PAC) para este modelo de aerogerador, sem o paralelismo com a rede elétrica, no caso mais crítico de distorção, considerando desde a situação em vazio até a condição de plena carga, com acréscimo de carga em degraus de $10 \%$.

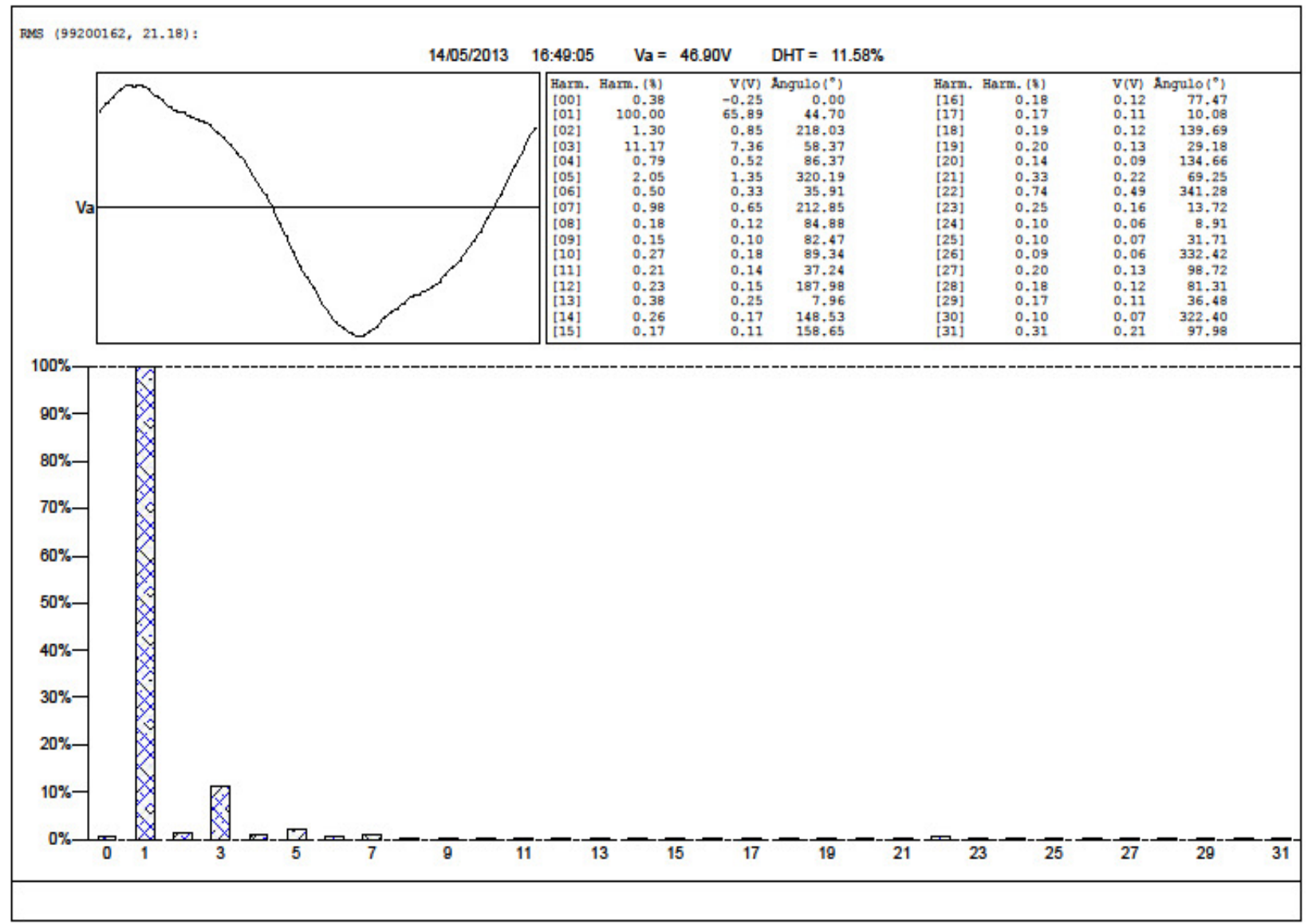

Figura 67 - Espectro de frequência da rede na pior situação do THDU, com GSRB, alimentando carga resistiva sem paralelismo com a rede elétrica 
A Figura 68 mostra a curva de distorção harmônica total de tensão no ponto de acoplamento comum (PAC), sem o paralelismo com a rede elétrica, para este modelo de aerogerador em função da variação de carga resistiva durante todo período de monitoramento, considerando desde a situação em vazio até a condição de plena carga, com acréscimo de carga em degraus de $10 \%$. Em destaque a distorção harmônica de corrente no período de medição.

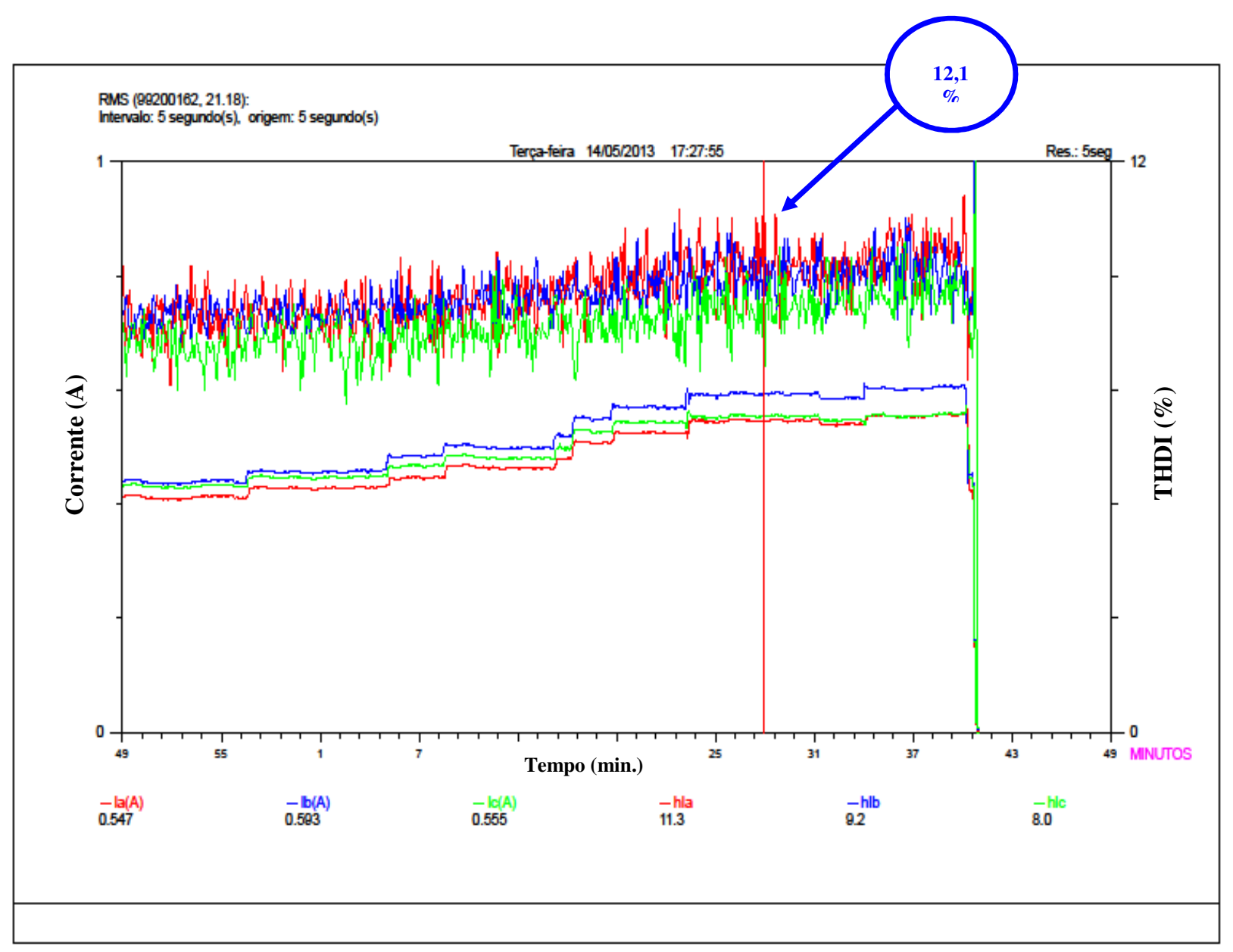

Figura 68 - Gráfico THDI com GSRB, alimentando carga resistiva diretamente sem paralelismo com a rede elétrica (variação de carga com degrau de $10 \%$.) 
A Figura 69 mostra a curva de distorção harmônica total de tensão no ponto de acoplamento comum (PAC) para este modelo de aerogerador, sem o paralelismo com a rede elétrica, em função da variação de carga resistiva durante todo período de monitoramento e as formas de onda de tensão no caso mais crítico de distorção, considerando desde a situação em vazio até a condição de plena carga, com acréscimo de carga em degraus de $10 \%$.

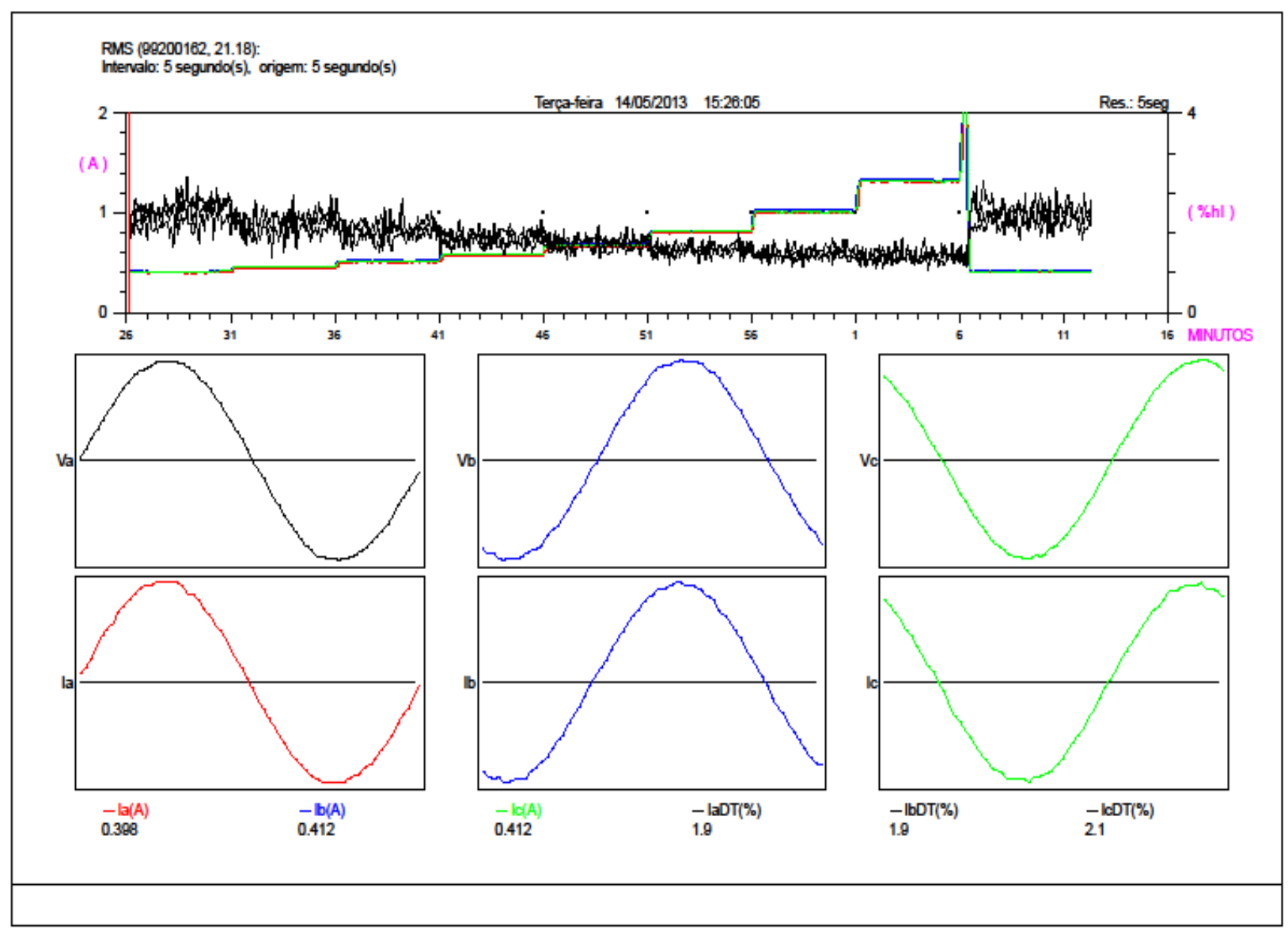

Figura 69 - Gráfico THDI da rede elétrica com formas de onda de tensão e corrente com GSRB, alimentando carga resistiva diretamente sem paralelismo com a rede elétrica (variação de carga com degrau de $10 \%$.) 
A Figura 70 mostra o espectro de frequência de tensão no ponto de acoplamento comum (PAC) para este modelo de aerogerador, sem o paralelismo com a rede elétrica, no caso mais crítico de distorção, considerando desde a situação em vazio até a condição de plena carga, com acréscimo de carga em degraus de $10 \%$.

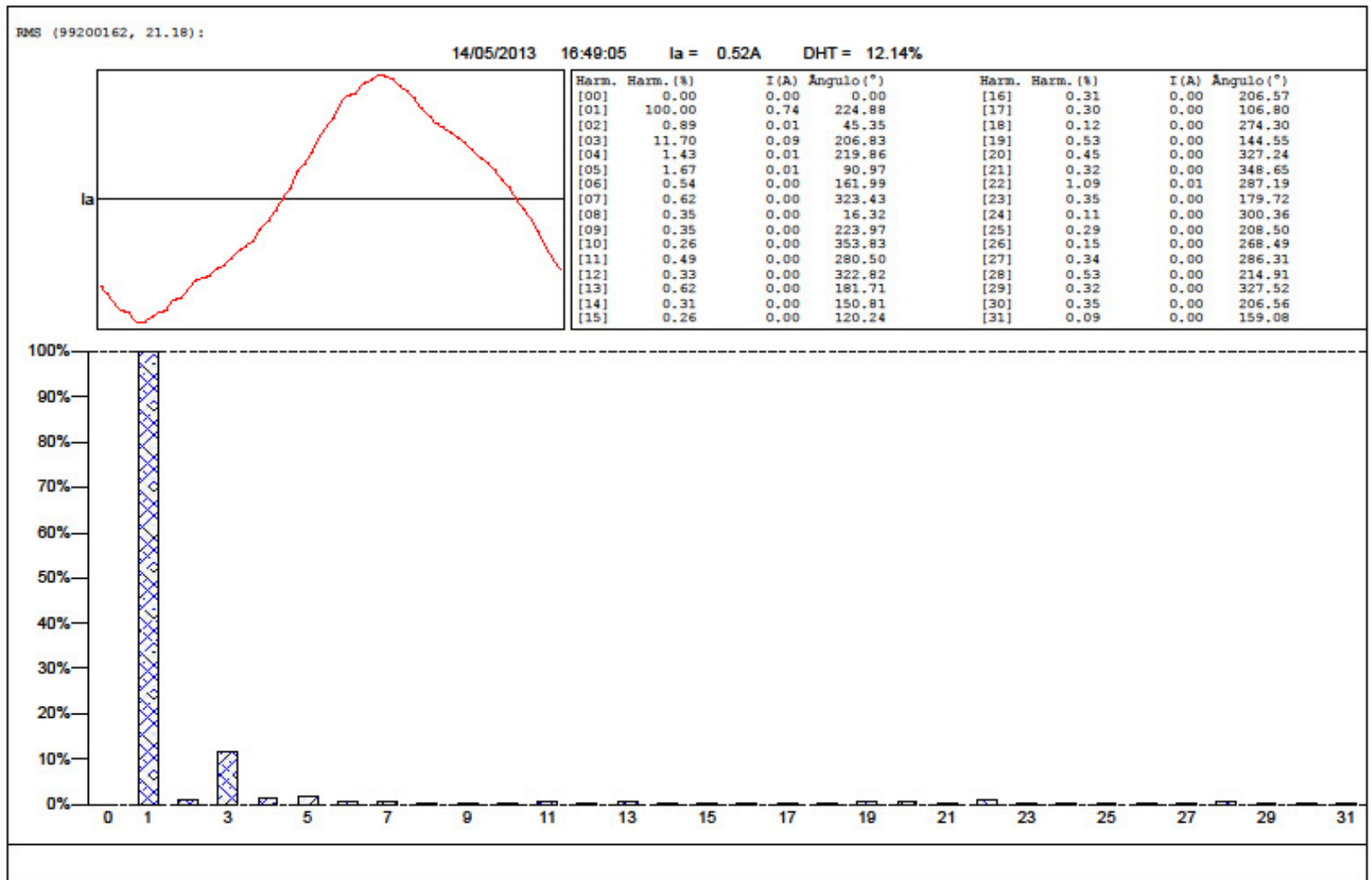

Figura 70 - Espectro de frequência da rede na pior situação do THDI, com GSRB, alimentando carga resistiva sem paralelismo com a rede elétrica 


\subsubsection{Medição do Gerador de Indução Duplamente Alimentado (GIDA) em condição de alimentação direta a carga sem paralelismo da rede}

Neste item são apresentados os resultados de medição das distorções harmônicas referentes ao modelo do aerogerador com Gerador de Indução Duplamente Alimentado (GIDA), ligado diretamente à carga (banco de reostatos ligados em estrela) e sem paralelismo com a rede da concessionária, a fim de mensurar a sua contribuição em termos de distorções harmônicas. Para tal o gerador foi inicialmente ligado em condição de paralelismo com a rede e após alguns instantes foi aberta a chave que o conectava ao sistema, quando então passou a alimentar a carga isoladamente. A Figura 71 mostra o esquema de ligação do modelo utilizado em parques eólicos e a Figura 72 apresenta o diagrama básico de ligação do modelo montado em laboratório.

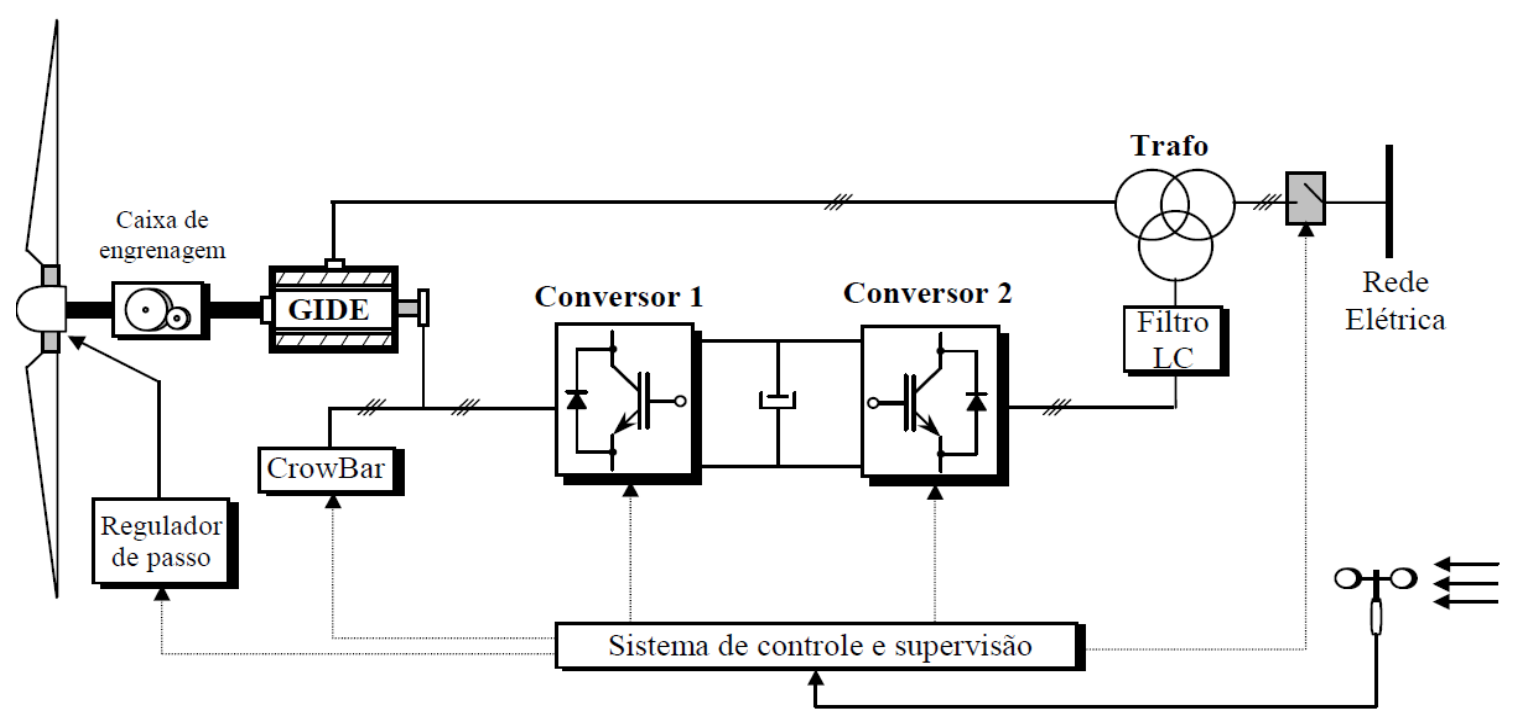

Figura 71 - Gerador de Indução com Dupla Alimentação (GIDA) - Diagrama Básico Fonte: Modelagem e Simulação de Unidades Eólicas para Estudos de Indicadores de Qualidade de Energia Elétrica - Trabalho de Pós Graduação - UFU 


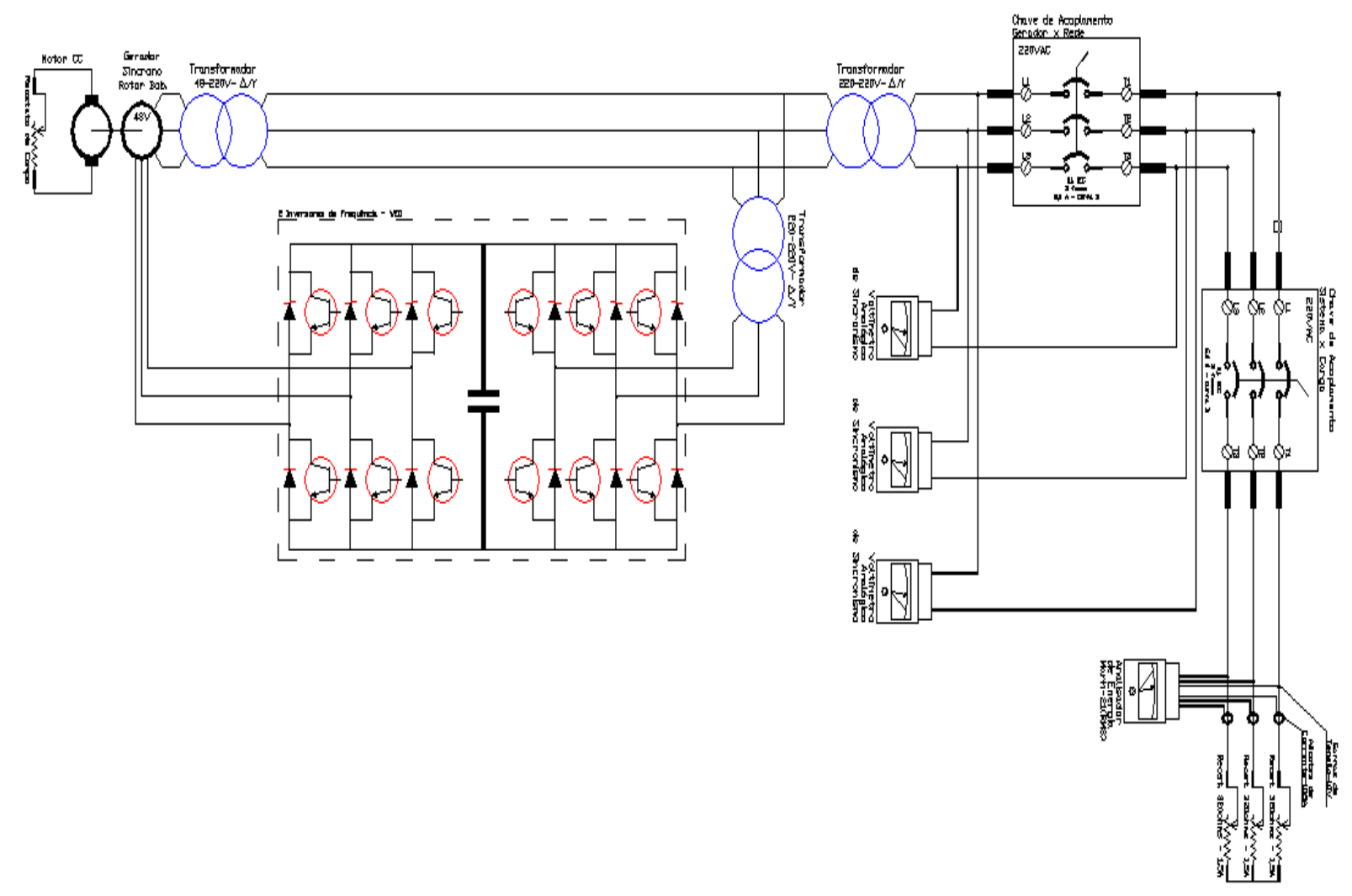

Figura 72 - Diagrama Básico de Ligação do Gerador Síncrono com Dupla Alimentação (GIDA) sem paralelismo com a rede elétrica, alimentando carga resistiva (variação de carga em degraus de 10\%) - montagem em laboratório. 
A Figura 73 mostra a curva de distorção harmônica total de tensão no ponto de acoplamento comum (PAC), sem o paralelismo com a rede elétrica, para este modelo de aerogerador em função da variação de carga resistiva durante todo período de monitoramento, considerando desde a situação em vazio até a condição de plena carga, com acréscimo de carga em degraus de 10\%. Em destaque a distorção harmônica de tensão no período de medição.

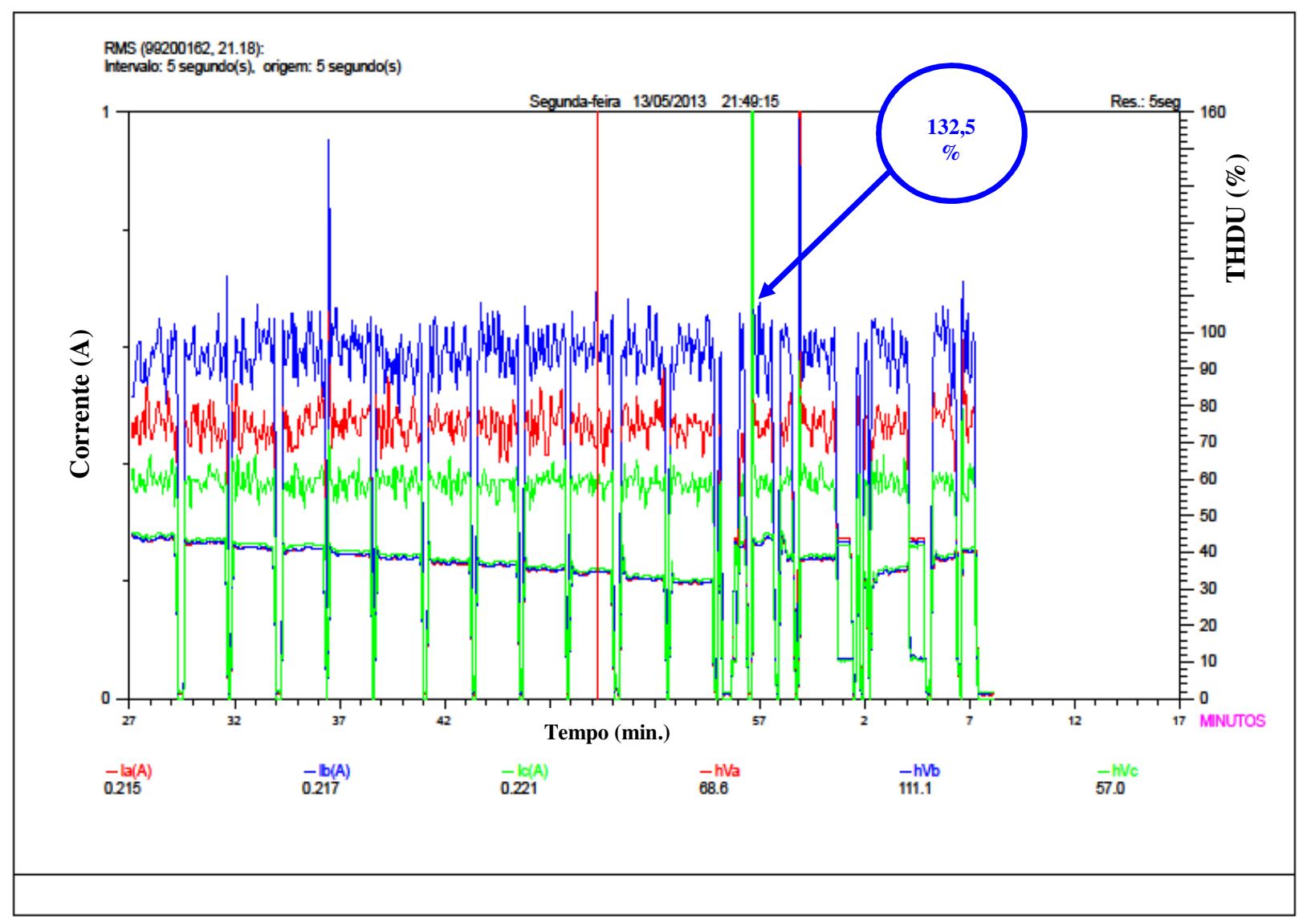

Figura 73 - Gráfico THDU com GIDA, alimentando carga resistiva diretamente sem paralelismo com a rede elétrica (variação de carga com degrau de $10 \%$.) 
A Figura 74 mostra a curva de distorção harmônica total de tensão no ponto de acoplamento comum (PAC) para este modelo de aerogerador, sem o paralelismo com a rede elétrica, em função da variação de carga resistiva durante todo período de monitoramento e as formas de onda de tensão no caso mais crítico de distorção, considerando desde a situação em vazio até a condição de plena carga, com acréscimo de carga em degraus de $10 \%$.

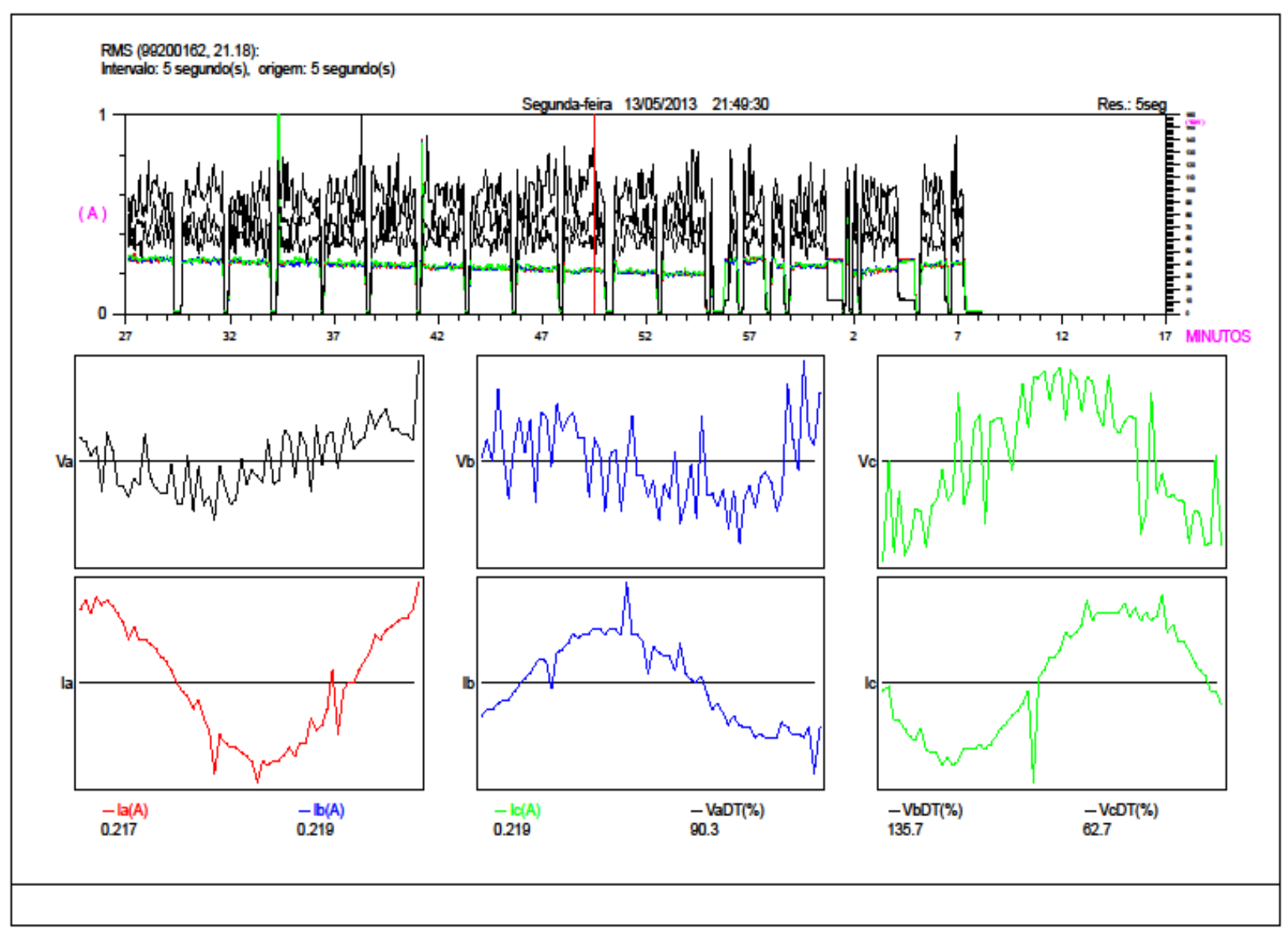

Figura 74 - Gráfico THDU da rede elétrica com formas de onda de tensão e corrente com GIDA, alimentando carga resistiva diretamente sem paralelismo com a rede elétrica (variação de carga com degrau de $10 \%$.) 
A Figura 75 mostra o espectro de frequência de tensão no ponto de acoplamento comum (PAC) para este modelo de aerogerador, sem o paralelismo com a rede elétrica, no caso mais crítico de distorção, considerando desde a situação em vazio até a condição de plena carga, com acréscimo de carga em degraus de $10 \%$.

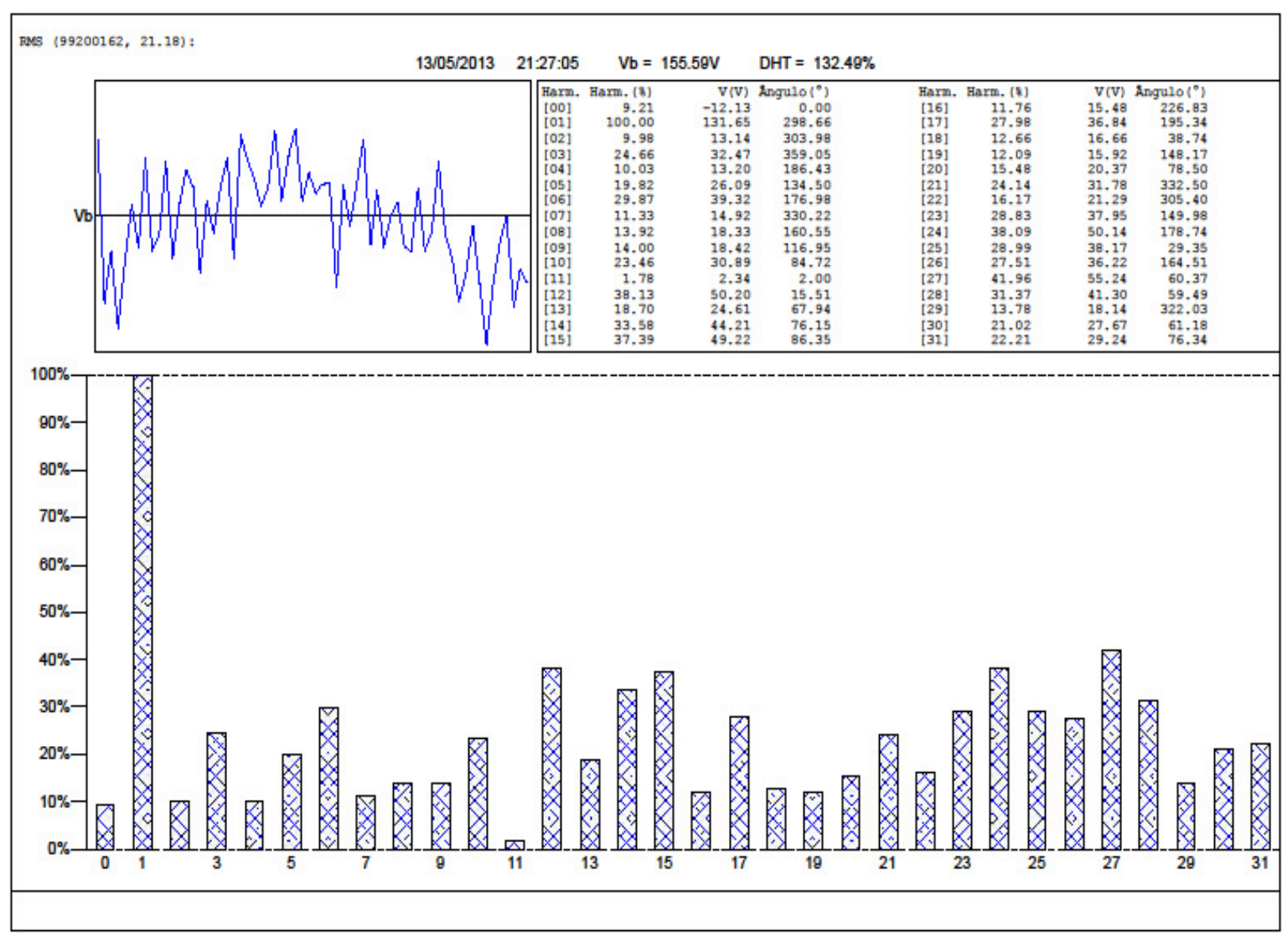

Figura 75 - Espectro de frequência da rede na pior situação do THDU, com GIDA, alimentando carga resistiva sem paralelismo com a rede elétrica 
A Figura 76 mostra a curva de distorção harmônica total de tensão no ponto de acoplamento comum (PAC), sem o paralelismo com a rede elétrica, para este modelo de aerogerador em função da variação de carga resistiva durante todo período de monitoramento, considerando desde a situação em vazio até a condição de plena carga, com acréscimo de carga em degraus de 10\%. Em destaque a distorção harmônica de corrente no período de medição.

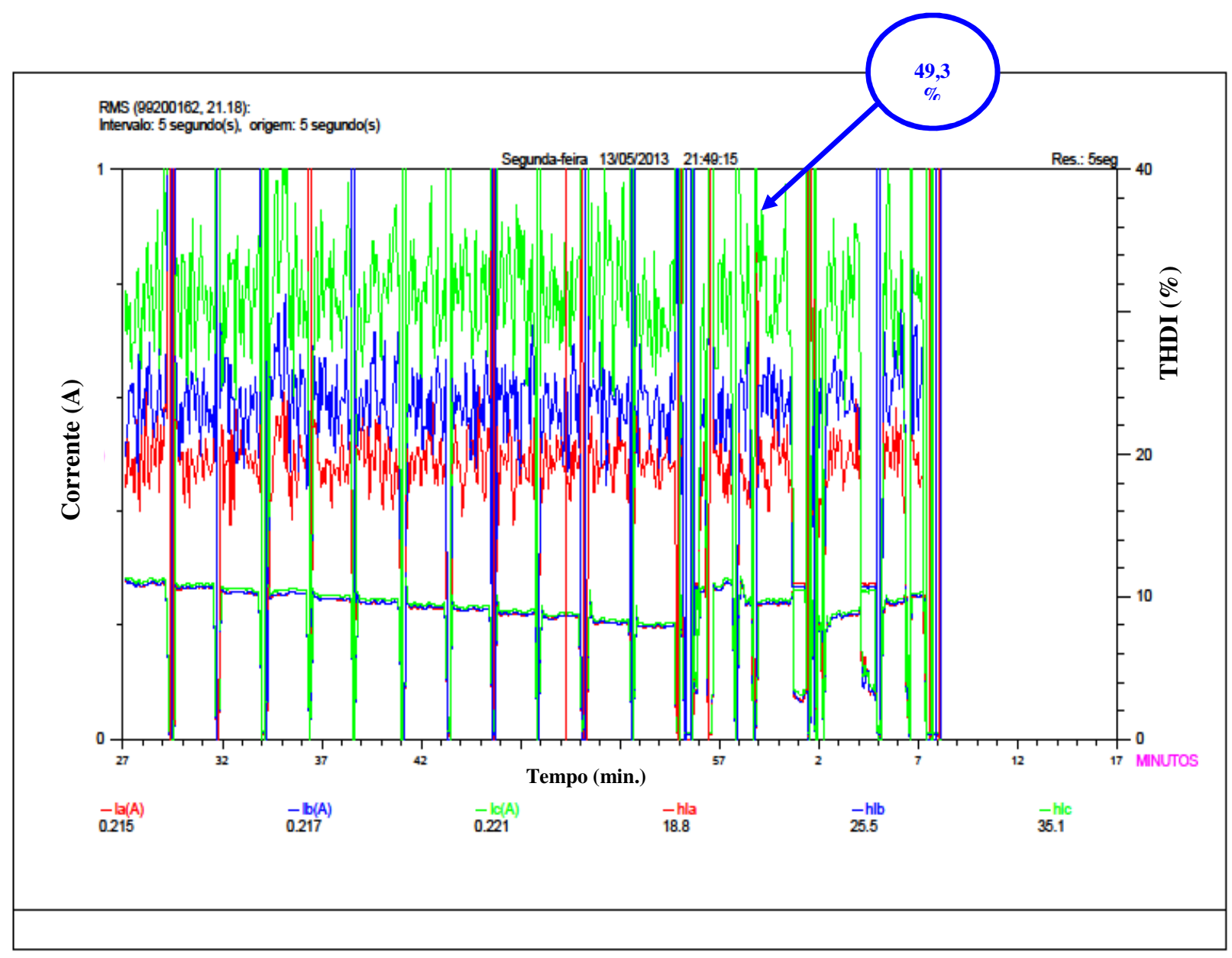

Figura 76 - Gráfico THDI com GIDA, alimentando carga resistiva diretamente sem paralelismo com a rede elétrica (variação de carga com degrau de 10\%.) 
A Figura 77 mostra a curva de distorção harmônica total de tensão no ponto de acoplamento comum (PAC) para este modelo de aerogerador, sem o paralelismo com a rede elétrica, em função da variação de carga resistiva durante todo período de monitoramento e as formas de onda de tensão no caso mais crítico de distorção, considerando desde a situação em vazio até a condição de plena carga, com acréscimo de carga em degraus de $10 \%$.

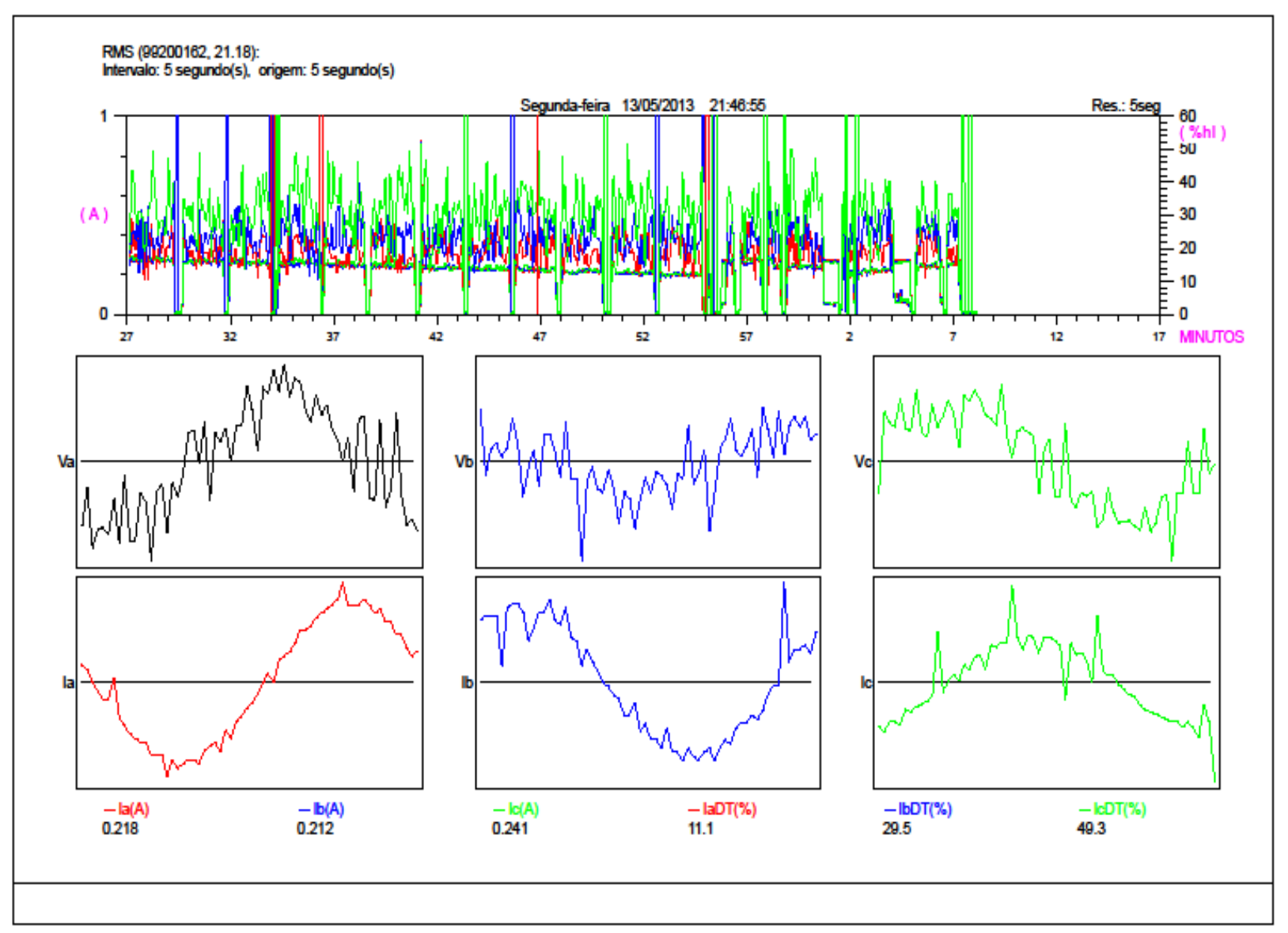

Figura 77 - Gráfico THDI da rede elétrica com formas de onda de tensão e corrente com GIDA, alimentando carga resistiva diretamente sem paralelismo com a rede elétrica (variação de carga com degrau de $10 \%$.) 
A Figura 78 mostra o espectro de frequência de tensão no ponto de acoplamento comum (PAC) para este modelo de aerogerador, sem o paralelismo com a rede elétrica, no caso mais crítico de distorção, considerando desde a situação em vazio até a condição de plena carga, com acréscimo de carga em degraus de $10 \%$.

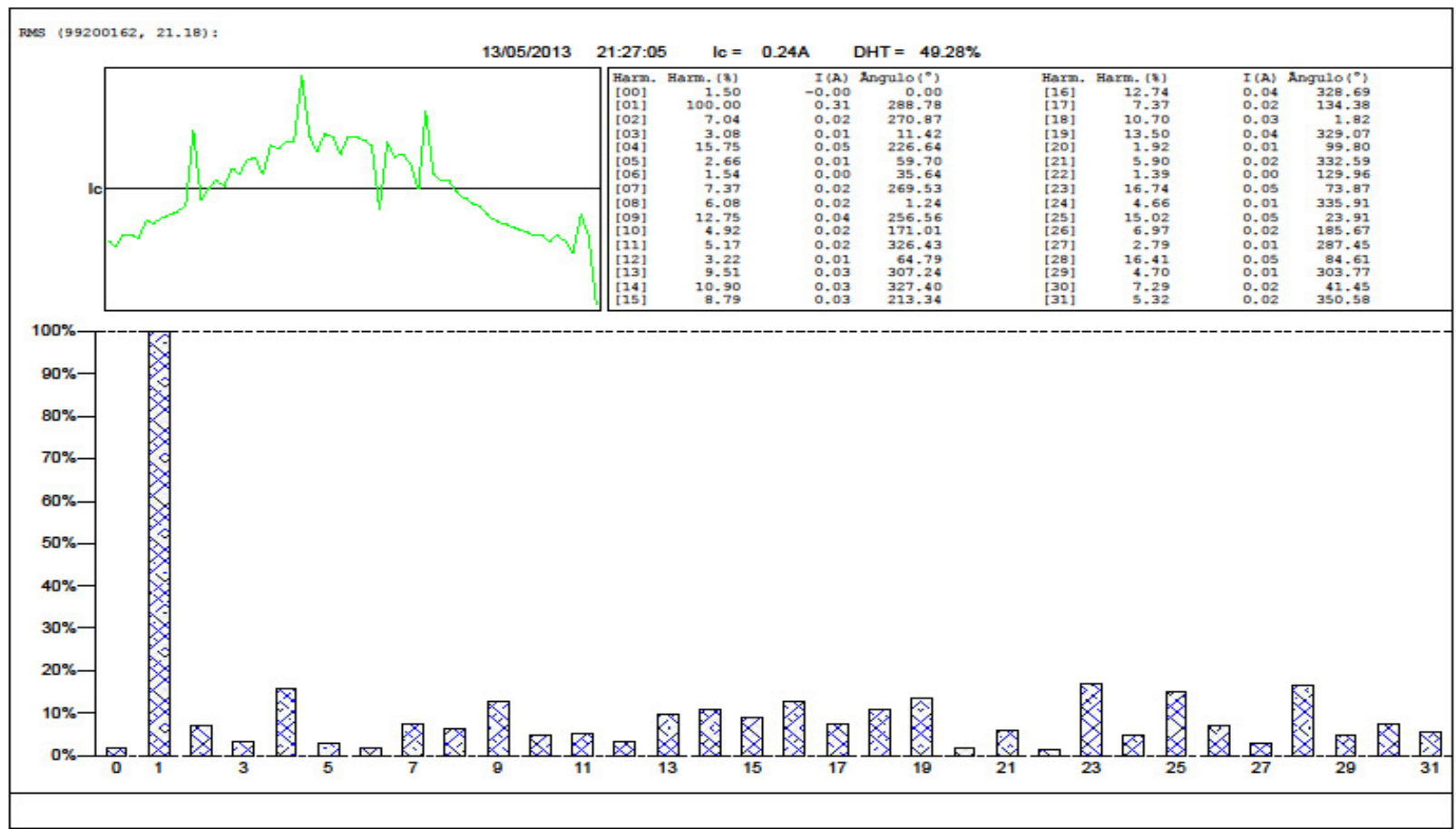

Figura 78 - Espectro de frequência da rede na pior situação do THDI, com GIDA, alimentando carga resistiva sem paralelismo com a rede elétrica 


\subsubsection{Medição do Gerador Síncrono com Rotor Bobinado (GSRB) realizada em um modelo real por um fabricante do mercado brasileiro}

Neste item são apresentados resultados de medição de distorções harmônicas, obtidos junto a um fabricante de aerogeradores nacional, na configuração com Gerador de Indução com Dupla Alimentação (GIDA), conectado à rede da concessionária de energia em um parque eólico. As medições foram realizadas de acordo com a norma IEC-61400-21, na qual se baseia a NBR-IEC-61400-21. A Figura 79 mostra o esquema de ligação desse tipo de aerogerador.

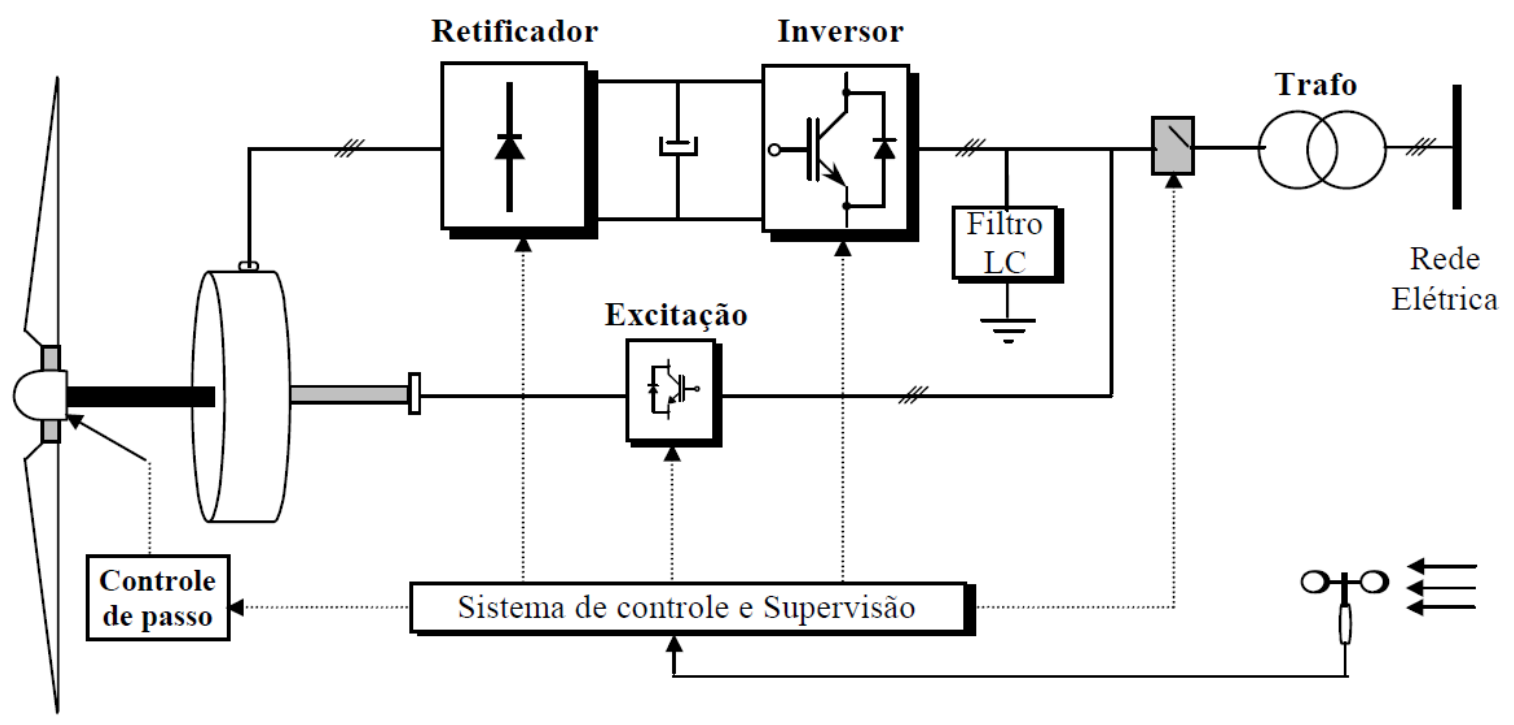

Figura 79 - Gerador Síncrono com Rotor Bobinado (GSRB)

Fonte: Turbinas Eólicas: Modelo, Análise e Controle do Gerador de Indução com Dupla Alimentação 
A Tabela 20 apresenta os dados de distorção harmônica de corrente THDI (\%) de um aerogerador instalado em um parque eólico com Gerador de Indução com Dupla Alimentação (GIDA) de $2.000 \mathrm{~kW}$, com corrente máxima de 2.887 A e tensão de $400 \mathrm{~V}$, conforme esquema de ligação da Figura 62, em condição de carga variando de 0 a 100\%, com degraus de $10 \%$.

\begin{tabular}{|c|c|c|c|c|c|c|c|c|c|c|c|}
\hline $\begin{array}{l}\text { Pbin (\%) } \\
\text { Nr/Ordem }\end{array}$ & $\begin{array}{c}0 \\
\mathrm{Ih} / \operatorname{In}(\%)\end{array}$ & $\begin{array}{c}10 \\
\mathrm{Ih} / \operatorname{In}(\%)\end{array}$ & $\begin{array}{c}20 \\
\operatorname{Ih} / \operatorname{In}(\%)\end{array}$ & $\begin{array}{c}30 \\
\mathrm{Ih} / \operatorname{In}(\%)\end{array}$ & $\begin{array}{c}40 \\
\mathrm{Ih} / \operatorname{In}(\%)\end{array}$ & $\begin{array}{c}50 \\
\mathrm{Ih} / \operatorname{In}(\%)\end{array}$ & $\begin{array}{c}60 \\
\operatorname{Ih} / \operatorname{In}(\%)\end{array}$ & $\begin{array}{c}70 \\
\mathrm{Ih} / \mathrm{In}(\%)\end{array}$ & $\begin{array}{c}80 \\
\mathrm{Ih} / \operatorname{In}(\%)\end{array}$ & $\begin{array}{c}90 \\
\mathrm{Ih} / \operatorname{In}(\%)\end{array}$ & $\begin{array}{c}100 \\
\operatorname{Ih} / \operatorname{In}(\%)\end{array}$ \\
\hline 2 & 0,05 & 0,07 & 0,08 & 0,09 & 0,09 & 0,11 & 0,12 & 0,14 & 0,12 & $\mathrm{O}, 19$ & 0,27 \\
\hline 3 & 0,14 & 0,14 & 0,14 & 0,14 & 0,13 & 0,13 & 0,12 & 0,13 & 0,13 & 0,14 & 0,18 \\
\hline 4 & 0,04 & 0,05 & 0,05 & 0,06 & 0,07 & 0,07 & 0,07 & 0,08 & 0,08 & 0,09 & 0,12 \\
\hline 5 & 0,23 & 0,36 & 0,51 & 0,51 & 0,38 & 0,35 & 0,42 & 0,47 & 0,43 & 0,46 & 0,58 \\
\hline 6 & 0,02 & 0,02 & 0,01 & 0,02 & 0,02 & 0,02 & 0,03 & 0,03 & 0,03 & 0,04 & 0,06 \\
\hline 7 & 0,47 & 0,63 & 0,62 & 0,52 & 0,53 & 0,51 & 0,62 & 0,67 & 0,00 & 0,64 & 0,58 \\
\hline 8 & 0,04 & 0,03 & 0,03 & 0,03 & 0,03 & 0,03 & 0,03 & 0,03 & 0,04 & 0,04 & 0,05 \\
\hline 9 & 0,07 & 0,07 & 0,08 & 0,07 & 0,07 & 0,07 & 0,08 & 0,08 & 0,08 & 0,08 & 0,08 \\
\hline 10 & 0,06 & 0,05 & 0,04 & 0,04 & 0,05 & 0,05 & 0,05 & 0,05 & 0,05 & 0,05 & 0,05 \\
\hline 11 & 0,24 & 0,54 & 053 & 0,43 & 0,41 & 0,36 & 0,26 & 0,31 & 0,28 & 0,28 & 0,38 \\
\hline 12 & 0,02 & 0,03 & 0,03 & 0,02 & 0,03 & 0,03 & 0,03 & 0,04 & 0,04 & 0,04 & 0,05 \\
\hline 13 & 0,25 & 0,45 & 0,40 & 0,23 & 0,25 & 0,26 & 0,21 & 0,27 & 0,21 & 0,27 & 0,33 \\
\hline 14 & 0,05 & 0,05 & 0,04 & 0,04 & 0,04 & 0,04 & 0,05 & 0,05 & 0,05 & 0,05 & 0,06 \\
\hline 15 & 0,05 & 0,06 & 0,06 & 0,05 & 0,05 & 0,06 & 0,07 & 0,07 & 0,07 & 0,07 & 0,09 \\
\hline 16 & 0,08 & 0,07 & 0,05 & 0,05 & 0,05 & 0,04 & 0,04 & 0,04 & 0,04 & 0,04 & 0,05 \\
\hline 17 & 0,39 & 0,35 & 0,28 & 0,19 & 0,14 & 0,14 & 0,16 & 0,14 & 0,16 & 0,15 & 0,23 \\
\hline 18 & 0,02 & 0,02 & 0,02 & 0,02 & 0,02 & 0,02 & 0,02 & 0,03 & 0,03 & 0,03 & 0,04 \\
\hline 19 & 0,11 & 0,16 & 0,14 & 0,00 & 0,07 & 0,05 & 0,05 & 0,07 & 0,05 & 0,06 & 0,13 \\
\hline 20 & 0,03 & 0,02 & 0,02 & 0,02 & 0,02 & 0,02 & 0,02 & 0,02 & 0,03 & 0,03 & 0,03 \\
\hline 21 & 0,02 & 0,02 & 0,02 & 0,02 & 0,02 & 0,02 & 0,02 & 0,02 & 0,02 & 0,03 & 0,03 \\
\hline 22 & 0,02 & 0,02 & 0,02 & 0,02 & 0,02 & 0,02 & 0,02 & 0,02 & 0,02 & 0,02 & 0,03 \\
\hline 23 & 0,11 & 0,12 & 0,11 & 0,07 & 0,06 & 0,06 & 0,06 & 0,07 & 0,07 & 0,08 & 0,09 \\
\hline 24 & 0,01 & 0,01 & 0,01 & 0,01 & 0,01 & 0,01 & 0,02 & 0,02 & 0,02 & 0,02 & 0,03 \\
\hline 25 & 0,07 & 0,05 & 0,04 & 0,03 & 0,04 & 0,02 & 0,02 & 0,03 & 0,03 & 0,04 & 0,05 \\
\hline 26 & 0,01 & 0,01 & 0,01 & 0,01 & 0,01 & 0,01 & 0,02 & 0,02 & 0,02 & 0,02 & 0,03 \\
\hline 27 & 0,05 & 0,04 & 0,14 & 0,05 & 0,07 & 0,04 & 0,08 & 0,09 & 0,05 & 0,14 & 0,16 \\
\hline 28 & 0,01 & 0,01 & 0,01 & 0,01 & 0,01 & 0,01 & 0,02 & 0,02 & 0,02 & 0,02 & 0,02 \\
\hline 29 & 0,04 & 0,06 & 0,05 & 0,03 & 0,03 & 0,03 & 0,03 & 0,03 & 0,03 & 0,03 & 0,05 \\
\hline 30 & 0,01 & 0,01 & 0,01 & 0,01 & 0,01 & 0,01 & 0,01 & 0,01 & 0,01 & 0,02 & 0,02 \\
\hline 31 & 0,03 & 0,03 & 0,05 & 0,04 & 0,03 & 0,02 & 0,02 & 0,02 & 0,02 & 0,02 & 0,03 \\
\hline 32 & 0,01 & 0,01 & 0,01 & 0,01 & 0,01 & 0,01 & 0,01 & 0,01 & 0,01 & 0,01 & 0,02 \\
\hline 33 & 0,01 & 0,01 & 0,01 & 0,01 & 0,01 & 0,01 & 0,01 & 0,01 & 0,01 & 0,01 & 0,02 \\
\hline 34 & 0,01 & 0,01 & 0,01 & 0,01 & 0,01 & 0,01 & 0,01 & 0,01 & 0,01 & 0,01 & 0,01 \\
\hline 35 & 0,02 & 0,03 & 0,03 & 0,02 & 0,02 & 0,02 & 0,02 & 0,02 & 0,02 & 0,02 & 0,02 \\
\hline 36 & 0,00 & 0,00 & 0,00 & 0,00 & 0,00 & 0,01 & 0,01 & 0,01 & 0,01 & 0,01 & 0,01 \\
\hline 37 & 0,01 & 0,02 & 0,03 & 0,02 & 0,02 & 0,02 & 0,01 & 0,01 & 0,01 & 0,01 & 0,02 \\
\hline 38 & 0,00 & 0,00 & 0,00 & 0,01 & 0,00 & 0,01 & 0,01 & 0,01 & 0,01 & 0,01 & 0,01 \\
\hline 39 & 0,00 & 0,00 & 0,00 & 0,00 & 0,00 & 0,01 & 0,01 & 0,01 & 0,01 & 0,01 & 0,01 \\
\hline 40 & 0,00 & 0,00 & 0,00 & 0,00 & 0,00 & 0,01 & 0,01 & 0,01 & 0,01 & 0,01 & 0,01 \\
\hline 41 & 0,01 & 0,01 & 0,02 & 0,01 & 0,01 & 0,01 & 0,01 & 0,01 & 0,01 & 0,01 & 0,02 \\
\hline 42 & 0,00 & 0,00 & 0,00 & 0,00 & 0,00 & 0,00 & 0,01 & 0,01 & 0,01 & 0,01 & 0,01 \\
\hline 43 & 0,01 & 0,01 & 0,02 & 0,02 & 0,01 & 0,01 & 0,01 & 0,01 & 0,01 & 0,01 & 0,01 \\
\hline 44 & 0,00 & 0,00 & 0,00 & 0,00 & 0,00 & 0,01 & 0,01 & 0,01 & 0,01 & 0,01 & 0,01 \\
\hline 45 & 0,00 & 0,00 & 0,00 & 0,00 & 0,00 & 0,01 & 0,01 & 0,01 & 0,01 & 0,01 & 0,01 \\
\hline 46 & 0,00 & 0,00 & 0,00 & 0,00 & 0,00 & 0,01 & 0,01 & 0,01 & 0,01 & 0,01 & 0,01 \\
\hline 47 & 0,01 & 0,01 & 0,01 & 0,01 & 0,01 & 0,01 & 0,01 & 0,01 & 0,01 & 0,01 & 0,01 \\
\hline 48 & 0,00 & 0,00 & 0,00 & 0,00 & 0,00 & 0,01 & 0,01 & 0,01 & 0,01 & 0,01 & 0,01 \\
\hline 49 & 0,00 & 0,01 & 0,01 & 0,01 & 0,01 & 0,01 & 0,01 & 0,01 & 0,01 & 0,01 & 0,01 \\
\hline 50 & 0,00 & 0,00 & 0,00 & 0,00 & 0,01 & 0,01 & 0,01 & 0,01 & 0,01 & 0,01 & 0,01 \\
\hline THD (\%) & 0,79 & 1,11 & 1,12 & 0,93 & 0,86 & 0,81 & 0,88 & 0,97 & 0,88 & 0,96 & 1,09 \\
\hline
\end{tabular}

Tabela 20 - Tabela de medição das distorções harmônicas de um modelo de aerogerador real de $2.000 \mathbf{~ k W}$ de potência e com sistema gerador tipo GSRB

Fonte: Dados fornecidos por um fabricante de aerogeradores nacional 
Na Tabela 21 são apresentados os resultados de medição da distorção harmônica de corrente THDI (\%) de um aerogerador instalado em um parque eólico com Gerador de Indução com Dupla Alimentação (GIDA) de 2.300 kW, com corrente máxima de 3.320 A e tensão de 400 V, conforme esquema de ligação da Figura 62, em condição de carga variando de 0 a 100\%, com degraus de $10 \%$.

\begin{tabular}{|c|c|c|c|c|c|c|c|c|c|c|c|}
\hline $\begin{array}{l}\text { PtIn (\%) } \\
\text { Nr./Order }\end{array}$ & $\begin{array}{c}0 \\
\mathrm{Ih} / \ln (\%)\end{array}$ & $\begin{array}{c}10 \\
\mathrm{Ih} / \ln (\%)\end{array}$ & $\begin{array}{c}20 \\
\operatorname{Ih} / \ln (\%)\end{array}$ & $\begin{array}{c}30 \\
\mathrm{Ih} / \ln (\%)\end{array}$ & $\begin{array}{c}40 \\
\mathrm{Ih} / \ln (\%)\end{array}$ & $\begin{array}{c}50 \\
\mathrm{Ih} / \ln (\%)\end{array}$ & $\begin{array}{c}60 \\
\operatorname{Ih} / \ln (\%)\end{array}$ & $\begin{array}{c}70 \\
\mathrm{Ih} / \ln (\%)\end{array}$ & $\begin{array}{c}80 \\
\operatorname{Ih} / \ln (\%)\end{array}$ & $\begin{array}{c}90 \\
\mathrm{Ih} / \ln (\%)\end{array}$ & $\begin{array}{c}100 \\
\operatorname{Ih} / \ln (\%)\end{array}$ \\
\hline $\begin{array}{l}2 \\
3\end{array}$ & $\begin{array}{l}0.02 \\
0.05\end{array}$ & $\begin{array}{l}0.03 \\
0.06\end{array}$ & $\begin{array}{l}0.04 \\
0.07\end{array}$ & $\begin{array}{l}0.04 \\
0.08\end{array}$ & $\begin{array}{l}0.05 \\
0.08\end{array}$ & $\begin{array}{l}0.06 \\
0.09\end{array}$ & $\begin{array}{l}0.07 \\
0.08\end{array}$ & $\begin{array}{l}0.00 \\
0.00\end{array}$ & $\begin{array}{l}0.10 \\
0.08\end{array}$ & 0.11 & 0.12 \\
\hline $\begin{array}{l}5 \\
4\end{array}$ & 0,03 & $\begin{array}{l}0,00 \\
0,04\end{array}$ & 0,05 & $\begin{array}{l}0,00 \\
0,06\end{array}$ & $\begin{array}{l}0,00 \\
0,07\end{array}$ & $\begin{array}{l}0,09 \\
0,08\end{array}$ & $\begin{array}{l}0,00 \\
0,10\end{array}$ & $\begin{array}{l}0,00 \\
0,10\end{array}$ & $\begin{array}{l}0,00 \\
0,09\end{array}$ & $\begin{array}{l}0,09 \\
0,09\end{array}$ & $\begin{array}{l}0,09 \\
0,09\end{array}$ \\
\hline 5 & 0,16 & 0,37 & 0,45 & 0,47 & 0,45 & 0,41 & 0,41 & 0,41 & 0,39 & 0,38 & 0,33 \\
\hline 6 & 0,02 & 0,03 & 0,03 & 0,03 & 0,03 & 0,03 & 0,04 & 0,04 & 0,05 & 0,06 & 0,06 \\
\hline 7 & 0,09 & 0,07 & 0,08 & 0,07 & 0,10 & 0,09 & 0,13 & 0,15 & 0,15 & 0,14 & 0,15 \\
\hline 8 & 0,02 & 0,03 & 0,04 & 0,04 & 0,04 & 0,05 & 0,05 & 0,05 & 0,05 & 0,06 & 0,06 \\
\hline 9 & 0,03 & 0,02 & 0,03 & 0,03 & 0,04 & 0,04 & 0,05 & 0,06 & 0,07 & 0,09 & 0,10 \\
\hline 10 & 0,02 & 0,03 & 0,04 & 0,03 & 0,04 & 0,04 & 0,05 & 0,05 & 0,07 & 0,08 & 0,08 \\
\hline 11 & 0,11 & 0,13 & 0,22 & 0,25 & 0,23 & 0,23 & 0,23 & 0,28 & 0,30 & 0,35 & 0,34 \\
\hline 12 & 0,02 & 0,02 & 0,02 & 0,03 & 0,03 & 0,04 & 0,05 & 0,06 & 0,08 & 0,10 & 0,11 \\
\hline 13 & 0,08 & 0,14 & 0,18 & 0,18 & 0,20 & 0,21 & 0,19 & 0,20 & 0,21 & 0,27 & 0,33 \\
\hline 14 & 0,02 & 0,03 & 0,04 & 0,04 & 0,04 & 0,05 & 0,06 & 0,00 & 0,11 & 0,14 & 0,14 \\
\hline 15 & 0,04 & 0,04 & 0,04 & 0,04 & 0,05 & 0,06 & 0,07 & 0,00 & 0,12 & 0,16 & 0,17 \\
\hline 16 & 0,03 & 0,03 & 0,03 & 0,03 & 0,04 & 0,04 & 0,04 & 0,06 & 0,00 & 0,11 & 0,12 \\
\hline 17 & 0,14 & 0,10 & 0,09 & 0,10 & 0,11 & 0,11 & 0,13 & 0,14 & 0,18 & 0,22 & 0,20 \\
\hline 18 & 0,02 & 0,02 & 0,02 & 0,02 & 0,02 & 0,03 & 0,03 & 0,04 & 0,06 & 0,08 & 0,09 \\
\hline 19 & 0,05 & 0,03 & 0,03 & 0,03 & 0,03 & 0,05 & 0,06 & 0,06 & 0,08 & 0,10 & 0,11 \\
\hline 20 & 0,01 & 0,01 & 0,01 & 0,01 & 0,02 & 0,02 & 0,03 & 0,03 & 0,05 & 0,06 & 0,07 \\
\hline 21 & 0,02 & 0,02 & 0,01 & 0,02 & 0,02 & 0,02 & 0,03 & 0,03 & 0,05 & 0,06 & 0,07 \\
\hline 22 & 0,01 & 0,01 & 0,01 & 0,01 & 0,01 & 0,02 & 0,02 & 0,03 & 0,04 & 0,05 & 0,06 \\
\hline 23 & 0,06 & 0,04 & 0,05 & 0,05 & 0,05 & 0,06 & 0,05 & 0,07 & 0,10 & 0,12 & 0,12 \\
\hline 24 & 0,01 & 0,01 & 0,01 & 0,01 & 0,01 & 0,02 & 0,02 & 0,03 & 0,04 & 0,04 & 0,05 \\
\hline 25 & 0,02 & 0,02 & 0,02 & 0,02 & 0,02 & 0,03 & 0,03 & 0,04 & 0,05 & 0,07 & 0,08 \\
\hline 26 & 0,01 & 0,01 & 0,01 & 0,01 & 0,01 & 0,01 & 0,02 & 0,02 & 0,03 & 0,04 & 0,04 \\
\hline 27 & 0,01 & 0,01 & 0,01 & 0,01 & 0,01 & 0,02 & 0,02 & 0,02 & 0,03 & 0,04 & 0,04 \\
\hline 28 & 0,01 & 0,01 & 0,01 & 0,01 & 0,01 & 0,01 & 0,02 & 0,02 & 0,03 & 0,03 & 0,04 \\
\hline 29 & 0,02 & 0,02 & 0,03 & 0,02 & 0,02 & 0,03 & 0,02 & 0,03 & 0,05 & 0,06 & 0,07 \\
\hline 30 & 0,01 & 0,01 & 0,01 & 0,01 & 0,01 & 0,01 & 0,01 & 0,01 & 0,02 & 0,03 & 0,03 \\
\hline 31 & 0,01 & 0,02 & 0,02 & 0,01 & 0,01 & 0,01 & 0,01 & 0,02 & 0,02 & 0,02 & 0,03 \\
\hline 32 & 0,00 & 0,00 & 0,00 & 0,01 & 0,01 & 0,01 & 0,01 & 0,01 & 0,02 & 0,02 & 0,02 \\
\hline 33 & 0,00 & 0,00 & 0,01 & 0,01 & 0,01 & 0,01 & 0,01 & 0,01 & 0,02 & 0,02 & 0,03 \\
\hline 34 & 0,00 & 0,00 & 0,00 & 0,00 & 0,01 & 0,01 & 0,01 & 0,01 & 0,01 & 0,02 & 0,02 \\
\hline 35 & 0,01 & 0,01 & 0,01 & 0,01 & 0,01 & 0,01 & 0,01 & 0,02 & 0,02 & 0,03 & 0,04 \\
\hline 36 & 0,00 & 0,00 & 0,00 & 0,00 & 0,01 & 0,01 & 0,01 & 0,01 & 0,01 & 0,02 & 0,02 \\
\hline 37 & 0,01 & 0,01 & 0,01 & 0,01 & 0,01 & 0,01 & 0,01 & 0,01 & 0,02 & 0,02 & 0,03 \\
\hline 38 & 0,00 & 0,00 & 0,00 & 0,00 & 0,01 & 0,01 & 0,01 & 0,01 & 0,01 & 0,02 & 0,02 \\
\hline 39 & 0,00 & 0,01 & 0,01 & 0,01 & 0,02 & 0,02 & 0,03 & 0,03 & 0,04 & 0,05 & 0,06 \\
\hline 40 & 0,00 & 0,00 & 0,00 & 0,00 & 0,01 & 0,01 & 0,01 & 0,01 & 0,01 & 0,02 & 0,02 \\
\hline 41 & 0,00 & 0,01 & 0,01 & 0,01 & 0,02 & 0,02 & 0,03 & 0,03 & 0,04 & 0,04 & 0,05 \\
\hline 42 & 0,00 & 0,00 & 0,00 & 0,00 & 0,00 & 0,01 & 0,01 & 0,01 & 0,01 & 0,01 & 0,02 \\
\hline 43 & 0,01 & 0,01 & 0,01 & 0,01 & 0,01 & 0,01 & 0,01 & 0,01 & 0,01 & 0,02 & 0,02 \\
\hline 44 & 0,00 & 0,00 & 0,00 & 0,00 & 0,00 & 0,00 & 0,01 & 0,01 & 0,01 & 0,01 & 0,01 \\
\hline 45 & 0,00 & 0,00 & 0,00 & 0,00 & 0,00 & 0,01 & 0.01 & 0,01 & 0,01 & 0,01 & 0,01 \\
\hline 46 & 0,00 & 0,00 & 0,00 & 0,00 & 0,00 & 0,00 & 0,01 & 0,01 & 0,01 & 0,01 & 0,01 \\
\hline 47 & 0,00 & 0,01 & 0,01 & 0,01 & 0,01 & 0,01 & 0,01 & 0,01 & 0,02 & 0,02 & 0,02 \\
\hline 48 & 0,00 & 0,00 & 0,00 & 0,00 & 0,00 & 0,00 & 0,01 & 0,01 & 0,01 & 0,01 & 0,01 \\
\hline 49 & 0,00 & 0,01 & 0,01 & 0,01 & 0,01 & 0,01 & 0,01 & 0,01 & 0,02 & 0,02 & 0,03 \\
\hline 50 & 0,00 & 0,00 & 0,00 & 0,00 & 0,00 & 0,00 & 0,01 & 0,01 & 0,01 & 0,01 & 0,01 \\
\hline THC(\%) & 0,29 & 0,45 & 0,56 & 0,58 & 0,58 & 0,57 & 0,58 & 0,62 & 0,66 & 0,75 & 0,74 \\
\hline
\end{tabular}

Tabela 21 - Tabela de medição das distorções harmônicas de um modelo de aerogerador real de $2.300 \mathrm{~kW}$ de potência e com sistema gerador tipo GSRB.

Fonte: Dados fornecidos por um fabricante de aerogeradores nacional. 


\subsubsection{Fotos da Montagem dos Modelos de Aerogeradores}

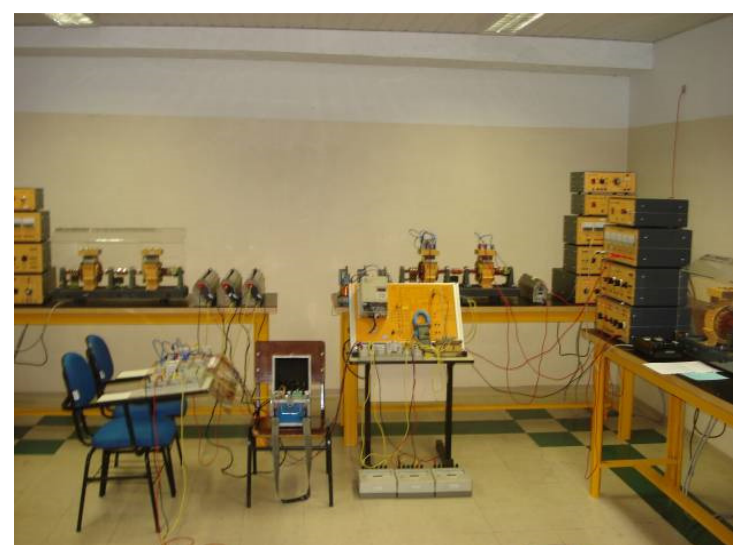

Figura 80 - Montagem do modelo para simulação dos aerogeradores com analisador de energia acoplado

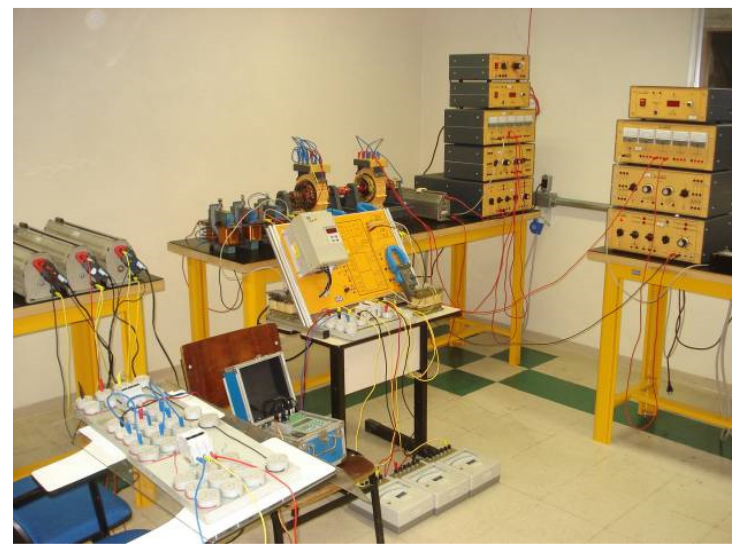

Figura 82 - Vista do modelo utilizado para montagem do aerogerador duplamente excitado (GIDA)

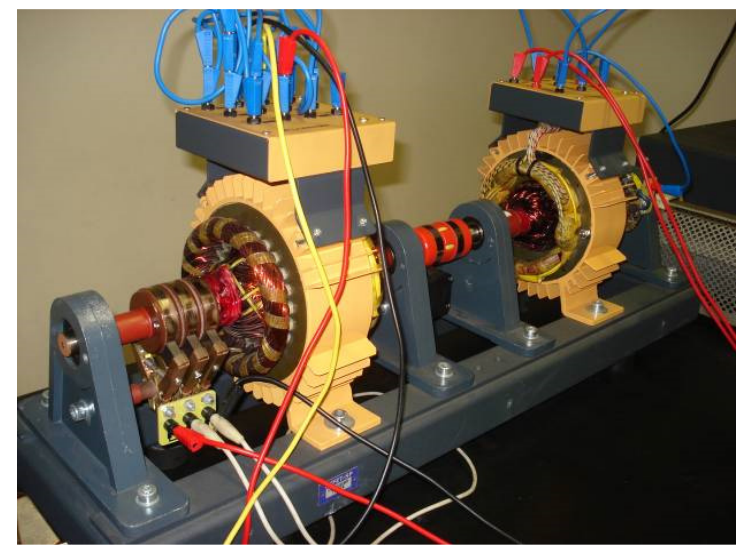

Figura 84 - Detalhe do grupo gerador de indução com motor CC, usado como turbina

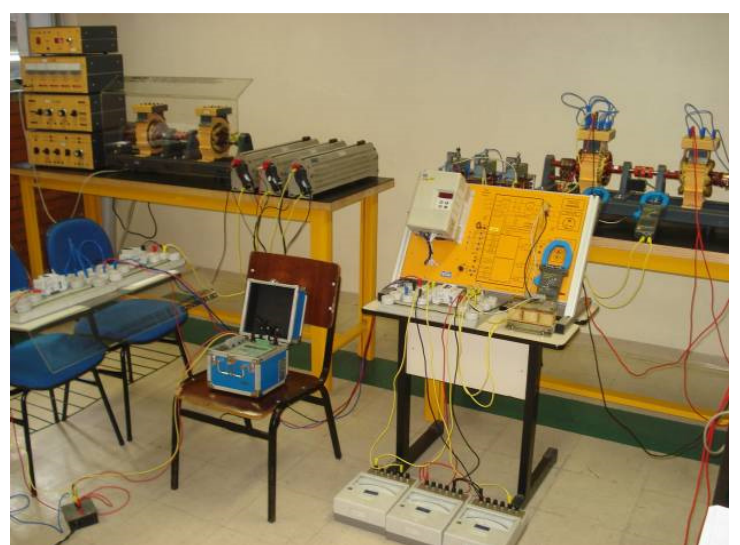

Figura 81 - Detalhe do inversor de frequência utilizado para regulação da frequência dos modelos

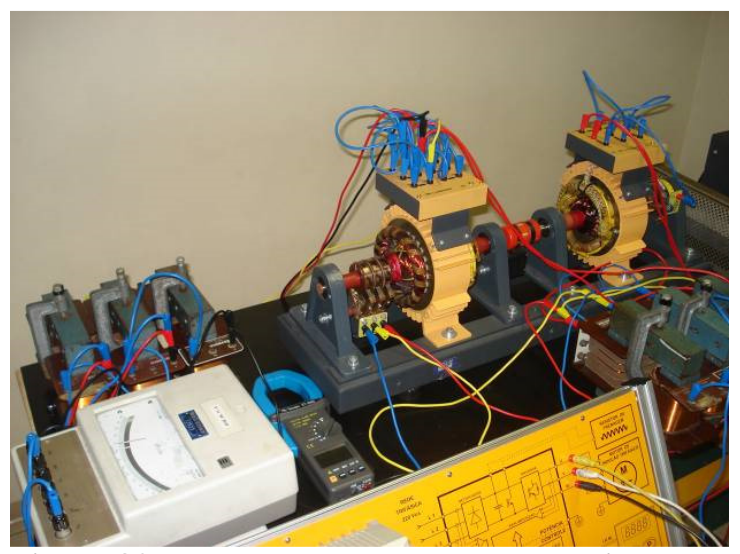

Figura 83 - Detalhe da montagem do conjunto gerador de indução utilizado como gerador síncrono (GSRB)

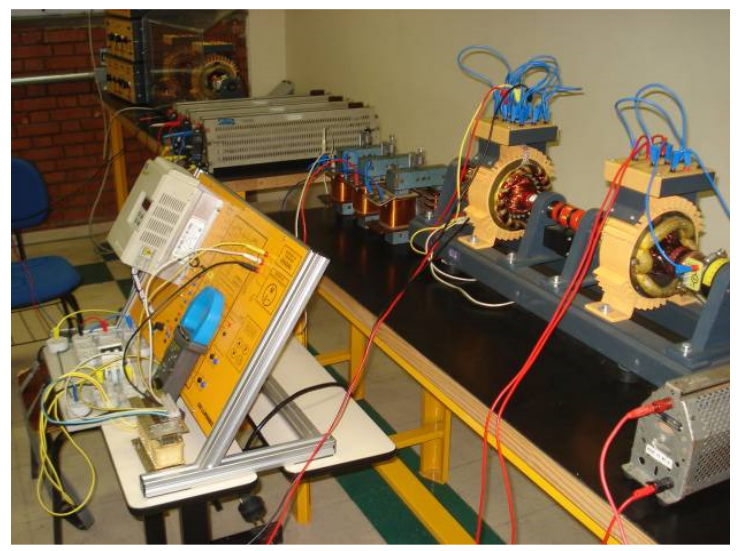

Figura 85 - Ligação do modelo GIGE nas cargas resistivas de simulação (reostatos) 


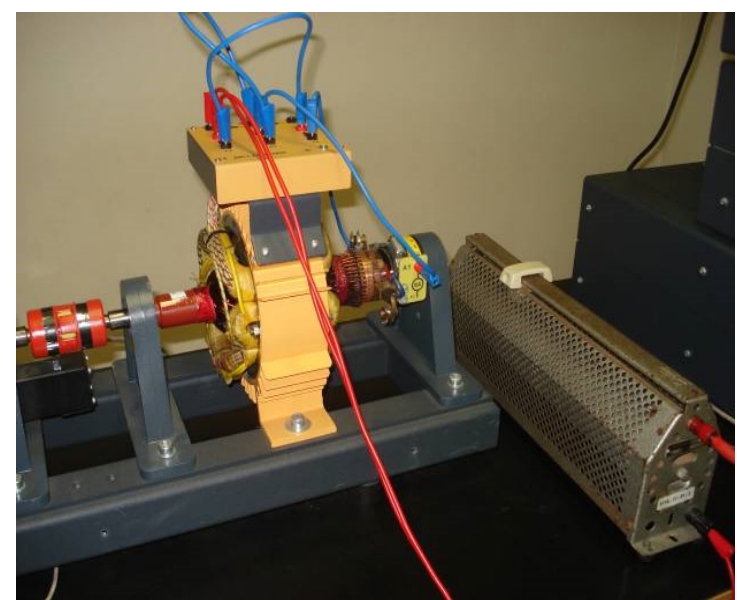

Figura 86 - Detalhe do motor CC utilizado como turbina E o reostato de campo para variação de velocidade

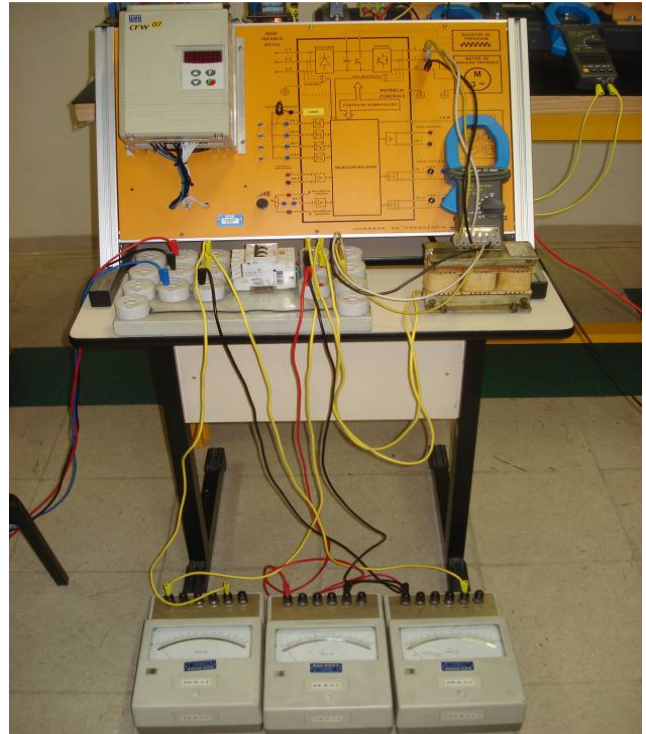

Figura 87 - Detalhe dos voltímetros ligados às fontes para o sincronismo do sistema (rede $x$ gerador)

\subsection{Análise}

Neste item faz-se a análise dos dados obtidos, comparando-se os tipos de aerogeradores analisados nas diversas situações de carga e em situação de alimentação individualizada da carga, bem como as duas medições realizadas por um fabricante em um determinado tipo de aerogerador amplamente utilizado no mercado, em diversas situações de carga, disponibilizadas para o presente estudo. Faz-se também uma estimativa do impacto, em termos de injeção de harmônicas, que um parque eólico produziria no ponto de acoplamento comum com a rede elétrica (PAC).

Convém ressaltar a dificuldade encontrada nas tentativas de se realizar medições em aerogeradores reais. As principais razões para tal dificuldade se devem em parte à desconfiança dos produtores, que muitas vezes acreditam que os resultados de um trabalho desse tipo podem restringir o funcionamento de seus investimentos na área de geração ou obrigá-los a investir pesadamente em dispositivos para atenuação desse tipo de distúrbio de energia nas instalações, e em parte pelas dificuldades do próprio ONS em liberar os parques geradores para realização desse tipo de estudo (variação de carga), segundo informações dos próprios responsáveis pelos parques eólicos. 
A Tabela 22 apresenta, de forma resumida, os principais dados obtidos experimentalmente, que possibilitam não só a comparação entre os resultados das medições em laboratório, com os modelos em diversas situações de carga, mas também destes com os dados de medições efetuadas diretamente em um parque eólico por um fabricante de aerogeradores.

\begin{tabular}{|c|c|c|c|c|c|c|c|c|c|c|}
\hline \multirow{3}{*}{$\begin{array}{c}\text { Situação de } \\
\text { Carga }(\%)\end{array}$} & \multicolumn{10}{|c|}{ Modelo de Aerogerador para Medição } \\
\hline & \multicolumn{2}{|c|}{ Rede } & \multicolumn{2}{|c|}{ GIGE } & \multicolumn{2}{|c|}{ GIDA } & \multicolumn{2}{|c|}{ GSRB } & \multicolumn{2}{|c|}{ GSRD-Fabricante } \\
\hline & $\operatorname{THDU}(\%)$ & THDI $(\%)$ & $\operatorname{THDU}(\%)$ & THDI $(\%)$ & THDU(\%) & THDI $(\%)$ & THDU(\%) & THDI $(\%)$ & $\operatorname{THDU}(\%)$ & THDI $(\%)$ \\
\hline $\begin{array}{c}\text { Geração } \\
\text { Individualizada }\end{array}$ & $* * *$ & $* * *$ & $* * *$ & $* * *$ & 119,94 & 41,13 & 11,58 & 12,00 & $* * *$ & $* * *$ \\
\hline 0 & 0,00 & 0,00 & 2,10 & 2,70 & 2,40 & 2,40 & 2,30 & 2,20 & 0,79 & 0,29 \\
\hline 10 & 3,10 & 3,10 & 2,40 & 2,90 & 2,40 & 2,50 & 2,20 & 2,40 & 1,11 & 0,45 \\
\hline 20 & 3,00 & 2,80 & 2,60 & 3,20 & 2,60 & 2,80 & 2,30 & 2,10 & 1,12 & 0,56 \\
\hline 30 & 2,70 & 2,70 & 2,50 & 3,20 & 2,70 & 2,50 & 2,30 & 1,80 & 0,93 & 0,58 \\
\hline 40 & 2,30 & 2,30 & 2,60 & 2,90 & 2,60 & 2,40 & 2,20 & 1,80 & 0,86 & 0,58 \\
\hline 50 & 2,50 & 2,40 & 2,50 & 2,60 & 2,80 & 2,90 & 2,30 & 1,60 & 0,81 & 0,57 \\
\hline 60 & 2,50 & 2,20 & 2,60 & 2,50 & 2,60 & 2,80 & 2,40 & 1,50 & 0,88 & 0,58 \\
\hline 70 & 1,90 & 1,90 & 2,50 & 2,50 & 2,90 & 2,50 & 2,30 & 1,30 & 0,97 & 0,62 \\
\hline 80 & 1,70 & 1,90 & 2,60 & 2,10 & 2,70 & 2,40 & 2,40 & 1,30 & 0,86 & 0,66 \\
\hline 90 & 1,70 & 1,80 & 2,50 & 1,90 & 2,60 & 2,20 & 2,40 & 1,20 & 0,96 & 0,75 \\
\hline 100 & 1,60 & 1,70 & 2,50 & 1,80 & 2,70 & 2,10 & 2,40 & 1,20 & 1,09 & 0,74 \\
\hline $\begin{array}{l}\text { THDMédio c/ } \\
\text { carga } \\
(10 \sim 100 \%)\end{array}$ & 2,30 & 2,28 & 2,53 & 2,56 & 2,66 & 2,51 & 2,32 & 1,62 & 0,96 & 0,61 \\
\hline
\end{tabular}

Tabela 22 - Tabela comparativa de valores de THD entre os modelos utilizados no experimento, em diversas situações de carga e dois aerogeradores reais instalados em parques eólicos

Nota-se, pelos resultados obtidos, que os níveis de harmônicas geradas pelos três modelos ensaiados, quando ligados em condição de paralelismo com a rede, ficaram próximos das distorções totais desta e acima dos valores medidos pelo fabricante de um aerogerador real. Entretanto, as medições dos modelos com Gerador Síncrono com Rotor Bobinado (GSRB) e Gerador de Indução Duplamente Alimentado (GIDA), quando alimentando diretamente a carga, sem o paralelismo com a rede, apresentaram valores significativos de distorção harmônica total, tanto de tensão (THDU) como de corrente (THDI). Tais resultados apontam a necessidade de desenvolvimento de estudos mais aprofundados sobre o tema em virtude do crescimento desse tipo de geração e da necessidade de se buscar as soluções mais adequadas de modo que não haja comprometimento da qualidade de energia do sistema elétrico. Já o modelo com Gerador de Indução com Gaiola de Esquilo (GIGE) não pode ser ensaiado dessa forma, pois não gera energia se não estiver em condição de paralelismo com a rede elétrica.

Com base no espectro de frequência referente aos dois experimentos supramencionados, isto é, sem o paralelismo com a rede, verificou-se na configuração GSRB uma predominância 
quase que exclusiva da harmônica de $3^{\mathrm{a}}$ ordem. Isso acarreta um desequilíbrio entre as correntes de fase (aumento da corrente residual) em função de ser esta uma harmônica de sequência nula, o que resulta no aumento da corrente do neutro em sistemas de distribuição. Os níveis de distorção harmônica total (tanto a THDU quanto a THDI) foram de aproximadamente $12 \%$, tendo ultrapassado os limites estabelecidos pela norma. Por sua vez, a configuração GIDA apresentou distorções harmônicas ainda mais significativas, da ordem de $120 \%$ para a THDU e $41 \%$ para a THDI. Tais resultados reforçam a importância do assunto, haja vista a previsão de acentuado crescimento dessa modalidade de geração elétrica no Brasil para os próximos anos.

Quanto ao espectro de frequência, embora os níveis das distorções sejam diferentes para corrente e para tensão, verifica-se nos dois casos uma distribuição quase que uniforme das distorções harmônicas de todas as ordens, com ligeira predominância das harmônicas de $3^{\mathrm{a}}$ ordem (harmônicas de sequência negativa), o que pode produzir o mesmo efeito da configuração GSRB, porém em nível mais acentuado.

Se os dados obtidos neste trabalho fossem extrapolados para um parque eólico real, como por exemplo o Parque Eólico de Osório, localizado no Rio Grande do Sul, que possui 75 unidades aerogeradoras de $2.000 \mathrm{~kW}$, modelo GSRB, totalizando $150.000 \mathrm{~kW}$ de potência instalada, a corrente harmônica no PAC poderia ser estimada conforme a equação abaixo (NBRIEC-61400-21):

$$
\operatorname{Ih} \sum=\sum_{i=1}^{N w t}\left(\frac{I h, i}{N i}\right)
$$

onde:

- $\mathrm{N}_{\mathrm{wt}}$ é o número de aerogeradores conectados ao mesmo PCC;

- Ih $\Sigma$ é a componente da h-ésima ordem da distorção harmônica de corrente no PCC;

- Ni é a relação de transformação do transformador da i-ésimo aerogerador;

- Ihi é a componente de h-ésima ordem da distorção harmônica de corrente do aerogerador de i-ésima ordem; 
Levando-se em conta as distorções obtidas pelo próprio fabricante no modelo de $2.000 \mathrm{~kW}$ e com o uso de transformadores de relações $400 \mathrm{~V}-34.500 \mathrm{~V}$ e $34.500 \mathrm{~V}-230.000 \mathrm{~V}$, o que corresponde a uma relação de tensão $\mathrm{N}=575$, obtém-se:

$$
\operatorname{Ih} \Sigma=0,1427 \%
$$

Esse valor é bem inferior aos valores de referência estabelecidos pela NBR-IEC-61400-21. Entretanto, caso sejam considerados os valores obtidos na simulação efetuada em laboratório quando da ligação do GSRB sem paralelismo com a rede (valor puro da distorção harmônica gerada), dentro das mesmas condições do parque eólico, obtém-se a seguinte condição de distorção harmônica total do parque:

$$
\operatorname{Ih} \Sigma=1,5144 \% \text {. }
$$

Tal valor é bem superior ao valor obtido na condição anterior, embora ainda se encontre abaixo dos valores de referência estabelecidos pela NBR-IEC-61400-21.

Evidentemente, quanto maior o número de aerogeradores ligados ao mesmo PAC, maior é a sua contribuição ao sistema em termos de distorções harmônicas. Embora tais distorções se atenuem quando da conexão dos aerogeradores à rede elétrica, é possível que, no caso de grande concentração de parques eólicos em uma dada região, o nível de distorções geradas pode eventualmente ultrapassar o limite estabelecido caso não sejam tomadas as medidas necessárias para solução do problema. 


\section{Conclusões}

Este trabalho teve por objetivo analisar as interferências e os níveis de distorção harmônica produzidos pelos principais tipos de aerogeradores utilizados no mercado de geração de energia eólica em função dos diferentes tipos de controle de tensão e frequência.

Os ensaios realizados em laboratório consistiram na avaliação dos níveis de distorção harmônica total de tensão e de corrente dos três modelos mais utilizados para geração eólica nos segmentos dos autoprodutores, produtores independentes e concessionárias de energia. Por meio de simulações em laboratório foram analisados o gerador síncrono com rotor bobinado (GSRB), o gerador de indução duplamente alimentado (GIDA) e o gerador de indução com gaiola de esquilo (GIGE). Após análise das principais metodologias de teste, foi adotado o procedimento preconizado pela ABNT-NBR-IEC-61400-21. Os resultados mostraram que, dependendo da situação, as distorções harmônicas e a interferência eletromagnética causadas por esse tipo de geração podem ser elevadas.

Quando ligados em condição de paralelismo com a rede elétrica, os três modelos ensaiados apresentaram níveis de geração de harmônicas semelhantes àqueles provenientes exclusivamente da rede de alimentação (isto é, sem a conexão dos modelos), porém acima dos valores medidos em dois aerogeradores instalados em um parque eólico.

As medições dos modelos GSRB e GIDA, quando alimentando diretamente a carga, sem o paralelismo com a rede, apresentaram valores significativos de distorção harmônica total, tanto de tensão (THDU) como de corrente (THDI). Com relação à configuração GSRB, verificou-se uma grande predominância da harmônica de $3^{\mathrm{a}}$ ordem, o que implica em aumento da corrente do neutro em sistemas de distribuição. Os níveis de distorção harmônica total tanto de tensão como de corrente foram de aproximadamente $12 \%$, tendo ultrapassado os limites estabelecidos pela ABNT-NBR-IEC-61400-21. Por sua vez, a configuração GIDA apresentou distorções harmônicas totais ainda mais significativas, da ordem de $120 \%$ para a tensão e de $41 \%$ para a corrente. 
A geração de energia por meio de fontes renováveis é importante sob vários aspectos. Além de questões relativas à preservação da natureza, as políticas de incentivo à produção de energia eólica são de muita importância para a redução dos riscos da falta de energia no mundo todo. Porém, é importante salientar que os problemas da geração harmônica decorrente dos sistemas de controle de frequência dos aerogeradores não devem ser ignorados. A contribuição dos geradores eólicos ao sistema, em termos de distorções harmônicas, tende a aumentar à medida que aumenta o número de aerogeradores ligados ao mesmo PAC. Embora a conexão à rede elétrica tenda a atenuar essas distorções, é possível que, no caso de grande concentração de parques eólicos em uma dada região, o nível de distorções geradas eventualmente ultrapasse o limite estabelecido caso não sejam tomadas medidas necessárias para solução do problema.

Os resultados obtidos ao longo deste trabalho apontam a necessidade de desenvolvimento de estudos mais aprofundados sobre o tema, haja vista o acentuado crescimento previsto para a geração eólica no Brasil nos próximos anos e a importância de se buscar as soluções mais adequadas para que não haja comprometimento da qualidade de energia do sistema elétrico.

Dentre as dificuldades encontradas para a realização de medições em aerogeradores reais podem ser destacadas aquelas associadas à liberação dos parques geradores, por parte do ONS, e também a desconfiança dos produtores, que muitas vezes acreditam que os resultados de um estudo desse tipo podem restringir o funcionamento de seus investimentos na área de geração ou obrigá-los a investir pesadamente em dispositivos para atenuação desse tipo de distúrbio. Apesar disso, a realização de medições em aerogeradores instalados em parques eólicos já em operação no sistema interligado nacional (SIN) seria de suma importância para uma análise mais completa do impacto das distorções harmônicas produzidas pela geração eólica. 


\section{Referências Bibliográficas}

ALVES, B. M. Sistema Especialista para Comando, Controle, Proteção e Supervisão de Usinas e Suas Subestações. Dissertação de Mestrado pela Universidade Federal de Uberlândia. MG. 2005.

ARRUDA, E. F. Estimação de Estados de Distorções Harmônicas em Sistemas Elétricos de Potência Utilizando Estratégias Evolutivas. Tese de Doutorado da Escola Politécnica da USP. São Paulo, 2008.

ASSOCIAÇÃO BRASILEIRA DE NORMAS TÉCNICAS. ABNT-NBR-IEC-61400-21 - Turbinas Eólicas - Parte 21: Medição e Avaliação das Características da Energia de Aerogeradores Conectados à Rede. São Paulo. 2010.

BRASIL. Agência Nacional de Energia Elétrica - ANEEL. Resolução 024, de 27 de janeiro de 2000. Estabelece as disposições relativas à Continuidade da Distribuição de energia elétrica às unidades consumidoras. Disponível em http://www.aneel.gov.br/ Acesso em 05 nov. 2009.

BRASIL. Agência Nacional de Energia Elétrica - ANEEL. Resolução 456, de 29 de novembro de 2000. Estabelecem, de forma atualizada e consolidada, as Condições Gerais de Fornecimento de Energia Elétrica. Disponível em http://www.aneel.gov.br/ Acesso em 05 nov. 2009.

BRASIL. Agência Nacional de Energia Elétrica - ANEEL. Resolução 414, de 09 de setembro de 2010. Estabelecem, de forma atualizada e consolidada, as Condições Gerais de Fornecimento de Energia Elétrica. Disponível em http://www.aneel.gov.br/ Acesso em 05 nov. 2009. 
BRASIL. Agência Nacional de Energia Elétrica - ANEEL. Resolução 505, de 26 de novembro de 2001. Estabelecem de forma atualizada e consolidada, as disposições relativas à conformidade dos níveis de tensão de energia elétrica em regime permanente. Disponível em http://www.aneel.gov.br/ Acesso em 05 nov. 2009.

BRASIL. Agência Nacional de Energia Elétrica - ANEEL. Resolução 345, de 16 de dezembro de 2008. Aprova os Procedimentos de Distribuição de Energia Elétrica no Sistema Elétrico Nacional - PRODIST, e dá outras providências. Disponível em http://www.aneel.gov.br/ Acesso em 05 nov. 2009.

BRASIL. Agência Nacional de Energia Elétrica - ANEEL. Resolução 346, de 16 de dezembro de 2008. Autoriza o Operador Nacional do Sistema Elétrico - ONS a utilizar as Curvas de Aversão a Risco das Regiões Sudeste/Centro-Oeste, Sul e Nordeste, atualizadas para o biênio compreendido de $1^{\circ}$ de janeiro de 2009 a 31 de dezembro de 2010. Disponível em http://www.aneel.gov.br/ Acesso em 05 nov. 2009.

BRASIL. Agência Nacional de Energia Elétrica - ANEEL. Resolução 395, de 15 de dezembro de 2009. Aprova os Procedimentos de Distribuição de Energia Elétrica no Sistema Elétrico Nacional - PRODIST, e dá outras providências. Disponível em http://www.aneel.gov.br/ Acesso em 10 mai. 2013.

BRASIL. Agência Nacional de Energia Elétrica - ANEEL. Resolução 424, de 17 de dezembro de 2010. Aprova a Revisão 2 dos Módulos 1, 2, 3, 5, 6, e 8 dos Procedimentos de Distribuição de Energia Elétrica no Sistema Elétrico Nacional - PRODIST, e dá outras providências. Disponível em http://www.aneel.gov.br/ Acesso em 10 mai. 2013.

DUGAN, R.C.; MACGRANAGHAN, M.F.; BEAUTY, H. W.; Eletrical Power Systems Quality, McGraw-Hill. Professional Engeneering Series. São Paulo, 1996. 
FERREIRA, H.T. Energia Eólica: Barreiras e sua participação no Setor Elétrico Brasileiro. Dissertação de Mestrado do Programa Interunidades de Pósgraduação em Energia (EP/FEA/IEE/IF). Universidade de São Paulo. 2008.

FREITAS, W.; VIEIRA JÚNIOR, J.C.M.; FRANÇA, A.L.M.; SILVA, L.C.P.; COSTA, V.F. Análise Comparativa entre Geradores Síncronos e Geradores de Indução com Rotor tipo Gaiola de Esquilo para Aplicação em Geração Distribuída, Revista Controle \& Automação - SBA. Sociedade Brasileira de Automática, v.16, p.332 - 344, 2006.

GREenwoOD, A. Electrical Transients in Power System, Second edition. John Wiley and Sons, Inc, Canadá, 1991.

KAZIBWE M. H., Wilson E., SENDAUlA; Eletric Power Quality Control Techniques, Springer. Reino Unido, Outubro, 1993.

MCGRANAGHAN, M. F.; DUGAN, R. C; SANTOSO, S. Estudo do comportamento do motor de indução trifásico submetido a problemas na qualidade de energia elétrica. Artigo Congresso Nacional de Iniciação Científica. Bauru - SP, 2009.

MENDONÇA, R. G.; NETO, L. M.; SILVA, R. V. R.; PAULA, S. C. M. Three-Phase Induction Generator Feeding a Single-Phase Electrical Distribution System - Time Domain Mathematical Model - IEEE - ACEMP 2001 - International Aegean Conference on Electrical Machines and Power Electronics - Jun, 27-29, 2001 - Kusadasi - Turkey.

NETO, L.M., CAMACHO, J.R., SALERNO, C.H., ALVARENGA, B.P. Analysis of a Three-Phase Induction Machine Including Time and Space Harmonic Effects: The A, B, C - Reference Frame. PES-IEEE Transaction on Energy Conversion, Volume 14, Nr.1, Março 1999. Artigo IEEE: PE-154-EC-0-10-1997.

OPERADOR NACIONAL DO SISTEMA. Resultado da Implantação do Horário de Verão (HV). Rio de Janeiro. 2001. 
OPERADOR NACIONAL DO SISTEMA. Histórico da Situação dos Reservatórios (Energia Armazenada por Regiões). Rio de Janeiro. 2008.

OPERADOR NACIONAL DO SISTEMA. Resolução Normativa 372/09 Procedimentos de Rede - Submódulo 2.8 - Instruções para Realização de Estudos e Medições de QEE Relacionados aos Novos Acessos à Rede Básica. Rio de Janeiro. 2009.

OPERADOR NACIONAL DO SISTEMA. Plano de Operação Energética 2012-2016. PEN-2013 Volume I. Rio de Janeiro. 2012.

PORTER G. J.; VANSCIVER, J.A. Power Quality Solutions Case Studies for Trobleshooters. The Fairmount Press, Inc. 700 Indian Trail. Lilburn, GA. 1998.

ROCCO, A. Máquinas Síncronas e Cargas não Lineares, Efeitos das Distorções Harmônicas, uma Análise Numérico-Experimental. Tese de Doutorado da Escola Politécnica da USP. São Paulo, 1998.

ROSAS, P.A.C.; ESTANQUEIRO, A.I. Guia de Projeto de Centrais Eólicas - Volume I. Centro Brasileiro de Energia Eólica. Recife, 2003.

SILVA, J. M. B.; ALVES, M.B.; GUIMARÃES, G.C.; MARTINS NETO, L. Estabilização de Pequenas Oscilações de Máquina Síncrona em Pequena Central Hidroelétrica com o Controle da Potencia Acelerante. - Comité de Estudio A1 - Máquinas Eléctricas Rotativas XIII Eriac Décimo Tercer Encuentro Regional Iberoamericano de Cigré. Março, 2009.

SIMÕES COSTA, A.J.A.; SILVA, A.S. e. Controle e Estabilidade de Sistemas Elétricos de Potência, 2000. Disponível em:

$<$ http://www.labspot.ufsc.br/ simoes/dincont/> Acesso em 16 nov. 2012. 